\title{
Design and analysis of a hybrid steel/composite pipe for high- pressure applications
}

\author{
William Jennings Briers III \\ West Virginia University
}

Follow this and additional works at: https://researchrepository.wvu.edu/etd

\section{Recommended Citation}

Briers, William Jennings III, "Design and analysis of a hybrid steel/composite pipe for high-pressure applications" (2001). Graduate Theses, Dissertations, and Problem Reports. 1335.

https://researchrepository.wvu.edu/etd/1335

This Thesis is protected by copyright and/or related rights. It has been brought to you by the The Research Repository @ WVU with permission from the rights-holder(s). You are free to use this Thesis in any way that is permitted by the copyright and related rights legislation that applies to your use. For other uses you must obtain permission from the rights-holder(s) directly, unless additional rights are indicated by a Creative Commons license in the record and/ or on the work itself. This Thesis has been accepted for inclusion in WVU Graduate Theses, Dissertations, and Problem Reports collection by an authorized administrator of The Research Repository @ WVU. For more information, please contact researchrepository@mail.wvu.edu. 


\title{
Design and Analysis of a Hybrid Steel/Composite Pipe for High-Pressure Applications
}

\author{
William Jennings Briers III \\ Thesis submitted to the \\ College of Engineering and Mineral Resources \\ at West Virginia University \\ in partial fulfillment of the requirements \\ for the degree of
}

\author{
Master of Science \\ in \\ Mechanical Engineering \\ Ever Barbero, Ph.D., Chair \\ Victor Mucino, Ph.D. \\ Gregory Thompson, Ph.D. \\ Department of Mechanical and Aerospace Engineering \\ Morgantown, West Virginia \\ 2001
}

Keywords: Autofrettage, Composite, Hybrid, Pipe, High-Pressure, Torque 


\section{ABSTRACT \\ Design and Analysis of a Hybrid Steel/Composite Pipe for High-Pressure Applications}

\section{William Jennings Briers III}

Once limited almost exclusively to aerospace applications, the use of composite materials has become widespread among many high performance industries. Today's petroleum industry is requiring piping systems to sustain high pressures, impact, rugged handling, and harsh environmental conditions such as corrosion and temperature. Advances in the last decade of engineered materials have opened the way for more conversions from metal to composites.

The objective of this research is to develop a lightweight composite pipe that meets the performance requirements of an existing high-pressure steel pipe. This development is crucial to the petroleum industry where hydraulic-fracturing services are demanding lighter weight materials while maintaining low cost and high reliability. A hybrid steel/composite pipe was designed and analyzed using the finite element analysis (FEA) programs SDRC ${ }^{\circledR}$ I-DEAS $^{\circledR}$ and ABAQUS ${ }^{\circledR}$. The design consisted of a thinwalled steel liner with a composite over-wrap. It employed the use of unique end fittings, which transfer longitudinal and torque loads from the steel to the composite. This research is believed to be the first instance where autofrettage is used on a metal lined composite pipe. Results from FEA were used to validate the design and fabricate a fullscale prototype. The prototype was successfully tested and exceeded maximum design pressure. 


\section{Dedication}

This document is dedicated to my father, William Jennings Briers Jr., who through a difficult battle with cancer did not survive to see this accomplishment. His expertise in engineering and wisdom in life was a tremendous source of encouragement and strength for me. He was a person with great character and integrity, an engineer with impeccable ethics, and most importantly a man with complete love for and faith in Jesus Christ. 


\section{Acknowledgments}

I thank God, above all, for giving me the strength and ability to accomplish this goal.

I would like to express great appreciation to Dr. Ever J. Barbero, my advisor, for his guidance throughout my studies at West Virginia University. His knowledge and experience was of tremendous value to this project and has helped to prepare me for a career in engineering.

I would like to thank Halliburton Company for funding this project. Especially, I am grateful to Stan Stephenson for overseeing my research and providing valuable insight based on his years of field experience.

I am very thankful for the assistance of my sister Becki Briers Booras, and my friend Ed Wen. I appreciate their support and helpful advice throughout this research.

I would also like to acknowledge my roommates, Andy Manzo and Eric Liese, for their understanding and patience during the conclusion of my writing. They were very kind for doing my share of the dishes.

I am especially grateful for the love and support of my mother, Sue Briers. I appreciate her constant encouragement and unfailing confidence in me. 
Table of Contents

Title Page $\quad$ i

Abstract

Dedication iii

Acknowledgements $\quad$ iv

Table of Contents $\quad$ v

List of Tables

List of Figures $\quad$ x

Nomenclature $\quad$ xiv

Chapter One: Introduction and Literature Review 1

$\begin{array}{ll}\text { 1.1 Introduction } & 1\end{array}$

1.2 Literature Review 4

1.2.1 Composite Materials $\quad 4$

1.2.2 Autofrettage 5

$\begin{array}{lll}\text { 1.2.3 Hybrid Composite Structure } & 8\end{array}$

Chapter Two: Initial Design and Analysis $\quad 11$

$\begin{array}{ll}\text { 2.1 Steel Axisymmetric Model } & 11\end{array}$

2.2 Composite Material Selection and Bi-Directional Laminate Design $\quad 13$

2.3 Three-Directional Laminate Design $\quad 22$

2.4 Hybrid Steel/Composite Axisymmetric Model 23

2.5 Optimization of Hybrid Design 28

$\begin{array}{ll}\text { 2.6 Bending Analysis } & 31\end{array}$ 
Chapter Three: Development and Analysis $\quad 53$

3.1 Hump Design for Longitudinal Stress

$\begin{array}{ll}\text { 3.2 Material Substitutions } & 56\end{array}$

3.3 Analysis of the Sleeve Design $\quad 57$

3.4 Ovalization Analysis

3.5 Track Design for Torsion Load 61

$\begin{array}{ll}\text { 3.6 Simplified Torque Analysis } & 63\end{array}$

3.7 Finite Element Analysis of the Track Design 65

$\begin{array}{ll}3.8 \text { Conclusions } & 67\end{array}$

Chapter Four: Fabrication and Testing 96

$\begin{array}{ll}\text { 4.1 Fabrication } & 96\end{array}$

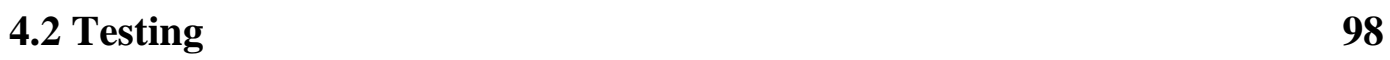

Chapter Five: Design Modification 102

$\begin{array}{ll}\text { Chapter Six: Conclusions and Recommendations } & 111\end{array}$

$\begin{array}{ll}\text { 6.1 Conclusions } & 111\end{array}$

$\begin{array}{ll}6.2 \text { Recommendations } & 112\end{array}$

$\begin{array}{ll}\text { References } & 115\end{array}$

Appendix A - Instructions for Modification and Analysis of the Hybrid 117

Steel/Composite Pipe Using SDRC ${ }^{\circledR}$ I-DEAS $^{\circledR}$ and ABAQUS ${ }^{\circledR}$

Appendix B - ABAQUS ${ }^{\circledR}$ Input File (hybrid1.inp) 151 


\section{List of Tables}

Chapter 2

2.2.1 - Orthotropic elastic material properties of AS4 in unidirectional and $\pm 20^{\circ}$ bi-directional lay-ups.

2.2.2 - Required composite thickness to autofrettage 0.155 inch thick steel according to bi-directional fiber orientation $\pm \theta$.

2.3.1 - Relation between orthotropic elastic material properties in the ABAQUS ${ }^{\circledR}$ coordinate system and the coordinate system used for calculations in Microsoft ${ }^{\circledR}$ Excel.

2.3.2 - Initial tri-directional hybrid design describing composite and steel thickness and equivalent orthotropic elastic material properties using AS4 composite in a $\left[ \pm 20^{\circ}, 90^{\circ}\right]$ lay-up.

2.3.3 - First Ply Failure and Fiber Failure values for the initial tridirectional hybrid design using AS4 composite in a $\left[ \pm 20^{\circ}, 90^{\circ}\right]$ lay-up.

2.4.1 - Description of limiting stresses and symbols for the steel and composite.

2.4.2 - Finite element analysis results for the initial tri-directional hybrid design incorporating hoop thickness from flawed equation.

2.4.3 - Finite element analysis results for the initial tri-directional hybrid design incorporating hoop thickness from corrected equation.

2.5.1 - Optimized tri-directional hybrid design describing composite and steel thickness and equivalent orthotropic elastic material properties for AS4 composite in a $\left[ \pm 20^{\circ}, 90^{\circ}\right]$ lay-up.

2.5.2 - First Ply Failure and Fiber Failure values for the optimized tridirectional hybrid design using AS4 composite in a $\left[ \pm 20^{\circ}, 90^{\circ}\right]$ lay-up.

2.5.3 - Finite element analysis results for the optimized tri-directional hybrid design.

Chapter 3

3.2.1 - Known properties of TR50 carbon fiber and EPON 828 epoxy. 
3.2.2 - Properties used in $\mathrm{CADEC}^{\odot}$ to determine transversely isotropic material properties for a unidirectional composite of TR50/EPON 828.

3.2.3 - Transversely isotropic elastic material properties for a unidirectional composite of TR50/EPON 828 produced in CADEC ${ }^{\odot}$.

3.3.1 - Sleeve design describing composite thickness, liner thickness and equivalent orthotropic elastic material properties for TR50 composite in a $\left[ \pm 20^{\circ}, 90^{\circ}\right]$ lay-up.

3.3.2 - First Ply Failure and Fiber Failure values for the sleeve design using TR50 composite in a $\left[ \pm 20^{\circ}, 90^{\circ}\right]$ lay-up.

3.3.3 - Finite element analysis results in steel and composite along the section of constant thickness, away from the hump/fitting.

3.3.4 - Equivalent orthotropic elastic material properties for TR50 composite in a $\left[90^{\circ}\right]$ lay-up.

3.3.5 - Maximum stress values from the FEM of the sleeve with reinforcement.

3.3.6 - Sensitivity FEA results from the section of constant thickness using 114 ksi yield strength steel.

3.3.7 - Sensitivity FEA results from the section of constant thickness using 126 ksi yield strength steel.

3.4.1 - Results from ovalization analysis showing the maximum stresses and safety factors at fiber failure for the steel and the three groups of composite elements.

3.6.1 - Values of $F F_{\text {shear }}, F_{F F}$ and $v_{h}$ for the simplified torque analysis.

3.7.1 - Results from the torque analysis describing the maximum shear stresses, fiber failure values and safety factors for the $\left[ \pm 20^{\circ}, 90^{\circ}\right]$ base composite and the $\left[ \pm 20^{\circ}\right]$ composite in the tracks.

Chapter 4

4.1 - Individual component and combined weights of the hybrid pipe.

Chapter 5

5.1 - Fiber properties of TR50 and $\operatorname{Kevlar}^{\circledR} 49$. 
5.2 - Orthotropic elastic material properties of TR50 and Kevlar ${ }^{\circledR} 49$ in separate unidirectional lay-ups.

5.3 - Modified design describing composite thickness, liner thickness and equivalent orthotropic elastic material properties for TR50 and $\operatorname{Kevlar}^{\circledR} 49$ in a $\left[ \pm 20^{\circ}, 90^{\circ}\right]$ lay-up.

5.4 - FEA results for the constant thickness section of the TR50/Kevlar ${ }^{\circledR}$ design.

5.5 - Maximum stresses and factors of safety from the finite element analysis of the TR50/Kevlar ${ }^{\circledR}$ design.

5.6 - Modified design of TR50 and $\operatorname{Kevlar}^{\circledR} 49$ in a $\left[ \pm 20^{\circ}, 90^{\circ}\right]$ lay-up with a $10 \%$ increase in base composite thickness.

5.7 - FEA results for the constant thickness section of the TR50/Kevlar ${ }^{\circledR}$ design with a $10 \%$ increase in base composite thickness.

5.8 - Maximum stresses and factors of safety from the TR50/Kevlar ${ }^{\circledR}$ design with a $10 \%$ increase in base composite thickness. 


\section{List of Figures}

Chapter 2

2.0.1 - Original pipe with hammer union fittings and wingnut.

2.0.2 - Stress resultant versus strain graph for the autofrettage process in the hoop direction.

2.1.1 - Steel axisymmetric model.

2.1.2 - FEM with boundary conditions.

2.2.1 - Thickness versus lay-up angle for a bi-directional laminate.

2.2.2 - Weight per length versus lay-up angle for a bi-directional laminate.

2.3.1 - Material coordinate systems for Microsoft ${ }^{\circledR}$ Excel and ABAQUS $^{\circledR}$.

2.3.2 - AS4 lay-up as defined in CADEC ${ }^{\odot}$.

2.4.1 - Hybrid axisymmetric model.

2.4.2 - FEM of hybrid pipe.

2.4.3 - FEM of hybrid pipe showing detail of gap elements and Coupled DOF.

2.5.1 - Four case comparison of steel thickness versus composite hoop thickness.

2.5.2 - Four case comparison of steel thickness versus weight of the steel and hoop wound composite.

2.5.3 - Four case comparison of steel thickness versus safety factor for the hoop wound fibers at autofrettage pressure.

2.5.4 - Four case comparison of steel thickness versus modified safety factor for the hoop wound fibers at autofrettage pressure.

2.6.1 - Pipe supported at midpoint for first beam bending scenario.

2.6.2 - Shear distribution for first beam bending scenario. 
2.6.4 - Shear distribution for second beam bending scenario.

2.6.5 - Pipe and boundary conditions for third beam bending scenario.

2.6.6 - Shear distribution for third beam bending scenario.

Chapter 3

3.1.1 - Initial hump design for longitudinal stress.

3.1.2 - FEM of initial hump design showing detail of gap elements on lower hump.

3.1.3 - Stress contour for initial hump design showing massive elongation and intersection of steel and composite.

3.1.4 - Meshed hump section showing detail of gap elements aligned normal to the spline curve of the hump.

3.1.5 - Sleeve design without composite over-wrap.

3.3.1 - Two case comparison of steel thickness versus modified safety factor for the hoop wound fibers at autofrettage pressure.

3.3.2 - Two case comparison of steel thickness versus weight of the steel and hoop wound composite.

3.3.3 - Exploded view of sleeve model showing the three parts.

3.3.4 - Meshed finite element model of the sleeve design.

3.3.5 - Exploded view of sleeve model with reinforcement over the humps.

3.3.6 - Diametric dimensions of the hump/fitting for the sleeve design.

3.3.7 - Thickness dimensions of the hump/fitting for the sleeve design.

3.3.8 - Longitudinal dimensions of the hump/fitting for the sleeve design.

3.3.9 - Angular dimensions of the hump/fitting for the sleeve design.

3.3.10 - Radial dimensions of the hump/fitting for the sleeve design.

3.4.1 - Cross-sectional and three-dimensional views of the model used for the ovalization analysis. 
3.4.2 - Three-dimensional view of the model with shaded area describing load location.

3.4.3 - Cross-sectional view of the model with arrows depicting seven rows of nodal forces.

3.4.4 - Cross-sectional and three-dimensional views of composite elements from which results were taken.

3.5.1 - Unwrapped view of the large hump showing dimensions of the track design.

3.5.2 - Dimensions of the track design in a cross-sectional view.

3.5.3 - Variable dimensions used to determine the track design.

3.5.4 - Diagram used to determine the radius of the track bottom at the bottleneck of the track design.

3.7.1 - Longitudinal cross-section of steel hump section without large hump.

3.7.2 - Solid model of steel hump section without large hump.

3.7.3 - Solid model of the four steel diamond shaped track forms.

3.7.4 - Solid model of the completed steel hump section with tracks.

3.7.5 - Meshed FEM of the steel hump section with tracks.

3.7.6 - Longitudinal cross-section of composite section including reinforcement.

3.7.7 - Solid model of composite section including reinforcement.

3.7.8 - Interior view of the composite showing diamond shaped cutouts.

3.7.9 - Meshed FEM of the composite part.

3.7.10 - End of steel mesh showing node, rigid bar elements and applied torque load.

3.7.11 - Steel part of the simplified model for the torque analysis. 
Chapter 4

$4.1-$ Hump/tracks showing $\pm 20^{\circ}$ carbon fibers and the triangular shaped void.

Chapter 5

5.1 - Exploded view of the sleeve model with base and reinforcement composites modeled as a single part.

\section{Chapter 6}

6.2.1 - Possible design of raised guides for aiding fiber alignment upon exiting the tracks into the turnaround area. 


\section{Nomenclature}

\section{English}

\section{$\underline{\text { Symbol }}$}

$a$

A

c

C

$d$

E

F

FF

FPF

$g$

G

I

$J$

$l$

m

M

$n$

$N$

$p$

$r$

$R$

$S$

S.F.

$t$

$T$

$U$

$v$

V

w

W
Description

Arc-length

Area

Center

Stiffness Matrix

Inner Diameter

Modulus

Force

Fiber Failure Stress

First Ply Failure Stress

Gravitational Constant

Shear Modulus

Moment of Inertia

Polar Moment of Inertia

Transformation cosine or length

Transformation cosine or mass

Moment

Transformation cosine

Stress resultant or number of tracks

Pressure

Radius

Reaction Force

Compliance Matrix

Safety Factor

Thickness

Torque

Strain Energy

Velocity

Percent Volume Fraction

Weight Per Length

Weight $\underline{\text { Unit }}$

in

$i n^{2}$

in

$-$

in

psi

$l b_{f}$

psi

psi

$\mathrm{ft} / \mathrm{s}^{2}$

psi

in $^{4}$

$i n^{4}$

-, in

$-, l b_{m}$ in- $l b_{f}$

-

lbf $/$ in

psi

in

$l b_{f}$

-

$-$

in

in-lb

in-lbf $\mathrm{in} / \mathrm{s}$

$\%$

lbf $/$ in

$l b_{f}$

\section{Greek}

\section{$\underline{\text { Symbol }}$}

$\varepsilon$

$\Delta$

$v$

$\rho$

$\sigma$
Description

Strain

Change in

Poisson's Ratio

Density

Stress $\underline{\text { Unit }}$

uin/in

-

$l b_{f} / \mathrm{in}^{3}$

psi 


\section{Greek (cont.)}

$\underline{\text { Symbol }}$

$\tau$

$\theta$

\section{Subscript}

\section{Symbol}

1

2

3

12, 21

13,31

23,32

$c$

$c 2$

$f$

fail

fitting

FPF

FF

h, hoop

H

limit

long

$m$

$\max$

$p$

$Q$

$Q c$

$R c$

$R s$

$s$

shear

track

Von Mises

Wing

Yield

$x$

$y$

$z$

$x y, y x$
Description

$\underline{\text { Unit }}$

Shear Stress

psi

Angle

\section{Description}

in the Fiber Direction

in the Transverse to Fiber Direction

in the Through Thickness Direction

In-Plane

Inter-Laminar Plane

Inter-Laminar Plane

of the Composite

of the Composite

of the Fiber

at Failure

of the Fitting

at First Ply Failure

at Fiber Failure

Hoop Composite or Direction

of the Hammer

Limiting Factor

Longitudinal Composite or Direction

of the Matrix/Resin

Maximum Value

of the Pipe

at Autofrettage Pressure

of the Composite at Autofrettage Pressure

of the Composite Post-Autofrettage

of the Steel Post-Autofrettage

of the Steel

Shear Value

of the Track

Calculated using Von Mises

of the Wing-Nut

at Yield Stress of the Steel

in the Global $x$ Direction

in the Global y Direction

in the Global z Direction

in the Global xy Plane 
Subscript (cont.)

Symbol

$x z, z x$

$y z, z y$

\section{Superscript}

$\underline{\text { Symbol }}$

$-1$

$T$

$\theta$
Description

in the Global xz Plane

in the Global yz Plane

Description

Matrix Inverse

Matrix Transpose

of the Angle $\theta$ 


\section{Chapter One}

\section{Introduction and Literature Review}

\subsection{Introduction}

Once limited almost exclusively to aerospace applications, the use of composite materials has become widespread among many high performance industries. Hydraulic fracturing applications in the petroleum industry are demanding components, including pipes, to meet higher production rates and stricter OSHA regulations. Advances in the last decade of the quality and capabilities of resin, fiber, and fabrication equipment and processes allow for more conversions from metal to composites [1]. Piping systems are required to sustain high pressures, impact, rugged handling, and harsh environmental conditions such as corrosion and temperature. Fluids used in hydraulic fracturing are very abrasive because they are loaded with sand and they may be quite corrosive too. Engineers are turning to advanced materials to meet tough design goals and are choosing composites as solutions to weight and durability problems.

The combination of a reinforcing material embedded in a matrix form a composite material. The reinforcing material is usually stronger and stiffer than the matrix. An example of modern composite construction is steel reinforced concrete, where steel is the reinforcement and concrete is the matrix. In general, a composite material is anisotropic. This means that the material's specific mechanical, electrical, and thermal properties differ depending upon the direction of the applied potential, be it pressure, voltage or temperature [1]. This differs from conventional isotropic materials such as steel or aluminum whose properties do not vary with direction. 
One way to increase performance of the composite is to combine two or more reinforcing materials in a common matrix to form a single hybrid laminate. The two most common methods of hybrid construction include "intraply" where reinforcing materials are mixed within a ply, perhaps by using special woven cloth, or "interply" where each ply consists of not more than one reinforcing material [2]. The interply construction method is more flexible and the material is more readily available, however intraply construction potentially displays better laminate properties and may suffer less from delamination. Hybridization allows the designer to obtain benefits of each reinforcing material while potentially reducing cost by applying the most expensive material only where needed.

Hybrids exhibit a response called the "hybrid effect," which describes an enhanced strain to failure as compared to a composite with only one reinforcing material [3,4]. An analogous effect also occurs which is described as "enhanced energy absorption to failure." This effect has the property that the energy absorbed by the hybrid can theoretically exceed that absorbed in an identically constructed composite consisting of only one of the reinforcing materials [5]. This derivative of the hybrid effect results in a more robust laminate that fails gradually, not catastrophically, as the higher modulus fibers fail before those with a lower modulus.

Hybridization can be applied selectively to complex structures for enhanced benefits. A successful design approach in combined loading applications is to align high modulus fibers in the direction of the maximum principle stress and low modulus fibers in the directions of the minimum principle stresses [5]. Hybrid construction may provide increased fatigue and impact strength properties. The addition of high modulus fibers to 
low modulus fibers substantially improves the fatigue properties of the low modulus material. Conversely, the addition of low modulus fibers to high modulus fibers improves the impact strength of the high modulus material [6].

This research focused on the design, analysis, and fabrication of a hybrid steel/composite discharge pipe to replace an existing all-steel pipe used by the Halliburton Company. Hybridization of a metal liner with carbon and glass fiber composite allows the following objectives to be reached:

1. Corrosion and abrasion resistance of steel as good as the conventional pipe.

2. Almost double the strain to failure of the steel liner by using autofrettage.

3. Lower weight.

4. Impact and handling resistance using glass-fiber composite over-wrap. Three significant factors were to be met to satisfy the design standards. The first requirement was to satisfy OSHA standards, which limit a man to carry no more than 50 lbs. This is a significant reduction in the weight of the original $105 \mathrm{lb}$ steel pipe. The second requirement was to withstand a maximum test pressure of $22.5 \mathrm{ksi}$ and low cycle fatigue strength of $15.0 \mathrm{ksi}$. The third requirement was to meet or exceed the physical requirements of the work environment, such as impact, abrasion, and the joint makeup of composite-metal interfaces. From the onset it was understood that a hybrid pipe keeping the standard Weco fittings might not reach the low $50 \mathrm{lb}$ objective. However, the standard fitting was kept to allow for installation of the hybrid pipe in normal field conditions. Replacing the Weco fittings by lighter ones was relegated to Phase II of this project. 


\subsection{Literature Review}

There is a vast amount of research on the subject of composite materials and their applications. A brief review of composites, autofrettage in structures, and hybrid composite construction is given here.

\subsubsection{Composite Materials}

Engineers are turning to advanced materials to meet tough design goals and are choosing composites as solutions to weight and durability problems. While there has been a steady increase in the use of composites in industry it has not replaced its heavier standard engineering material counterparts such as aluminum and steel. An aluminum alloy used in aerospace applications will have a yield strength near $70 \mathrm{ksi}$ at a specific gravity of 2.8 whereas a good carbon fiber reinforced plastic (CFRP) laminate in unidirectional form can exhibit a tensile strength close to $435 \mathrm{ksi}$ at a specific gravity of 1.6 [7]. While unidirectional CFRP has higher strength and lower weight than aluminum, its mechanical properties in directions other than along the fibers are very low. One of Boeing's twin jets, the 777, was the corporation's first commercial airplane with a primary structure of composites [8]. Boeing engineers shaved $2600 \mathrm{lbs}$ off the aircraft's structural weight. Nearly $9 \%$ of the plane's structural weight consists of composites, ten times the amount used on the 757 and 767.

The investigations of Potter et al. [7] determined there are two basic responses that the aerospace community can make to further develop its market place. The first is to develop lower cost manufacturing processes. The second is to attempt to apply new thinking to the design process and to allow greater weight saving to be made so as to 
move the competition between metals and composites to a new level without losing sight of maintainability, damage, repair and costs.

Jim Shobert, President of Polygon Company, states that despite his company's experience in the composites field, he still must spend a lot of time educating engineers. He maintains that the "metal mentality" must be fought and engineers must understand that parts that are produced with composites may or may not resemble the metal part it replaces. As a result, Polygon applications engineers work with design engineers to explain the special properties and advantages of composites. Recent Polygon projects have resulted in improved orthopedic fixators with a $20 \%$ reduction in weight from the conventional stainless steel/aluminum construction by replacing metal crossbar section with CFRP. The new design allows radiolucency so physicians can $\mathrm{x}$-ray through the device to monitor bone growth and healing [9].

Harvey and Kremer [10] states that the use of composite materials in cryogenic fuel lines will present important weight savings for the Reusable Launch Vehicle (RLV). Their research funded by NASA developed an all composite 12 inch diameter fuel line capable of carrying liquid hydrogen at cryogenic temperature. The fabricated part weighs less than $20 \%$ of a 'state of the art' fuel line and was successfully tested. Such weightsaving capabilities prove that composites are an extremely valuable engineering material.

\subsubsection{Autofrettage}

Autofrettage is a pre-stressing technique, which for metal lined composite pressure vessels consists of internally pressurizing the vessel until the metal is stressed beyond its elastic range and therefore upon release of the load the composite introduces 
residual compressive stresses in the liner. This procedure produces increased yield strength in the metal and extends its usable elastic range.

In situations where fatigue life may not meet design goals, the use of an autofrettage that introduces beneficial residual compressive stresses may provide a solution. Segall [11] et al. investigated the feasibility of the fatigue life of thick-walled cylinders with cross-bores by using a localized autofrettage technique. This technique utilized the high stress concentration at the cross-bore to induce localized residual stresses using relatively low internal pressures. The researchers used elastic-plastic finite element (FE) calculations in conjunction with an elastic fracture-mechanics model of a quarter-circular crack situated at the intersection of the cross-bore and the cylinder inner diameter to conservatively calculate the extent of the fatigue life improvement. Results showed significant improvement in cylinder life due to the localized residual stresses. Another important advantage of a localized technique is that it will allow an autofrettage after the cylinder has been machined to its final dimensions.

In a study on the fatigue life of cannon tubes with evacuator holes, Underwood et al. [12] measured the effects of various amounts of autofrettage by overstrain. It was shown that the measured fatigue life and the initiation position of the fatigue crack along the evacuator hole was affected by overstrain. By increasing the amount of autofrettage the crack initiation was moved along the hole from a location near the inner radius of the tube to a mid-wall position. Up to a four-fold increase in fatigue life was noticed with a change from 0 to 100 percent overstrain.

Hussain et al. [13] investigated the redistribution of residual stresses of an autofrettaged tube due to geometrical changes such as keyways, rifling, cracks, etc. Their 
research produce a method to simulate partial autofrettage residual stressed in thickwalled cylinders. The technique developed provides a means of incorporating redistributed residual stress into the stress analysis of autofrettaged cylinders. Such an analysis method may be necessary to better understand the effects of geometrical discontinuities on an overstrained pressure vessel.

Finite element methods were employed by Feng et al. [14] to model lowtemperature autofrettage of smooth thick-walled tubes of austenitic stainless steel AISI 304 L. The research objective was to show the greater efficiency of low-temperature autofrettage over the same process at room temperature. It was theorized that at lower temperatures, a higher beneficial residual compressive hoop stress would be introduced at the inner part of the tube. Based on FE calculations, it was concluded that the lowtemperature process is a better solution and should more significantly enhance the resistance to fatigue.

Autofrettage of aluminum-lined composite pressure vessels for compressed natural gas has been discussed in [2] among others. Liu and Hirano [15] discussed the design of fiber reinforced plastics (FRP) pressure vessels with load-carrying metallic liners. The design concept included autofrettage to generate compressive residual stress in the liner, which resulted in an increased usable elastic range and a higher yield stress. Their research established an outline design approach and a method of detailed analysis including the use of finite element methods. This resulted in a higher structural efficiency for FRP pressure vessel design. The outcome from experimental testing showed good agreement between actual and predicted burst pressures. 


\subsubsection{Hybrid Composite Structure}

Hybrid composites are an important engineering material. A hybrid material usually contains two or more types of fibers interlaminated or intermingled in a common matrix. Hybrids have several advantages, such as the improvement of crack-arresting properties, fracture toughness, and cost reduction by decreasing the amount of the more expensive fiber. Research on hybrid composites had grown rapidly in recent years as reviewed by Fukada and Chou [16]. Their work examines the load redistribution in a hybrid composite sheet due to fiber breakage. The stress concentration factors of a unidirectional hybrid composite with discontinuous fibers were calculated using a shearlag analysis. The result of the analysis indicated that in a hybrid composite containing both high modulus and low modulus fiber, the stress concentration factor on the high modulus fibers adjacent to a crack is lower than that in an all-high modulus fiber composite for the same number of fractured fibers. Thus it is possible for the high modulus fibers in a hybrid composite to sustain higher loading and elongation than in the all-high modulus fiber composite, and a "hybrid effect" could be realized.

Karbhari et al. [17] determined the progressive crush response of braided tubes is significantly affected by hybridization. Both the use of different types of fibers in combination (glass, carbon and $\operatorname{Kevlar}^{\circledR}$ ) and different yield rovings were studied. Triaxial braiding was shown to be the most efficient while optimum performance was reached through the use of carbon fibers in the axial direction. It was seen that the use of axial fibers in the braid architecture significantly increased the crush performance as well as retaining post-crush integrity. The best performance was shown by the glass-carbon

and $\operatorname{Kevlar}^{\circledR}$-carbon hybrids, where the carbon fibers were used in the axial direction, 
with movement constrained by the glass or Kevlar ${ }^{\circledR}$ braided yarns. Based on their results, it is clear that significant tailoring of crush performance and crush mechanisms is possible through hybridization.

A general mathematical formulation by Dhillon et al. [18] for the optimum design of unstiffened and stiffened, composite, hybrid plate girders. Using the generalized geometric programming (GGP) technique, the composite-hybrid-plate-girder problem was formulated as a mathematical problem that uses the weight of the girder as the objective function, with the section properties and strengths providing the problem constraints. It was concluded that GGP provides an effective method for the design of composite hybrid plate girders, offering savings in cost and design time and demonstrating the cost effectiveness of web stiffeners in plate girder design.

Kim and Mai [19] studied the stress transfer in a multiple fiber composite subjected to uniaxial tension. The model composite was treated as a three-cylinder assemblage, which consisted of a central fiber, a matrix annulus and a composite medium. The researchers conducted a parametric study and found that fiber fragmentation becomes increasingly difficult as the stiffness of the average composite medium increases. Conversely, the interfacial debonding becomes easier as this medium is stiffened. These findings imply that for aligned discontinuous fiber composites the stability and the energy absorption capability of the fracture process can be enhanced by increasing the fiber volume fraction and the elastic modulus of the matrix.

The efforts of Chaudhuri and Garala [20] focused on improving the compressive strength of CFRP by using a hybrid carbon/glass commingling concept. It was determined that the formation and propagation of fiber kink bands at the microscopic 
level (triggered by the fiber misalignment and waviness defects formed during the manufacturing process) leading to a shear crippling failure at the macroscopic level, is the dominant compressive failure mode. The researchers theorized that one way to improve compressive strength is through the use of a commingled (at the tow level) hybrid fiber system. Experimental data suggested enhancement of the compressive and flexural strengths of the composite material even with a small percentage $(15 \%)$ of glass fibers in commingled hybrid composites. More significantly, inspection of the failed compression test coupons demonstrated that this small amount of glass fibers is effective in changing the failure mode away from the catastrophic kink band failure mode.

Hybrid construction may allow a designer to increase laminate stiffness without sacrificing much strength. Analysis by Glenn et al. [5] showed that hybridizing glass with small amounts of carbon initially resulted in reduced laminate strength. However, at around $30 \%$ carbon concentration, analysis showed that the hybrid strength recovered $70 \%$ of the pure glass strength while stiffness exceeded that of pure glass by a $100 \%$ for low modulus carbon.

It is clear that hybrid composite materials can be beneficial to the design of a structure. The addition of strong fibers to weak fibers can be advantageous, but it is inferred that the weaker fibers can decrease the strength of a laminate of strong fibers. It is noted that great care must be taken in designing a hybrid composite to maximize the use of the positive qualities of the various materials. 


\section{Chapter Two}

\section{Initial Design and Analysis}

The steel pipe used by Halliburton Company has a wall thickness of 0.31 inch, an inner diameter of 2.0 inches, and a length of 120 inches. The pipe has Weco 1502 hammer unions as shown in Figure 2.0.1. Initially, it was decided that making modifications to the existing pipe would simplify fabrication of the new design. The pipe would be turned down on a lathe to a specified diameter consistent with the wall thickness of the new design, and then filament wound with carbon fibers and epoxy resin.

It was recognized that the pipe would undergo low cycle fatigue during operation, therefore autofrettage was desired. The goal was to achieve the largest elastic range possible. Therefore the composite was to be designed to stress the steel to within $95 \%$ of compressive yield once the autofrettage pressure is removed. This would almost double the effective elastic region of the stress-strain curve. Figure 2.0.2 shows the stress resultant (stress multiplied by pipe thickness) versus strain curves for the steel pipe, composite and the steel after yield for hoop stress. It was desired to autofrettage the pipe at $22.5 \mathrm{ksi}$, which is the test pressure required by Halliburton. This is also 1.5 times the working pressure.

Computer aided FEA was used to meet the complex analytical demands of the project. $\quad$ SDRC $^{\circledR}$ I-DEAS $^{\circledR}$ was used jointly with ABAQUS ${ }^{\circledR}$ for most of the twodimensional analyses.

\subsection{Steel Axisymmetric Model}

To validate the FEA software for the design of the hybrid pipe, an I-DEAS $^{\circledR}$ model, all_steel.mf1, of the original steel pipe was developed and solved. An analysis 
was performed using an axisymmetric finite element model (FEM). The FEM consisted of two-dimensional axisymmetric elements, which act like three-dimensional solid elements that revolve around a specified axis. This type of model was chosen because it requires far less elements than a three dimensional model and therefore greatly reduces the time needed to solve.

The geometry of the model consisted of a simplified longitudinal cross-section of the pipe Figure 2.1.1. As seen in the figure, this was modeled as one fitting and a 20 inch section of pipe with constant thickness. The end of the pipe with constant thickness was restrained from having longitudinal translation, while the rest was free to expand and elongate. An internal pressure load was simulated by applying a distributed load on the "element free edges" closest to the axis of revolution, and a longitudinal force at the pipe's free end. Figure 2.1.2 shows the meshed model with boundary conditions. The longitudinal force, which simulated the axial pressure load was calculated using

$$
F_{\text {long }}=\pi r^{2} p
$$

where $r$ is the inner radius of the pipe and $p$ is the applied pressure. The internal pressure was $30.0 \mathrm{ksi}$. The elastic material properties of the elements were consistent with those of generic isotropic steel with an elastic modulus of $30000 \mathrm{ksi}$ and a Poisson's Ratio of 0.29. The plastic material properties were defined by a yield strength of $93.5 \mathrm{ksi}$, an ultimate strength of $115 \mathrm{ksi}$ and $21 \%$ elongation at failure.

A second FEA software package was used to reach a solution for this model. ABAQUS $^{\circledR}$ was chosen due to its ability to solve quickly as well as its ability to perform elastic-plastic analyses, which was crucial to designing the autofrettage process. The solver in SDRC $^{\circledR}$ I-DEAS $^{\circledR}$ is not as powerful and is much slower than ABAQUS ${ }^{\circledR}$. The 
model was exported from I-DEAS ${ }^{\circledR}$ into an input file called all_steel.inp and solved using ABAQUS $^{\circledR}$. The solution to the model was imported back into I-DEAS ${ }^{\circledR}$ for post processing.

The maximum Von Mises stress in the steel, displayed by I-DEAS ${ }^{\circledR}$, was 96.4 ksi. The Von Mises stress is defined as [21]

$$
\sigma_{\text {von mises }}=\sqrt{\frac{1}{2}\left[\left(\sigma_{I}-\sigma_{I I}\right)^{2}+\left(\sigma_{I}-\sigma_{I I I}\right)^{2}+\left(\sigma_{I I}-\sigma_{I I I}\right)^{2}\right]}
$$

where $\sigma_{I}, \sigma_{I I}$ and $\sigma_{I I I}$ are principal stresses equal to $\sigma_{x}, \sigma_{y}$ and $\sigma_{z}$ respectively for internal pressure loading. This result was conservative compared to the actual tests of the pipe. The reason for the discrepancy was because the finite element model had just over 50 elements, resulting in a coarse mesh that produced a stiff representation of the pipe. The solution was satisfactory and the method was deemed suitable for the analysis of the steel and composite hybrid.

\subsection{Composite Material Selection and Bi-Directional Laminate Design}

Initially, AS4 carbon-epoxy composite was chosen because of its material properties and relatively low cost. Orthotropic elastic material properties for AS4 in a unidirectional composite were recorded by Barbero [22] and are shown in Table 2.2.1. Some of these properties are derived as follows assuming the unidirectional composite is transversely isotropic

$$
\begin{aligned}
E_{3} & =E_{2} \\
G_{13} & =G_{12} \\
v_{13} & =v_{12} \\
v_{32} & =v_{23} \\
v_{31} & =v_{21} \\
v_{21} & =v_{12} \frac{E_{2}}{E_{1}}
\end{aligned}
$$


Microsoft ${ }^{\circledR}$ Excel spreadsheet as4_bi-directional.xls was used to calculate the equivalent orthotropic elastic material properties of a bi-directional composite lay-up (i.e. $\left.\pm 45^{\circ}, \pm 62^{\circ}\right)$. The calculations were performed for a two-ply laminate with each layer having a unit thickness.

The stiffness matrix $[\mathrm{C}]$ was computed for a $0^{\circ}$ unidirectional AS4 composite

$$
[C]=\left[\begin{array}{cccccc}
C_{11} & C_{12} & C_{13} & 0 & 0 & 0 \\
C_{12} & C_{22} & C_{23} & 0 & 0 & 0 \\
C_{13} & C_{23} & C_{33} & 0 & 0 & 0 \\
0 & 0 & 0 & C_{44} & 0 & 0 \\
0 & 0 & 0 & 0 & C_{55} & 0 \\
0 & 0 & 0 & 0 & 0 & C_{66}
\end{array}\right]
$$

with the components calculated in terms of orthotropic elastic material constants as shown below [23]

$$
\begin{gathered}
C_{11}=\frac{1-v_{23} v_{32}}{E_{2} E_{3} \Delta} \\
C_{12}=\frac{v_{21}+v_{31} v_{23}}{E_{2} E_{3} \Delta} \\
C_{13}=\frac{v_{31}+v_{21} v_{32}}{E_{2} E_{3} \Delta} \\
C_{22}=\frac{1-v_{13} v_{31}}{E_{1} E_{3} \Delta} \\
C_{23}=\frac{v_{32}+v_{12} v_{31}}{E_{1} E_{3} \Delta} \\
C_{33}=\frac{1-v_{12} v_{21}}{E_{1} E_{2} \Delta} \\
C_{44}=G_{23} \\
C_{55}=G_{13} \\
C_{66}=G_{12} \\
\Delta=\frac{1-v_{12} v_{21}-v_{23} v_{32}-v_{13} v_{31}-2 v_{21} v_{32} v_{13}}{E_{1} E_{2} E_{3}}
\end{gathered}
$$

The stiffness matrix $\left[C^{(\theta)}\right]$ was calculated for a fiber orientation of $\theta$ using the transformation matrices $[T]$ and $[T]^{T}$ (transpose of $[T]$ ) as

$$
\left[C^{(\theta)}\right]=[T]^{T}[C][T]
$$


where $[T]$ is

$$
[T]=\left[\begin{array}{cccccc}
l_{1}^{2} & m_{1}^{2} & n_{1}^{2} & m_{1} n_{1} & l_{1} n_{1} & l_{1} m_{1} \\
l_{2}^{2} & m_{2}^{2} & n_{2}^{2} & m_{2} n_{2} & l_{2} n_{2} & l_{2} m_{2} \\
l_{3}^{2} & m_{3}^{2} & n_{3}^{2} & m_{3} n_{3} & l_{3} n_{3} & l_{3} m_{3} \\
2 l_{2} l_{3} & 2 m_{2} m_{3} & 2 n_{2} n_{3} & m_{2} n_{3}+n_{2} m_{3} & l_{2} n_{3}+n_{2} l_{3} & l_{2} m_{3}+m_{2} l_{3} \\
2 l_{1} l_{3} & 2 m_{1} m_{3} & 2 n_{1} n_{3} & m_{1} n_{3}+n_{1} m_{3} & l_{1} n_{3}+n_{1} l_{3} & l_{1} m_{3}+m_{1} l_{3} \\
2 l_{1} l_{2} & 2 m_{1} m_{2} & 2 n_{1} n_{2} & m_{1} n_{2}+n_{1} m_{2} & l_{1} n_{2}+n_{1} l_{2} & l_{1} m_{2}+m_{1} l_{2}
\end{array}\right]
$$

and the components are defined as

$$
\begin{array}{lll}
l_{1}=\cos \theta & m_{1}=\sin \theta & n_{1}=0 \\
l_{2}=-\sin \theta & m_{2}=\cos \theta & n_{2}=0 \\
l_{3}=0 & m_{3}=0 & n_{3}=1
\end{array}
$$

The stiffness matrix of the second layer, $\left[C^{(-\theta)}\right]$,was calculated as described above with a negative theta. The stiffness matrix of the bi-directional laminate, $\left[C^{( \pm \theta)}\right.$, was produced by combining the components of $\left[C^{(\theta)}\right]$ with those of $\left[C^{(-\theta)}\right]$ as described below

$$
C_{i j}^{( \pm \theta)}=\frac{t C_{i j}^{(\theta)}+t C_{i j}^{(-\theta)}}{2 t}
$$

where $t$ is the thickness of one layer.

The compliance matrix $[S]$ is the inverse of the stiffness matrix

$$
[S]=\left[C^{( \pm \theta)}\right]^{-1}
$$

The compliance matrix is described in terms of orthotropic elastic material constants as

$$
[S]=\left[\begin{array}{cccccc}
\frac{1}{E_{1}} & -\frac{v_{12}}{E_{1}} & -\frac{v_{13}}{E_{1}} & 0 & 0 & 0 \\
-\frac{v_{12}}{E_{1}} & \frac{1}{E_{2}} & -\frac{v_{23}}{E_{2}} & 0 & 0 & 0 \\
-\frac{v_{13}}{E_{1}} & -\frac{v_{23}}{E_{2}} & \frac{1}{E_{3}} & 0 & 0 & 0 \\
0 & 0 & 0 & \frac{1}{G_{23}} & 0 & 0 \\
0 & 0 & 0 & 0 & \frac{1}{G_{13}} & 0 \\
0 & 0 & 0 & 0 & 0 & \frac{1}{G_{12}}
\end{array}\right]
$$


The equivalent elastic material properties of the laminate were calculated from the components of the compliance matrix. These are defined as

$$
\begin{array}{llll}
E_{1}=\frac{1}{S_{11}} & G_{12}=\frac{1}{S_{66}} & v_{12}=-S_{12} E_{1} & v_{32}=-S_{32} E_{3} \\
E_{2}=\frac{1}{S_{22}} & G_{13}=\frac{1}{S_{55}} & v_{13}=-S_{13} E_{1} & v_{21}=-S_{21} E_{2} \\
E_{3}=\frac{1}{S_{33}} & G_{23}=\frac{1}{S_{44}} & v_{23}=-S_{23} E_{2} & v_{31}=-S_{31} E_{3}
\end{array}
$$

Equations (2.2.2) through (2.2.8) were used to determine the equivalent orthotropic material properties of AS4 for each bi-directional lay-up from $0^{\circ}$ to $90^{\circ}$ in $5^{\circ}$ increments (i.e. $0^{\circ}, \pm 5^{\circ}, \pm 10^{\circ} \ldots \pm 85^{\circ}, 90^{\circ}$ ). An example of the orthotropic material properties before and after transformation is shown in Table 2.2.1. These material properties were then used to determine the required composite thickness for the longitudinal and hoop stresses.

Derivations were performed to determine the thickness of the composite to autofrettage the steel pipe to $95 \%$ of compressive yield. These equations describe the stress resultant versus strain graph in Figure 2.0.2.

First, it was assumed that the strain in the composite is equal to the strain in the steel

$$
\varepsilon_{c}=\varepsilon_{s}
$$

The yield stress of steel was denoted by $\sigma_{\text {yield }}$ and the yield strain by $\mathcal{\varepsilon}_{\text {yield }}$. The yield strain $\varepsilon_{\text {yield }}$ was determined from

$$
\varepsilon_{\text {yield }}=\frac{\sigma_{\text {yield }}}{E_{s}}
$$

where $E_{s}$ is the modulus of elasticity of steel. Since the composite is linear and elastic, the stress in the composite for any load is 


$$
\sigma_{c}=\varepsilon_{c} E_{\text {hoop }}
$$

where $E_{\text {hoop }}$ is the modulus of elasticity of the composite in the hoop direction $\left(90^{\circ}\right.$ from the longitudinal axis). The stress in the in the hoop direction of a pipe is calculated from

$$
\sigma_{h}=\frac{p d}{2 t}
$$

where $p$ is the applied internal pressure, $d$ is the inner diameter of the pipe and $t$ is the wall thickness. The stress resultant $N$, is the tensile force per unit length, along the edge of a plate, and is calculated as

$$
N=\sigma t
$$

The stress resultant in the hoop direction of the hybrid pipe was derived by substituting (2.2.12) into (2.2.13), as shown

$$
N_{h}=\sigma_{h} t=\frac{p d}{2}
$$

Due to the hybrid design of the pipe, $N_{h}$ is a function of $N_{c}$ and $N_{s}$, which are the hoop stress resultants in the composite and steel respectively. This is essentially a force balance equation as shown below

$$
N_{h}=N_{c}+N_{s}
$$

where

$$
N_{s}=\sigma_{\text {yield }} t_{s}
$$

and

$$
N_{c}=\sigma_{c} t_{\text {hoop }}
$$

where $t_{\text {hoop }}$ is the thickness of the composite. For the autofrettage load, the components $N_{h}$ and $N_{s}$ are known, equation (2.2.15) can be rearranged to form

$$
N_{Q_{c}}=N_{h}-N_{s}
$$


If the thickness of the composite is chosen, then the hoop stress can be found from

$$
\sigma_{Q_{c}}=\frac{N_{Q_{c}}}{t_{\text {hoop }}}
$$

then the hoop strain in the composite and the steel can be determined from

$$
\varepsilon_{Q}=\frac{\sigma_{Q_{c}}}{E_{\text {hoop }}}
$$

The drop of hoop strain, $\Delta \varepsilon_{c 2}$, in the composite up to the point when the steel is at $95 \%$ of compressive yield stress has two components, the drop from autofrettage stress to zero stress and the 0.95 drop to $95 \%$ of compressive yield,

$$
\Delta \varepsilon_{c 2}=(1+0.95) \varepsilon_{\text {yield }}=1.95 \varepsilon_{\text {yield }}
$$

as seen in Figure 2.0.2. From this number, the drop in hoop force per unit length, $\Delta N_{c 2}$, is

$$
\Delta N_{c 2}=\Delta \sigma_{c 2} t_{\text {hoop }}
$$

where $\Delta \sigma_{c 2}$ is the drop in hoop stress in the composite

$$
\Delta \sigma_{c 2}=E_{\text {hoop }} \Delta \varepsilon_{c 2}
$$

Equation (2.2.22) is also represented by

$$
\Delta N_{c 2}=N_{Q_{c}}-N_{R_{c}}
$$

where $N_{Q c}$ was found from (2.2.18) and $N_{R c}$ is

$$
N_{R_{c}}=.95 \sigma_{\text {yield }} t_{s}
$$

The thickness of the composite for the hoop stress criteria was determined by combining equations (2.2.22) and (2.2.23) to get

$$
t_{\text {hoop }}=\frac{\Delta N_{c 2}}{E_{\text {hoop }} \Delta \varepsilon_{c 2}}
$$

which was expanded to 


$$
t_{\text {hoop }}=\frac{\frac{p d}{2}-1.95 \sigma_{\text {yield }} t_{s}}{1.95 \varepsilon_{\text {yield }} E_{\text {hoop }}}
$$

The above derivation was based on the drop in hoop strain and the drop in the hoop stress resultant. A second derivation was performed to confirm the first. It was based on the fact that the hoop stress resultants in the composite and steel after autofrettage must be equal and opposite as seen in Figure 2.0.2. They must also be equal to $95 \%$ of the compressive yield stress resultant of steel as shown

$$
N_{R_{c}}=N_{R_{S}}=.95 N_{s}
$$

this was expanded using (2.2.13) to form

$$
\sigma_{R_{c}} t_{\text {hoop }}=.95 \sigma_{\text {yield }} t_{s}
$$

The composite thickness for autofrettage in the hoop direction was found from (2.2.29) to be

$$
t_{\text {hoop }}=\frac{.95 \sigma_{\text {yield }} t_{s}}{\sigma_{R_{c}}}
$$

where $\sigma_{R c}$ is

$$
\sigma_{R_{C}}=\left(\varepsilon_{Q}-1.95 \varepsilon_{\text {yield }}\right) E_{\text {hoop }}
$$

and $\varepsilon_{Q}$ was determined from equations (2.2.14) through (2.2.20) to be

$$
\varepsilon_{Q}=\frac{\frac{p d}{2}-\sigma_{\text {yield }} t_{s}}{t_{\text {hoop }} E_{\text {hoop }}}
$$

By substituting (2.2.31) and (2.2.32) into (2.2.30) and rearranging, $t_{\text {hoop }}$ becomes equation (2.2.27) and thus reinforces the first derivation. Comparison between results based on (2.2.27) and FEA were not favorable because the simplified analysis neglects the 
longitudinal stress. Therefore, a safety factor of 1.95 was applied resulting in the modified hoop thickness

$$
t_{\text {hoop }}=\frac{\frac{p d}{2}-1.95 \sigma_{\text {yield }} t_{s}}{\varepsilon_{\text {yield }} E_{\text {hoop }}}
$$

Equation (2.2.33) was used in Microsoft $^{\circledR}$ Excel to calculate the required thickness of the composite to autofrettage the pipe in the hoop direction. This value was calculated for a steel pipe with a two-inch inner diameter and wall thickness of 0.155 inch, which is half of the thickness of the original pipe. The yield strength of the steel was chosen to be $52 \mathrm{ksi}$. The autofrettage pressure, $p$, was $22.5 \mathrm{ksi}$. The composite's modulus of elasticity in the hoop direction, $E_{\text {hoop }}$, was calculated for 19 different bidirectional fiber orientations ranging from $0^{\circ}$ to $90^{\circ}$ in $5^{\circ}$ increments. The value of $t_{\text {hoop }}$ was calculated for each of the 19 cases and is shown in Table 2.2.2.

The equations to calculate the thickness of the composite for longitudinal load were derived. The static equilibrium equation of the pipe is

$$
F=F_{c}+F_{s}
$$

where $F$ is the longitudinal force due to the internal pressure load

$$
F=\pi r^{2} p
$$

$F_{c}$ and $F_{s}$ are the reaction forces in the composite and steel respectively

$$
\begin{aligned}
& F_{c}=\sigma_{\text {long }} A_{c} \\
& F_{s}=\sigma_{\text {yield }} A_{s}
\end{aligned}
$$

where $A_{c}$ and $A_{s}$ are the cross-sectional areas of the composite and steel respectively. By substituting equations (2.2.36) and (2.2.37) into equation (2.2.34), the equilibrium equation becomes 


$$
F=\sigma_{\text {long }} A_{c}+\sigma_{\text {yield }} A_{s}
$$

This equation was rearranged to solve for $A_{c}$ as shown below

$$
A_{c}=\frac{F-\sigma_{\text {yield }} A_{s}}{\sigma_{\text {long }}}
$$

The stress in the composite, $\sigma_{\text {long }}$, at $\sigma_{\text {yield }}$ can be represented by

$$
\sigma_{\text {long }}=\varepsilon_{\text {yield }} E_{\text {long }}
$$

where $E_{\text {long }}$ is the modulus of elasticity of the composite in the longitudinal direction. By substitution, $A_{c}$ is

$$
A_{c}=\frac{\pi r^{2} p-\sigma_{\text {yield }} A_{s}}{\varepsilon_{\text {yield }} E_{\text {long }}}
$$

The cross-sectional area of the steel is

$$
A_{s}=\pi\left\{\left(r+t_{s}\right)^{2}-r^{2}\right\}
$$

The thickness of the composite was found by rearranging the following equation

$$
A_{c}=\pi\left\{\left(r+t_{s}+t_{\text {long }}\right)^{2}-\left(r+t_{s}\right)^{2}\right\}
$$

to get

$$
t_{\text {long }}=\sqrt{\frac{A_{c}}{\pi}+\left(r+t_{s}\right)^{2}}-\left(r+t_{s}\right)
$$

where $t_{\text {long }}$ is the thickness of the composite and the value for $A_{c}$ in (2.2.44) comes from equation (2.2.41).

The composite's modulus of elasticity in the longitudinal direction, $E_{\text {long, }}$, was calculated for the same 19 bi-directional fiber orientations as described earlier. The value of $t_{\text {long }}$ for longitudinal loading was calculated for each of the 19 cases and is shown in Table 2.2.2. 
The composite thickness was plotted versus the bi-directional lay-up angle for the longitudinal stress and the hoop stress as shown in Figure 2.2.1. The optimum fiber layup angle was determined to be at the angle at which the two curves cross, approximately $\pm 50^{\circ}$.

The weight per unit length of the steel pipe, $w_{s}$, was calculated using the following formula

$$
w_{s}=12 \rho_{s}\left\{\pi\left[\left(r+t_{s}\right)^{2}-r^{2}\right]\right\}
$$

where $\rho_{s}$ is the density of steel. The weight per unit length of the composite over-wrap is

$$
w_{c}=12 \rho_{c}\left\{\pi\left[\left(r+t_{s}+t_{c}\right)^{2}-\left(r+t_{s}\right)^{2}\right]\right\}
$$

where $\rho_{c}$ is the density of AS4 composite, $t_{c}$ is the thickness and is equal to either $t_{\text {hoop }}$ or $t_{\text {long. }}$ The total weight per unit length, $w_{p}$, of the hybrid pipe is

$$
w_{p}=w_{s}+w_{c}
$$

The weight per unit length for $t_{\text {hoop }}$ and $t_{\text {long }}$ was plotted versus the bi-directional fiber orientation $\theta$ as shown in Figure 2.2.2. The required composite thickness for the optimum lay-up of $\pm 58^{\circ}$ proved to be quite large and would result in a hybrid pipe that outweighs the original steel pipe. It was determined that a bi-directional lay-up resulted in an inefficient use of composite material for this loading condition. Further analysis was required to determine the optimum laminate design.

\subsection{Three-Directional Laminate Design}

To minimize the thickness of the composite, a three-directional lay-up was considered. The thickness required to sustain hoop stress is minimized when fibers are oriented at $90^{\circ}$ from the longitudinal axis. In the same manner, the minimum thickness 
required to withstand longitudinal stress is when fibers are oriented at $0^{\circ}$. Filament winding does not have the capability to place fibers at $0^{\circ}$, therefore an orientation of $\pm 20^{\circ}$ was chosen for the longitudinal component. This combination of $+20^{\circ},-20^{\circ}$ and $90^{\circ}$ was designed using Microsoft ${ }^{\circledR}$ Excel.

A new spreadsheet original_hybrid_as4_tri-directional.xls was created to calculate the transformation matrices for a three-directional composite. The procedure in section 2.2 for determining the equivalent orthotropic material properties was modified for the tri-directional laminate. Three stiffness matrices, $\left[C^{(20)}\right],\left[C^{(-20)}\right]$ and $\left[C^{(90)}\right]$, were computed for the unidirectional layers. The stiffness matrix of the tri-directional laminate, $\left[C^{( \pm 20,90)}\right]$, was produced by combining the components of $\left[C^{(20)}\right]$ with those of $\left[C^{(-20)}\right]$ and those of $\left[C^{(90)}\right]$ as described below

$$
C_{i j}^{( \pm 20,90)}=\frac{t_{20} C_{i j}^{(20)}+t_{-20} C_{i j}^{(-20)}+t_{90} C_{i j}^{(90)}}{t_{20}+t_{-20}+t_{90}}
$$

where $t_{20}$ and $t_{-20}$ were each equal to half of $t_{\text {llong }}$ calculated at $\pm 20^{\circ}$ and $t_{90}$ was equal to $t_{\text {ihoop }}$ calculated at $90^{\circ}$. The compliance matrix was formed using (2.2.5) and then the equivalent elastic material properties were calculated using equation (2.2.7). The calculated orthotropic material properties are based on the coordinate system of the unidirectional composite, which is different from the coordinate system in ABAQUS ${ }^{\circledR}$. Figure 2.3.1 depicts the material and ABAQUS ${ }^{\circledR}$ coordinate systems and Table 2.3.1 describes the relation between the properties from the two. These properties as well as lay-up thickness are listed in Table 2.3.2.

Computer Aided Design Environment for Composites $\left(\mathrm{CADEC}^{\odot}, 1998\right)$ was used to determine the First Ply Failure (FPF) values, stresses at which the composite begins to 
develop cracks in the resin, and Fiber Failure (FF) values, stresses at which catastrophic fiber failure occurs. The elastic material properties of unidirectional AS4 were used along with the shear, tensile, and compressive strength values of the resin and fiber. Figure 2.3.2 is the laminate definition window from $\mathrm{CADEC}^{\odot}$ describing the lay-up. The program was used to estimate the FPF and FF in the hoop and longitudinal directions for a composite with specified lay-up angles and layer thickness. Table 2.3.3 shows the values of FPF and FF for the tri-directional design described in Table 2.3.2.

\subsection{Hybrid Steel/Composite Axisymmetric Model}

A new axisymmetric FEM, original_hybrid.mfl, was created to analyze the steel/composite design in the same manner as the steel FEM in section 2.1. This new model incorporated two separate layers as shown in Figure 2.4.1. The inner layer was 0.155 inch steel with an outer 0.264 inch composite layer. The two layers were separated by a 0.005 inch gap. The actual pipe would not have a gap between the steel and the composite, but it was modeled this way to simplify the application of gap elements between the two materials. Gap elements prevent the parts from passing through one another when one part is displaced into the spaced occupied by another. These elements were attached between two nodes, one on each part, having close proximity (this procedure is described in Appendix A). Figure 2.4.2 shows the lower half of the meshed model with boundary conditions and details of the gap elements. The gap elements will allow the nodes to separate freely but prevents intersection.

The pressure load was applied and the parts were restrained as described in section 2.1. The elastic material properties of the steel elements were defined consistently with those of generic isotropic steel. The orthotropic material properties, 
engineering constants [24], of the composite and the plastic material definition of the steel were defined after exporting the model to ABAQUS ${ }^{\circledR}$ in file hybridl.inp.

Plastic material properties of 4130 steel were attained from Shigley and Mischke [21], but it was unclear what type of heat treatment would be used on the design, so initially the plastic properties of 4130 annealed were chosen for the analysis. The input file was modified to define the yield strength as $52 \mathrm{ksi}$ and the plastic region of the stressstrain curve to be from $52 \mathrm{ksi}$ to $81 \mathrm{ksi}$ with a $28 \%$ elongation at rupture. The orthotropic elastic material properties of the composite were changed to be consistent with those calculated in Excel. The load step was modified into three steps. The first load step increased from 0.0 to $22.5 \mathrm{ksi}$ internal pressure, which is the autofretage load to yield the steel. The second load step decreased from 22.5 back to $0.0 \mathrm{ksi}$, which shows how much the steel is compressed under the composite. The final load step increased from 0.0 to $15.0 \mathrm{ksi}$ internal pressure, which is to simulate working pressure under normal conditions after the autofretage process is complete. The ABAQUS ${ }^{\circledR}$ input file is displayed in Appendix B.

The model was input into the ABAQUS ${ }^{\circledR}$ solver. The results were recorded in a “.fil" file which was imported into I-DEAS ${ }^{\circledR}$ for post processing. The file was translated into an I-DEAS ${ }^{\circledR}$ Universal file and then opened for viewing. The post processor in I-DEAS ${ }^{\circledast}$ is icon based which makes it more user friendly than the text command based post processor in ABAQUS ${ }^{\circledR}$. Once in I-DEAS ${ }^{\circledR}$, the result file was found to be missing and upon inspection of the data and message files created by ABAQUS ${ }^{\circledR}$, it was discovered that the model was unable to solve. Error messages indicated that the steel elements were experiencing strains, which exceeded the defined stress-strain curve in the 
material properties section of the input file. The solver was unable to calculate logical results and subsequently terminated the process before reaching a solution.

In an attempt to reach a temporary solution, the plastic region of the stress-strain curve was redefined from $52 \mathrm{ksi}$ to $200 \mathrm{ksi}$ instead of $52 \mathrm{ksi}$ to $85 \mathrm{ksi}$. The ABAQUS ${ }^{\circledR}$ model was solved again producing the same errors; however, to less of an extent as the first run. The stress-strain curve was modified several more times producing the same errors. Finally, the curve exceeded $1000 \mathrm{ksi}$ and a solution was reached. The model was translated into I-DEAS ${ }^{\circledR}$ and the results viewed in its post processor. At this time, the reason behind the errors became clear. The steel was elongating freely, underneath the composite, to the point of catastrophic failure. The end of the composite was not fastened to the steel in a manner in which the longitudinal stress could be transferred from the steel into the composite. This simple oversight was corrected through the use of coupled degrees of freedom (Coupled DOF), see Appendix A. This is a means by which one or more slave nodes are made to conform to a specified set of translations and/or rotations dependent on one master node. This was done in I-DEAS ${ }^{\circledR}$ on 8 pairs of nodes at the end of the composite closest to the fitting. The steel nodes were defined to be the independent master nodes, with each one coupled with the closest available free node on the composite. Details of the Coupled DOF can be seen in Figure 2.4.3.

The model was then exported to ABAQUS ${ }^{\circledR}$ and the plastic material properties of the steel were set to the correct values. A solution was reached and the message and data files were examined and showed zero errors. The model was imported back into $\mathrm{I}-D E A S^{\circledR}$ and viewed in the post processor. The Von Mises stress values for the steel were recorded at each load step, but Von Mises is not a valid method for use with 
orthotropic materials. It is not out of the ordinary for the material properties of composites to differ in all three coordinate planes, such is the case with this hybrid design. Therefore, it was necessary to view the $\mathrm{X}, \mathrm{Y}$ and $\mathrm{Z}$ stresses separately for the composite elements. The analysis was focused mainly on the hoop stresses (Z-axis) and the longitudinal stresses (Y-axis). There was a high stress concentration at the location of the longitudinal force because the load was not well distributed over several nodes, therefore the stress values near that location were neglected. The max stresses in the composite's hoop and longitudinal directions were recorded and the safety factor, S.F., for the steel at yield and ultimate as well as for the composite at FPF and FF were calculated. The equation for the factor of safety is

$$
\text { S.F. }=\frac{\sigma_{\text {limit }}}{\sigma}
$$

where $\sigma$ is the stress in the steel or composite as calculated by I-DEAS ${ }^{\circledR}$ and $\sigma_{\text {limit }}$ is the limiting strength criteria as shown in Table 2.4.1. The steel elements exceeded the yield point during the first load step and the composite elements did not reach First Ply Failure. The results of the second load step, $0.0 \mathrm{ksi}$, showed that the steel elements were under compressive stress and reached $87.5 \%$ of compressive yield. The third load step, $15 \mathrm{ksi}$, showed good results with a 2.37 factor of safety to yield the steel and 3.88 S.F. for failure. The stresses and factors of safety at each load step are shown in Table 2.4.2.

\subsection{Optimization of the Hybrid Design}

In order to optimize the weight of the design, Excel spreadsheet as4_\&_t800_with_52ksi_\&_100ksi.xls was created. It calculated the required composite thickness when the steel thickness varied from 0.31 inch to 0.01 inch, in 0.01 inch increments. It was used to compare two different types of 4130 steel with yields of $52 \mathrm{ksi}$ 
and $100 \mathrm{ksi}$. It also compared two different CFRPs, AS4 and T800. Four cases were formed: AS4 with $52 \mathrm{ksi}$ yield, AS4 with $100 \mathrm{ksi}$ yield, T800 with 52 ksi yield and T800 with 100 ksi yield.

The same methods as described in the previous sections were used for computing composite thickness due to each specified steel thickness. The $\left[ \pm 20^{\circ}, 90^{\circ}\right]$ design was used in all scenarios. The thickness of steel was plotted versus the composite thickness needed to perform the autofrettage process, see Figure 2.5.1. From this plot it can be seen that for steel yield strength of $52 \mathrm{ksi}$, the pipe cannot be autofrettaged when $t_{s}$ is greater than 0.21 inch (the composite would have zero thickness). The same is true for $100 \mathrm{ksi}$ steel with a thickness greater than 0.11. Figure 2.5.2 shows the steel thickness versus the weight of steel and the hoop-wound composite. It became clear from this graph that increasing the steel yield strength decreases the weight of the pipe. A third graph, Figure 2.5.3, was created to show the thickness of the steel versus the safety factor for the hoop-wound fibers at autofrettage pressure. The safety factor was found from

$$
\text { S.F. }=\frac{N_{\max }}{N_{h}}
$$

where $N_{h}$ was found from (2.2.14) and the maximum stress resultant, $N_{\max }$, is

$$
N_{\max }=N_{s}+N_{F F_{\text {hoop }}}
$$

Equation (2.2.13) was used to calculate the stress resultants of the steel at yield and of the hoop-wound composite at Fiber Failure, $N_{s}$ and $N_{F F h o o p}$ respectively.

The factor of safety graph was needed to choose a steel and composite combination with the same performance standards as the original pipe. From this plot, it was realized that a thickness range existed where the $52 \mathrm{ksi}$ steel had a factor of safety below 1.0 and would not withstand the autofrettage load. It was also noticed that for the 
$100 \mathrm{ksi}$ steel, there existed a range where the thickness could be reduced without the need for any composite to be added; however, the safety factor was reduced linearly to 1.0. Secondly, it was noted that beyond this region the safety factor continued to decrease below 1.0. Once the steel dropped below a certain thickness, the safety factor increased and passed the 1.0 mark. This plot revealed that for some steel thickness, more composite material was needed to keep the pipe from bursting than was needed for autofrettage.

The spreadsheet was modified to calculate the thickness of the hoop composite needed to keep the pipe from failing

$$
t_{\text {hoop-fail }}=\frac{N_{h}-N_{s}}{F F_{\text {hoop }}}
$$

This equation comes from rearranging (2.2.15) and was calculated for each thickness of steel. Excel compared the composite thickness needed to autofrettage against the thickness needed to prevent failure and chose the greater of the two. This changed the safety factor plot as shown in Figure 2.5.4. The first thickness range of the $100 \mathrm{ksi}$ steel remained the same with the safety factor decreasing to 1.0 as the steel thickness decreased. At this point, composite material was added to keep the pipe from failing, thus creating a region where the steel thickness decreased while the safety factor remained at 1.0. After the thickness of the steel decreased below 0.10 inch, the safety factor increased linearly since the composite material required for autofrettage was greater than that needed to prevent failure. On the other hand, the $52 \mathrm{ksi}$ steel required the addition of composite even at its thickest and produced a S.F. of 1.0 until the steel thickness decreased below 0.22. 
The safety factor of the original steel pipe was 1.5 when pressurized to $22.5 \mathrm{ksi}$. It was desired that the hybrid pipe have approximately the same safety factor. As the safety factor increased, the steel thickness decreased toward impractical dimensions. Therefore, from the graph, a steel thickness of 0.07 inch for $100 \mathrm{ksi}$ steel and AS4 composite was chosen for FEA because it had a factor of safety equal to 1.632. AS4 was chosen because the high cost T800 carbon fiber did not afford a great difference in calculated performance.

The lay-up angles and thickness from Excel were input into CADEC $^{\odot}$ to determine the composite's strength. The thickness and equivalent elastic material properties of the optimized design are shown in Table 2.5.1. The orthotropic properties were converted into the coordinate system used in $\mathrm{ABAQUS}^{\circledR}$ as previously described. The FPF and FF values of the composite for the hoop and longitudinal directions are shown in Table 2.5.2.

A new FEM was created in I-DEAS $^{\circledR}$ according to the optimized design. It followed the same form as the previous models, using two layers of axisymmetric elements separated by gap elements. The thickness of the steel elements and the $\left[ \pm 20^{\circ}\right.$, $90^{\circ}$ ] composite elements followed Table 2.5.1. The boundary conditions and loads were applied in the same manner as described for earlier models. The FEM was exported to ABAQUS $^{\circledR}$ to be edited and solved. The new composite material properties from Excel and the plastic material definition for the steel were input. The ultimate stress for the steel was chosen to be $118 \mathrm{ksi}$ at $22 \%$ elongation [21]. As in the previous FEA, the loading was divided into three steps and the model was solved. 
After a solution had been reached, the model was imported into I-DEAS ${ }^{\circledR}$ to view the results. Table 2.5.3 shows the stresses and safety factors at each load step. It was determined that the composite was withstanding the loads and was allowing the steel to yield in the first load step. The steel then reached $81 \%$ of compressive yield during the second step. The model also faired well under the third load step, which is working pressure after autofrettage. Although the stresses exceeded the First Ply Failure, the composite did not reach Fiber Failure.

It was determined that the yield strength of the steel is an extremely important factor with respect to weight reduction. The $100 \mathrm{ksi}$ steel proved to be superior to the 52 ksi steel for this application. It was also determined that the weight of the pipe could be reduced further by an increased fiber elastic modulus. When compared to AS4, T800 showed a minimal improvement in performance but this was overshadowed by its higher cost. Therefore AS4 was determined to be the fiber of choice.

\subsection{Bending Analysis}

Through finite element analysis, the pipe was proven to perform under pressure loads of $22.5 \mathrm{ksi}$. The following analyses were performed to determine the bending stress under certain load cases and the maximum bending load for a simply supported beam. The strength contribution of the thin-walled steel was neglected in these analyses in order to simplify the calculations. All bending analyses were performed by hand.

The first load case simulated a situation in which a worker carries the pipe at its midpoint. This was modeled as a beam with the moment of inertia of the composite over-wrap calculated as

$$
I=\pi r^{3} t
$$


where $r$ is the inner radius of the composite over-wrap and $t$ is its thickness. It was loaded with a concentrated load, $W_{\text {fitting }}$, at each end, equal to the weight of the fittings, and a distributed load along the entire length of the pipe to simulate the weight of the composite plus the thin-walled steel. The weight of each fitting is $4.57 \mathrm{lbs}$. The distributed load, $w_{p}$, is the total weight per length of the hybrid pipe without fittings and was calculated using (2.2.47). A single positive concentrated load in the middle of the beam was used as the support point and was calculated as

$$
R=2 W_{\text {fiting }}+w_{c} l+w_{s} l
$$

where $l$ is the pipe length between fittings. Figure 2.6.1 shows the pipe with the described boundary conditions.

A shear diagram was plotted, Figure 2.6.2, and the maximum moment was equal to one of the shaded areas enclosed by the $x$-axis and the curve in the shear diagram, as calculated by (2.6.3).

$$
M_{\text {max }}=\frac{l}{2} W_{\text {fiting }}+\frac{1}{2}\left\{\frac{l}{2}\left(\frac{R}{2}-W_{\text {fititing }}\right)\right\}
$$

The maximum stress, $\sigma_{\max }$, was calculated from

$$
\sigma_{\max }=\frac{M_{\max } c}{I}
$$

where $c$ is the outer radius of the composite.

The analysis showed that the pipe would withstand this load case with an extremely large safety factor of 95 .

The second beam bending analysis was performed for three quarters of the pipe cantilevered off of a platform, while the remaining 2.5 feet support the pipe. A negative load, $R_{2}$, was applied on the end resting on the platform and a positive resultant load, $R_{l}$, 
was applied two feet from that end to simulate the edge of the platform. A uniform distributed load, $w_{p}$, was applied on the entire length of the pipe simulating its weight per unit length. Concentrated loads, $W_{\text {fitting }}$, were applied at each end of the pipe to simulate weight of the fittings. Figure 2.6.3 describes this load scenario. A force balance equation was created as follows

$$
\sum F_{y}=-w_{p} l-2 W_{\text {fiting }}+R_{1}-R_{2}=0
$$

This was rearranged to solve for $R_{2}$ in term of the other components as

$$
R_{2}=R_{1}-w_{p} l-2 W_{\text {fitting }}
$$

The values of the resultants were found using the moment balance equation about $R_{2}$, as shown

$$
\sum M_{R_{2}}=\left(\frac{w_{p}}{4}\right)\left(\frac{l}{8}\right)-R_{1}\left(\frac{l}{4}\right)+\left(\frac{3 w_{p}}{4}\right)\left(\frac{5 l}{8}\right)+W_{\text {fiting }} l=0
$$

The value for $R_{l}$ was found by rearranging the above equation as follows

$$
R_{1}=\left(\frac{4}{l}\right)\left\{\left(\frac{w_{p}}{4}\right)\left(\frac{l}{8}\right)+\left(\frac{3 w_{p}}{4}\right)\left(\frac{5 l}{8}\right)+W_{\text {fiting }} l\right\}
$$

and $R_{l}$ was found by back substitution into (2.6.6).

A shear diagram was drawn and used to find the maximum moment, which was used in the bending stress equation. The shear distribution is shown in Figure 2.6.4. $M_{\max }$ was equal to the area of one of the shaded regions in the shear diagram as calculated from

$$
M_{\max }=\frac{l}{4}\left(W_{\text {fitting }}+R_{2}\right)+\frac{1}{2}\left\{\frac{l}{4}\left(\frac{l}{4} w_{p}\right)\right\}
$$

The maximum stress, $\sigma_{\max }$, was calculated from (2.6.4). This analysis resulted in a large safety factor of 47 . 
The final bending analysis was for a simply supported pipe. This analysis was useful for determining what would happen to the pipe if a worker stood or sat on it at it's midpoint. The model consisted of a beam loaded with a uniform distributed load equal to the total weight of the composite and the steel. It had simply supported boundary conditions and a concentrated load of $250 \mathrm{lbs}$ applied midway between the pipe ends. This load case is pictured in Figure 2.6.5.

The reaction forces, $R_{1}$ and $R_{2}$, were equal due to the symmetric boundary conditions and were calculated by

$$
R_{1}=R_{2}=\left(\frac{w_{p} l+2 W_{\text {fiting }}+250}{2}\right)
$$

The shear distribution is shown in Figure 2.6.6 and was used to calculate the maximum moment from the following

$$
M_{\max }=\frac{l}{2}(125)+\frac{1}{2}\left\{\frac{l}{2}\left(\frac{l}{2} w_{p}\right)\right\}
$$

The maximum stress, $\sigma_{\max }$, was calculated from (2.6.4). This analysis resulted in a satisfactory safety factor of 8.1.

It was desired to determine the maximum load the pipe could withstand for the simply supported beam scenario. A reverse calculation was performed by defining the maximum allowable bending stress as equal to the longitudinal Fiber Failure value of the composite as shown

$$
\sigma_{\text {max }}=F F_{\text {long }}
$$

The maximum moment was determined by rearranging (2.6.4) to get

$$
M_{\text {max }}=\frac{\sigma_{\text {max }} I}{c}
$$


and the maximum allowable force, $F_{\max }$, was calculated by

$$
F_{\text {max }}=2\left\{\frac{2}{l}\left[M_{\text {max }}-\frac{1}{2}\left\{\frac{l}{2}\left(\frac{l}{2} w_{p}\right)\right\}\right]\right\}
$$

The calculated maximum force, using the equations above, was $2146 \mathrm{lbs}$. The maximum force was also calculated using

$$
F_{\max }=S \cdot F \cdot * F
$$

where $F$ is the $250 \mathrm{lb}$ load from the previous analysis and S.F. is 8.1 . This resulted in a maximum force of $2025 \mathrm{lbs}$, which is slightly conservative when compared to the results from (2.6.14).

\subsection{Conclusions}

From the research and analysis recorded in this chapter it was concluded that:

- Finite element analysis using I-DEAS and ABAQUS with a two dimensional axisymmetric model produces valuable results upon which design decisions can be made.

- A bi-directional composite lay-up is not as efficient as a tri-directional laminate.

- The equation derived for determining the thickness of the hoop wound composite was proven to be inaccurate and was increased by a factor of 1.95 to obtain good results from the finite element analysis.

- Steel with higher yield strength is more efficient.

- The FEM of the tri-directional design predicted that the pipe would withstand the $22.5 \mathrm{ksi}$ internal pressure and would be autofrettaged to produce a residual stress $81 \%$ of compressive yield for a steel with a yield strength of $100 \mathrm{ksi}$. 
- The bending analysis predicted that the pipe could withstand a load of over $2000 \mathrm{lbs}$ applied at the middle of the pipe with simply supported boundary conditions. 
Table 2.2.1 - Orthotropic elastic material properties of AS4 in unidirectional and $\pm 20^{\circ}$ bi-directional lay-ups.

\begin{tabular}{|c|c|c|}
\hline & Unidirectional & $\pm 20^{\circ} \mathrm{Bi}$-directional \\
\hline$E_{1}=$ & $2.060 \mathrm{E}+07$ & $1.426 \mathrm{E}+07$ \\
\hline$E_{2}=$ & $1.494 \mathrm{E}+06$ & $1.684 \mathrm{E}+06$ \\
\hline$E_{3}=$ & $1.494 \mathrm{E}+06$ & $1.530 \mathrm{E}+06$ \\
\hline$G_{12}=$ & $1.044 \mathrm{E}+06$ & $2.823 E+06$ \\
\hline$G_{13}=$ & $1.044 \mathrm{E}+06$ & $9.413 \mathrm{E}+05$ \\
\hline$G_{23}=$ & $1.640 \mathrm{E}+05$ & $2.669 \mathrm{E}+05$ \\
\hline$v_{12}=$ & 0.270 & 1.109 \\
\hline$v_{13}=$ & 0.270 & 0.008 \\
\hline$v_{23}=$ & 0.290 & 0.258 \\
\hline$v_{32}=$ & 0.290 & 0.234 \\
\hline$v_{21}=$ & 0.020 & 0.131 \\
\hline$v_{31}=$ & 0.020 & 0.001 \\
\hline
\end{tabular}

Table 2.2.2 - Required composite thickness to autofrettage 0.155 inch thick steel according to bidirectional fiber orientation $\pm \theta$.

\begin{tabular}{|c|c|c|c|c|}
\hline $\boldsymbol{\pm} \boldsymbol{\theta}$ & $\boldsymbol{E}_{\text {hoop }}[\mathrm{psi}]$ & $\boldsymbol{t}_{\text {hoop }}[\mathrm{in}]$ & $\boldsymbol{E}_{\text {long }}$ [psi] & $\boldsymbol{t}_{\text {long }}[\mathrm{in}]$ \\
\hline 0 & $1.494 \mathrm{E}+06$ & 2.775 & $2.060 \mathrm{E}+07$ & 0.061 \\
\hline 5 & $1.504 \mathrm{E}+06$ & 2.757 & $2.024 \mathrm{E}+07$ & 0.062 \\
\hline 10 & $1.535 \mathrm{E}+06$ & 2.700 & $1.910 \mathrm{E}+07$ & 0.065 \\
\hline 15 & $1.592 \mathrm{E}+06$ & 2.603 & $1.706 \mathrm{E}+07$ & 0.073 \\
\hline 20 & $1.684 \mathrm{E}+06$ & 2.462 & $1.426 \mathrm{E}+07$ & 0.087 \\
\hline 25 & $1.823 \mathrm{E}+06$ & 2.274 & $1.118 \mathrm{E}+07$ & 0.109 \\
\hline 30 & $2.032 \mathrm{E}+06$ & 2.040 & $8.380 \mathrm{E}+06$ & 0.144 \\
\hline 35 & $2.347 \mathrm{E}+06$ & 1.767 & $6.183 \mathrm{E}+06$ & 0.191 \\
\hline 40 & $2.821 \mathrm{E}+06$ & 1.470 & $4.608 \mathrm{E}+06$ & 0.251 \\
\hline 45 & $3.536 \mathrm{E}+06$ & 1.173 & $3.536 \mathrm{E}+06$ & 0.319 \\
\hline 50 & $4.608 \mathrm{E}+06$ & 0.900 & $2.821 \mathrm{E}+06$ & 0.389 \\
\hline 55 & $6.183 \mathrm{E}+06$ & 0.671 & $2.347 \mathrm{E}+06$ & 0.456 \\
\hline 60 & $8.380 \mathrm{E}+06$ & 0.495 & $2.032 \mathrm{E}+06$ & 0.515 \\
\hline 65 & $1.118 \mathrm{E}+07$ & 0.371 & $1.823 \mathrm{E}+06$ & 0.565 \\
\hline 70 & $1.426 \mathrm{E}+07$ & 0.291 & $1.684 \mathrm{E}+06$ & 0.603 \\
\hline 75 & $1.706 \mathrm{E}+07$ & 0.243 & $1.592 \mathrm{E}+06$ & 0.632 \\
\hline 80 & $1.910 \mathrm{E}+07$ & 0.217 & $1.535 \mathrm{E}+06$ & 0.651 \\
\hline 85 & $2.024 \mathrm{E}+07$ & 0.205 & $1.504 \mathrm{E}+06$ & 0.662 \\
\hline 90 & $2.060 \mathrm{E}+07$ & 0.190 & $1.494 \mathrm{E}+06$ & 0.666 \\
\hline
\end{tabular}




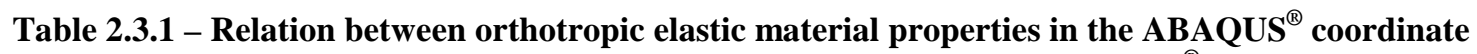
system and the coordinate system used for calculations in Microsoft ${ }^{\circledR}$ Excel.

\begin{tabular}{|c|c|}
\hline Excel & ABAQUS $^{\circledR}$ \\
\hline$E_{1}$ & $E_{y}$ \\
\hline$E_{2}$ & $E_{z}$ \\
\hline$E_{3}$ & $E_{x}$ \\
\hline$G_{12}$ & $G_{y z}$ \\
\hline$G_{13}$ & $G_{x y}$ \\
\hline$G_{23}$ & $G_{x z}$ \\
\hline$v_{12}$ & $v_{y z}$ \\
\hline$v_{13}$ & Not used \\
\hline$v_{23}$ & Not used \\
\hline$v_{32}$ & $v_{x z}$ \\
\hline$v_{21}$ & Not used \\
\hline$v_{31}$ & $v_{x y}$ \\
\hline
\end{tabular}

Table 2.3.2 - Initial tri-directional hybrid design describing composite and steel thickness and equivalent orthotropic elastic material properties using AS4 composite in a $\left[ \pm 20^{\circ}, 90^{\circ}\right]$ lay-up.

\begin{tabular}{|cc|}
\hline$E_{x}=$ & $1.677 \mathrm{E}+06 \mathrm{psi}$ \\
\hline$E_{y}=$ & $6.229 \mathrm{E}+06 \mathrm{psi}$ \\
\hline$E_{z}=$ & $1.464 \mathrm{E}+07 \mathrm{psi}$ \\
\hline$v_{x y}=$ & 0.0967 \\
\hline$v_{x z}=$ & 0.0366 \\
\hline$v_{y z}=$ & 0.0654 \\
\hline$G_{x y}=$ & $1.606 \mathrm{E}+06 \mathrm{psi}$ \\
\hline$G_{x z}=$ & $4.093 \mathrm{E}+05 \mathrm{psi}$ \\
\hline$G_{y z}=$ & $7.990 \mathrm{E}+05 \mathrm{psi}$ \\
\hline$t_{20}=$ & $0.086 \mathrm{in}$ \\
\hline$t_{90}=$ & $0.179 \mathrm{in}$ \\
\hline$t_{[20,90]}=$ & $0.264 \mathrm{in}$ \\
\hline$t_{s}=$ & $0.155 \mathrm{in}$ \\
\hline$\sigma_{s}=$ & $5.200 \mathrm{E}+04 \mathrm{psi}$ \\
\hline
\end{tabular}


Table 2.3.3 - First Ply Failure and Fiber Failure values for the initial tri-directional hybrid design using AS4 composite in a $\left[ \pm 20^{\circ}, 90^{\circ}\right]$ lay-up.

\begin{tabular}{|c|c|c|}
\cline { 2 - 3 } \multicolumn{1}{c|}{} & Hoop & Longitudinal \\
\hline $\mathbf{F P F}=$ & $8.490 \mathrm{E}+04$ & $3.425 \mathrm{E}+04$ \\
\hline $\mathbf{F F}=$ & $1.900 \mathrm{E}+05$ & $8.990 \mathrm{E}+04$ \\
\hline
\end{tabular}

Table 2.4.1 - Description of limiting stresses and symbols for the steel and composite.

\begin{tabular}{|c|c|c|c|c|}
\hline Material & Calculated Stress & Symbol & Limiting Stress & Symbol \\
\hline \multirow{2}{*}{ Steel } & $\begin{array}{c}\text { Von Mises } \\
\text { Stress }\end{array}$ & \multirow{2}{*}{$\sigma_{\text {Von Mises }}$} & Yield Stress & $\sigma_{\text {yield }}$ \\
\cline { 4 - 5 } & Ultimate Stress & $\sigma_{\text {ult }}$ \\
\hline Composite (hoop) & Hoop Stress & \multirow{2}{*}{$\sigma_{\text {hoop }}$} & First Ply Failure & $\mathrm{FPF}_{\text {hoop }}$ \\
\cline { 4 - 5 } Composite (long.) & $\begin{array}{c}\text { Longitudinal } \\
\text { Stress }\end{array}$ & \multirow{2}{*}{$\sigma_{\text {long }}$} & Fiber Failure & $\mathrm{FF}_{\text {hoop }}$ \\
\cline { 4 - 5 } & & First Ply Failure & $\mathrm{FPF}_{\text {long }}$ \\
\cline { 4 - 5 } & & Fiber Failure & $\mathrm{FF}_{\text {long }}$ \\
\hline
\end{tabular}

Table 2.4.2 - Finite element analysis results for the initial tri-directional hybrid design incorporating hoop thickness from flawed equation.

\begin{tabular}{|c|c|c|c|c|c|}
\hline \multicolumn{6}{|c|}{$t_{s}=0.155, t_{\left[ \pm 20^{\circ}, 90^{\circ}\right]}=0.264 \mathrm{w} / 52 \mathrm{ksi}$ Steel } \\
\hline Steel & $\sigma_{\text {Von Mises }}[k s i]$ & $\sigma_{\text {Yield }}[k s i]$ & S.F. & $\sigma_{\text {Ult }}[k s i]$ & S.F. \\
\hline Test & 52.80 & 52.00 & 0.98 & 85 & 1.61 \\
\hline Zero & 45.50 & 52.00 & 1.14 & 85 & 1.87 \\
\hline Work & 21.90 & 52.00 & 2.37 & 85 & 3.88 \\
\hline$[ \pm 20,90]$ & $\sigma_{\text {hoop }}[k s i]$ & $\mathrm{FPF}_{\text {hoop }}[\mathrm{ksi}]$ & S.F. & $\mathrm{FF}_{\text {hoop }}[\mathrm{ksi}]$ & S.F. \\
\hline Test & 68.10 & 84.90 & 1.25 & 190.00 & 2.79 \\
\hline Zero & 36.40 & 84.90 & 2.33 & 190.00 & 5.22 \\
\hline \multirow[t]{2}{*}{ Work } & 57.60 & 84.90 & 1.47 & 190.00 & 3.30 \\
\hline & $\sigma_{\text {long }}[k s i]$ & $\mathrm{FPF}_{\text {long }}[\mathrm{ksi}]$ & S.F. & $\mathrm{FF}_{\text {long }}[\mathrm{ksi}]$ & S.F. \\
\hline Test & 20.60 & 34.25 & 1.66 & 89.99 & 4.37 \\
\hline Zero & 13.30 & 34.25 & 2.58 & 89.99 & 6.77 \\
\hline Work & 18.20 & 34.25 & 1.88 & 89.99 & 4.94 \\
\hline
\end{tabular}


Table 2.4.3 - Finite element analysis results for the initial tri-directional hybrid design incorporating hoop thickness from corrected equation.

\begin{tabular}{|c|c|c|c|c|c|}
\hline \multicolumn{6}{|c|}{$t_{s}=0.155, t_{\left[ \pm 20^{\circ}, 90^{\circ}\right]}=0.184 \mathrm{w} / 52 \mathrm{ksi}$ Steel } \\
\hline Steel & $\sigma_{\text {Von Mises }}[k s i]$ & $\sigma_{\text {Yield }}[k s i]$ & S.F. & $\sigma_{\mathrm{Ult}}[\mathrm{ksi}]$ & S.F. \\
\hline Test & 53.30 & 52.00 & 0.98 & 81.00 & 1.52 \\
\hline Zero & 53.30 & 52.00 & 0.98 & 81.00 & 1.52 \\
\hline Work & 19.80 & 52.00 & 2.63 & 81.00 & 4.09 \\
\hline$[ \pm 20,90]$ & $\sigma_{\text {hoop }}[k s i]$ & $\mathrm{FPF}_{\text {hoop }}[\mathrm{ksi}]$ & S.F. & $\mathrm{FF}_{\text {hoop }}[\mathrm{ksi}]$ & S.F. \\
\hline Test & 91.70 & 67.40 & 0.74 & 150.46 & 1.64 \\
\hline Zero & 58.90 & 67.40 & 1.14 & 150.46 & 2.55 \\
\hline \multirow[t]{2}{*}{ Work } & 80.00 & 67.40 & 0.84 & 150.46 & 1.88 \\
\hline & $\sigma_{\text {long }}[k s i]$ & $\mathrm{FPF}_{\text {long }}[\mathrm{ksi}]$ & S.F. & $\mathrm{FF}_{\text {long }}[\mathrm{ksi}]$ & S.F. \\
\hline Test & 32.50 & 47.64 & 1.47 & 125.54 & 3.86 \\
\hline Zero & 22.50 & 47.64 & 2.12 & 125.54 & 5.58 \\
\hline Work & 29.10 & 47.64 & 1.64 & 125.54 & 4.31 \\
\hline
\end{tabular}

Table 2.5.1 - Optimized tri-directional hybrid design describing composite and steel thickness and equivalent orthotropic elastic material properties for AS4 composite in a $\left[ \pm 20^{\circ}, 90^{\circ}\right]$ lay-up.

\begin{tabular}{|c|c|}
\hline$E_{x}=$ & $1.6915 \mathrm{E}+06 \mathrm{psi}$ \\
\hline$E_{y}=$ & $1.0283 \mathrm{E}+07 \mathrm{psi}$ \\
\hline$E_{z}=$ & 9.3876E+06psi \\
\hline$v_{x y}=$ & $5.3081 \mathrm{E}-02$ \\
\hline$v_{x z}=$ & 5.9179E-02 \\
\hline$v_{y z}=$ & $1.5231 \mathrm{E}-01$ \\
\hline$G_{x y}=$ & $6.2510 \mathrm{E}+05 \mathrm{psi}$ \\
\hline$G_{x z}=$ & $5.8315 \mathrm{E}+05 \mathrm{psi}$ \\
\hline$G_{y z}=$ & $2.0993 \mathrm{E}+06 \mathrm{psi}$ \\
\hline$t_{20}=$ & $0.076 \mathrm{in}$ \\
\hline$t_{90}=$ & $0.129 \mathrm{in}$ \\
\hline$t_{[20,90]}=$ & $0.205 \mathrm{in}$ \\
\hline$t_{s}=$ & $0.070 \mathrm{in}$ \\
\hline$\sigma_{s}=$ & $1.00 \mathrm{E}+05 \mathrm{psi}$ \\
\hline
\end{tabular}


Table 2.5.2 - First Ply Failure and Fiber Failure values for the optimized tri-directional hybrid design using AS4 composite in a $\left[ \pm 20^{\circ}, 90^{\circ}\right]$ lay-up.

\begin{tabular}{|c|c|c|}
\cline { 2 - 3 } \multicolumn{1}{c|}{} & Hoop & Longitude \\
\hline $\mathbf{F P F}=$ & $7.854 \mathrm{E}+04$ & $3.932 \mathrm{E}+04$ \\
\hline $\mathbf{F F}=$ & $1.746 \mathrm{E}+05$ & $1.034 \mathrm{E}+05$ \\
\hline
\end{tabular}

Table 2.5.3 - Finite element analysis results for the optimized tri-directional hybrid design.

\begin{tabular}{|c|c|c|c|c|c|}
\hline \multicolumn{6}{|c|}{$t_{s}=0.07 t_{\left[ \pm 20^{\circ}, 90^{\circ}\right]}=0.205 \mathrm{w} / 100 \mathrm{ksi}$ Steel } \\
\hline Steel & $\sigma_{\text {Von Mises }}[k s i]$ & $\sigma_{\text {Yield }}[k s i]$ & S.F. & $\sigma_{\text {Ult }}[k s i]$ & S.F. \\
\hline Test & 101.00 & 100.00 & 0.99 & 118.00 & 1.17 \\
\hline Zero & 81.40 & 100.00 & 1.23 & 118.00 & 1.45 \\
\hline Work & 41.40 & 100.00 & 2.42 & 118.00 & 2.85 \\
\hline$[ \pm 20,90]$ & $\sigma_{\text {hoop }}[k s i]$ & $\mathrm{FPF}_{\text {hoop }}[\mathrm{ksi}]$ & S.F. & $\mathrm{FF}_{\text {hoop }}[\mathrm{ksi}]$ & S.F. \\
\hline Test & 83.80 & 78.54 & 0.94 & 174.60 & 2.08 \\
\hline Zero & 36.00 & 78.54 & 2.18 & 174.60 & 4.85 \\
\hline \multirow[t]{2}{*}{ Work } & 67.90 & 78.54 & 1.16 & 174.60 & 2.57 \\
\hline & $\sigma_{\text {long }}[k s i]$ & $\mathrm{FPF}_{\text {long }}[\mathrm{ksi}]$ & S.F. & $\mathrm{FF}_{\text {long }}[\mathrm{ksi}]$ & S.F. \\
\hline Test & 31.60 & 39.32 & 1.24 & 103.40 & 3.27 \\
\hline Zero & 12.20 & 39.32 & 3.22 & 103.40 & 8.48 \\
\hline Work & 25.10 & 39.32 & 1.57 & 103.40 & 4.12 \\
\hline
\end{tabular}




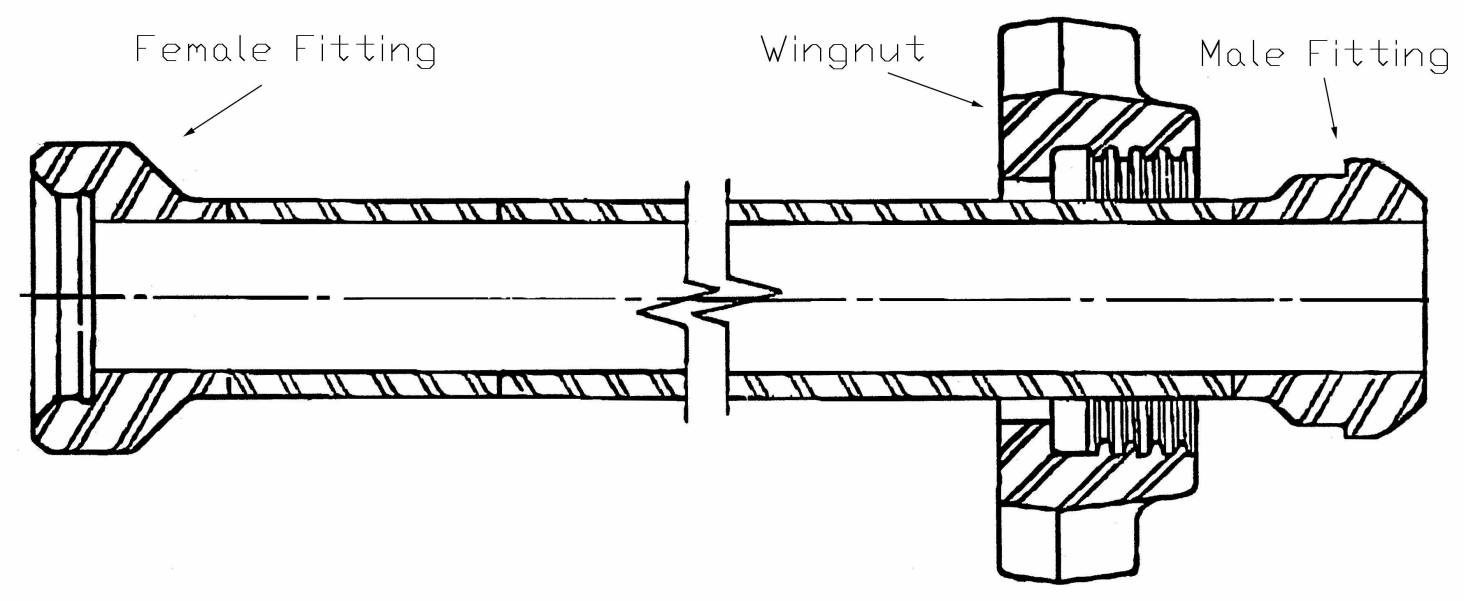

Figure 2.0.1 - Original pipe with hammer union fittings and wingnut. 


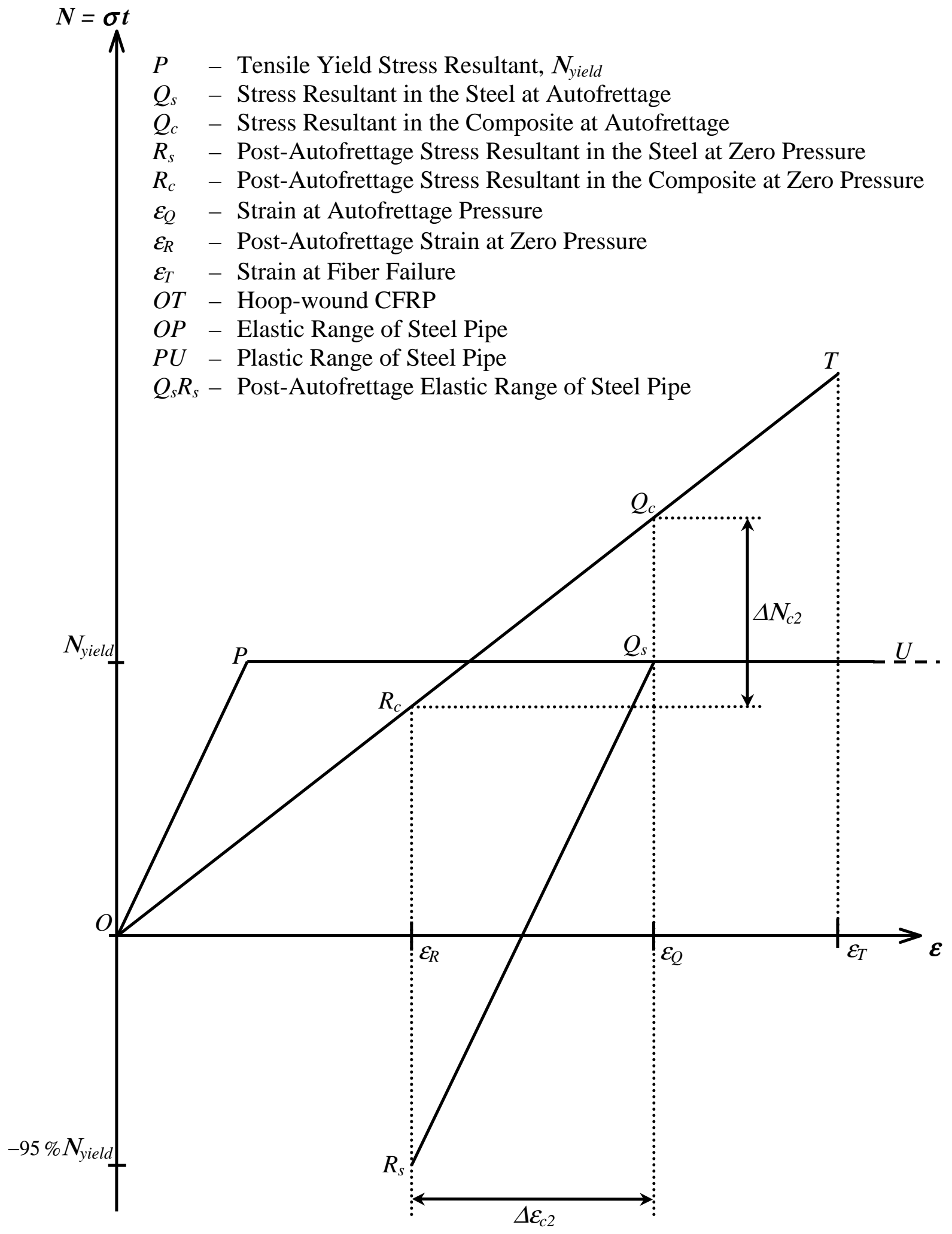

Figure 2.0.2 - Stress resultant versus strain graph for the autofrettage process in the hoop direction. 


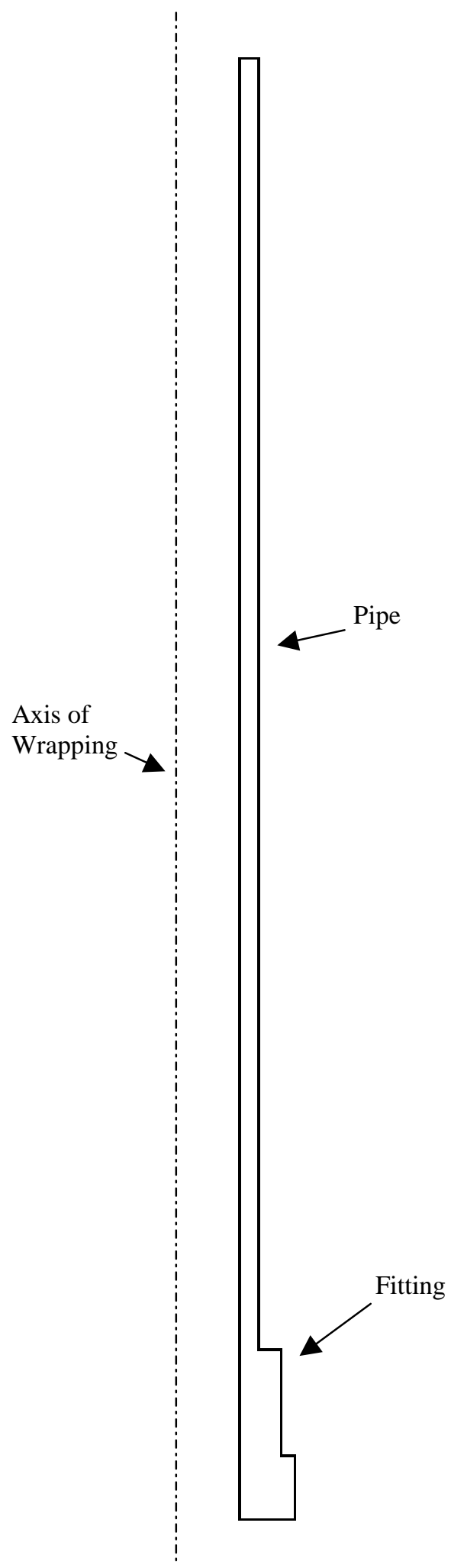

Figure 2.1.1 - Steel axisymmetric model.

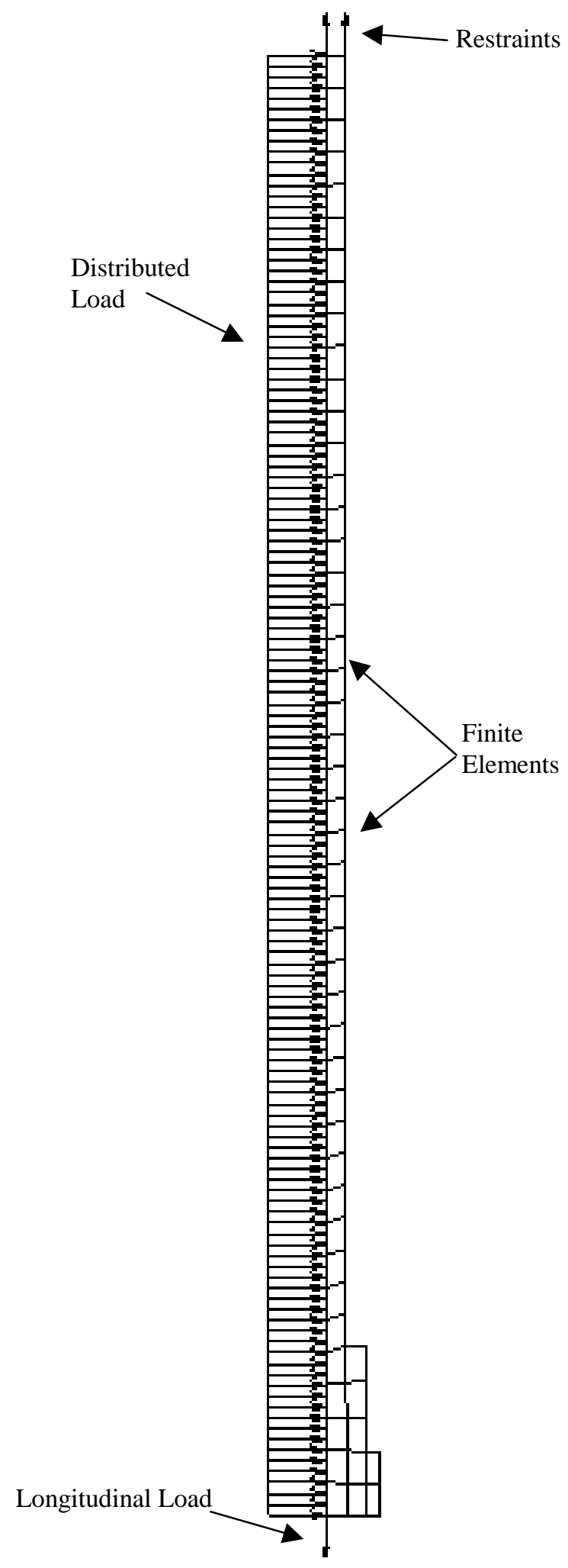

Figure 2.1.2 - FEM with boundary conditions. 


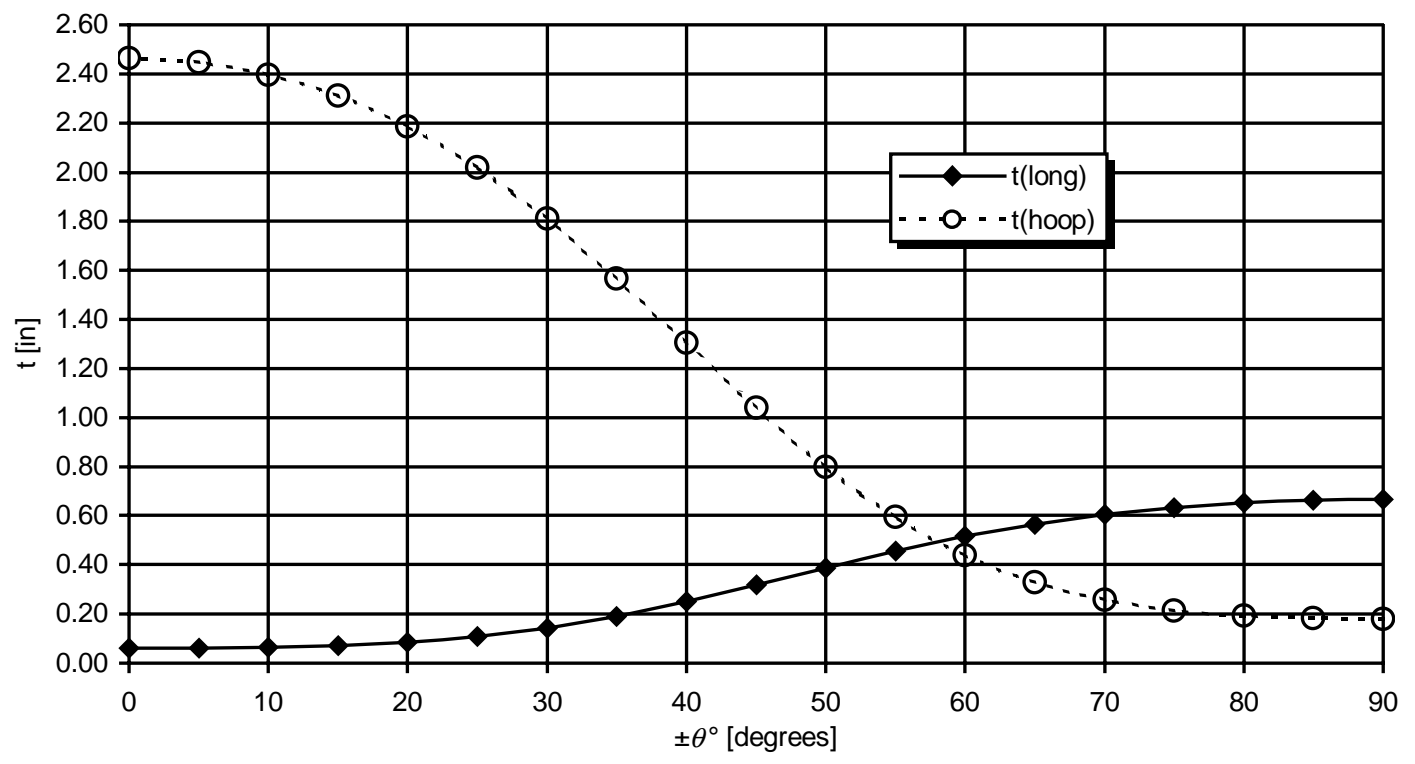

Figure 2.2.1 - Thickness versus lay-up angle for a bi-directional laminate.

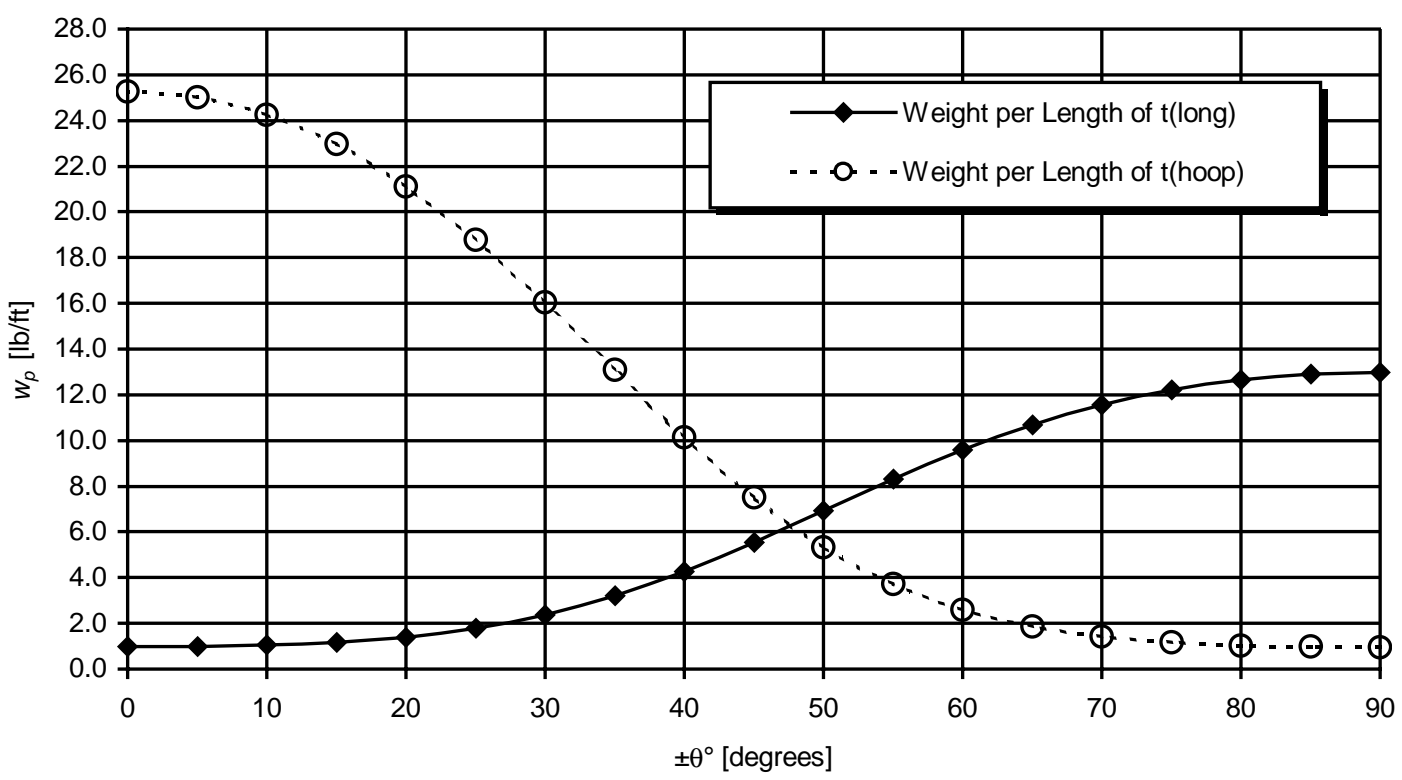

Figure 2.2.2 - Weight per length versus lay-up angle for a bi-directional laminate. 

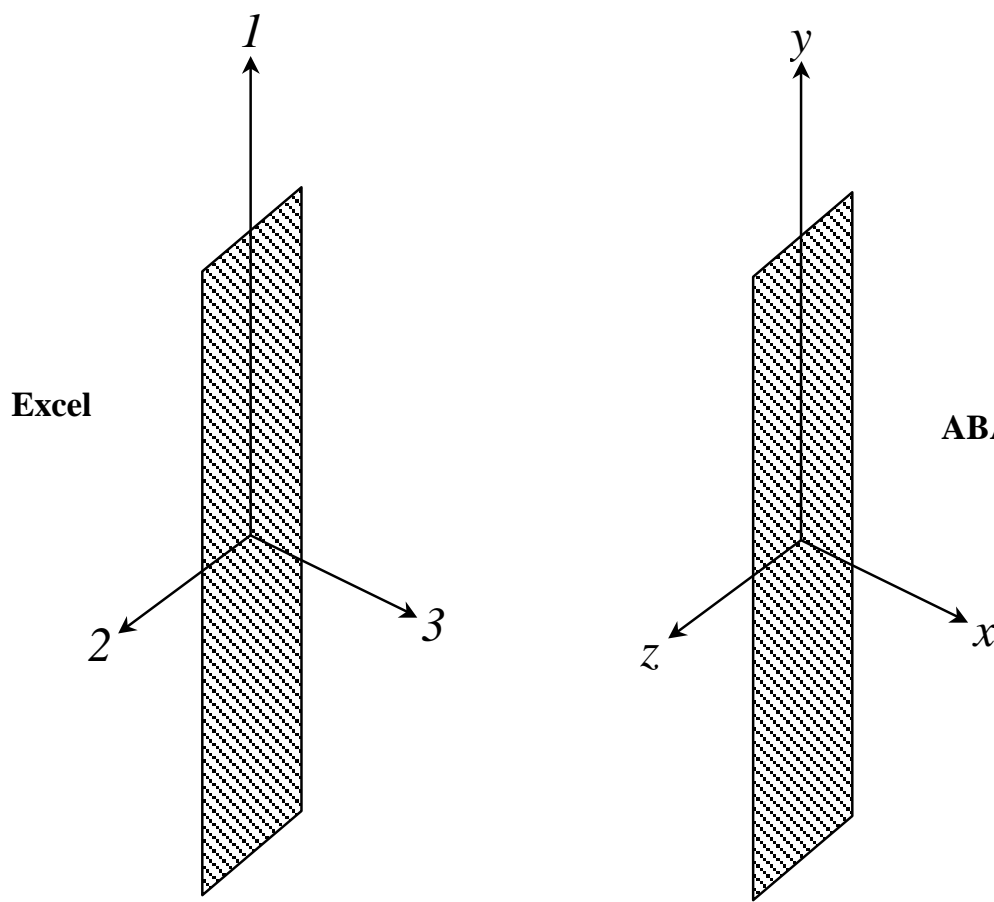

Figure 2.3.1 - Material coordinate systems for Microsoft $^{\circledR}$ Excel and ABAQUS $^{\circledR}$.

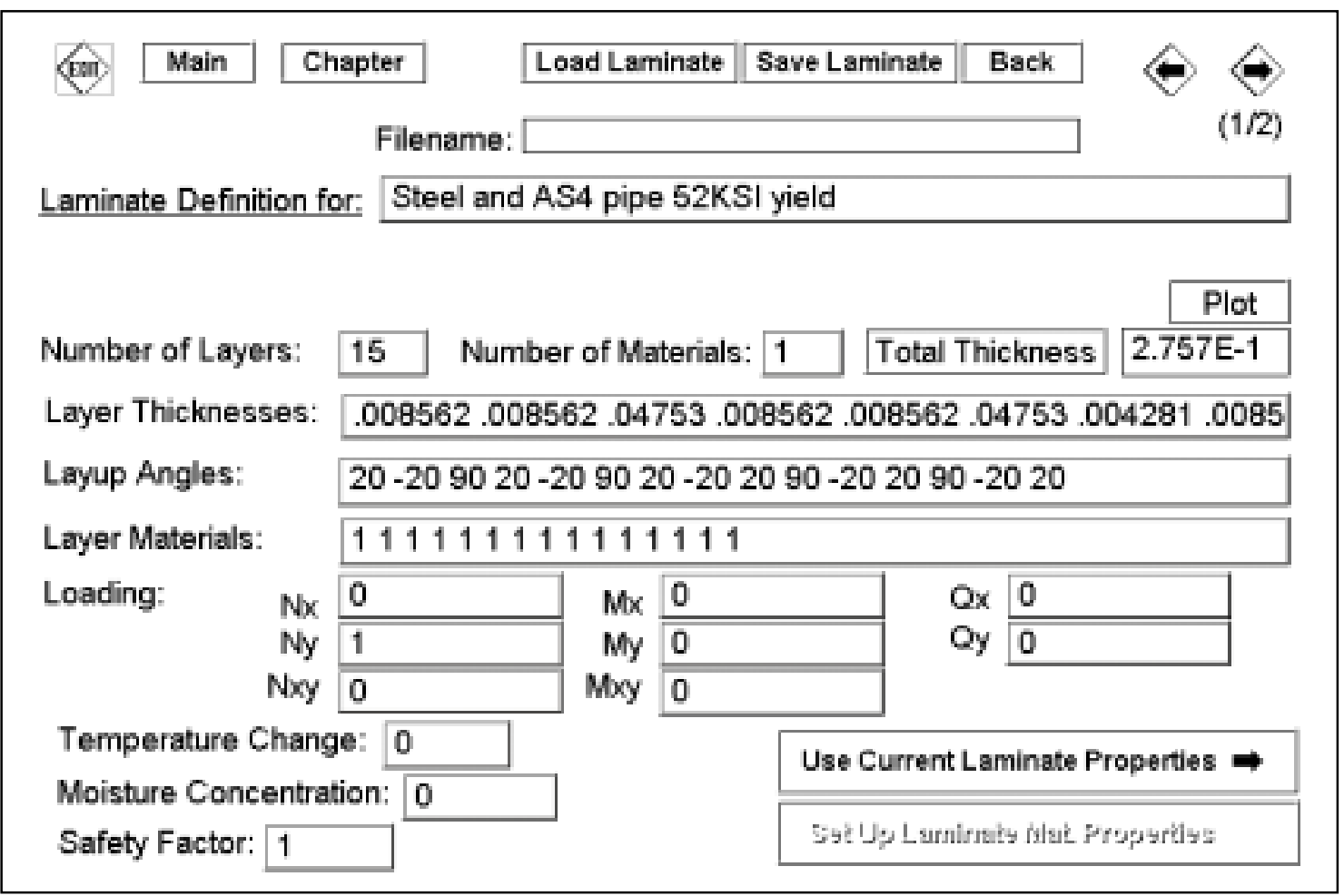

Figure 2.3.2 - AS4 lay-up as defined in CADEC $^{\odot}$. 


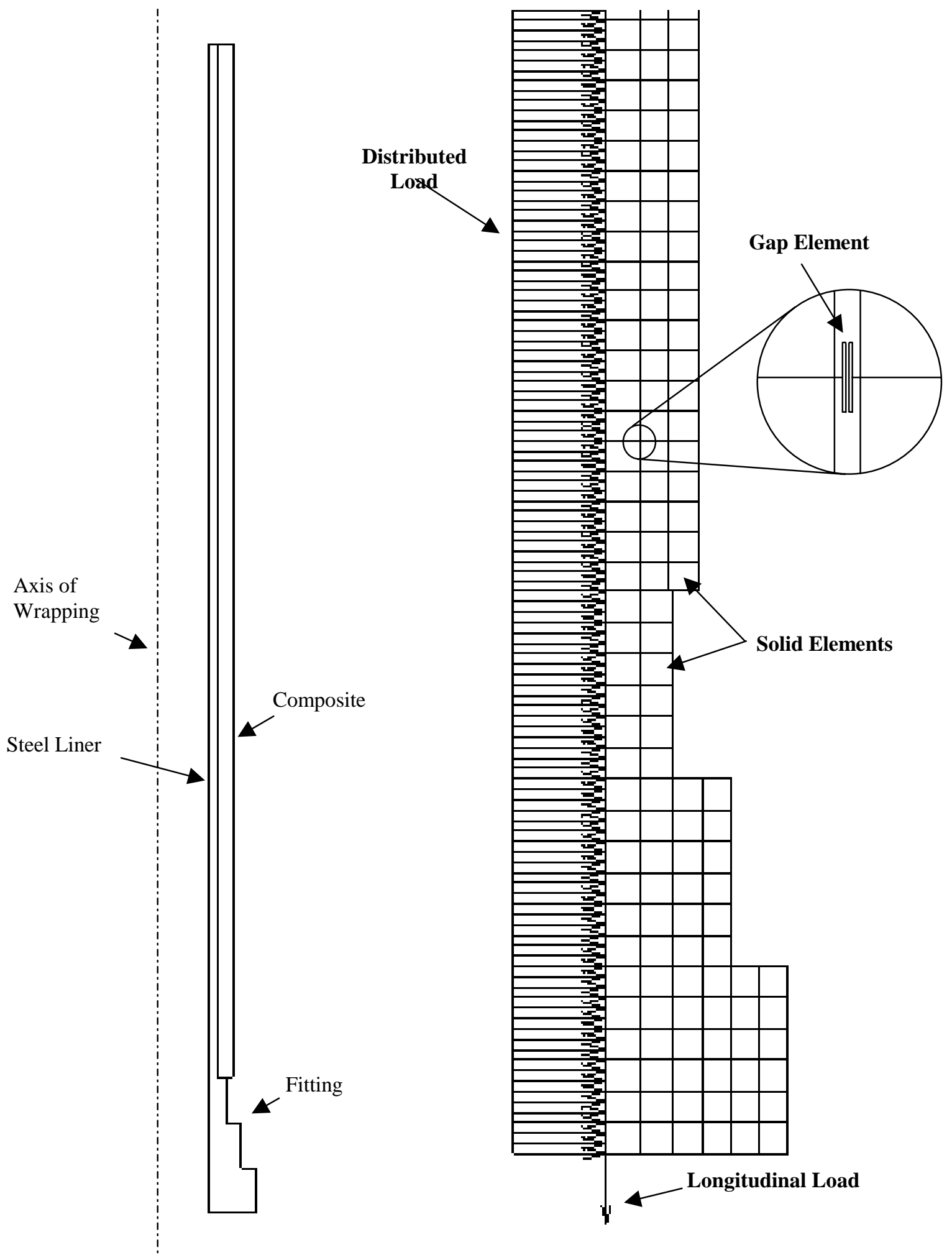

Figure 2.4.1 - Hybrid axisymmetric model.

Figure 2.4.2 - FEM of hybrid pipe. 


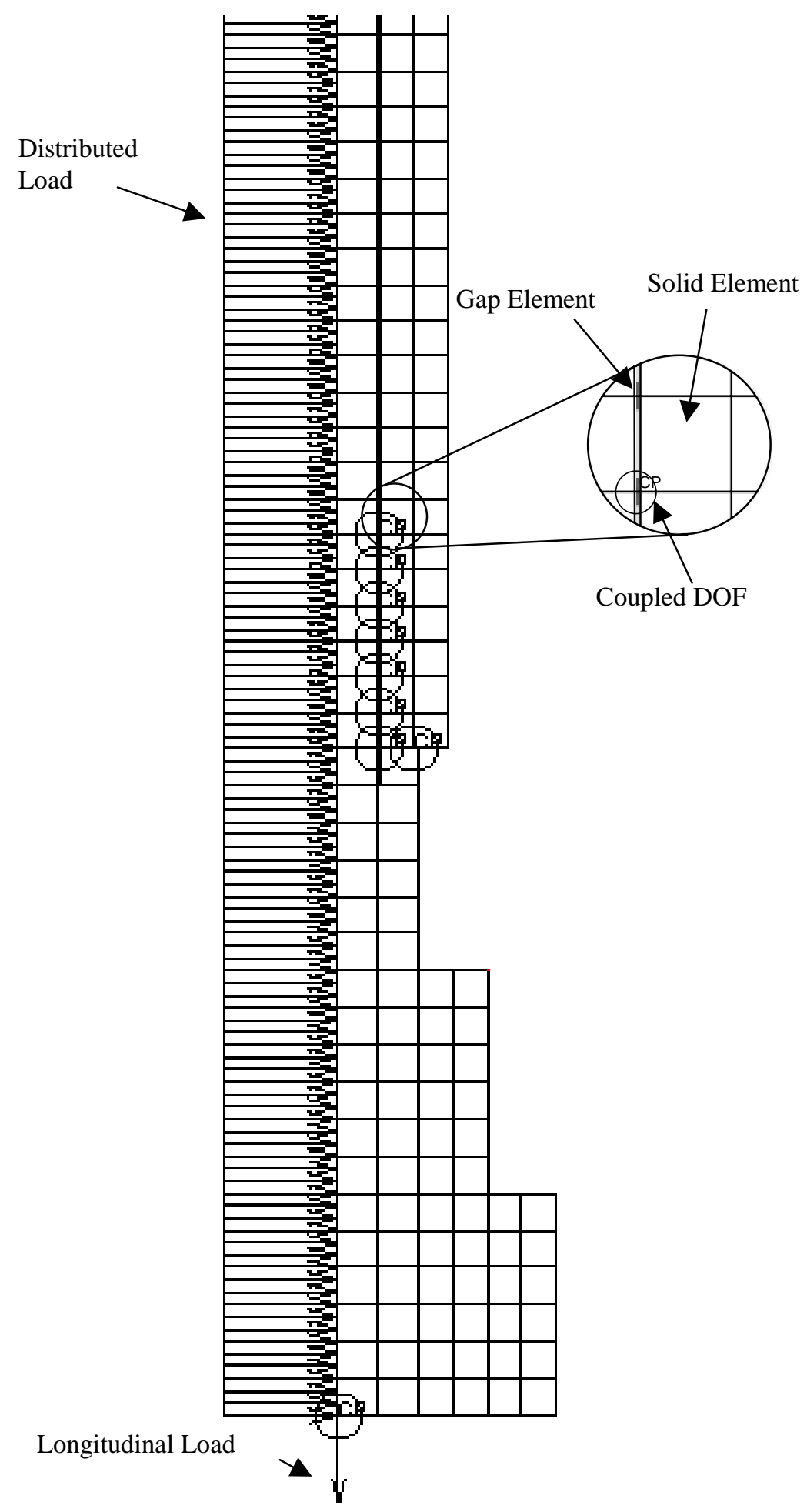

Figure 2.4.3 - FEM of hybrid pipe showing detail of gap elements and Coupled DOF. 


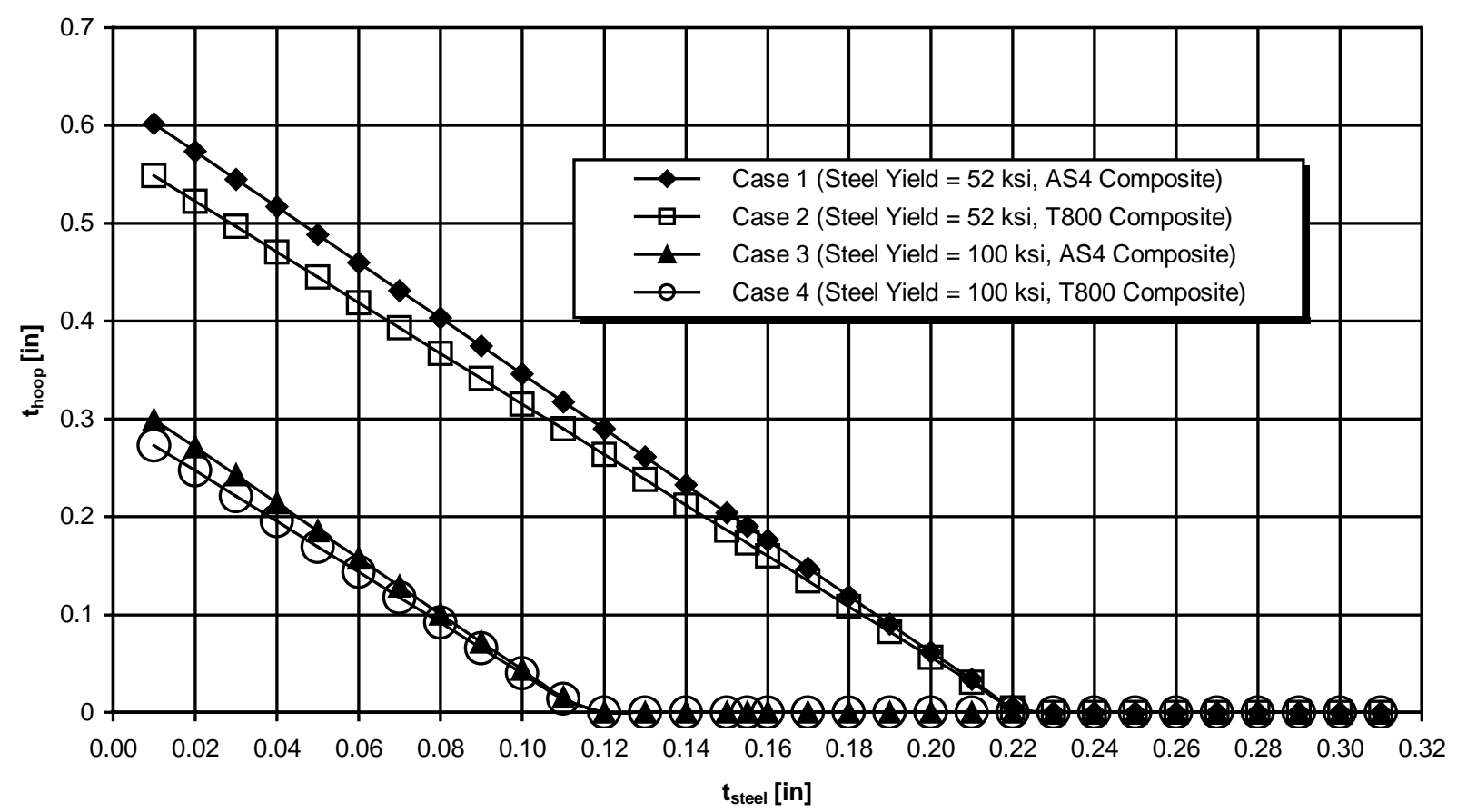

Figure 2.5.1 - Four case comparison of steel thickness versus composite hoop thickness.

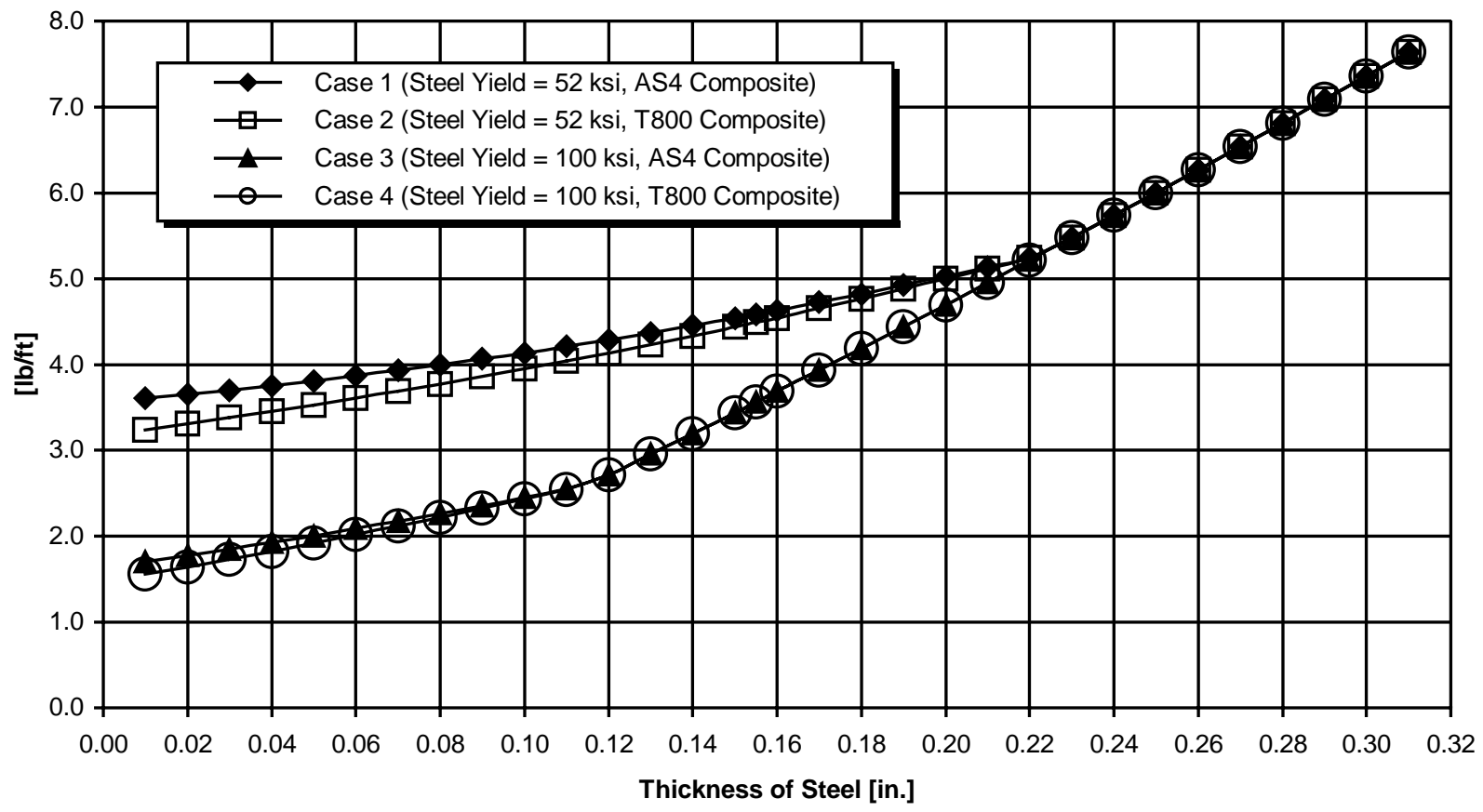

Figure 2.5.2 - Four case comparison of steel thickness versus weight of the steel and hoop-wound composite. 


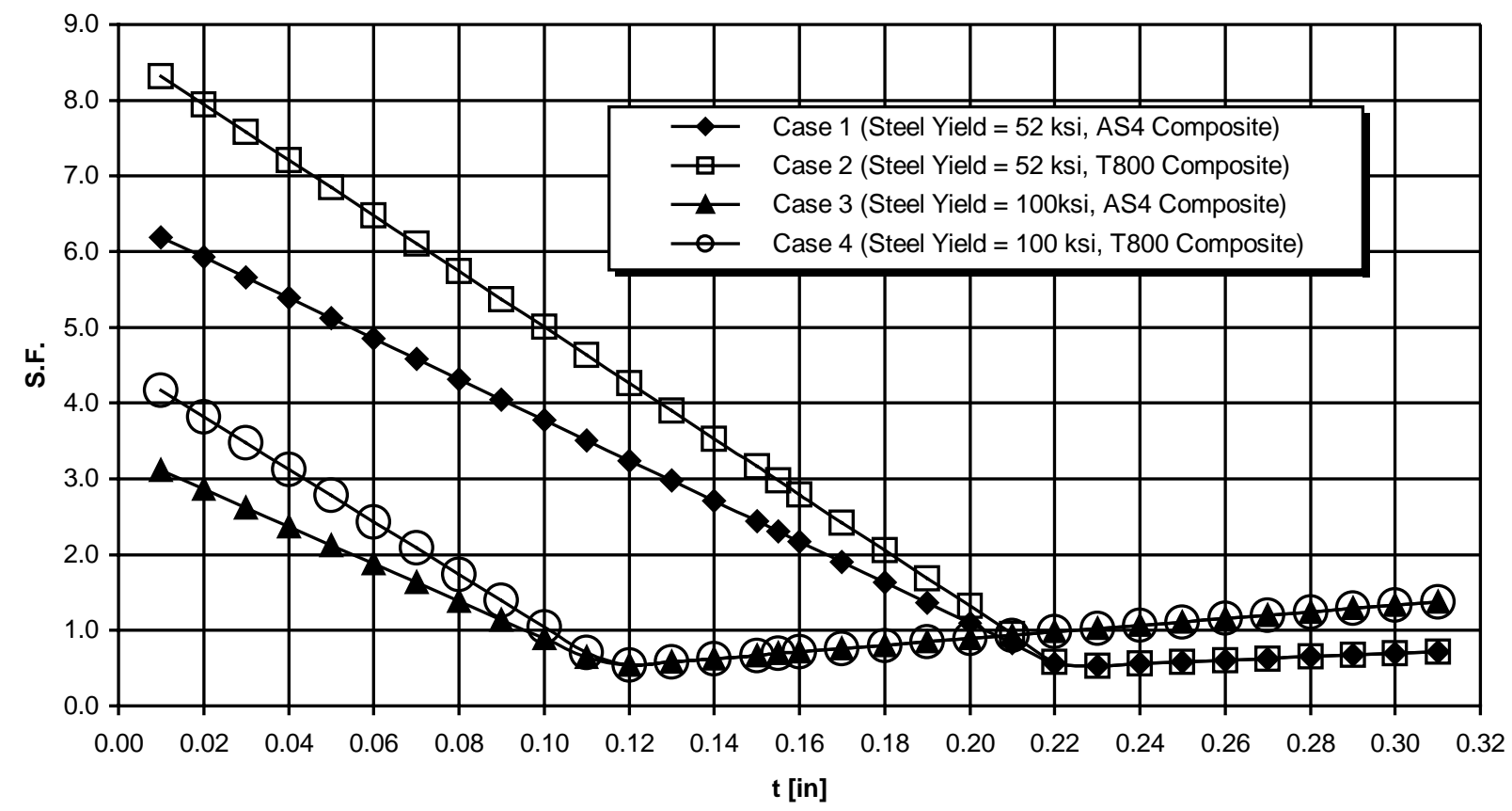

Figure 2.5.3 - Four case comparison of steel thickness versus safety factor for the hoopwound fibers at autofrettage pressure.

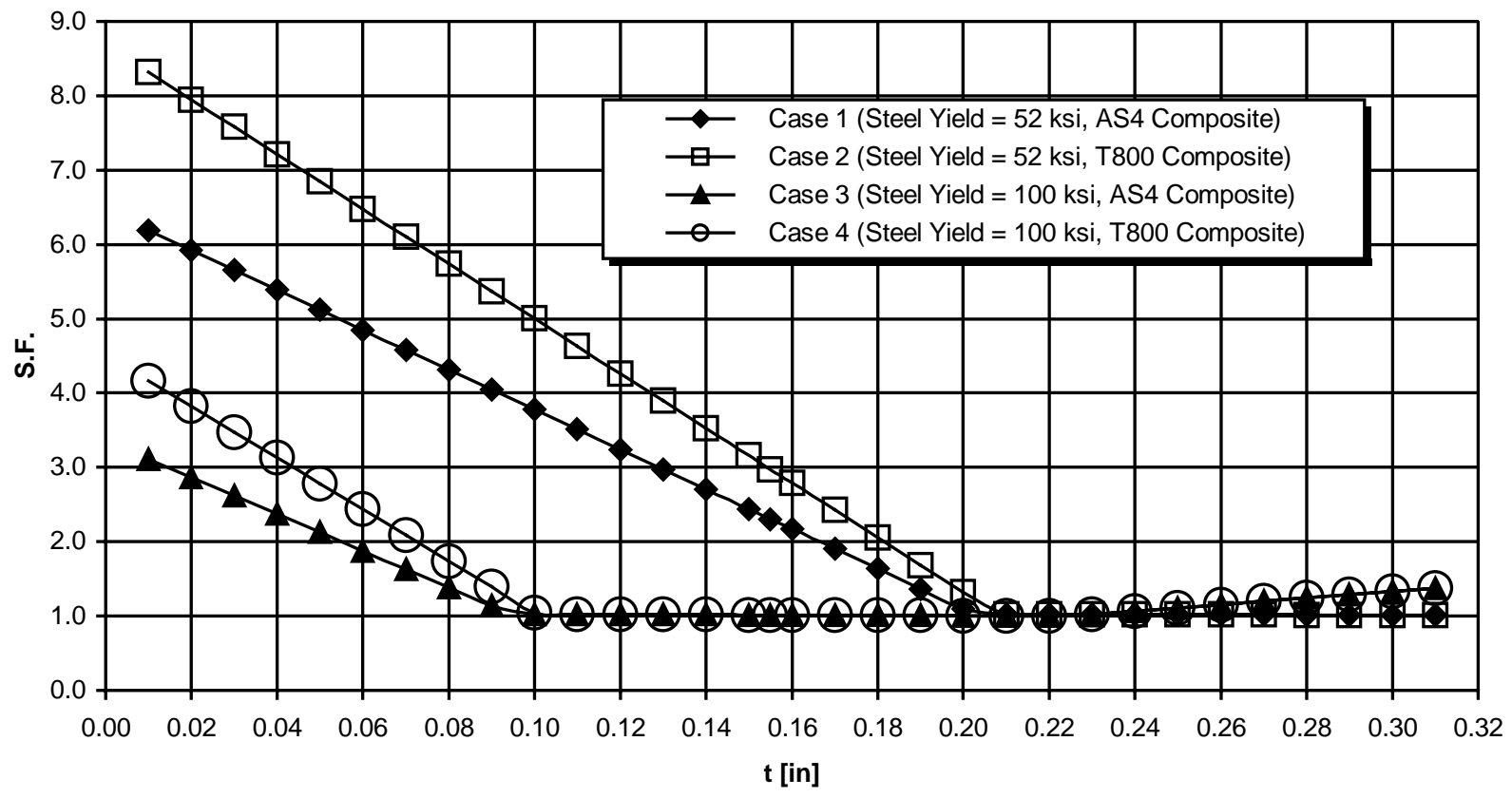

Figure 2.5.4 - Four case comparison of steel thickness versus modified safety factor for the hoop-wound fibers at autofrettage pressure. 


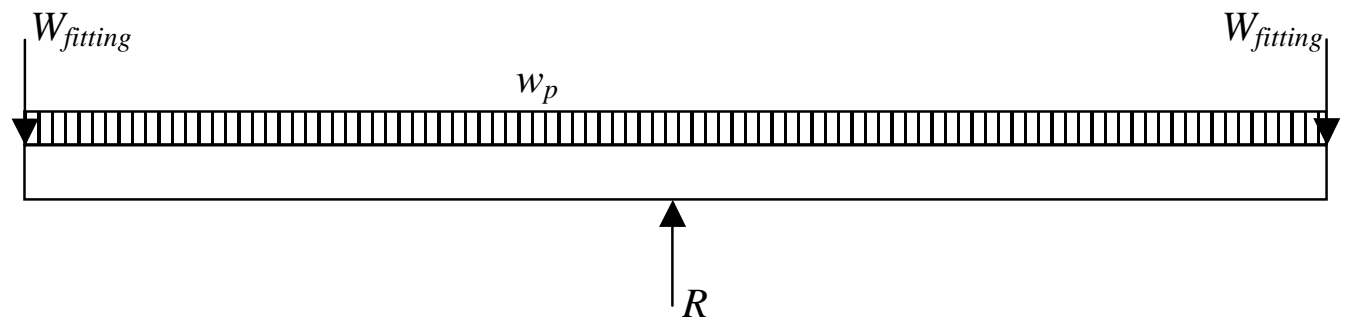

Figure 2.6.1 - Pipe supported at midpoint for first beam bending scenario.

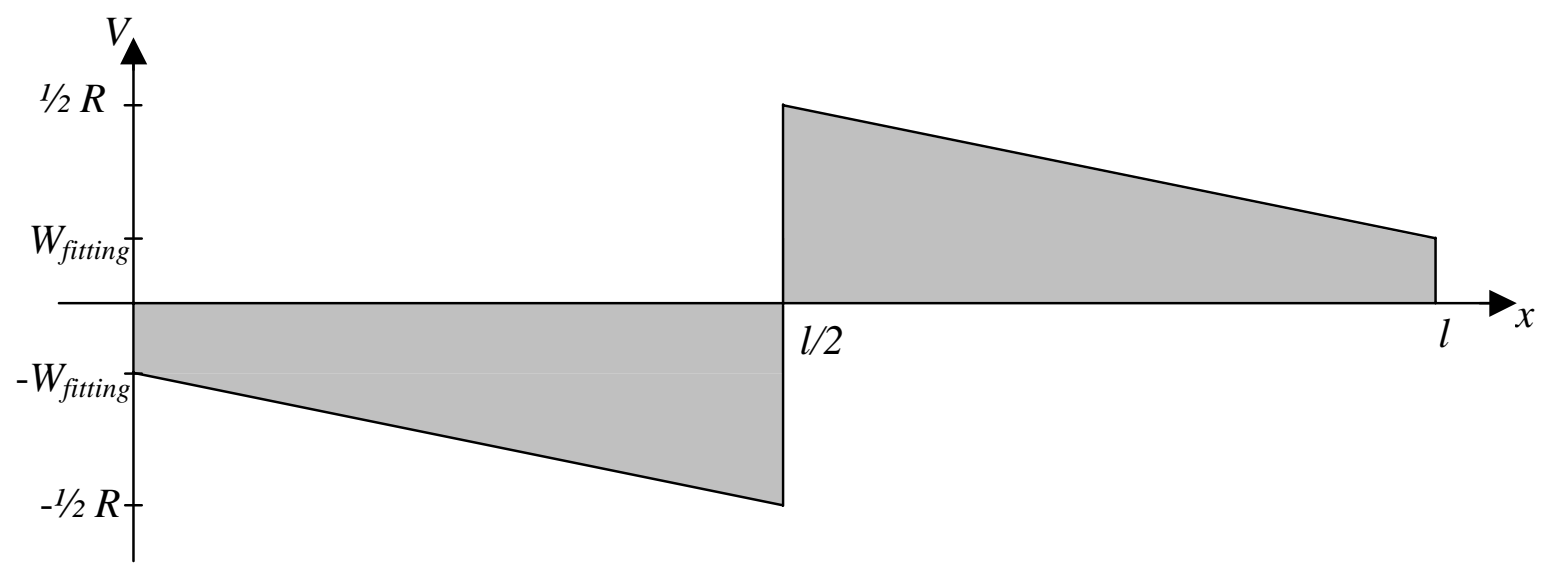

Figure 2.6.2 - Shear distribution for first beam bending scenario.

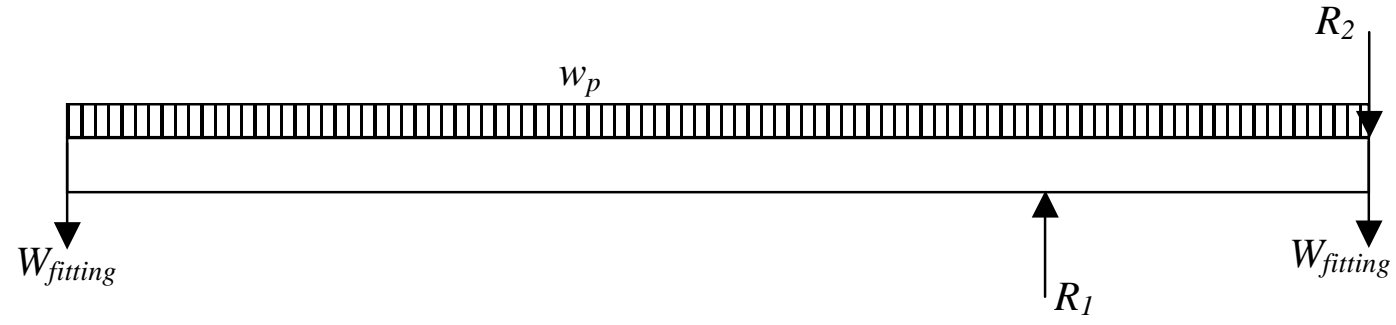

Figure 2.6.3 - Pipe and boundary conditions for second beam bending scenario.

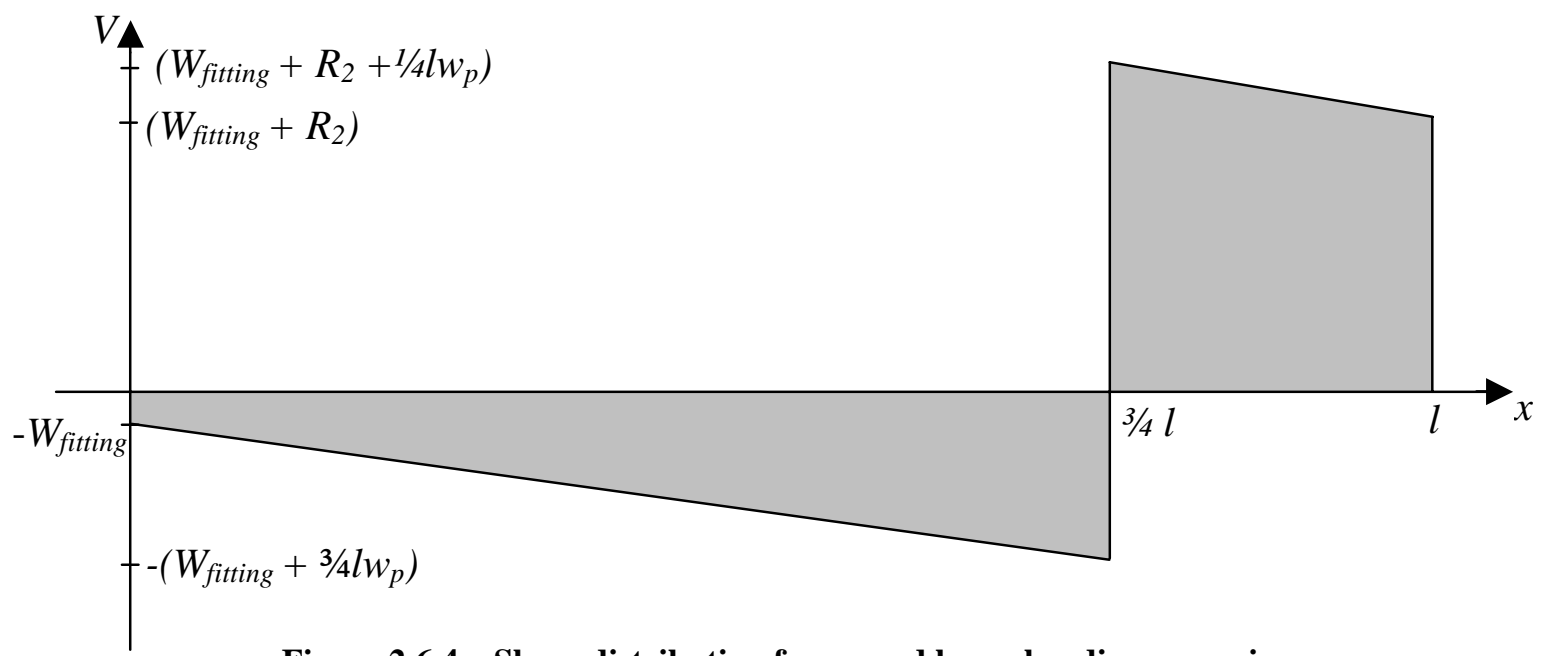

Figure 2.6.4 - Shear distribution for second beam bending scenario. 


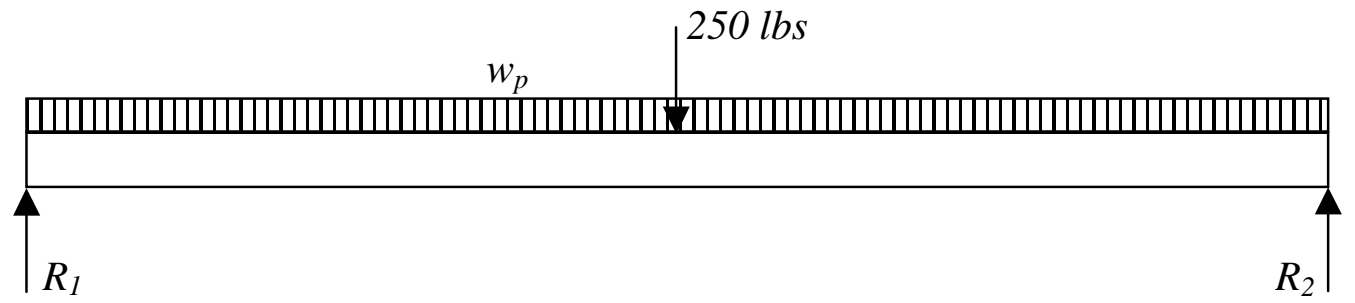

Figure 2.6.5 - Pipe and boundary conditions for third beam bending scenario.

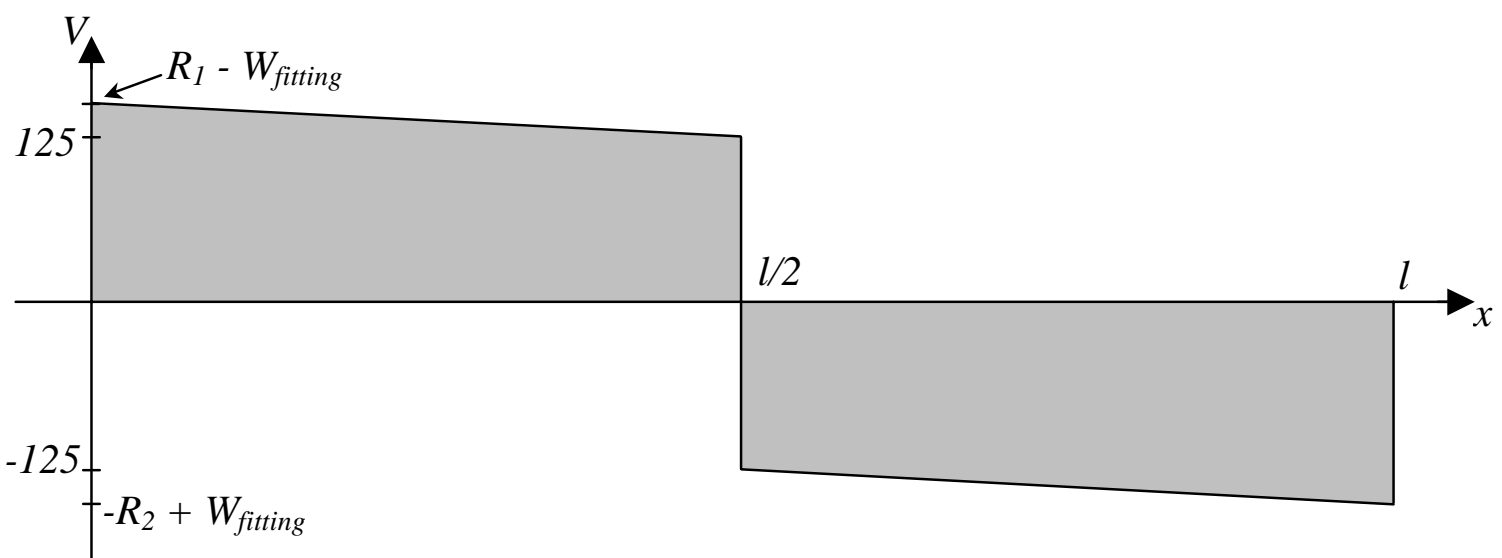

Figure 2.6.6 - Shear distribution for third beam bending scenario. 


\section{Chapter Three}

\section{Development and Analysis}

From the preliminary analyses and inspection of the design requirements, several areas of concern were revealed in which further development of the design was required. First, it was noticed from the analysis in $\mathbf{2 . 4}$ that the design had no means of transferring the longitudinal stress component of the pressure load from the steel to the composite. Second, it was realized that hazards exist in the work environment that could crush or damage the pipe. Lastly, the observation was made that the pipe would undergo a torque loading during the joining of two pipes with a threaded wing-nut. This chapter addresses each of these issues and provides solutions to promote the success of the pipe.

\subsection{Hump Design for Longitudinal Stress}

All of the previously described finite element models relied on node coupling to prevent the steel from sliding and ultimately failing beneath the composite. The design of mechanical interlock was required for the composite to sustain the longitudinal stress. Modifications to the steel pipe were needed. Two options were considered. The first was to design raised pins on the surface of the steel close to the fittings. However, this design would have left sections void of composite due to the pins separating the fiber strands. The second option was to gradually enlarge the diameter of the pipe for a section, then decrease the diameter in the same manner forming a hump around the pipe for the composite to grip. This option was chosen due to ease of fabrication and pipe uniformity.

The design consisted of a hump at each end of the pipe, directly before the fittings. During pressurization, the steel elongates and the hump acts as a wedge underneath the composite. It was determined that two humps on each end would be 
better than a single hump by providing an added safety factor as well as a more gradual increase in wall thickness from the body of the pipe to the fitting, thus avoiding stress concentrations. This design is shown in Figure 3.1.1.

An axisymmetric model of the hump design was created in I-DEAS ${ }^{\circledR}$. The geometry of the humps was produced using splines (smooth curves formed through plotted points). A maximum hump thickness of 0.31 inch was chosen because it was the thickness of the original steel pipe. The thickness of the constant cross-section region between the outer hump and the fitting was arbitrarily chosen to be 0.2 inch.

After the hump dimensions were modeled, the composite section was created according to the thickness requirements listed in Table 2.5.1. The model was meshed as in previous models using 4-node axisymmetric elements. Gap elements were added between the nodes of the steel and the composite. The hump section of the meshed model without boundary conditions can be seen in Figure 3.1.2. Boundary conditions and loads were defined as in previous models and the FEM was exported to ABAQUS ${ }^{\circledR}$. The load and material properties were edited and a solution to the model was attempted. ABAQUS $^{\circledR}$ returned errors, which indicated that the model was yielding beyond the material definition. These errors had occurred in previous models, thus the same temporary adjustment of the plastic material definition for the steel was used. The ABAQUS $^{\circledR}$ solver reached a solution with this modification and the results were imported into I-DEAS ${ }^{\circledR}$ and viewed. The composite appeared to be allowing the humps to pass under it, thereby letting the steel yield to the point of massive elongation as shown in Figure 3.1.3. It was determined that the gap elements were not preventing the intersection of the two materials and that the steel elements of the hump were passing 
through the composite elements. After careful inspection of the model, the conclusion was reached that the gap elements were not properly aligned to prevent longitudinal translation. The node pairs separated by gap elements were aligned perpendicularly to the longitudinal axis as shown in the hump detail of Figure 3.1.2. This prevented the composite from expanding in the hoop direction but not along the longitudinal direction because gap elements do not prohibit sliding. Next, to solve the problem, the humps were partitioned into sections to facilitate alignment between the nodes of the hump and those on the composite in an arrangement normal to the spline. The FEM was re-meshed and Figure 3.1.4 shows the hump section and gap elements with modified alignment.

The model was exported and solved in ABAQUS ${ }^{\circledR}$ and the results were analyzed in I-DEAS ${ }^{\circledR}$. The new node layout provided the proper alignment for the gap elements to prevent the two parts from sliding and intersecting. The results showed that the humps were enabling the composite to hold onto the steel; however, stress concentrations in the steel were found at the transitions into the first and second humps and along the 0.2 inch thick region between the outer hump and the fitting. This excessive stress in the transitions was due to the abrupt change from thin to thick steel and required changing the shape of the humps to be longer with more shallow slopes. The high stress in the section between the outer hump and fitting was due to the fact that the thickness was less than the original 0.31 inch thickness of the all steel pipe. Since the prototype was to be made from an existing steel pipe, the maximum thickness for the humps could not exceed the pipe's wall thickness. Therefore the humps were to be made by removing material on either side of the hump area, leaving a smaller wall thickness than the original pipe, consequently reducing the load bearing capabilities in that area. 
It was clear that the steel between the outer hump and the fitting could not have a smaller thickness than the original pipe. Therefore the last hump had to have a thickness greater than 0.31 inch. A new model was created with larger humps, the inner having 0.31 inch maximum thickness and the outer hump having 0.51 inch thickness. This model produced the desired safety factor for the steel and gave the composite an even greater feature on which to hold. However, it presented the problem of how to attain a steel thickness greater than that of the original pipe. A possible solution was to add weld metal to the original pipe at the location of the large hump. A second possibility was to fabricate custom end fittings, which include the two humps, and weld them onto a thinwalled pipe. The second possibility was chosen but required a change in the design.

It was initially suggested that end fittings be custom made and friction-welded to a thin-walled pipe in the same way the all-steel pipe is fabricated. This design would cause a problem once in service because a thin weld would be required for the union between fitting and pipe and would be the concentration point of erosion by the transported fluids. This erosion is not a problem in the all-steel pipe due to the large wall thickness. Therefore, the location of the weld was moved to the opposite end of the fitting and was no longer on the surface of flow but was between the fitting and the outer surface of the pipe. This required the pipe to pass through the humps and the fitting, therefore all the radial dimension of the hump-fitting had to be increased to accommodate this new "sleeve" design. Also, the humps were elongated to have smoother transitions to help prevent stress concentrations. A diagram of this design is shown in Figure 3.1.5. 


\subsection{Material Substitution}

Upon selection of FMW Rubber Products, Inc. in Bridgeport, West Virginia as the company to filament wind the prototype, the design and materials were discussed. It was discovered that the original carbon fiber AS4, chosen at the onset of this project was more costly than expected. After investigation of alternate choices, a generic carbon fiber, TR50, was chosen because of its material properties and reduced cost. Its fiber elastic modulus was comparable to that of AS4 while its ultimate strength was greater than AS4. EPON 828 epoxy resin cured with EPI-CURE 3140 Polymide Curing Agent [25] was the chosen resin as recommended by FMW due to positive experiences with the product. The known properties of TR50 and EPON 828 with EPI-CURE 3140 are shown in Table 3.2.1.

The material properties for a composite of TR50 and EPON 828 were unknown. The standard methods for determining these properties are through experimental testing, which is costly and time consuming. An alternative to experimental analysis would be to numerically calculate the material properties from the known properties of the fiber and resin, which were provided by the manufacturers. $\mathrm{CADEC}^{\odot}$ was used to perform the calculations but some of the required values were not known and were taken from the properties of AS4/3501-6 [22]. Table 3.2.2 shows the properties and values, which were

input into $\mathrm{CADEC}^{\odot}$. The transversely isotropic elastic material properties for a unidirectional composite of TR50/EPON 828 were computed and are shown in Table 3.2.3.

The question of what yield strength to use in the prototype became more important as the project continued. Up to this point, all analyses were performed using 
the properties of 4130 as chosen from Mechanical Engineering Design $5^{\text {th }}$ Edition [21]. When the question was posed to Halliburton, two steel options were given in reply. The pipe could be heat treated to have a yield strength of $93 \mathrm{ksi}$ or $120 \mathrm{ksi}$, so a comparative analysis was necessary to make a final choice.

\subsection{Analysis of the Sleeve Design}

The properties of TR50/EPON 828, $93 \mathrm{ksi}$ steel and $120 \mathrm{ksi}$ steel were input into Excel spreadsheet TR50_with_93ksi_\&_120ksi.xls to determine the required composite thickness of the hoop and longitudinal layers according to the thickness range of steel. Figure 3.3.1 is a graph of the factor of safety for the hoop loading versus the steel thickness for the two scenarios and Figure 3.3.2 is the weight of the steel and hoopwound composite plotted against the steel thickness. It was recommended to and accepted by Halliburton that the $120 \mathrm{ksi}$ steel be used for the prototypes due to the reduced design weight compared to the $93 \mathrm{ksi}$ steel. After considering the safety factor graph, a steel liner was chosen by Halliburton with a 0.065 inch wall thickness and 1.995 inch inner diameter. The thickness and equivalent elastic material properties of the $\left[ \pm 20^{\circ}\right.$, $90^{\circ}$ ] composite with 0.065 inch steel are shown in Table 3.3.1, the orthotropic properties

were converted into the $\mathrm{ABAQUS}^{\circledR}$ coordinate system as described in the previous chapter. The FPF and FF values of the composite for the hoop and longitudinal directions with a 17\% knockdown due to filament winding are shown in Table 3.3.2. Previous analyses did not include such a strength reduction.

The sleeve design was modeled and analyzed using I-DEAS $^{\circledR}$ and ABAQUS $^{\circledR}$ respectively. The FEM consisted of three parts: the steel pipe liner, the hump/fitting sleeve and the composite as shown in the exploded diagram of Figure 3.3.3. A change in 
element selection was made, to 8-node axisymmetric elements, instead of the 4-node elements of previous models, to generate a more accurate representation of the actual pipe. Figure 3.3.4 shows the FEM after the nodes and elements were meshed. The parts were separated from one another by $0.005 "$ gaps. Gap elements were used to define the contact between the liner and sleeve, the liner and composite, and the sleeve and composite. The assembly was restrained and loaded with an internal pressure, as previously described.

The model was exported, modified, solved in ABAQUS ${ }^{\circledR}$, and imported back into I-DEAS $^{\circledR}$. The results in the steel and composite taken along the constant thickness section show that the steel yields and is compressed to $74 \%$ of yield after autofrettage, as shown in Table 3.3.3. The results in the composite over the humps showed that the composite was near failure and was in need of reinforcement along that region to prevent the humps from moving.

A layer of hoop-wound composite, 0.125 inch thick, was added overtop of the $\left[ \pm 20^{\circ}, 90^{\circ}\right]$ base composite on the humps as shown in the exploded diagram in Figure 3.3.5. The equivalent orthotropic material properties of the reinforcement is shown in Table 3.3.4. Coupled degrees of freedom were used to join the $\left[90^{\circ}\right]$ reinforcing composite to the $\left[ \pm 20^{\circ}, 90^{\circ}\right]$ base. The material properties of the composite elements were defined to be orthotropic and were divided into two groups: base composite material, COMP2090, and the reinforcement material, COMP90. When analyzed, this design produced the same results in the constant thickness section as in Table 3.3.3, but displayed maximum stresses (Von Mises, hoop and longitudinal) throughout the entire model as shown in Table 3.3.5. It can be seen from this table that stress concentrations, 
near the steel ultimate stress, exist in the hump/fitting and the liner. It was determined that these concentrations were at a location that would not affect the success of the pipe.

It was also realized that the $120 \mathrm{ksi}$ yield strength for the steel might not be accurate. A sensitivity analysis was performed to determine the effects of a $\pm 5 \%$ change in the yield strength of the steel for the design based on $120 \mathrm{ksi}$ yield strength. The same FEM from the analysis above was used and only required the modification of the plastic material definition of the steel. For the first case the material was defined with a yield strength of $114 \mathrm{ksi}$ and an ultimate strength of $119 \mathrm{ksi}$. The model was solved in ABAQUS $^{\circledR}$, viewed in I-DEAS ${ }^{\circledR}$ and the results are recorded in Table 3.3.6. It can be seen that the liner is autofrettaged but is within $84.7 \%$ of compressive yield, which is greater than the same design with $120 \mathrm{ksi}$ steel. The safety factors in the composite are reduced but not drastically.

For the final case the material was defined with a yield strength of $126 \mathrm{ksi}$ and an ultimate strength of $132 \mathrm{ksi}$. The model was solved in ABAQUS ${ }^{\circledR}$, viewed in I-DEAS ${ }^{\circledR}$ and the results are recorded in Table 3.3.7. It can be seen that the liner is autofrettaged but is within $63.6 \%$ of compressive yield, which is less than the same design with $120 \mathrm{ksi}$ steel. The safety factors in the composite show a slight increase over those in Table 3.3.3.

The sleeve design proved to be a good method for transferring the longitudinal load from the fitting to the composite and alleviating the longitudinal stress in the liner. It was also concluded from the sensitivity analysis that a $\pm 5 \%$ change in the yield strength of the steel will mainly affect the amount of autofrettage but was deemed as 
acceptable tolerances. Diagrams of the sleeve with dimensions are found in Figures 3.3.6 through 3.3.10.

\subsection{Ovalization Analysis}

It was determined that in the rugged work environment of the petroleum industry, the pipe could undergo unique stress situations for which it was not designed. One possible scenerio would be for a load to be applied in such a way that might crush or ovalize the pipe. This situation could occur if the pipe were to be run over by a vehicle. A finite element analysis was performed using SDRC $^{\circledR}$ I-DEAS $^{\circledR}$ to simulate a heavy truck resting one tire upon the pipe positioned horizontally on the ground.

The pipe was modeled as two tubes, one inside the other separated by a 0.005 inch gap. To save solution time, the pipe was cut in half longitudinally as seen in Figure 3.4.1. The model was meshed with 8-node block shaped elements. The material properties of generic isotropic steel were assigned to the elements of the inner tube and the orthotropic elastic material properties from Table 3.3.1 were assigned to the elements of the outer tube. Since the model is cylindrical the composite's orthotropic properties change around the pipe. The global coordinate system in I-DEAS ${ }^{\circledR}$ is Cartesian, so a second system using cylindrical coordinates was created for the composite elements to reference thus allowing proper material alignment.

Due to the amount of finite elements in the model, the gap elements used in previous models were impractical. Instead, a contact set was created. This is a means of defining contact between elements of one part with the elements of another part by specifying a maximum gap distance for which the program would search. When the 
program finds two elements with a gap between them less than or equal to the maximum gap distance, a contact is defined between them thus preventing intersection.

The model was loaded by applying concentrated forces to the nodes in the shaded area of Figure 3.4.2. The area covers 12 inches along the longitude of the pipe and 0.81 inch in width. Forces were applied to seven rows of nodes, 111 in each row for a total of 777 forces. Figure 3.4.3 shows the cross-sectional view of the mesh with 7 rows of forces. Each force in the three left-most rows was equal to $4 \mathrm{lbs}$, the next two rows were made up of $3 \mathrm{lb}$ forces and the remaining two right-most rows consisted of $2 \mathrm{lb}$ forces. The sum total of the 777 forces was equal to $2442 \mathrm{lbs}$. This represents the tire load of an equipment truck used by Halliburton Company.

The nodes located on planar surfaces were restrained with symmetric boundary conditions as follows:

1) Nodes on planar surfaces parallel to the xy-plane were restrained from having z-translation, $\mathrm{x}$-rotation and y-rotation.

2) Nodes on planar surfaces parallel to the yz-plane were restrained from having $\mathrm{x}$-translation, y-rotation and z-rotation.

The model was solved and the maximum Von Mises stress in the steel was recorded but the stresses in the composite could only be recorded in three areas. I-DEAS $^{\circledR}$ displays stress components along the $\mathrm{x}, \mathrm{y}$ and $\mathrm{z}$ axes, but the composite material follows a cylindrical coordinate system so the results were recorded only for the three groups of elements shown in Figure 3.4.4. These results are displayed in Table 3.4.1. It was concluded that the pipe could withstand the ovalization loading with a minimum safety factor of 5.49 . 


\subsection{Track Design for Torsion Load}

It was realized that the Weco 1502 hammer unions used to join two pipes would create a torque load in the pipe. This would be negligible in the original steel pipe but would cause problems for the hybrid design. These unions consist of a wing-nut joining a threaded female fitting on one pipe to a male fitting on another pipe, as shown in Figure 2.0.1. The nut is hand tightened and then struck repeatedly on the wings with a $5 \mathrm{lb}$ hammer until a ringing sound is heard, signifying metal-to-metal contact. The hammer's striking point is approximately 4.5 inches from the center of the pipe, which can cause a considerable amount of torque depending on the person swinging the hammer. The existing design had no physical provision for torque loading and would result in buckling failure in the thin-walled steel beneath the composite.

It was determined that the hump closest to the fitting would be machined in such a way so that the fiber could grip the steel and allow torque to transfer from the steel to the composite. A track design was chosen which consisted of four hourglass shaped tracks milled through the hump, as shown in the unwrapped drawing in Figure 3.5.1 and the cross-sectional view in Figure 3.5.2. The geometry of the tracks was designed based on the lay-up angle and cross-sectional area of the $\pm 20^{\circ}$ fibers. It was decided that the narrow section, the bottleneck, of the hourglass would be located at the thickest point of the hump and the cross-sectional area of the four tracks at the bottleneck must equal the total cross-sectional area of the $\pm 20^{\circ}$ fibers, $A_{c}$ from (2.2.42), as in the following equation

$$
A_{c}=N A_{\text {track }}
$$

where $N$ is the number of tracks and $A_{\text {track }}$ is the cross-sectional area at the bottleneck of one track, calculated by 


$$
A_{\text {track }}=\pi\left(r_{2}^{2}-r_{1}^{2}\right) \frac{\theta}{360}
$$

where $r_{1}$ and $r_{2}$ are the radii of the bottom and top of the track respectively and $\theta$ is the angle between the walls of the track. Figure 3.5.3 describes $r_{1}, r_{2}$ and $\theta$. The value for $r_{2}$ was known because it is the radius of the top of the large hump. The value of $r_{1}$ was determined trigonometrically from Figure 3.5.4 and the angle $\theta$ was found by combining (3.5.1) and (3.5.2) to get

$$
\theta=\frac{360 A_{c}}{N \pi\left(r_{2}^{2}-r_{1}^{2}\right)}
$$

Using $\theta$, the arc lengths at the top and bottom of the bottleneck, $a_{1}$ and $a_{2}$ respectively, were calculated with

$$
a=\frac{2 \pi r \theta}{360}
$$

During filament winding, the $\pm 20^{\circ}$ fibers would fill the tracks and be covered by $90^{\circ}$ reinforcing fibers. As the wing-nut is tightened, the load would be transferred through the walls into the composite. Two analyses of this modified design were performed to determine the stress on the composite in the track section and the maximum allowable force and hammer velocity that could be applied to the wing-nut.

\subsection{Simplified Torque Analysis}

The composite was analyzed to determine the maximum impact force that could be applied to the wing-nut. The composite over-wrap was analyzed by itself because it was desired that the steel bear as little of the stress as possible.

The polar moment of inertia of the composite was calculated by

$$
J=\frac{\pi}{32}\left((2 r+2 t)^{4}-(2 r)^{4}\right)
$$


where $r$ is the inner radius of the composite and $t$ is its thickness. The equation for torsional stress is

$$
\tau=\frac{T(r+t)}{J}
$$

where $T$ is the applied torque which is represented by

$$
T=r_{\text {wing }} F
$$

with $r_{\text {wing }}$ as the radius of the striking point of the hammer on the wing-nut and $F$ is the force applied to the wing-nut. By combining (3.6.2) with (3.6.3) and replacing $\tau$ with the ultimate in-plane shear strength of the laminate, $F F_{\text {shear }}$ (with $17 \%$ knockdown for filament winding), the maximum force was calculated as

$$
F_{F F}=\frac{F F_{\text {shear }} J}{r_{\text {wing }}(r+t)}
$$

and is reported in Table 3.6.1. This table also shows the torque, $T_{F F}$, at shear failure calculated using (3.6.3).

Since this is an impact loading, the impact velocity of the hammer was calculated according to the maximum force. The strain energy of the composite, $U$, and the kinetic energy of the hammer, $U_{H}$, must satisfy the principle of conservation of energy as shown

$$
U_{H}=U
$$

The strain energy equation is

$$
U=\frac{T^{2} l}{2 G_{y z} J}
$$

where $l$ is the length of the pipe and $G_{y z}$ is the in-plane shear modulus of the composite. The kinetic energy of the hammer is

$$
U_{H}=\frac{1}{2} m_{H} v_{H}^{2}
$$


where $v_{H}$ is the velocity of the hammer and $m_{H}$ is its mass calculated as

$$
m_{H}=\frac{W_{H}}{g}
$$

where $W_{H}$ is its weight and $g$ is the gravitational constant equal to $32.2 \mathrm{ft} / \mathrm{s}^{2}$. The maximum hammer velocity was determined by rearranging equations (3.6.5) through (3.6.7) to get

$$
v_{H}=\sqrt{\frac{T^{2} l}{m_{H} G_{y z} J}}=\sqrt{\frac{\left(r_{\text {wing }} F_{F F}\right)^{2} l}{\frac{W_{H}}{g} G_{y z} J}}
$$

The values of $F F_{\text {shear }}, F_{F F}, T_{F F}$ and $v_{H}$ are recorded in Table 3.6.1. It is concluded from this analysis that the wing-nut cannot be tightened with an impact velocity greater than $7.76 \mathrm{ft} / \mathrm{sec}$ when using a $5 \mathrm{lb}$ hammer.

\subsection{Finite Element Analysis of the Track Design}

The complexity of the track design required the use of FEA. SDRC ${ }^{\circledR}$ I-DEAS $^{\circledR}$ was used to create a three-dimensional model of the hump section. In an effort to reduce the computing time, the fitting and thin-walled steel pipe was not modeled.

The geometry of the humps was created by revolving a two-dimensional crosssection that resembled the axisymmetric model but displayed a flat region in place of the large hump, Figure 3.7.1. This produced a part with one hump and a smooth tapered section for the base of the large hump/tracks, Figure 3.7.2. The tracks were designed to be four hourglass shaped channels through the humps, which would leave four raised diamond shapes at the former location of the large hump. The diamonds were formed by revolving a hump shaped cross-section and then cutting away four hourglass shaped tracks. The diamonds are shown in Figure 3.7.3. These diamonds were then joined to 
the steel hump section to produce the part found in Figure 3.7.4. The part was meshed with 8-node block shaped solid elements and is shown in Figure 3.7.5. The material properties of the elements were consistent with generic isotropic steel without plastic properties defined.

The composite was modeled in the same manner as the steel hump section. First, a longitudinal cross-section of the $\left[ \pm 20^{\circ}, 90^{\circ}\right]$ base with the $\left[90^{\circ}\right]$ reinforcement was modeled and is shown in Figure 3.7.6. This part was revolved to form the solid model in Figure 3.7.7. The composite was now formed but lacked the internal geometry to interlock with the hourglass shaped tracks of the steel hump. A copy of the four diamond shaped track forms was used to cut the composite. An interior view of the composite with cutouts is shown in Figure 3.7.8. The composite model was meshed and is shown in Figure 3.7.9. Material properties were created for three orthotropic materials, the $\left[ \pm 20^{\circ}, 90^{\circ}\right]$ base composite, $\left[90^{\circ}\right]$ reinforcing composite and the $\left[ \pm 20^{\circ}\right]$ composite in the tracks. A cylindrical coordinate system was created and the three composite materials were then aligned to it in the same way as in the ovalization model.

The two meshes, steel and composite, were appended into one FEM and boundary conditions were created. In order to prevent the steel elements from intersecting the composite, contact had to be defined. Due to the complexity and massive amount of finite elements in the model, a contact set was used as described earlier. The composite elements at the end closest to the small hump were restrained from having any translation. The torque was to be applied to the steel elements at the opposite end of the model, but to apply the load uniformly it was required to be on the longitudinal axis of the pipe. Since loads must be applied on nodes or elements, a modification to the steel 
mesh was needed. A node was created on the longitudinal axis at the fitting end of the model and 2-node rigid bar elements were created between this node and the nodes of the steel mesh as shown in Figure 3.7.10. Since the simplified torque analysis predicted a maximum torque of 4437 in-lbs, an axial torque of 5000 in-lbs was applied to the node, as shown in the figure, and the rigid elements transferred the load from the center node to the steel.

A solution to the model was attempted but was unreachable because of the number of elements, contact definition and complexity of the analysis. So the model was simplified to facilitate a solution. The small hump and composite covering the small hump was removed and the straight region between the hump/tracks and the fitting end was shortened. The steel part of this model is shown in Figure 3.7.11. A solution was reached and the stresses in the composite are recorded in Table 3.7.1. It is shown that the safety factor in the base composite was 1.03 at 5000 in-lbs of torque. This reinforces the simplified torque analysis, which calculated the maximum allowable torque to be 4437 in-lbs. It is also noticed that the safety factor in the $\pm 20^{\circ}$ track composite was 2.64 at 5000 in-lbs, which relieves concerns of failure in the track region due to torque loading. These results proved that the track design is a valid method for transferring the torque load from the fitting to the composite.

\subsection{Conclusions}

From the research and analysis recorded in this chapter it was concluded that:

- The steel pipe between the last hump and the fitting must be as thick as the original steel pipe because the composite in that region does not help carry longitudinal stress. 
- Gap elements must be aligned normal to the contour of the edge of contact to prevent intersection of the parts.

- The sleeve design was chosen to avoid a weld where it may be eroded/corroded.

- $\mathrm{CADEC}^{\odot}$ was used to predict properties of composites based on fiber and resin properties.

- Care must be taken when writing the coordinate system for the material properties and when converting the material coordinate system to the global system of I-DEAS ${ }^{\circledR}$ and ABAQUS ${ }^{\circledR}$.

- The sensitivity analysis showed that $\pm 5 \%$ difference in the yield strength of the steel is acceptable, but a greater tolerance is not recommended because it compromises the compressive stress limit at zero pressure.

- The ovalization analysis proved that the pipe can withstand extremely large crush loads from workplace hazards.

- The track design proved to be an effective method for transferring the torque applied during the joining of two pipes.

- The simplified torque analysis predicted that the base composite could withstand the torque produced by a hammer striking the wing-nut with a maximum velocity of 7.76 $\mathrm{ft} / \mathrm{sec}$.

- The FEA of the track design predicted that the base composite would fail before the $\pm 20^{\circ}$ composite in the tracks. It also reinforced the results from the simplified torque analysis. 
Table 3.2.1 - Known properties of TR50 carbon fiber and EPON 828 epoxy.

\begin{tabular}{|lcc|}
\hline \multicolumn{3}{|c|}{ Fiber Properties } \\
\hline Fiber Tensile Modulus, [psi] & $=34500000$ \\
Fiber Tensile Ultimate Strength, [psi] & $=526000$ \\
\hline \multicolumn{2}{|c|}{ Resin Properties } \\
\hline Heat Deflection Temperature, [C] & $=$ & 72 \\
Ultimate Tensile Strength, [psi] & $=$ & 7300 \\
Tensile Elongation, [\%] & $=$ & 11.8 \\
Initial Tensile Modulus, [psi] & $=$ & 320000 \\
Ultimate Flexural Strength, [psi] & $=$ & 12000 \\
Flexural Deflection, [in] & $=$ & 0.6 \\
Initial Flexural Modulus, [psi] & $=340000$ \\
Ultimate Compression Stregth [psi] & $=34000$ \\
Compression Yield Strength, [psi] & $=$ & 9100 \\
lzod Impact, [ft-lb/inch notch] & $=$ & 0.88 \\
Hardness, Shore D & $=$ & 82 \\
Water Absorption & $=$ & 0.33 \\
Weight Loss & $=$ & 0.05 \\
Dielectric Constant & $=$ & 3.41 \\
Dissipation Factor & $=$ & 0.018 \\
\hline
\end{tabular}

Table 3.2.2 - Properties used in $\mathrm{CADEC}^{\odot}$ to determine transversely isotropic material properties for a unidirectional composite of TR50/EPON 828.

\begin{tabular}{|c|c|}
\hline Fiber Properties & Resin Prop \\
\hline$E_{f}=3.45 \mathrm{E}+07$ & $E_{m}=3.20 \mathrm{E}+05$ \\
\hline 0.22 & $v_{m}=$ \\
\hline$\alpha_{f}=5.40 \mathrm{E}-06$ & $\alpha_{m}=3.00 \mathrm{E}-05$ \\
\hline $\boldsymbol{k}_{f}=$ & $k_{m}=$ \\
\hline 0.60 & $\rho_{m}=$ \\
\hline$a / b=$ & $\beta_{m}=$ \\
\hline 0.066 & $V_{v}=$ \\
\hline$\sigma_{f a}=5.26 \mathrm{E}+05$ & $\sigma_{m u}=7.30 \mathrm{E}+03$ \\
\hline$\Omega=$ & $\sigma_{m u c}=3.40 \mathrm{E}+04$ \\
\hline & $\tau_{m u}=3.65 \mathrm{E}+03$ \\
\hline
\end{tabular}


Table 3.2.3 - Transversely isotropic elastic material properties for a unidirectional composite of TR50/EPON 828 produced in CADEC $^{\odot}$.

\begin{tabular}{|c|}
\hline Properties \\
\hline$E_{1}=2.08 \mathrm{E}+07$ \\
$E_{2}=1.67 \mathrm{E}+06$ \\
$G_{12}=4.50 \mathrm{E}+05$ \\
$G_{23}=3.98 \mathrm{E}+05$ \\
$V_{12}=0.284$ \\
$V_{23}=0.573$ \\
\hline
\end{tabular}

Table 3.3.1 - Sleeve design describing composite thickness, liner thickness and equivalent orthotropic elastic material properties for TR50 composite in a $\left[ \pm 20^{\circ}, 90^{\circ}\right]$ lay-up.

$\begin{aligned} E_{x}= & 2.26 \mathrm{E}+06 \mathrm{psi} \\ E_{y}= & 7.83 \mathrm{E}+06 \mathrm{psi} \\ E_{z}= & 1.27 \mathrm{E}+07 \mathrm{psi} \\ \boldsymbol{v}_{x y}= & 1.39 \mathrm{E}-01 \\ \boldsymbol{v}_{x z}= & 7.27 \mathrm{E}-02 \\ \boldsymbol{v}_{y z}= & 1.03 \mathrm{E}-01 \\ G_{x y}= & 4.17 \mathrm{E}+05 \mathrm{psi} \\ G_{x z}= & 4.31 \mathrm{E}+05 \mathrm{psi} \\ G_{y z}= & 1.31 \mathrm{E}+06 \mathrm{psi} \\ \boldsymbol{t}_{20}= & 0.0602 \mathrm{in} \\ \boldsymbol{t}_{90}= & 0.0834 \mathrm{in} \\ \boldsymbol{t}_{\text {total }}= & 0.1436 \mathrm{in} \\ \boldsymbol{t}_{s}= & 0.065 \mathrm{in} \\ \boldsymbol{I D}_{\boldsymbol{s}}= & 1.995 \mathrm{in} \\ \boldsymbol{\sigma}_{s}= & 1.20 \mathrm{E}+05 \mathrm{psi}\end{aligned}$


Table 3.3.2 - First Ply Failure and Fiber Failure values for the sleeve design using TR50 composite in a $\left[ \pm 20^{\circ}, \mathbf{9 0}^{\circ}\right]$ lay-up.

\begin{tabular}{|c|c|c|c|c|}
\cline { 2 - 5 } \multicolumn{1}{c|}{} & Hoop & Hoop w/ 17\% Knockdown & Longitude & Long w/ 17\% Knockdown \\
\hline FPF $[$ psi] $=$ & $3.525 \mathrm{E}+04$ & $2.926 \mathrm{E}+04$ & $1.954 \mathrm{E}+04$ & $1.622 \mathrm{E}+04$ \\
\hline FF $[\mathrm{psi}]=$ & $1.931 \mathrm{E}+05$ & $1.603 \mathrm{E}+05$ & $1.356 \mathrm{E}+05$ & $1.126 \mathrm{E}+05$ \\
\hline
\end{tabular}

Table 3.3.3 - Finite element analysis results in steel and composite along the section of constant thickness, away from the hump/fitting.

\begin{tabular}{|c|c|c|c|c|c|}
\hline \multicolumn{6}{|c|}{$t_{s}=.065 t_{\left[ \pm 20^{\circ}, 90^{\circ}\right]}=.1436 \mathrm{w} / 120 \mathrm{ksi}$ Steel } \\
\hline Liner & $\sigma_{\text {Von Mises }}[\mathrm{ksi}]$ & $\sigma_{\text {Yield }}[k s i]$ & S.F. & $\sigma_{\mathrm{Ult}}[\mathrm{ksi}]$ & S.F. \\
\hline Test & 120 & 120 & 1.00 & 126 & 1.05 \\
\hline Zero & 88.4 & 120 & 1.36 & 126 & 1.43 \\
\hline Work & 64.2 & 120 & 1.87 & 126 & 1.96 \\
\hline$\left[ \pm 20^{\circ}, 90^{\circ}\right]$ & $\sigma_{\text {hoop }}[k s i]$ & $\mathrm{FPF}_{\text {hoop }}[\mathrm{ksi}]$ & S.F. & $\mathrm{FF}_{\text {hoop }}[\mathrm{ksi}]$ & S.F. \\
\hline Test & 117 & 29.26 & 0.25 & 160.28 & 1.37 \\
\hline Zero & 45.1 & 29.26 & 0.65 & 160.28 & 3.55 \\
\hline \multirow[t]{2}{*}{ Work } & 93.3 & 29.26 & 0.31 & 160.28 & 1.72 \\
\hline & $\sigma_{\text {long }}[k s i]$ & $\mathrm{FPF}_{\text {long }}[\mathrm{ksi}]$ & S.F. & $\mathrm{FF}_{\text {long }}[\mathrm{ksi}]$ & S.F. \\
\hline Test & 35.2 & 16.22 & 0.46 & 112.57 & 3.20 \\
\hline Zero & 12 & 16.22 & 1.35 & 112.57 & 9.38 \\
\hline Work & 27.6 & 16.22 & 0.59 & 112.57 & 4.08 \\
\hline
\end{tabular}

Table 3.3.4 - Equivalent orthotropic elastic material properties for TR50 composite in a $\left[90^{\circ}\right]$ lay-up.

$$
\begin{array}{ll}
E_{x}= & 1.665 \mathrm{E}+06 \mathrm{psi} \\
E_{y}= & 1.665 \mathrm{E}+06 \mathrm{psi} \\
E_{z}= & 2.082 \mathrm{E}+07 \mathrm{psi} \\
v_{x y}= & 5.73 \mathrm{E}-01 \\
v_{x z}= & 2.27 \mathrm{E}-02 \\
v_{y z}= & 2.27 \mathrm{E}-02 \\
G_{x y}=3.976 \mathrm{E}+05 \mathrm{psi} \\
G_{x z}=4.499 \mathrm{E}+05 \mathrm{psi} \\
G_{y z}=4.499 \mathrm{E}+05 \mathrm{psi}
\end{array}
$$


Table 3.3.5 - Maximum stress values from the FEM of the sleeve with reinforcement.

\begin{tabular}{|c|c|c|c|c|c|}
\hline \multicolumn{6}{|c|}{$t_{s}=.065 t_{\left[ \pm 20^{\circ}, 90^{\circ}\right]=.1436 \mathrm{w} / 120 \mathrm{ksi} \text { Steel }}$} \\
\hline Liner & $\sigma_{\text {Von Mises }}[k s i]$ & $\sigma_{\text {Yield }}[k s i]$ & S.F. & $\sigma_{\mathrm{Ult}}[\mathrm{ksi}]$ & S.F. \\
\hline Test & 124.80 & 120.00 & 0.96 & 126.78 & 1.02 \\
\hline Zero & 106.50 & 120.00 & 1.13 & 126.78 & 1.19 \\
\hline Work & 90.20 & 120.00 & 1.33 & 126.78 & 1.41 \\
\hline Burst & 129.70 & 120.00 & 0.93 & 126.78 & 0.98 \\
\hline Humps & $\sigma_{\text {Von Mises }}[k s i]$ & $\sigma_{\text {Yield }}[k s i]$ & S.F. & $\sigma_{\text {Ult }}[k s i]$ & S.F. \\
\hline Test & 126.30 & 120.00 & 0.95 & 126.78 & 1.00 \\
\hline Zero & 71.30 & 120.00 & 1.68 & 126.78 & 1.78 \\
\hline Work & 99.70 & 120.00 & 1.20 & 126.78 & 1.27 \\
\hline Burst & 124.60 & 120.00 & 0.96 & 126.78 & 1.02 \\
\hline$\left[ \pm 20^{\circ}, 90^{\circ}\right]$ & $\sigma_{\text {hoop }}[k s i]$ & $\mathrm{FPF}_{\text {hoop }}[\mathrm{ksi}]$ & S.F. & $\mathrm{FF}_{\text {hoop }}[\mathrm{ksi}]$ & S.F. \\
\hline Test & 118.10 & 29.26 & 0.25 & 160.28 & 1.36 \\
\hline Zero & 45.60 & 29.26 & 0.64 & 160.28 & 3.51 \\
\hline Work & 94.00 & 29.26 & 0.31 & 160.28 & 1.71 \\
\hline \multirow[t]{2}{*}{ Burst } & 184.20 & 29.26 & 0.16 & 160.28 & 0.87 \\
\hline & $\sigma_{\text {long }}[k s i]$ & $\mathrm{FPF}_{\text {long }}[\mathrm{ksi}]$ & S.F. & $\mathrm{FF}_{\text {long }}[\mathrm{ksi}]$ & S.F. \\
\hline Test & 53.60 & 16.22 & 0.30 & 112.57 & 2.10 \\
\hline Zero & 21.50 & 16.22 & 0.75 & 112.57 & 5.24 \\
\hline Work & 43.00 & 16.22 & 0.38 & 112.57 & 2.62 \\
\hline Burst & 96.30 & 16.22 & 0.17 & 112.57 & 1.17 \\
\hline$\left[90^{\circ}\right]$ & $\sigma_{\text {hoop }}[k s i]$ & $\mathrm{FPF}_{\text {hoop }}[\mathrm{ksi}]$ & S.F. & $\mathrm{FF}_{\text {hoop }}[\mathrm{ksi}]$ & S.F. \\
\hline Test & 120.40 & 263.11 & 2.19 & 263.11 & 2.19 \\
\hline Zero & 46.70 & 263.11 & 5.63 & 263.11 & 5.63 \\
\hline Work & 93.50 & 263.11 & 2.81 & 263.11 & 2.81 \\
\hline \multirow[t]{2}{*}{ Burst } & 196.30 & 263.11 & 1.34 & 263.11 & 1.34 \\
\hline & $\sigma_{\text {long }}[k s i]$ & $\mathrm{FPF}_{\text {long }}[\mathrm{ksi}]$ & S.F. & $\mathrm{FF}_{\text {long }}[\mathrm{ksi}]$ & S.F. \\
\hline Test & 17.50 & 3.69 & 0.21 & - & - \\
\hline Zero & 8.50 & 3.69 & 0.43 & - & - \\
\hline Work & 14.40 & 3.69 & 0.26 & - & - \\
\hline Burst & 33.20 & 3.69 & 0.11 & - & - \\
\hline
\end{tabular}


Table 3.3.6 - Sensitivity FEA results from the section of constant thickness using 114 ksi yield strength steel.

\begin{tabular}{|c|c|c|c|c|c|}
\hline \multicolumn{6}{|c|}{$t_{s}=.065 t_{\left[ \pm 20^{\circ}, 90^{\circ}\right]}=.1436 \mathrm{w} / 114 \mathrm{ksi}$ Steel } \\
\hline Liner & $\sigma_{\text {Von Mises }}[k s i]$ & $\sigma_{\text {Yield }}[k s i]$ & S.F. & $\sigma_{U l t}[k s i]$ & S.F. \\
\hline Test & 114.35 & 114.00 & 1.00 & 119.00 & 1.04 \\
\hline Zero & 96.59 & 114.00 & 1.18 & 119.00 & 1.23 \\
\hline Work & 58.37 & 114.00 & 1.95 & 119.00 & 2.04 \\
\hline$\left[ \pm 20^{\circ}, 90^{\circ}\right]$ & $\sigma_{\text {hoop }}[k s i]$ & $\mathrm{FPF}_{\text {hoop }}[\mathrm{ksi}]$ & S.F. & $\mathrm{FF}_{\text {hoop }}[\mathrm{ksi}]$ & S.F. \\
\hline Test & 120.50 & 30.67 & 0.25 & 168.00 & 1.39 \\
\hline Zero & 49.87 & 30.67 & 0.61 & 168.00 & 3.37 \\
\hline \multirow[t]{2}{*}{ Work } & 97.00 & 30.67 & 0.32 & 168.00 & 1.73 \\
\hline & $\sigma_{\text {long }}[k s i]$ & $\mathrm{FPF}_{\text {long }}[\mathrm{ksi}]$ & S.F. & $\mathrm{FF}_{\text {long }}[\mathrm{ksi}]$ & S.F. \\
\hline Test & 37.33 & 17.00 & 0.46 & 117.97 & 3.16 \\
\hline Zero & 13.77 & 17.00 & 1.23 & 117.97 & 8.57 \\
\hline Work & 29.66 & 17.00 & 0.57 & 117.97 & 3.98 \\
\hline
\end{tabular}

Table 3.3.7 - Sensitivity FEA results from the section of constant thickness using $126 \mathrm{ksi}$ yield strength steel.

\begin{tabular}{|c|c|c|c|c|c|}
\hline \multicolumn{6}{|c|}{$t_{s}=.065 t_{\left[ \pm 20^{\circ}, 90^{\circ}\right]}=.1436 \mathrm{w} / 114 \mathrm{ksi}$ Steel } \\
\hline Liner & $\sigma_{\text {Von Mises }}[\mathrm{ksi}]$ & $\sigma_{\text {Yield }}[k s i]$ & S.F. & $\sigma_{\text {Ult }}[k s i]$ & S.F. \\
\hline Test & 126.30 & 126.00 & 1.00 & 132.00 & 1.05 \\
\hline Zero & 80.16 & 126.00 & 1.57 & 132.00 & 1.65 \\
\hline Work & 66.89 & 126.00 & 1.88 & 132.00 & 1.97 \\
\hline$\left[ \pm 20^{\circ}, 90^{\circ}\right]$ & $\sigma_{\text {hoop }}[k s i]$ & $\mathrm{FPF}_{\text {hoop }}[\mathrm{ksi}]$ & S.F. & $\mathrm{FF}_{\text {hoop }}[\mathrm{ksi}]$ & S.F. \\
\hline Test & 111.20 & 30.67 & 0.28 & 168.00 & 1.51 \\
\hline Zero & 40.88 & 30.67 & 0.75 & 168.00 & 4.11 \\
\hline \multirow[t]{2}{*}{ Work } & 87.76 & 30.67 & 0.35 & 168.00 & 1.91 \\
\hline & $\sigma_{\text {long }}[k s i]$ & $\mathrm{FPF}_{\text {long }}[\mathrm{ksi}]$ & S.F. & $\mathrm{FF}_{\text {long }}[\mathrm{ksi}]$ & S.F. \\
\hline Test & 37.64 & 17.00 & 0.45 & 117.97 & 3.13 \\
\hline Zero & 15.25 & 17.00 & 1.11 & 117.97 & 7.74 \\
\hline Work & 30.18 & 17.00 & 0.56 & 117.97 & 3.91 \\
\hline
\end{tabular}


Table 3.4.1 - Results from ovalization analysis showing the maximum stresses and safety factors at fiber failure for the steel and the three groups of composite elements.

\begin{tabular}{|c|c|}
\hline \multicolumn{2}{|c|}{ Liner } \\
\hline \multicolumn{2}{|c|}{$\sigma_{\text {Von Mises }}[p s i]=17200$} \\
\hline S.F. & $=6.98$ \\
\hline \multicolumn{2}{|c|}{$\left[ \pm 20^{\circ}, 90^{\circ}\right]$ Group \#1 } \\
\hline \multirow{4}{*}{$\begin{array}{c}\sigma_{\text {hoop }}[p s i] \\
\text { S.F. } \\
\sigma_{\text {long }}[p s i] \\
\text { S.F. }\end{array}$} & $=-18900$ \\
\hline & $=8.47$ \\
\hline & $=20400$ \\
\hline & $=5.49$ \\
\hline \multicolumn{2}{|c|}{$\left[ \pm 20^{\circ}, 90^{\circ}\right]$ Group \#2 } \\
\hline \multirow{4}{*}{$\begin{array}{c}\sigma_{\text {hoop }}[p s i] \\
\text { S.F. } \\
\sigma_{\text {long }}[p s i] \\
\text { S.F. }\end{array}$} & $=-17500$ \\
\hline & $=9.14$ \\
\hline & $=7180$ \\
\hline & $=15.60$ \\
\hline \multicolumn{2}{|c|}{$\left[ \pm 20^{\circ}, 90^{\circ}\right]$ Group \#3 } \\
\hline$\sigma_{\text {hoop }}[p s i]$ & $=-13500$ \\
\hline S.F. & $=11.85$ \\
\hline$\sigma_{\text {long }}[p s i]$ & $=7780$ \\
\hline S.F. & $=14.40$ \\
\hline
\end{tabular}

Table 3.6.1 - Values of $F F_{\text {shear }}, F_{F F}$ and $v_{H}$ for the simplified torque analysis.

\begin{tabular}{|c|c|c|}
\hline$F F_{\text {shear }}[p s i]$ & $=$ & 4850 \\
\hline$F F_{\text {shear }}[p s i]$ w/ 17\% knockdown & & 4025 \\
\hline$F_{F F}[I b s]$ & $=$ & 986 \\
\hline$T_{F F}[i n-I b s]$ & $=$ & 4437 \\
\hline$v_{H}[\mathrm{in} / \mathrm{sec}]$ & $=$ & 93 \\
\hline$v_{H}[f t / s e c]$ & $=$ & 7.76 \\
\hline
\end{tabular}

Table 3.7.1 - Results from the torque analysis describing the maximum shear stresses, fiber failure values and safety factors for the $\left[ \pm 20^{\circ}, 90^{\circ}\right]$ base composite and the $\left[ \pm 20^{\circ}\right]$ composite in the tracks.

\begin{tabular}{|c|c|}
\hline \multicolumn{2}{|c|}{$\left[ \pm 20^{\circ}, 90^{\circ}\right]$ Base } \\
\hline$\tau_{\max }[p s i]$ & $=3920$ \\
\hline $\mathrm{FF}_{\text {shear }}[\mathrm{psi}]$ & $=4025$ \\
\hline S.F. & $=1.03$ \\
\hline \multicolumn{2}{|c|}{$\left[ \pm 20^{\circ}\right]$ Tracks } \\
\hline$\tau_{\max }[p s i]$ & $=2910$ \\
\hline $\mathrm{FF}_{\text {shear }}[\mathrm{psi}]$ & 7689 \\
\hline S.F. & $=2.64$ \\
\hline
\end{tabular}




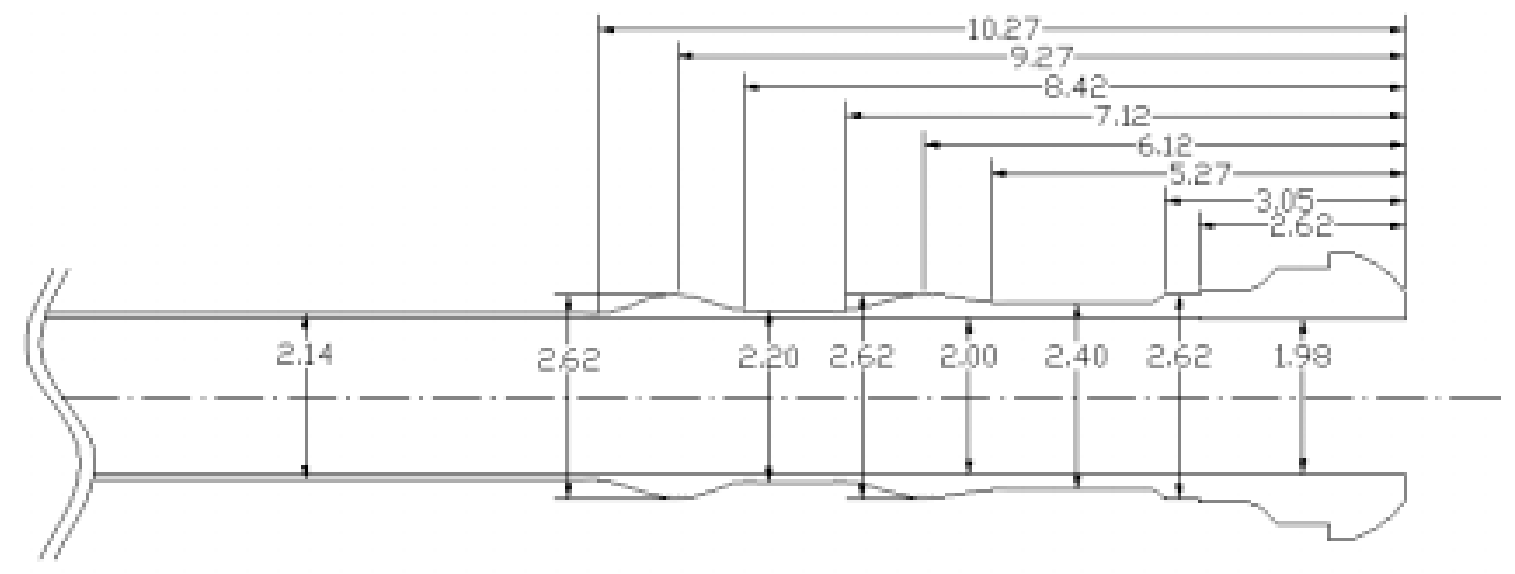

Figure 3.1.1 - Initial hump design for longitudinal stress.
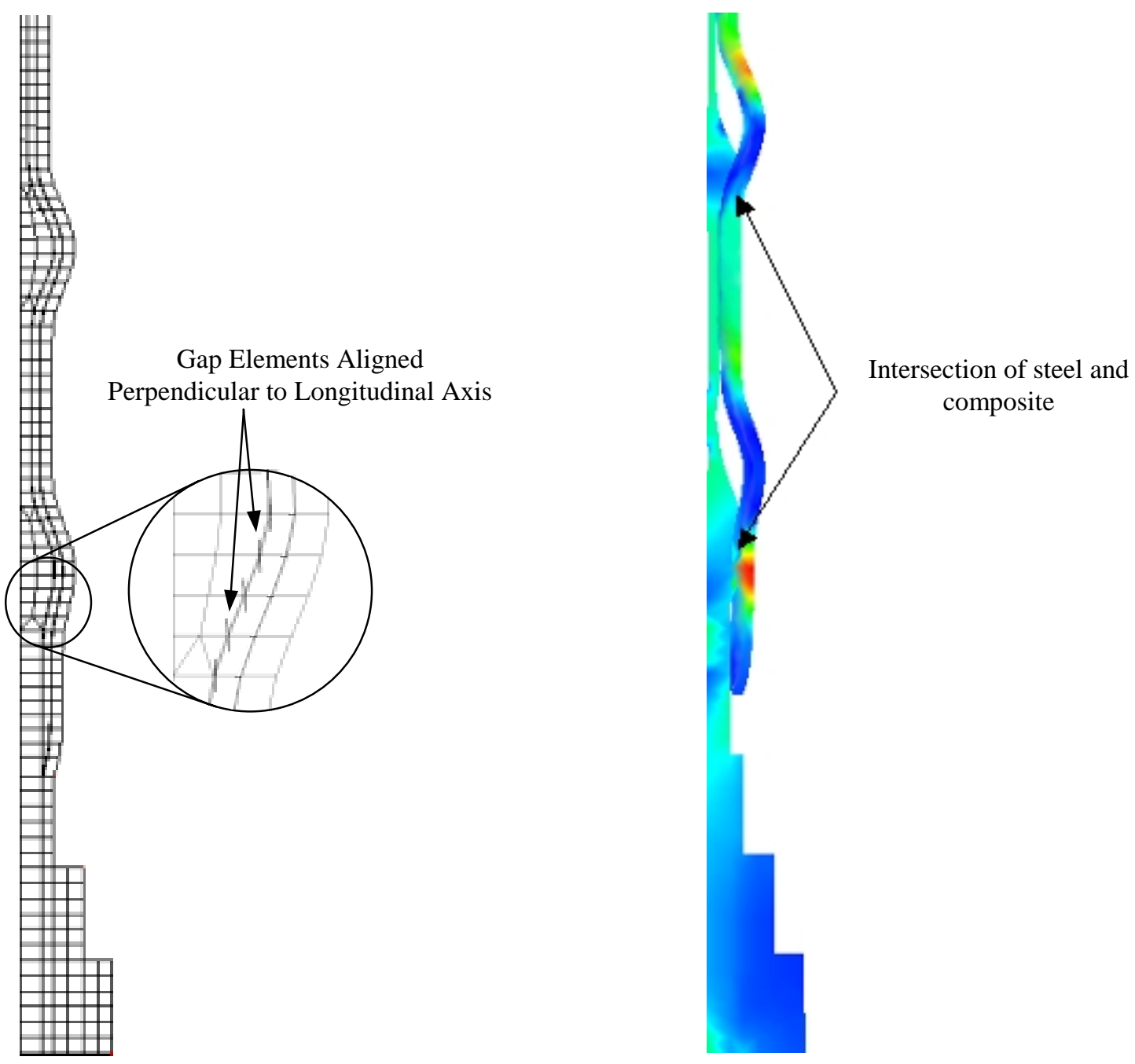

Figure 3.1.2 - FEM of initial hump design showing detail of gap elements on lower hump.
Figure 3.1.3 - Stress contour for initial hump design showing massive elongation and intersection of steel and composite. 


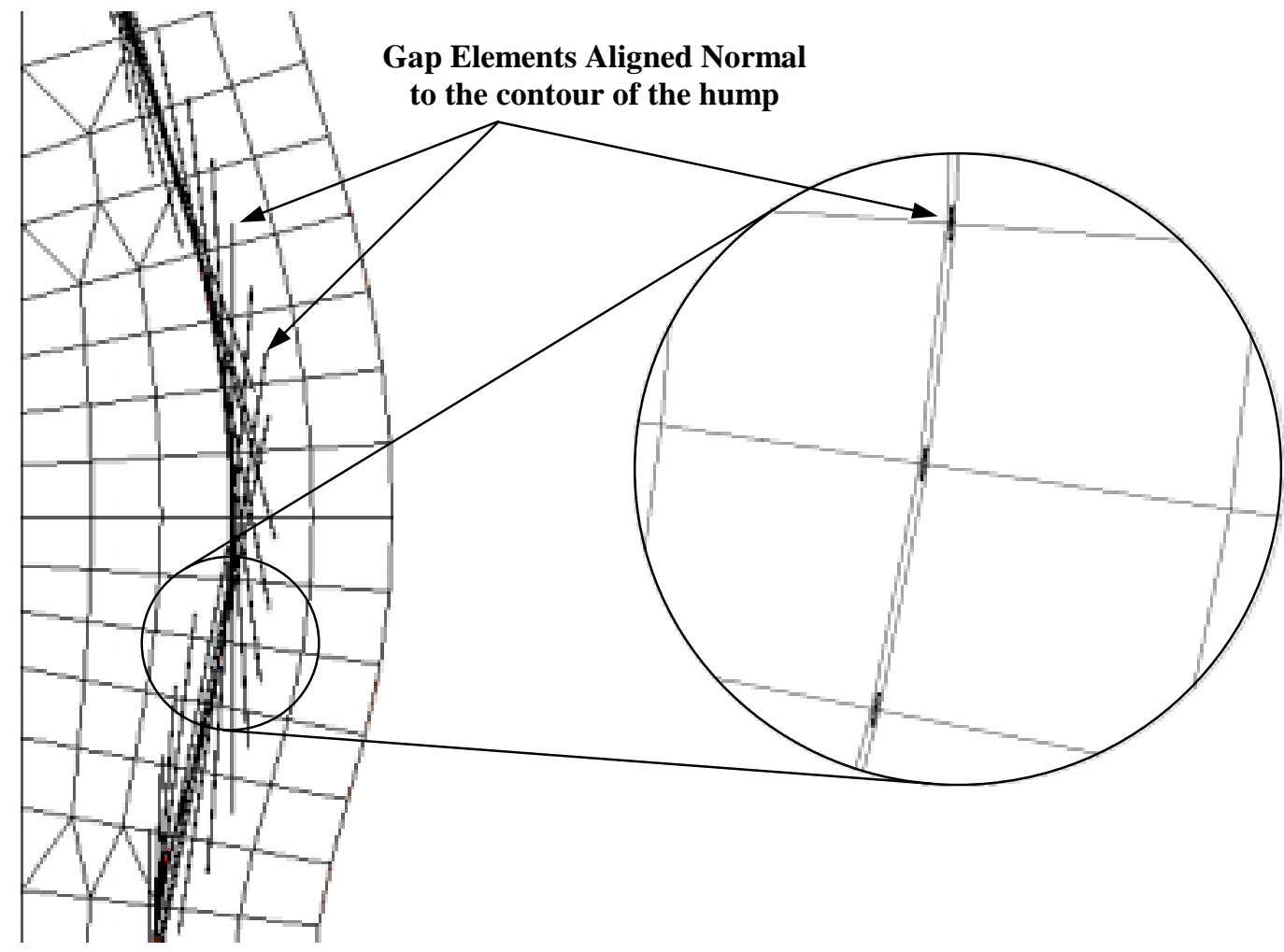

Figure 3.1.4 - Meshed hump section showing detail of gap elements aligned normal to the spline curve of the hump.

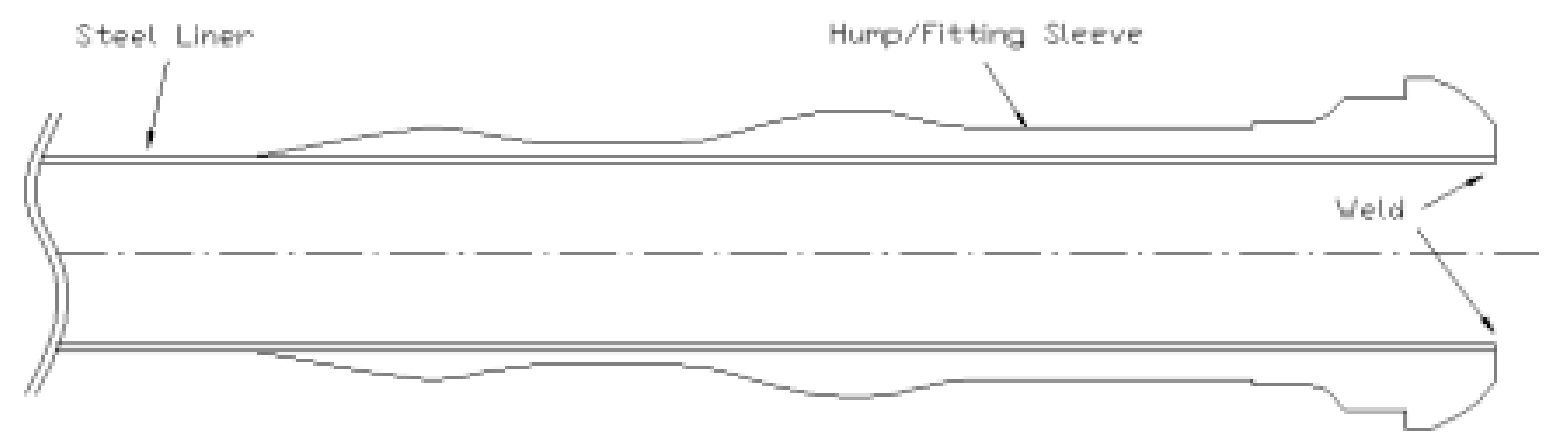

Figure 3.1.5 - Sleeve design without composite over-wrap. 


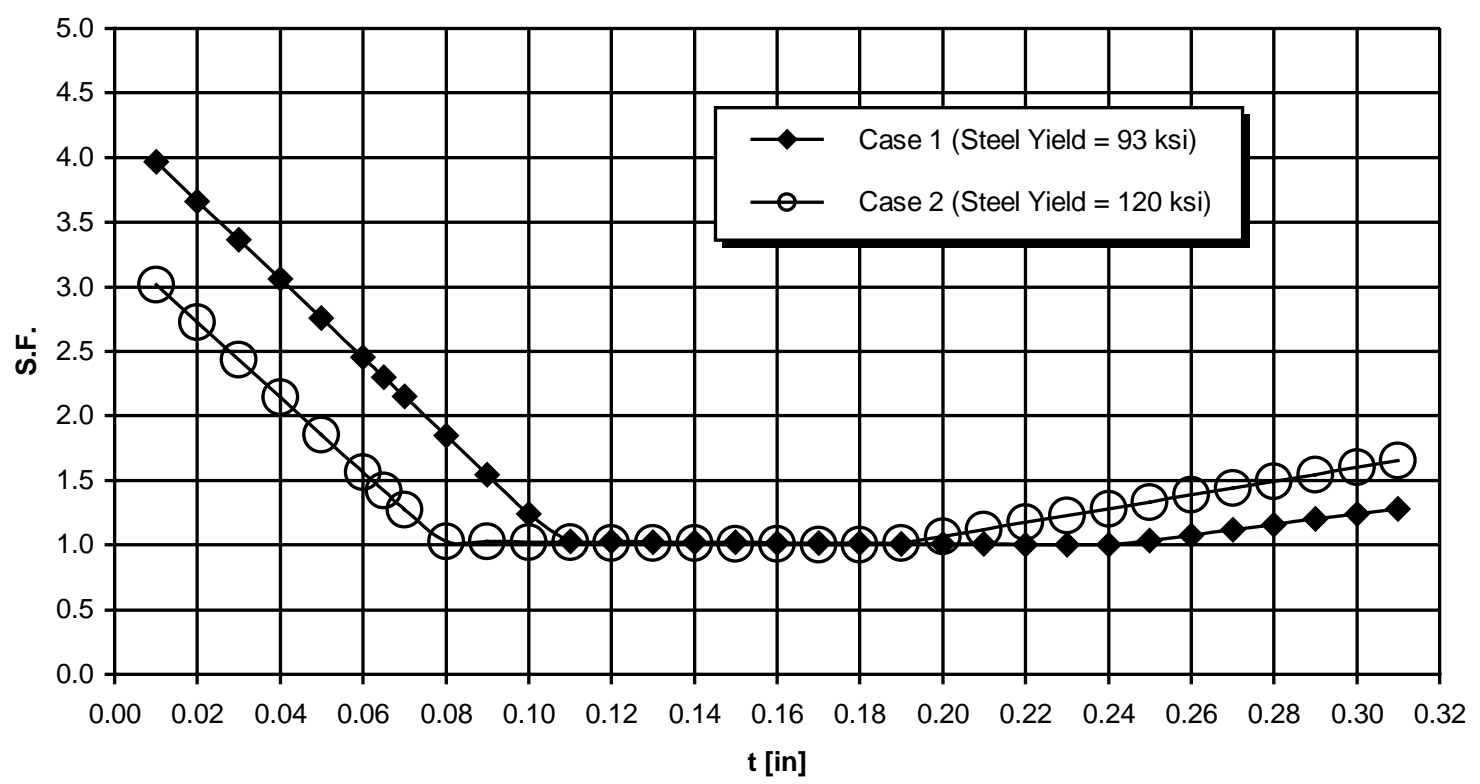

Figure 3.3.1 - Two case comparison of steel thickness versus modified safety factor for the hoop-wound fibers at autofrettage pressure.

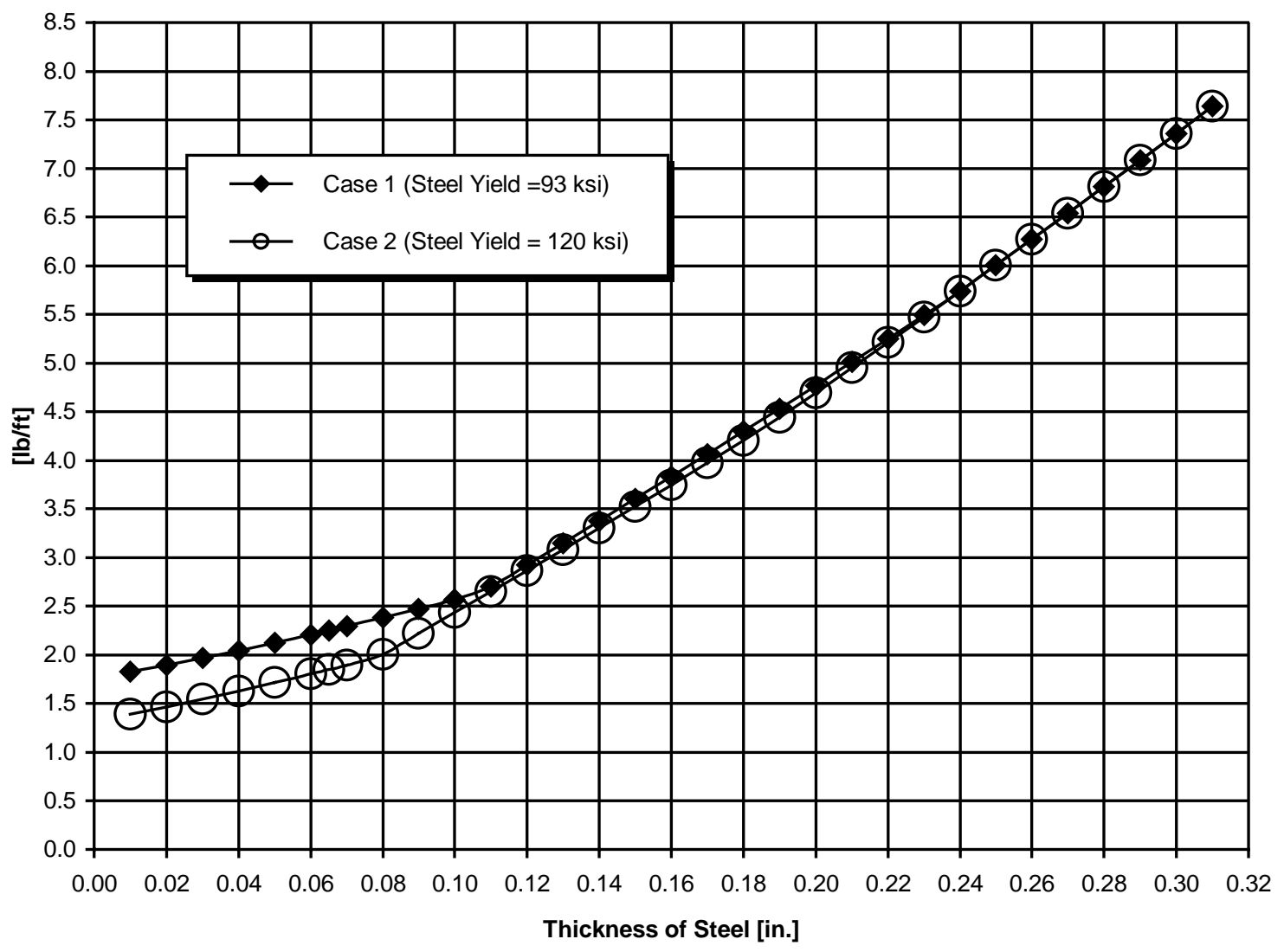

Figure 3.3.2 - Two case comparison of steel thickness versus weight of the steel and hoop-wound composite. 

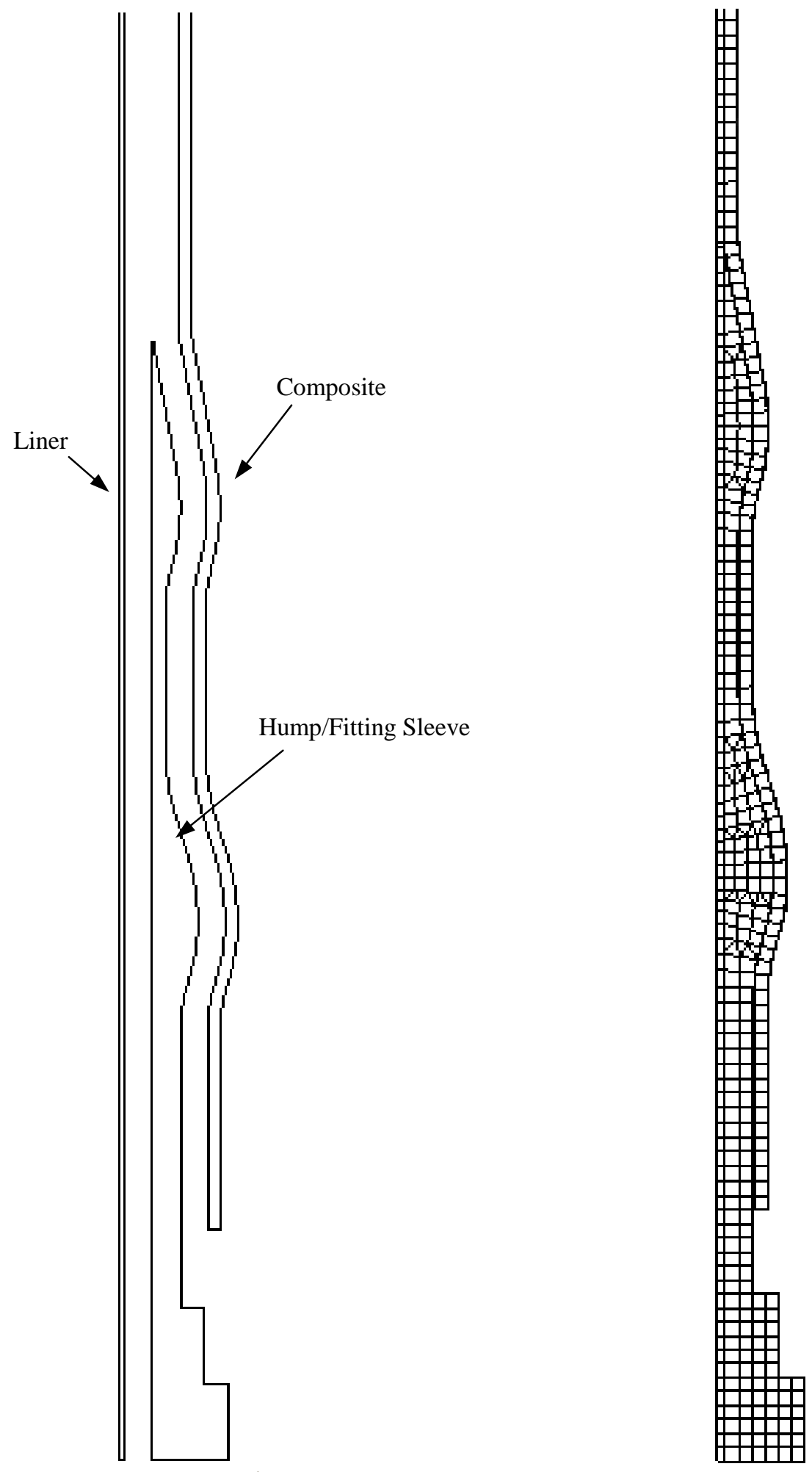

Figure 3.3.3 - Exploded view of sleeve model showing the three parts.

Figure 3.3.4 - Meshed finite element model of the sleeve design. 


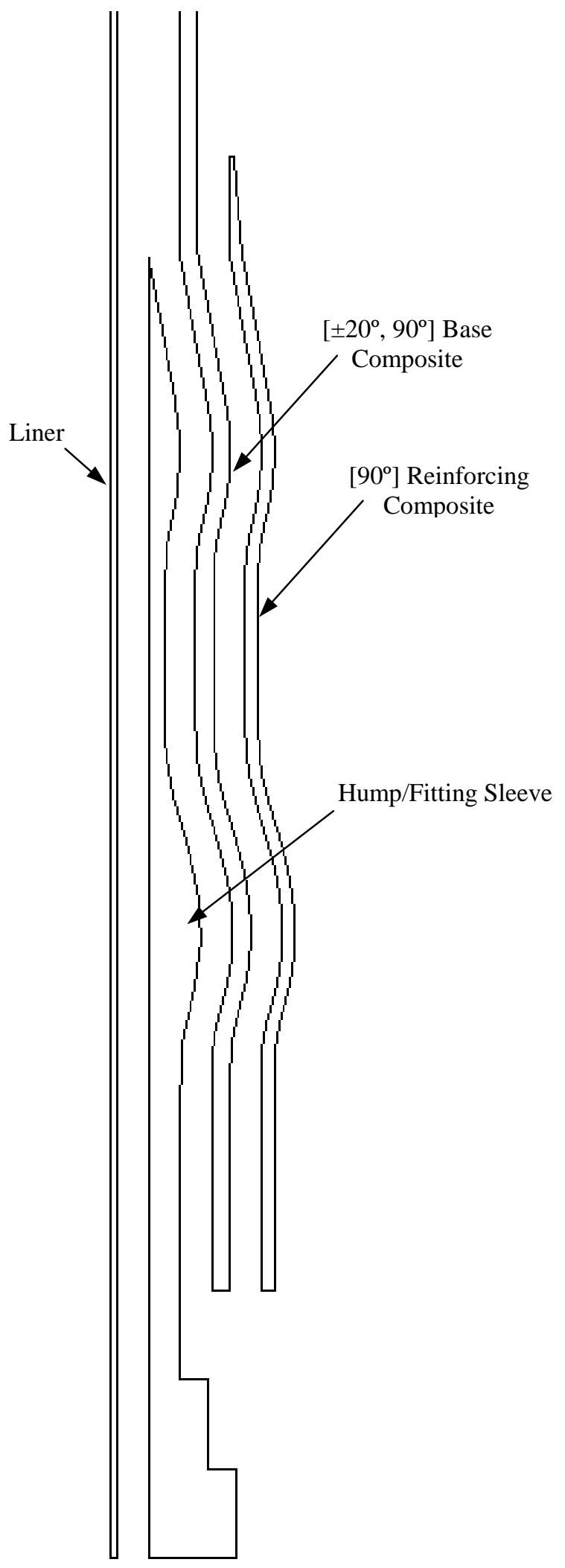

Figure 3.3.5 - Exploded view of sleeve model with reinforcement over the humps. 


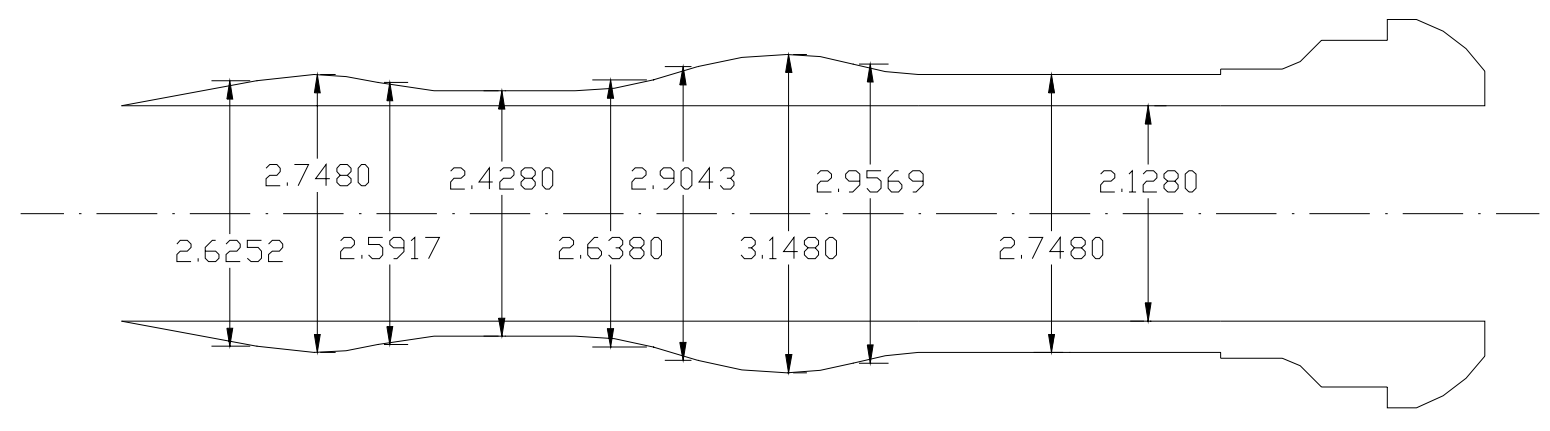

Figure 3.3.6 - Diametric dimensions of the hump/fitting for the sleeve design.

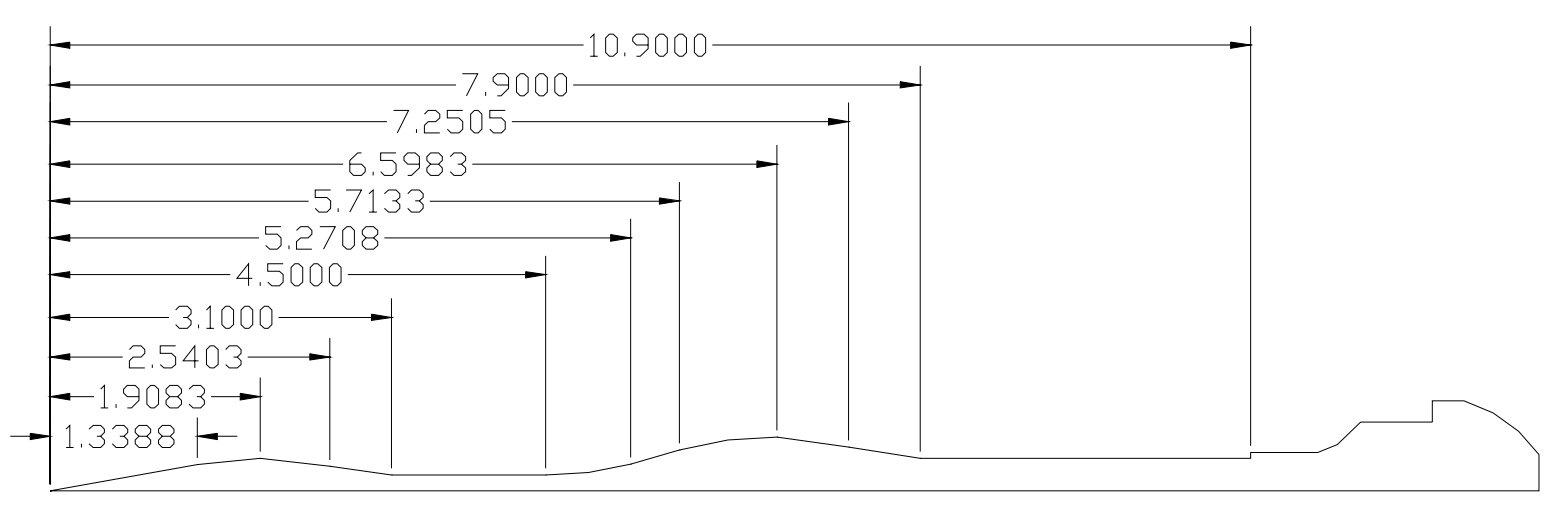

Figure 3.3.7 - Thickness dimensions of the hump/fitting for the sleeve design.

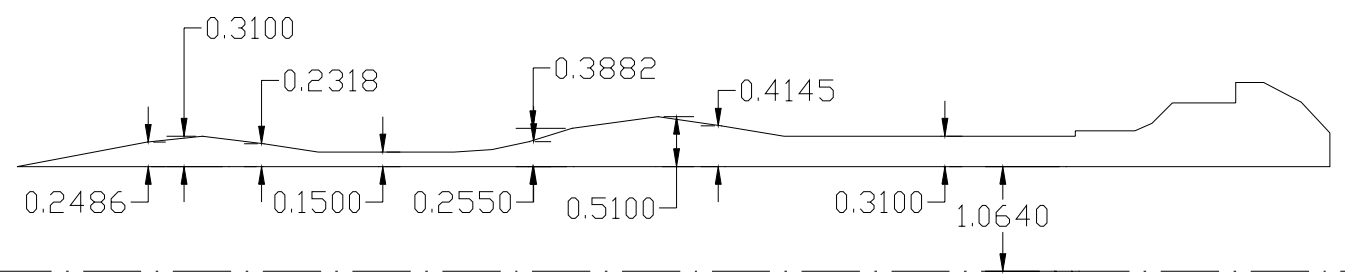

Figure 3.3.8 - Longitudinal dimensions of the hump/fitting for the sleeve design. 


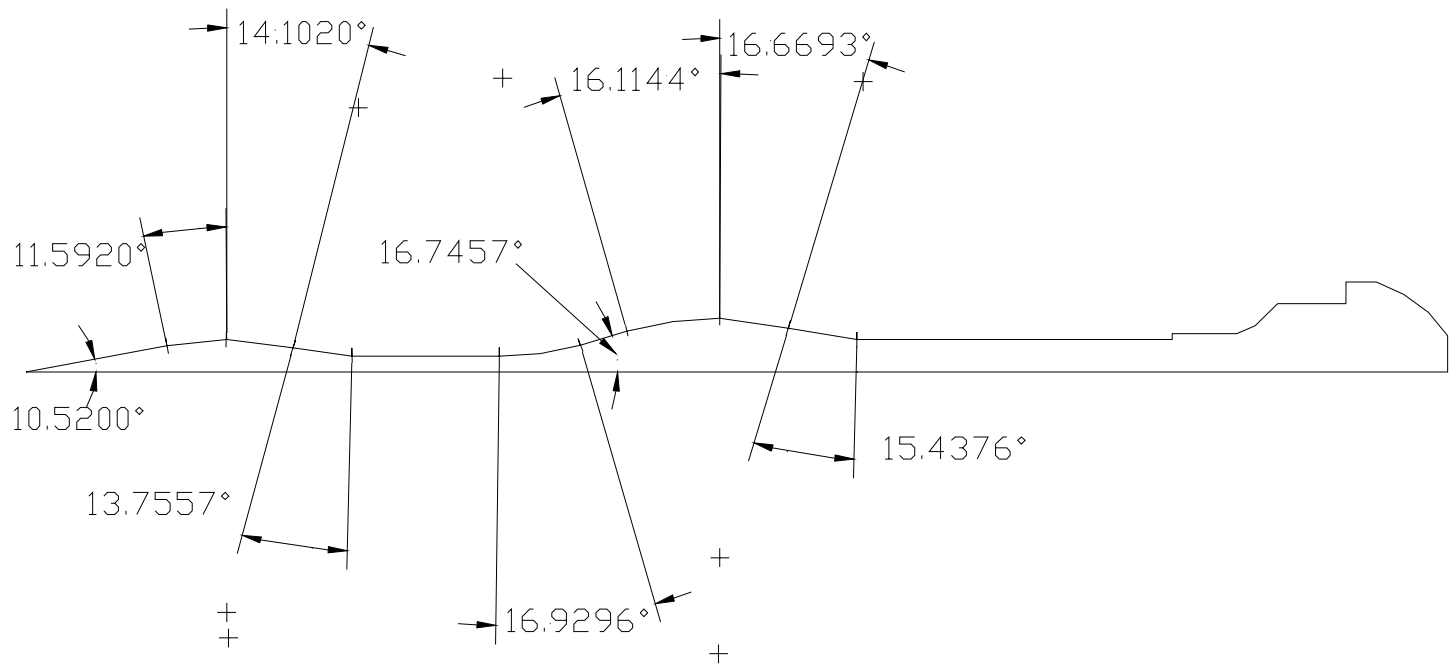

Figure 3.3.9 - Angular dimensions of the hump/fitting for the sleeve design.

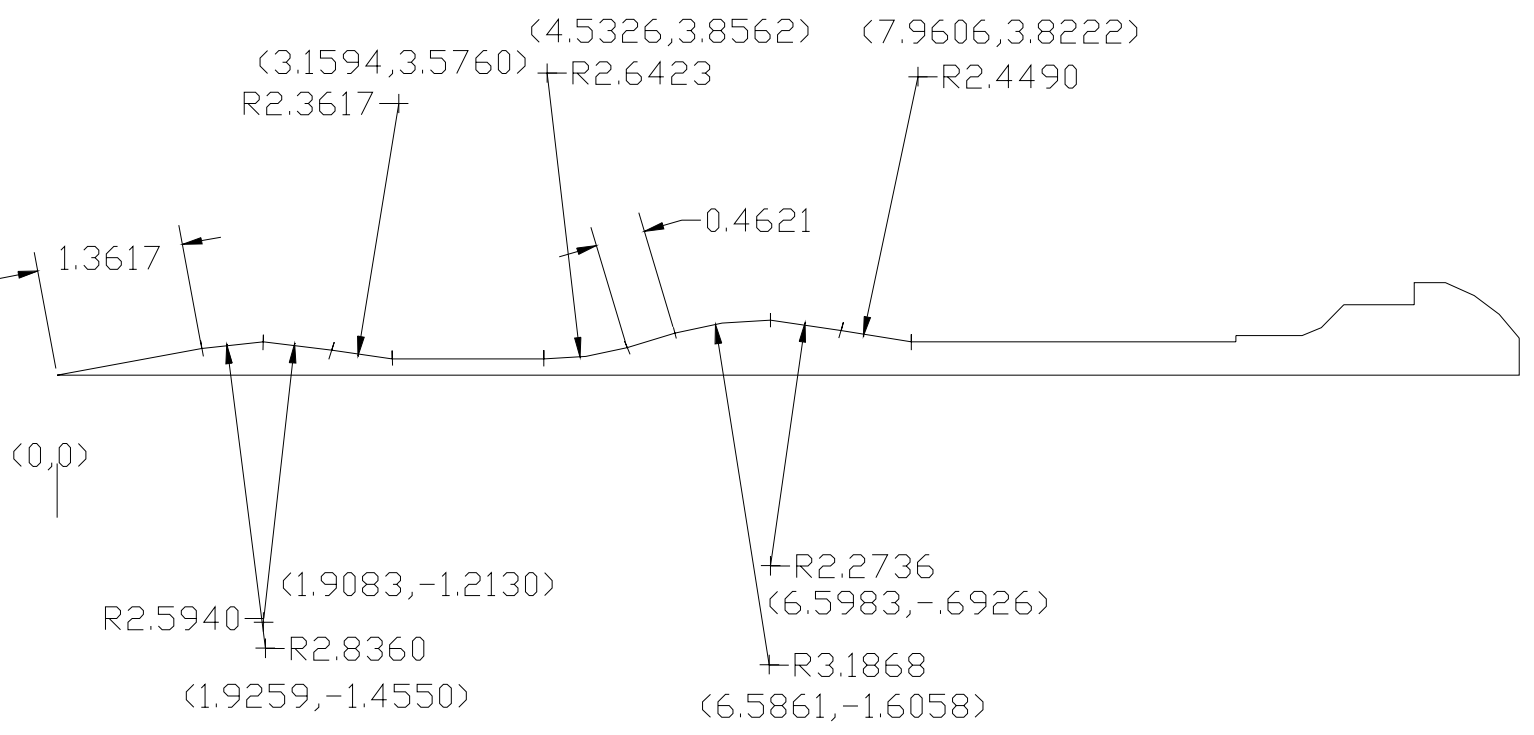

Figure 3.3.10 - Radial dimensions of the hump/fitting for the sleeve design. 


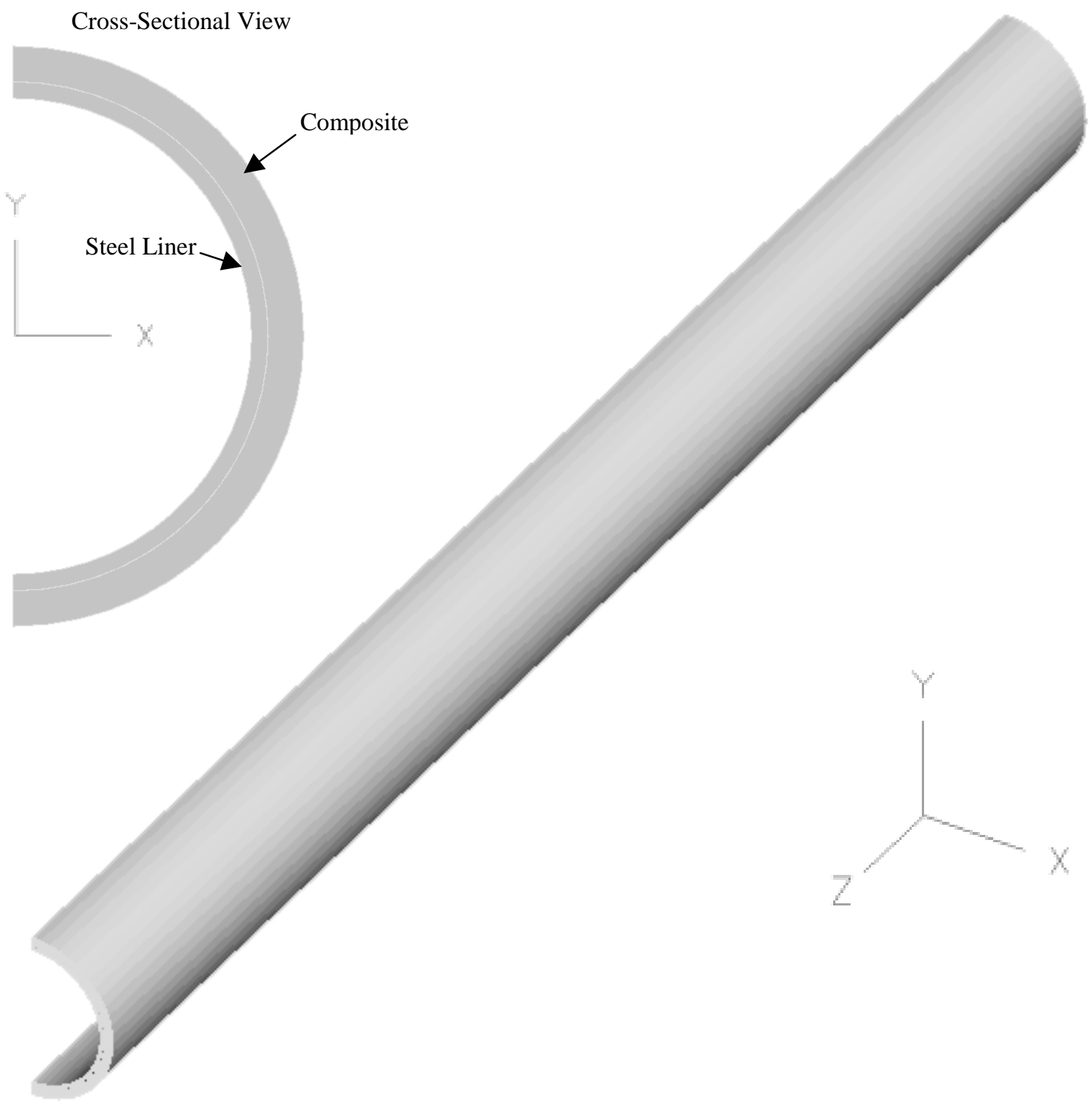

Figure 3.4.1 - Cross-sectional and three-dimensional views of the model used for the ovalization analysis. 


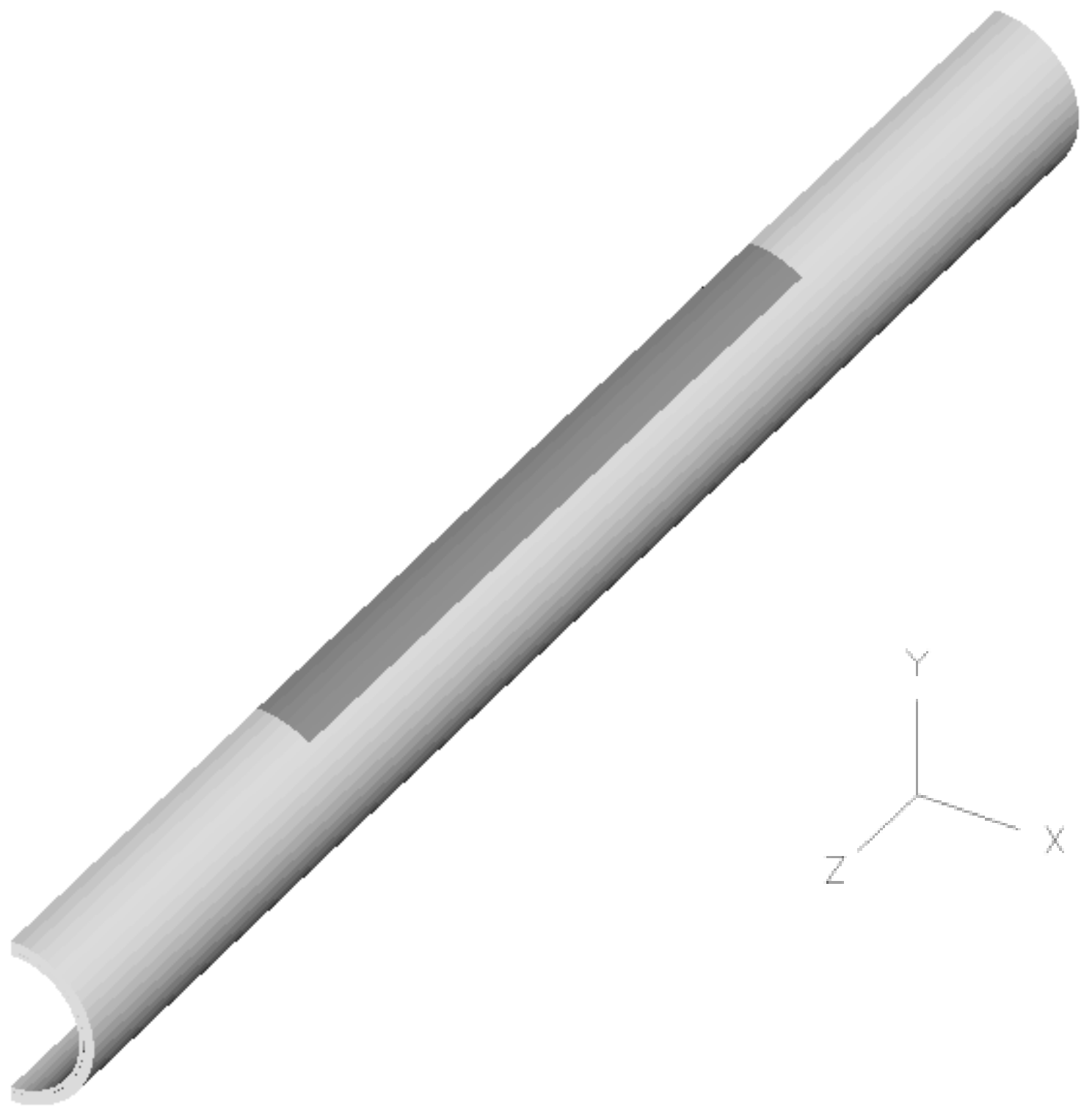

Figure 3.4.2 - Three-dimensional view of the model with shaded area describing load location. 


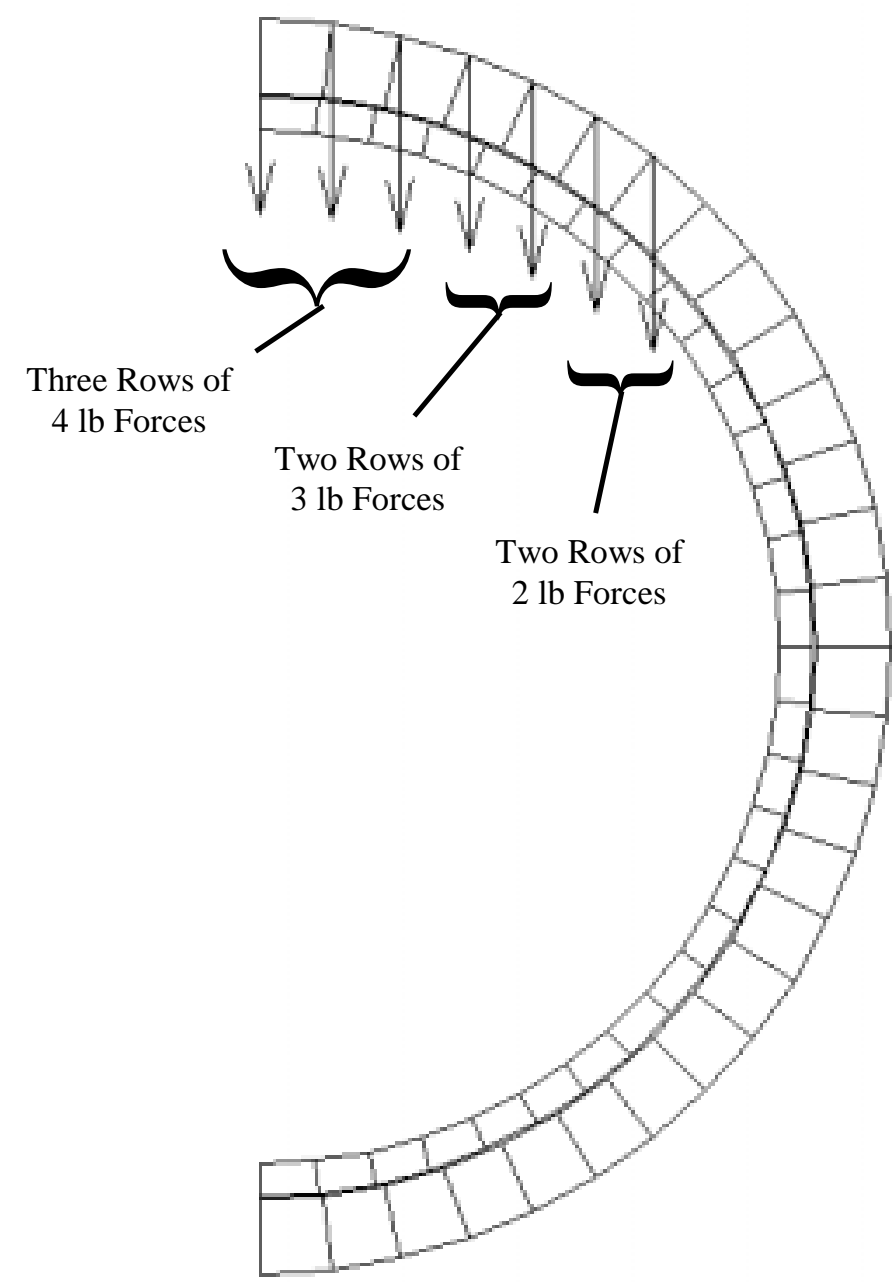

Figure 3.4.3 - Cross-sectional view of the model with arrows depicting seven rows of nodal forces. 


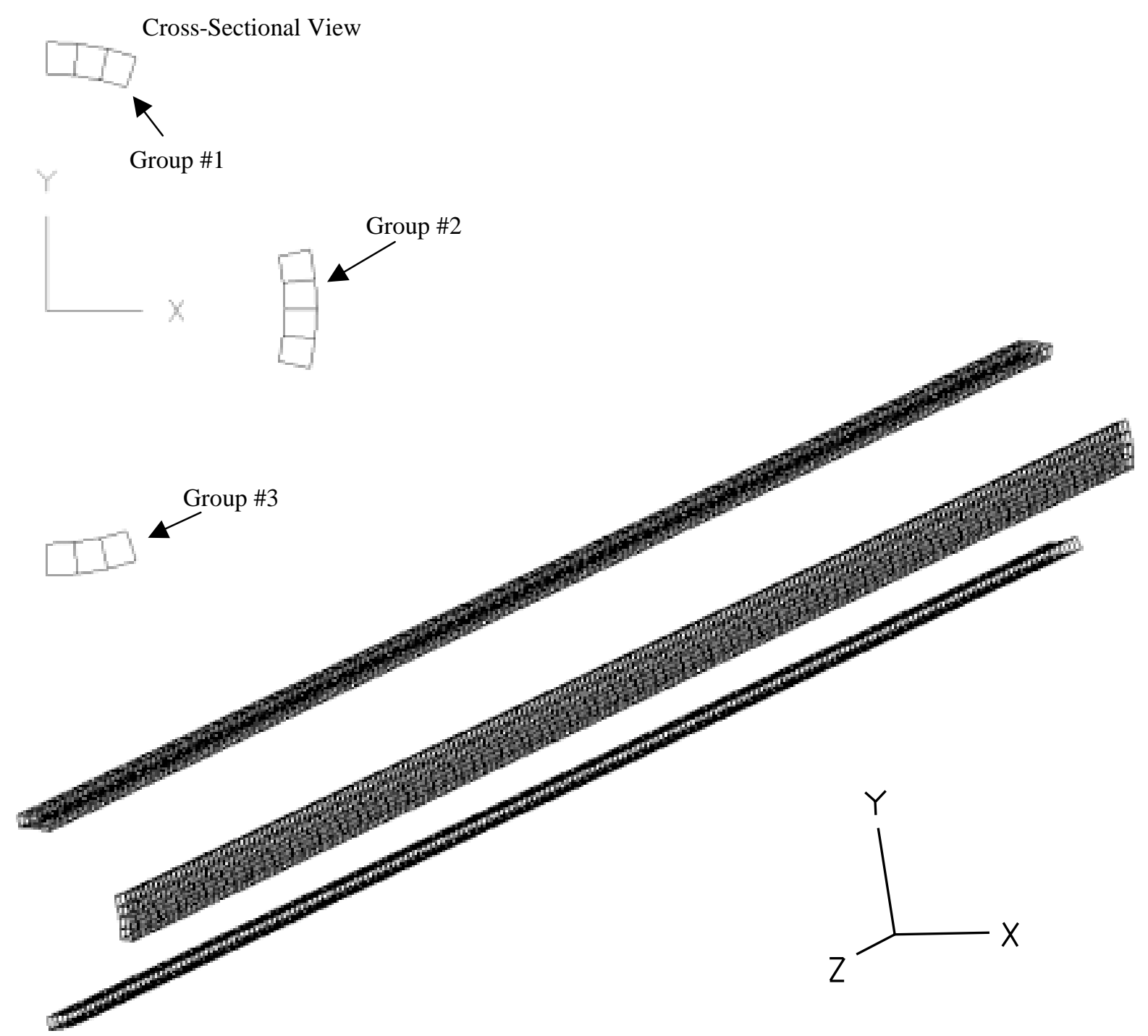

Figure 3.4.4 - Cross-sectional and three-dimensional views of composite elements from which results were taken. 


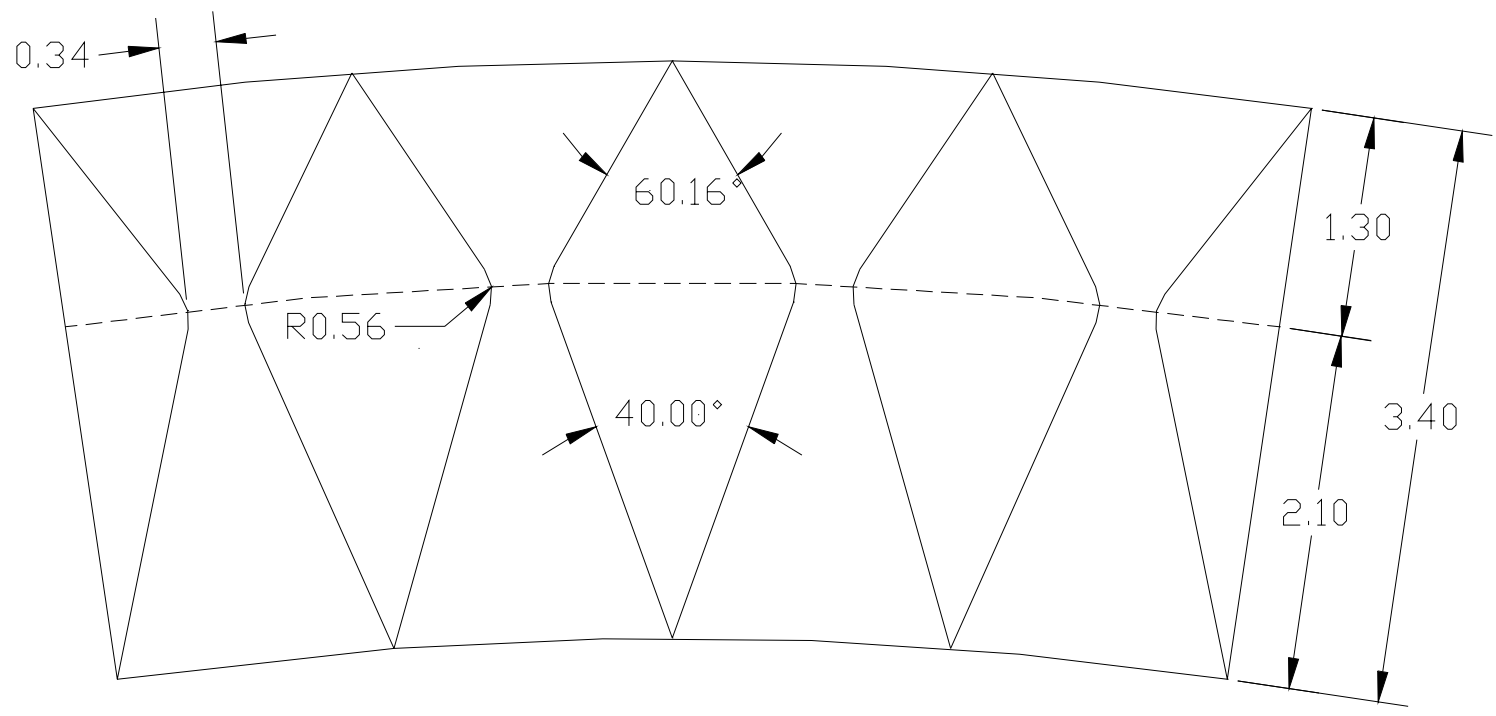

Figure 3.5.1 - Unwrapped view of the large hump showing dimensions of the track design.

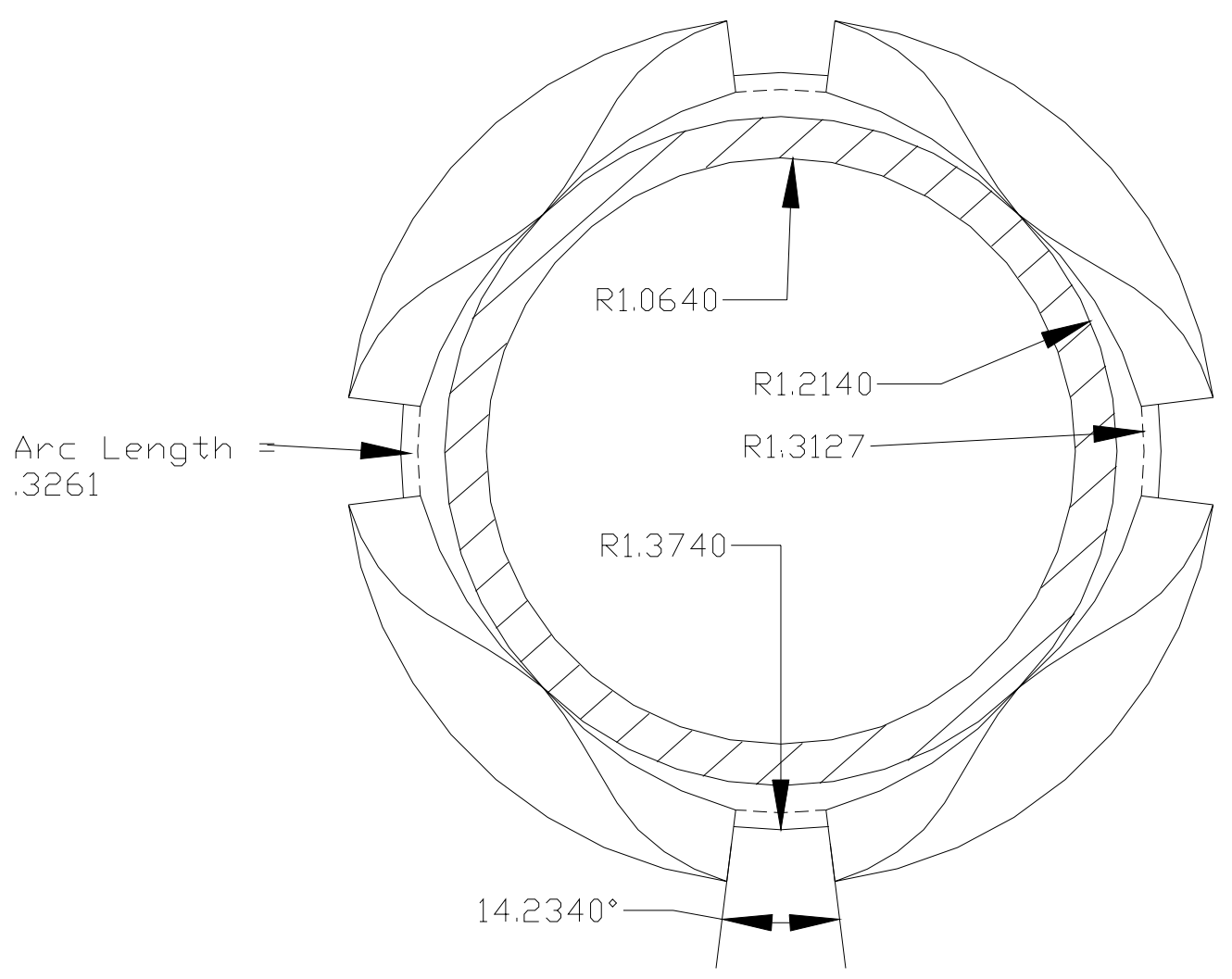

Figure 3.5.2 - Dimensions of the track design in a cross-sectional view. 


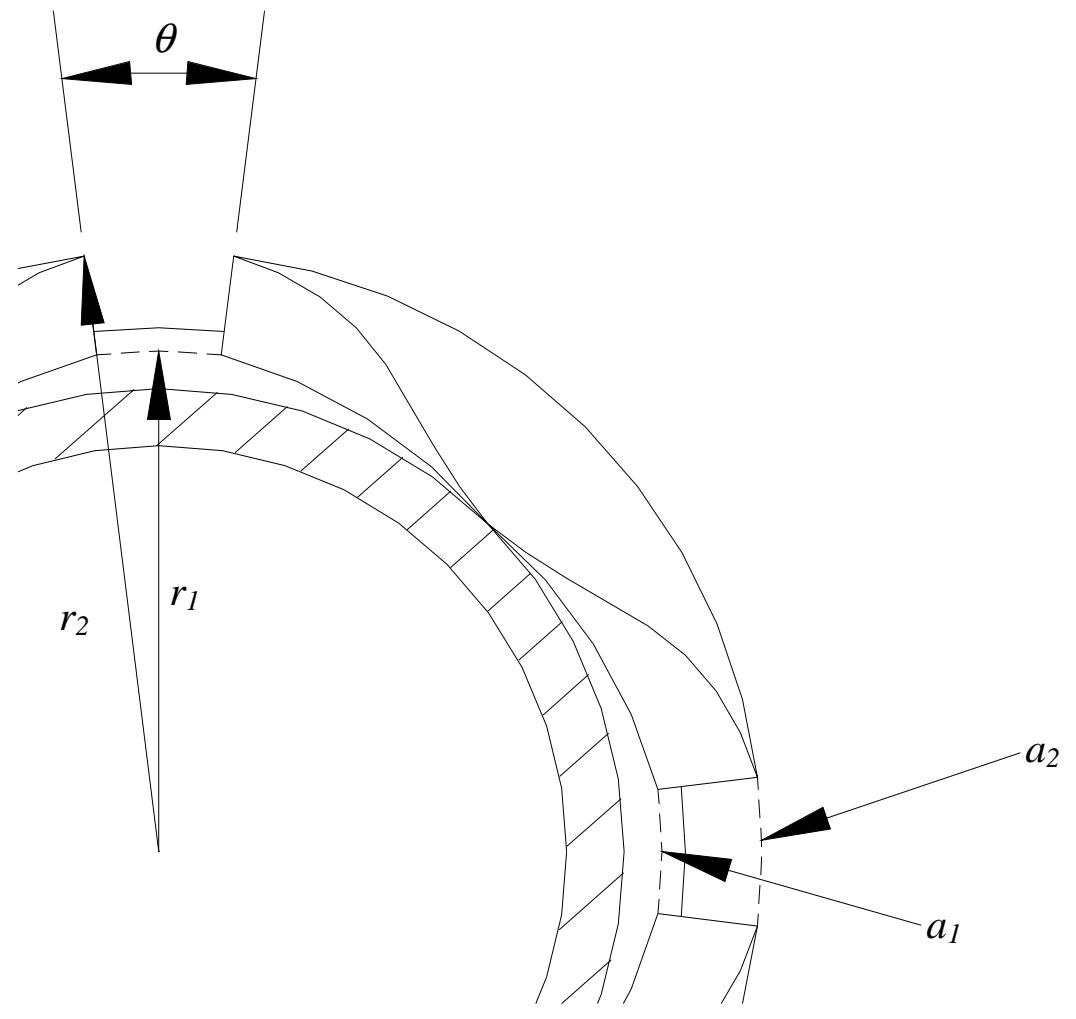

Figure 3.5.3 - Variable dimensions used to determine the track design.

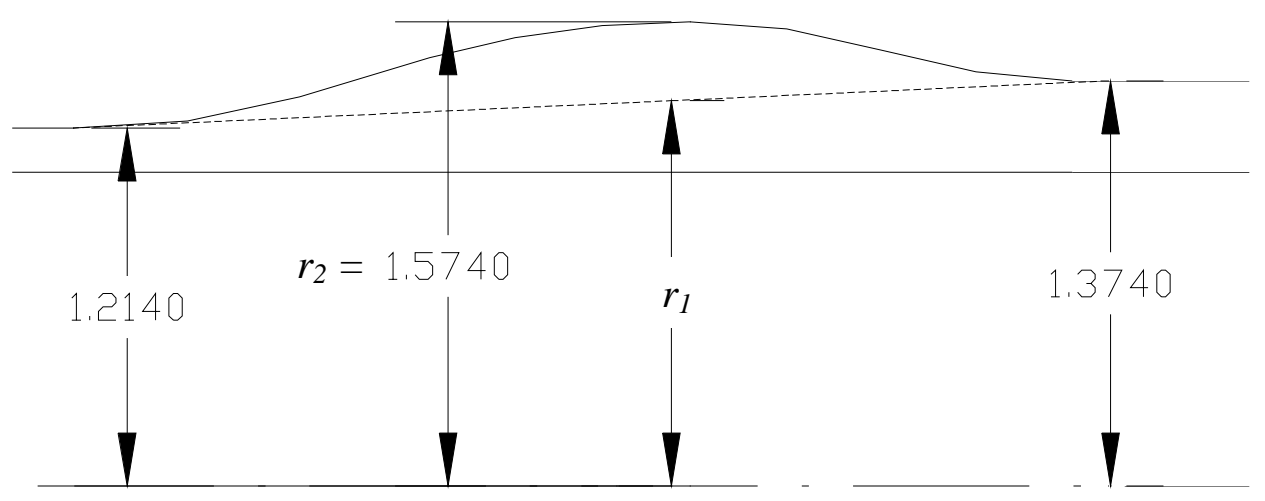

Figure 3.5.4 - Diagram used to determine the radius of the track bottom at the bottleneck of the track design. 


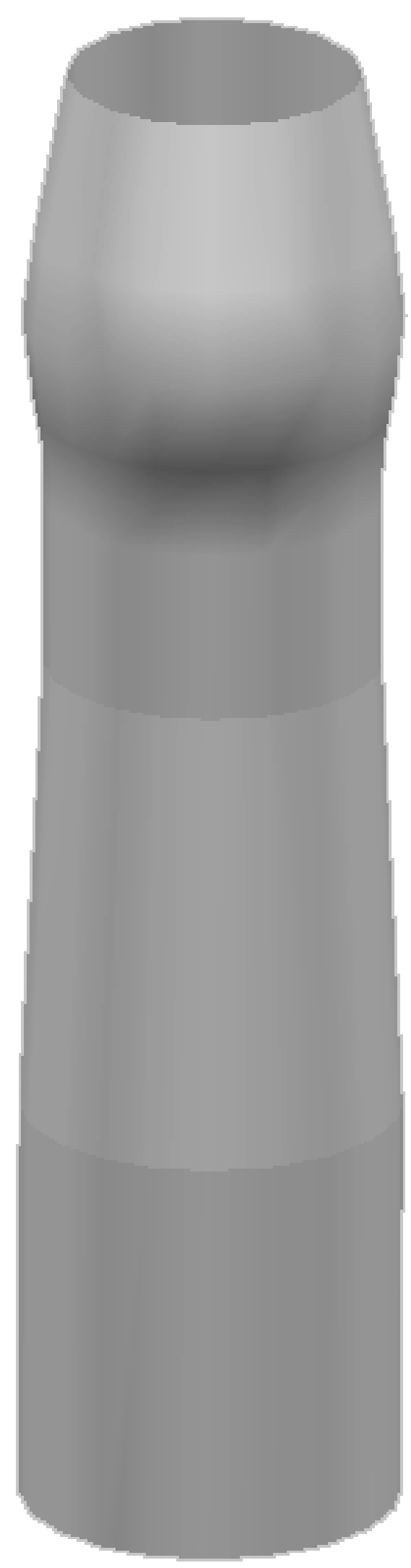

Figure 3.7.1 - Longitudinal cross-section of steel hump section without large hump.

Figure 3.7.2 - Solid model of steel hump section without large hump. 


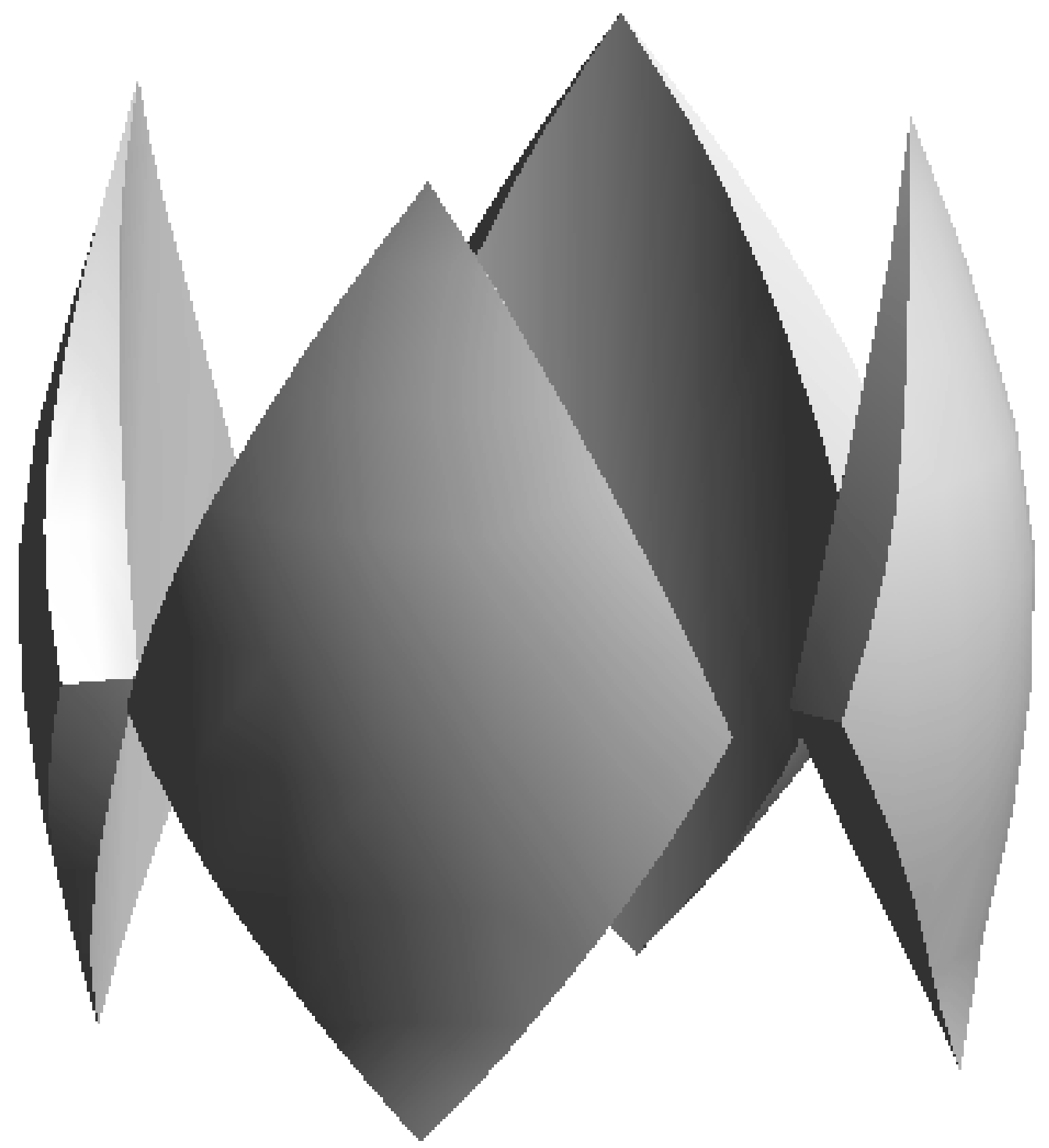

Figure 3.7.3 - Solid model of the four steel diamond shaped track forms. 


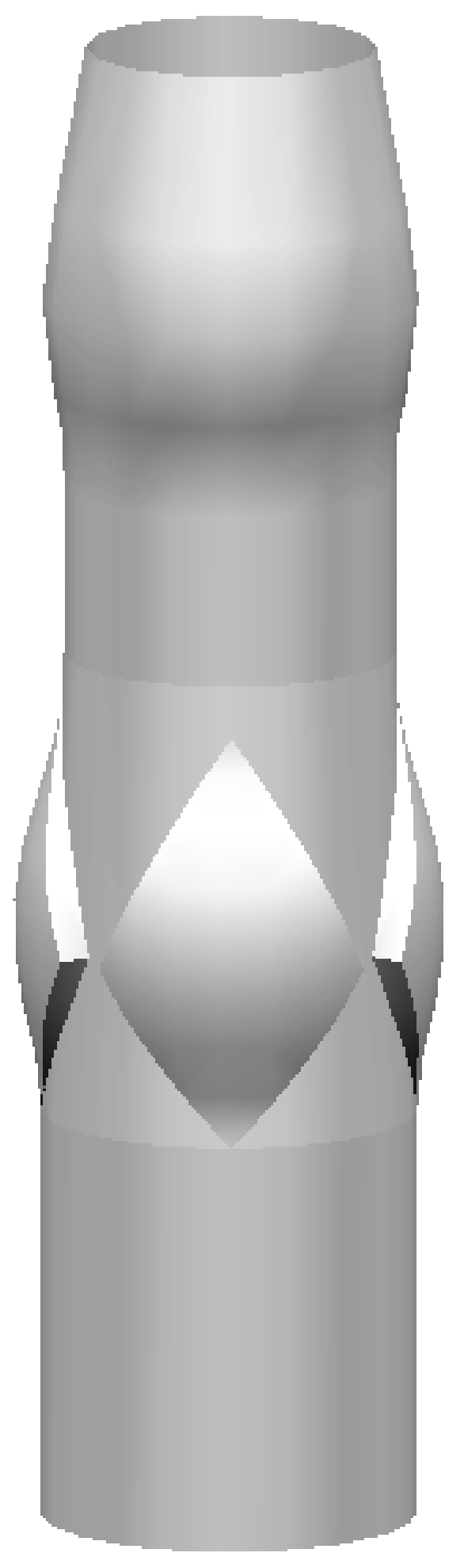

Figure 3.7.4 - Solid model of the completed steel hump section with tracks.

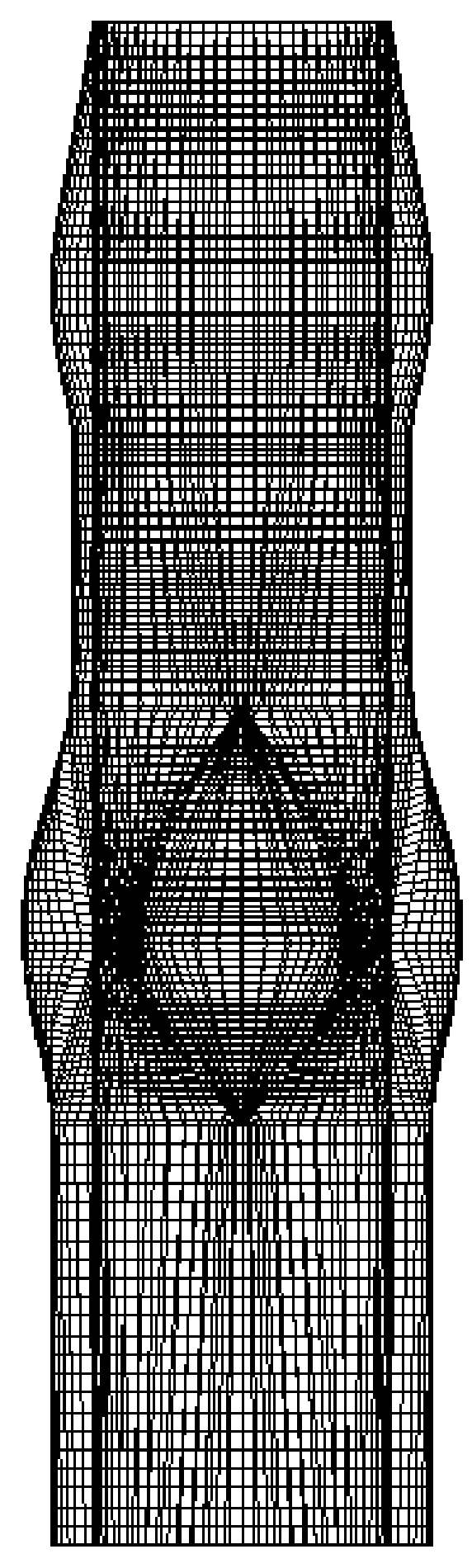

Figure 3.7.5 - Meshed FEM of the steel hump section with tracks. 

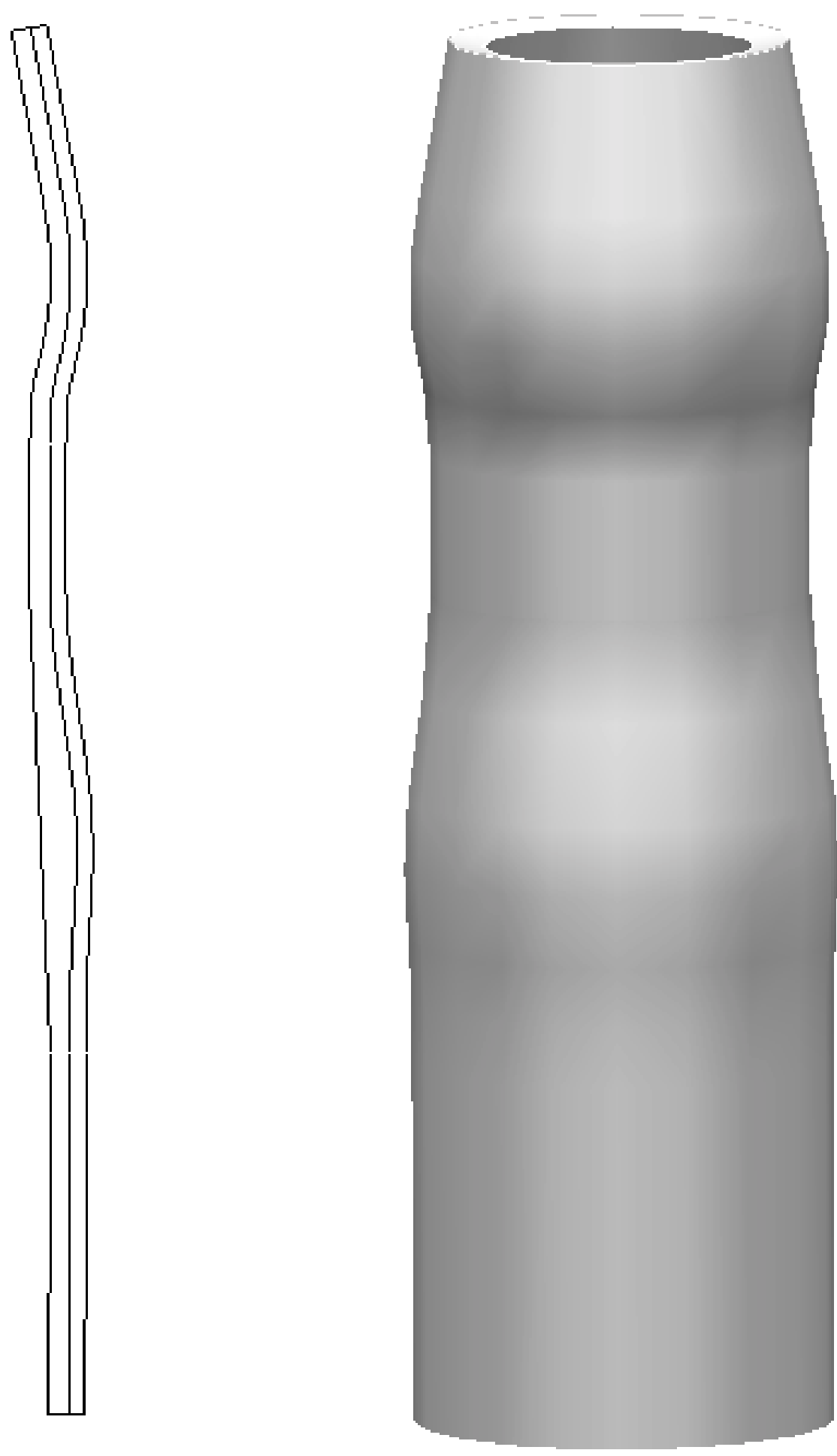

Figure 3.7.6 - Longitudinal cross-section of composite section including reinforcement.

Figure 3.7.7 - Solid model of composite section including reinforcement. 


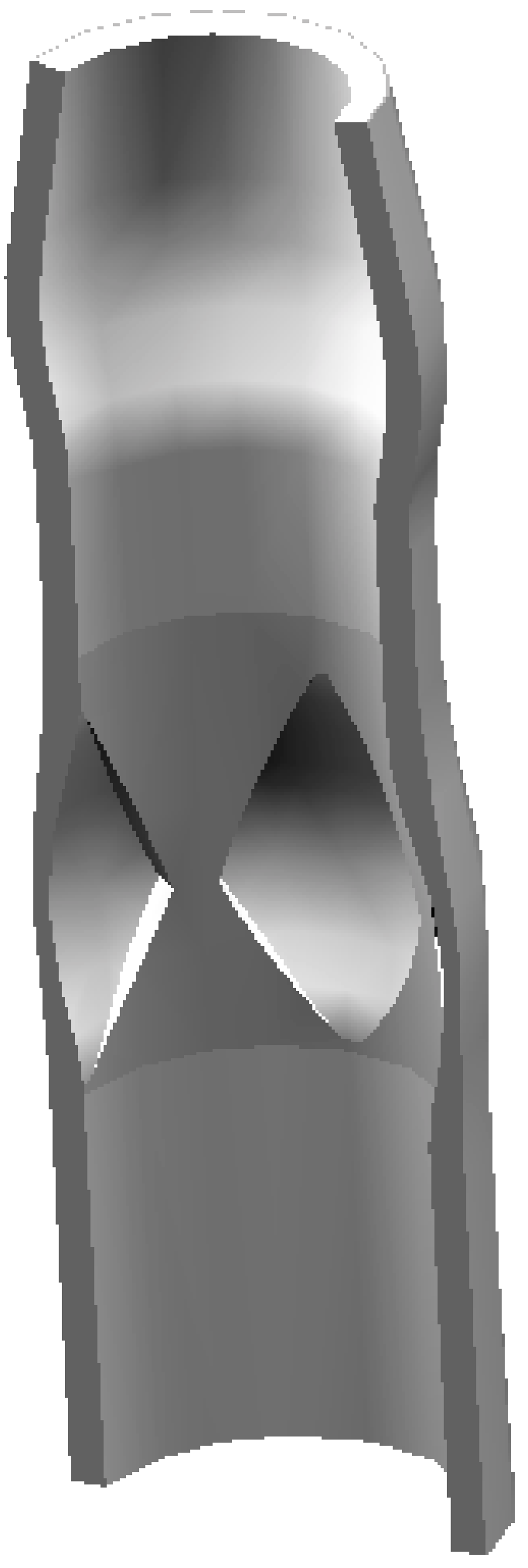

Figure 3.7.8 - Interior view of the composite showing diamond shaped cutouts.

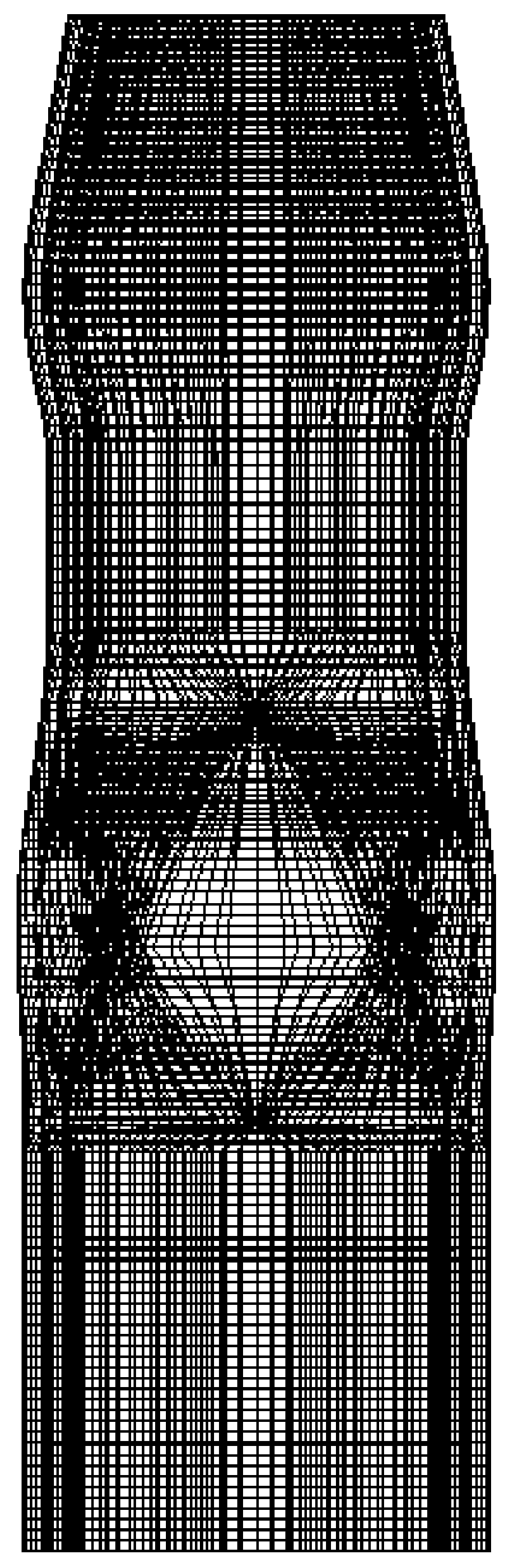

Figure 3.7.9 - Meshed FEM of the composite part. 


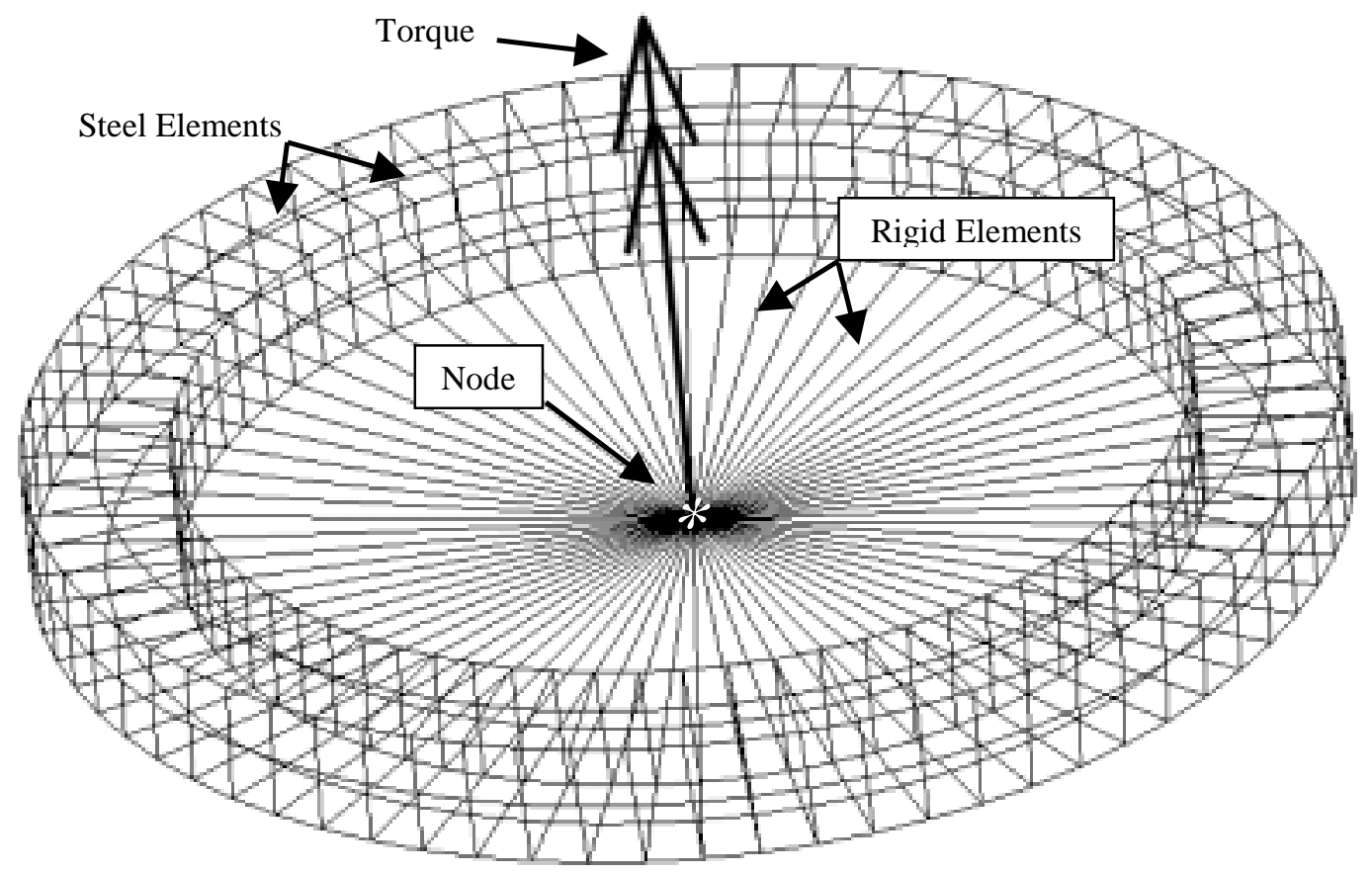

Figure 3.7.10 - End of steel mesh showing node, rigid bar elements and applied torque load. 


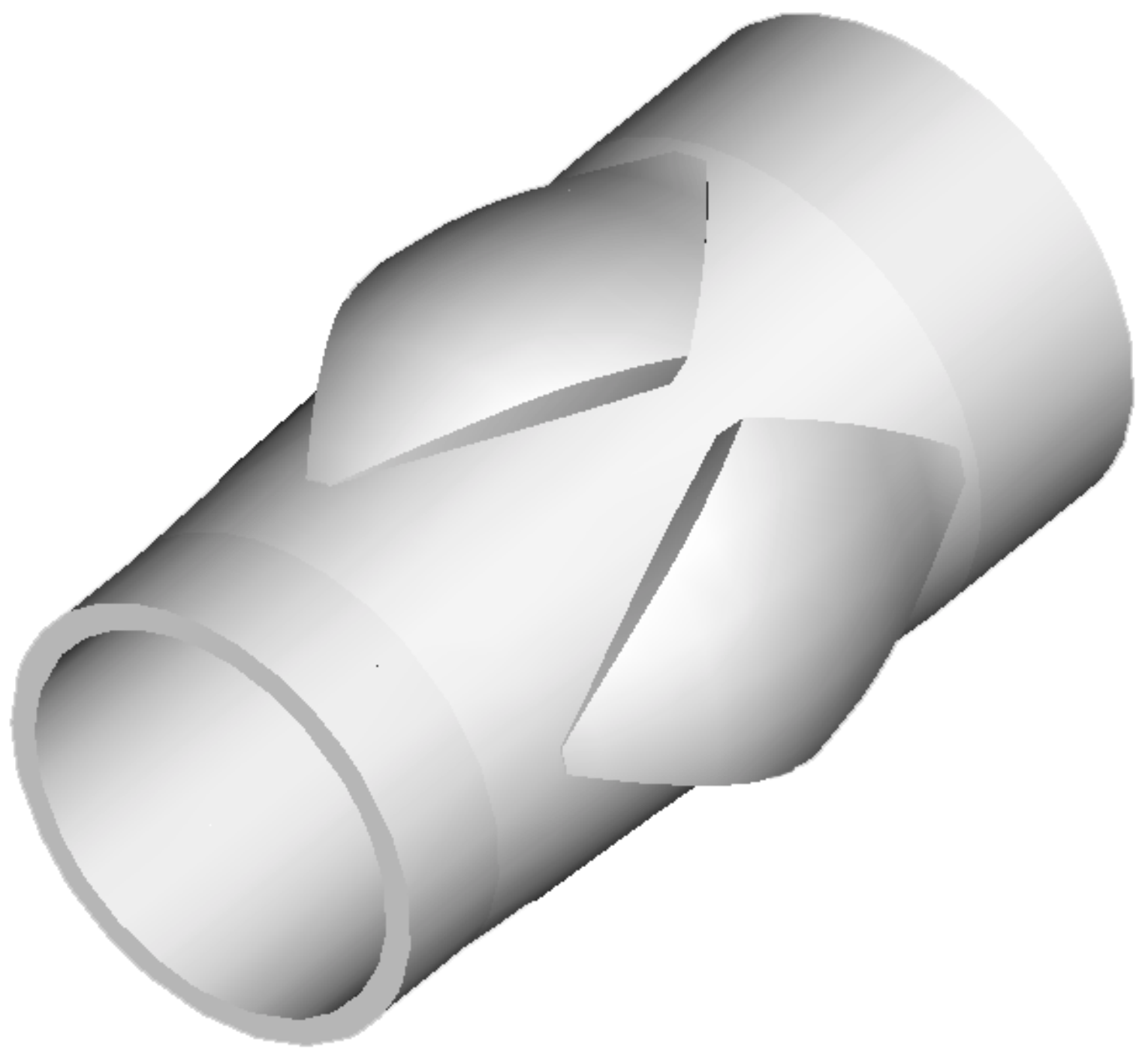

Figure 3.7.11 - Steel part of the simplified model for the torque analysis. 


\section{Chapter Four}

\section{Fabrication and Testing}

\subsection{Fabrication}

Upon completion of the design and analyses, shop drawings for the fabrication of the steel liner and fittings were submitted to Stan Stephenson at Halliburton Company. The hump/track fittings were machined from 4130 steel and were positioned and welded at the ends of the 10 foot liner, which was also made of 4130 steel. Residual stresses were introduced into the steel through the welding process requiring a heat treatment for relief. A furnace stress relieve at $900 \mathrm{~F}$ was performed for one hour on each end of the pipe. The temperature was verified with the use of a thermocouple and the time was monitored. After the pipes cooled, Loctite 290 was introduced into the gap between the hump/track sleeve and the liner to seal and protect the pipe from internal corrosion and rust.

Four steel prototypes were produced and delivered to FMW Rubber Products, Inc. in Bridgeport, West Virginia. Composite design specifications were given to Don Mott at FMW and one prototype was prepared and fabricated as described below.

The pipe was cleaned, degreased and coated with a paint-on insulation, Siloxirane \#32 with Catalyst \#32 from Advanced Polymer Coatings, to prevent galvanic corrosion between the steel liner and the carbon fibers. The computer-controlled filament-winding machine was prepared and the ends of the mandrel were inserted into the mounting chucks. The placement of the fibers was controlled by the computer as the pipe rotated. The first layer was $\pm 20^{\circ}$ followed by a $90^{\circ}$ layer and alternated in this manner until the total required thickness for the two layer orientations were fulfilled. The $\pm 20^{\circ}$ fibers were 
wound and allowed to pass over the inner humps and through the tracks on the outer humps at which point they were turned around for a pass in the opposite direction. The $90^{\circ}$ fibers were wound only over the body of the pipe and the inner humps. They were not allowed on the outer humps because this would block the tracks and not allow the $\pm 20^{\circ}$ fibers to be placed properly. As the fibers were placed on the rotating pipe, the operator distributed and removed excess resin by dragging a wide, flat, flexible piece of plastic along the composite thereby spreading and extracting the extra epoxy. During placement of the $\pm 20^{\circ}$ fibers through the tracks, it was noticed that there were four triangular shaped areas, between the mouth of each track and the turnaround space, that were absent of fibers. Figure 4.1 shows the area void of composite. It was determined that due to the angle of the fibers exiting the tracks, that area could not be covered and would leave a void space underneath the $90^{\circ}$ reinforcement composite. It was also noticed that the fibers did not always fall nicely into the tracks and required manual adjustment by the operator, sometime involving halting the winder and reversing the rotation to unwind that section. A suggestion was made for future pipes to have raised triangular shaped guides welded or bonded to the void region to aid in automating the placement of fibers into and exiting the track at the turnaround area.

Diametric measurements were taken upon completion of each layer to gage and adjust the computer program for accuracy and to assure a fiber volume fraction of $60 \%$ by volume. After all layers were complete, additional $90^{\circ}$ fibers were wound over the outer track/humps to restrain the underlying fibers. The 0.125 inch $90^{\circ}$ reinforcing layer was then wound over both sets of humps. 
The process experienced downtime for mechanical problems and break periods for the operators. After such interludes, the resin began to harden and required the introduction of heat from a hand held heat gun, essentially to melt the epoxy and promote bonding of new layers.

After all the layers of the carbon/epoxy were completed, a protective layer of glass fiber was added using the same resin. The pipe was finished without a soft impact resistant layer of padding, as more research was needed to determine the best material for impact protection.

The weights of the mandrel, steel liner, composite and completed hybrid pipe are shown in Table 4.1. The hybrid pipe yields a $29.5 \%$ weight reduction when compared to the original all-steel pipe, which weighs $105 \mathrm{lbs}$. The pipe was shipped to Halliburton Co. in Duncan, Oklahoma for testing. The remaining three pipes, at the completion of this research, were stored at FMW ready for fabrication according to current and future design changes.

\subsection{Testing}

The pipe was tested at Halliburton Company. The pipe was installed in the test chamber by tightening the wing-nuts with a sledge hammer. The pipe was visually inspected for signs of composite damage due to the torque applied during mounting, but neither micro-cracks nor fiber breakage was found. The prototype was slowly pressurized with water to the autofrettage load of $22.5 \mathrm{ksi}$ and held for one minute before unloading. After the load was removed, the pipe was disconnected from the test fixture and visually inspected. It was noticed that the interior of the pipe had no visible defects such as bulges or kinks and the exterior showed no signs of damaged fibers or micro- 
cracks in the resin. The pipe was reconnected and slowly loaded to $29.4 \mathrm{ksi}$ at which point catastrophic failure occurred. According to Table 3.3.3, the safety factor in the hoop direction of the base composite was 1.36 at $22.5 \mathrm{ksi}$, therefore the predicted pipe failure was to be at $30.8 \mathrm{ksi}$ which proved to be a good representation of the actual test. However, metal pipes typically fail by splitting along its longitude, which is an acceptable failure mode. The prototype failed by breaking into three separate parts. It appears that it first started to split along the longitude but after the crack lengthened beyond 6 inches, it was unable to continue and both ends of the crack changed direction and progressed hoop-wise around the pipe, thus resulting in a short section breaking free of the two end sections. This outcome was not expected due to the safety factors presented in Table 3.3.3 and Table 3.3.5. The theoretical results from the region of constant thickness, where the rupture occurred, revealed that the longitudinal safety factor of the base composite at autofrettage was about 2.34 times greater than the safety factor in the hoop direction. It is believed that the discrepancy was due to the fact that the FF values from CADEC were based on unidirectional loading conditions. This is acceptable for the $90^{\circ}$ component of the base composite because it focuses nearly its entire strength in the hoop direction. But the $\pm 20^{\circ}$ fibers have the ability to bear stress in the hoop and longitudinal directions. Since the longitudinal component was analyzed with only the longitudinal FF stress in mind, the added stress from the combined loading proved to be too much. The mode of failure was deemed unacceptable and modifications to the design were required. 
Table 4.1 - Individual component and combined weights of the hybrid pipe.

\begin{tabular}{|c|c|}
\hline Description & Weight [lbs.] \\
\hline Mandrel & 89 \\
\hline $\begin{array}{c}\text { Steel Liner with } \\
\text { Fittings and Wing-Nut }\end{array}$ & 57 \\
\hline Composite & 17 \\
\hline Completed Pipe & 74 \\
\hline
\end{tabular}




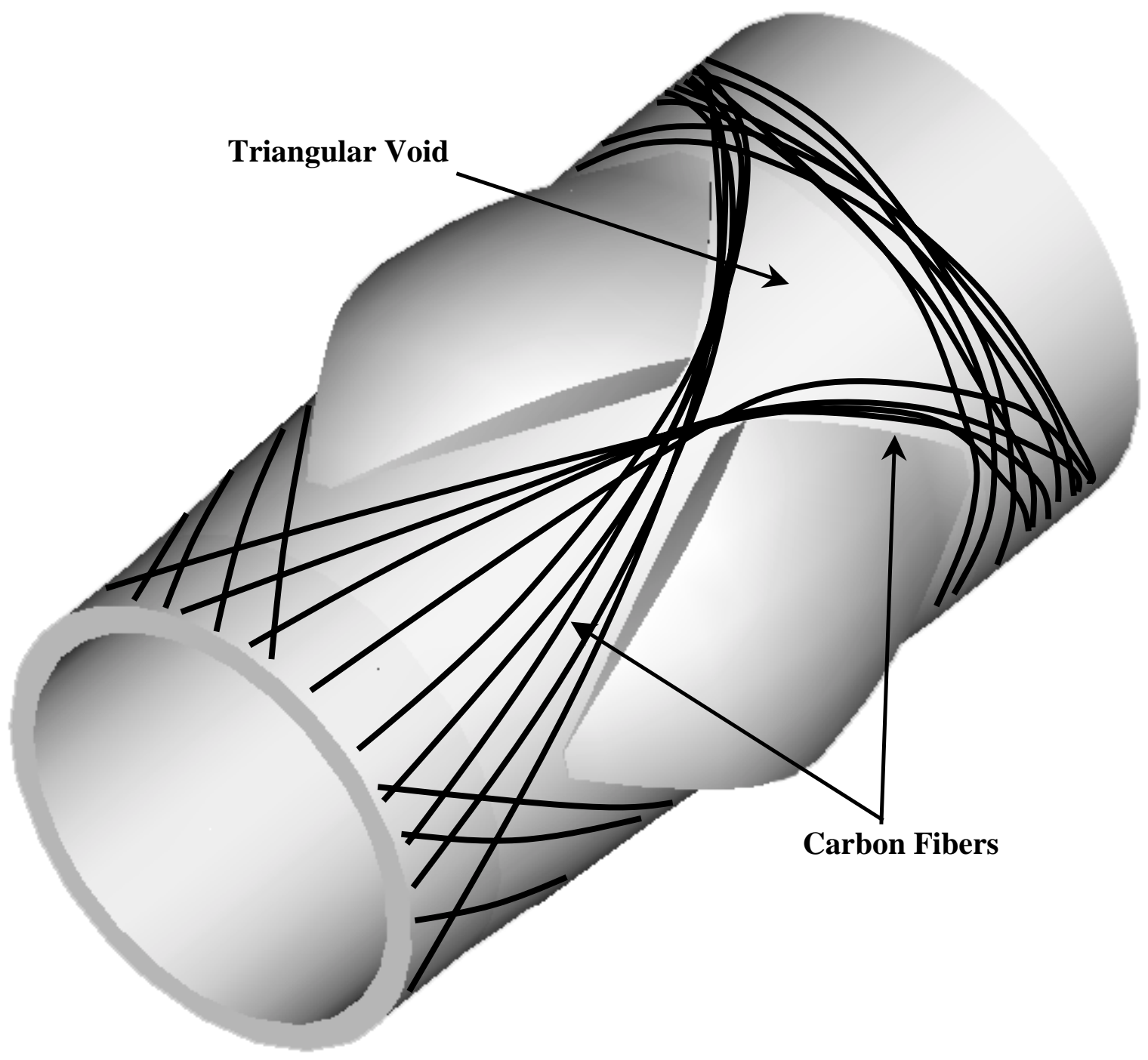

Figure 4.1 - Hump/tracks showing $\pm 20^{\circ}$ carbon fibers and the triangular shaped void. 


\section{Chapter Five}

\section{Design Modification}

From the failure mode of the prototype, it was determined that the design of the $\left[ \pm 20^{\circ}\right]$ component of the base composite must be modified to produce the desired longitudinal splitting during pipe failure. A hybrid composite consisting of TR50 hoopwound fibers and $\operatorname{Kevlar}^{\circledR} 49$ longitudinal fibers was analyzed for the redesigned base composite. Kevlar $^{\circledR} 49$ was chosen due to its high elongation to failure and its fiber ultimate strength, which matches that of TR50. These properties and the elastic modulus of each fiber are listed in Table 5.1. Table 5.2 shows the elastic properties of TR50 and Kevlar $^{\circledR} 49$ in separate unidirectional composites with epoxy resin EPON 828.

An Excel spreadsheet, kevlar_carbon.xls, was created using the same methods and equations as previous spreadsheets but was modified so that equations related to the $\left[ \pm 20^{\circ}\right]$ portion of the composite relied on the material properties of Kevlar ${ }^{\circledR} 49$. As in previous spreadsheets, this one produced the equivalent orthotropic material properties and thickness for the base material to be modeled and analyzed using I-DEAS ${ }^{\circledR}$ and ABAQUS ${ }^{\circledR}$ respectively. These values are shown in Table 5.3.

The design was modeled in much the same way as earlier models but a change was made concerning the reinforcing composite. The hoop-wound reinforcement in previous models was joined to the base composite using Coupled DOF, but for all the analyses performed for the redesigned prototype the reinforcement and the base were modeled together as one part without a gap. This part was partitioned using the procedure listed in Appendix A according to the prescribed thickness of each material. An exploded diagram of the model is shown in Figure 5.1. 
The model was meshed, restrained, loaded and exported to ABAQUS ${ }^{\circledR}$. The load steps and material definitions were modified in a text editor as in previous models. The model was solved and imported into I-DEAS ${ }^{\circledR}$ for post processing. Table 5.4 reports the stresses along the constant thickness region of the pipe and shows that the longitudinal safety factor in the base composite at Test pressure, $22.5 \mathrm{ksi}$, was 4.39 which is 3.25 times the 1.35 safety factor in the hoop direction. The hoop safety factor is nearly equivalent to the one recorded at Test pressure in Table 3.3.3 while the longitudinal safety factor shows a $37 \%$ improvement for this model. The ratios of longitudinal to hoop safety factors show a $39 \%$ improvement in the constant thickness region of this model.

The maximum stresses and safety factors for the entire model are shown in Table 5.5. During Test pressure, the longitudinal safety factor in the base composite was 2.93 which is a $40 \%$ improvement over the value found in Table 3.3 .5 while the hoop safety showed little change with a drop of $1.5 \%$ in this model. It was concluded that this design is a great improvement over the design that was produced and tested, but further analysis was performed to determine the effects of increasing the thickness of the composite by $10 \%$.

Equivalent material properties were calculated in Microsoft ${ }^{\circledR}$ Excel for the $10 \%$ increase. Theses properties as well as thickness values are shown in Table 5.6 and were used to create a new axisymmetric model in I-DEAS ${ }^{\circledR}$. The model was solved in $\mathrm{ABAQUS}^{\circledR}$ and the results from the constant thickness region are shown in Table 5.7. It is seen that the safety factors in the base composite increased over the previous model but the ratio of the longitudinal safety factor to the hoop safety factor is 3.26 , which is nearly 
the same as the last model. The maximum stresses and factors of safety for the entire model are displayed in Table 5.8. From the analysis results it was determined that while the safety factors increased and would promote a higher burst pressure, the composite thickness was increased and would add more weight to the prototype. So it was decided that the original TR50/Kevlar ${ }^{\circledR} 49$ design was a more practical and efficient design, and therefore is recommended for the second prototype. 
Table 5.1 - Fiber properties of TR50 and $\operatorname{Kevlar}^{\circledR} 49$.

\begin{tabular}{|c|c|c|}
\cline { 2 - 3 } \multicolumn{1}{c|}{} & TR50 & Kevlar \\
\hline$E_{f}[p s i]=$ & $3.45 \mathrm{E}+07$ & $1.90 \mathrm{E}+07$ \\
$\boldsymbol{\varepsilon}_{f}[\%]=$ & $1.29 \mathrm{E}+00$ & $1.80 \mathrm{E}+00$ \\
$\sigma_{f}[p s i]=$ & $5.26 \mathrm{E}+05$ & $5.25 \mathrm{E}+05$ \\
\hline
\end{tabular}

Table 5.2 - Orthotropic elastic material properties of TR50 and Kevlar ${ }^{\circledR} 49$ in separate unidirectional lay-ups.

\begin{tabular}{|c|c|c|}
\hline & TR50 & Kevlar $^{\circledR} 49$ \\
\hline$E_{1}=$ & $2.08 \mathrm{E}+07$ & $1.15 \mathrm{E}+07$ \\
\hline$E_{2}=$ & $1.67 \mathrm{E}+06$ & $1.60 \mathrm{E}+06$ \\
\hline$E_{3}=$ & $1.67 \mathrm{E}+06$ & $1.60 \mathrm{E}+06$ \\
\hline$G_{12}=$ & $4.50 \mathrm{E}+05$ & 4.37E+05 \\
\hline$G_{13}=$ & $4.50 \mathrm{E}+05$ & $4.37 \mathrm{E}+05$ \\
\hline$G_{23}=$ & $3.98 \mathrm{E}+05$ & $3.88 \mathrm{E}+05$ \\
\hline$v_{12}=$ & 2.84E-01 & 3.62E-01 \\
\hline$v_{13}=$ & 2.84E-01 & 3.62E-01 \\
\hline$v_{23}=$ & 5.73E-01 & 5.73E-01 \\
\hline$v_{32}=$ & 5.73E-01 & 5.73E-01 \\
\hline$v_{21}=$ & 2.27E-02 & 5.01E-02 \\
\hline$v_{31}=$ & 2.27E-02 & $5.01 \mathrm{E}-02$ \\
\hline
\end{tabular}

Table 5.3 - Modified design describing composite thickness, liner thickness and equivalent orthotropic elastic material properties for TR50 and $\mathrm{Kevlar}^{\circledR} 49$ in a $\left[ \pm 20^{\circ}, 90^{\circ}\right]$ lay-up.

$\begin{aligned} E_{x}[p s i] & =2.13 \mathrm{E}+06 \\ E_{y}[p s i] & =5.54 \mathrm{E}+06 \\ E_{z}[p s i] & =1.10 \mathrm{E}+07 \\ v_{x y} & =0.2049 \\ v_{x z} & =0.0806 \\ v_{y z} & =0.0967 \\ G_{x y}[p s i] & =4.15 \mathrm{E}+05 \\ G_{x z}[p s i] & =4.21 \mathrm{E}+05 \\ G_{y z}[p s i] & =9.92 \mathrm{E}+05 \\ t_{k e v l a r[20]}[i n] & =0.0906 \\ t_{T R 50[90]}[i n] & =0.0875 \\ t_{[20,90]}[i n] & =0.1781 \\ t_{s}[i n] & =0.0650 \\ \sigma_{s}[p s i] & =1.20 \mathrm{E}+05\end{aligned}$


Table 5.4 - FEA results for the constant thickness section of the TR50/Kevlar ${ }^{\circledR}$ design.

\begin{tabular}{|c|c|c|c|c|c|}
\hline \multicolumn{6}{|c|}{$t_{\text {steel }}=.065 \quad t_{\left[ \pm 20^{\circ}, 90^{\circ}\right]}=.178 \mathrm{w} / 120 \mathrm{ksi}$ Steel } \\
\hline Liner & $\sigma_{\text {Von Mises }}[k s i]$ & $\sigma_{\text {Yield }}[k s i]$ & S.F. & $\sigma_{\text {Ult }}[k s i]$ & S.F. \\
\hline Test & 120.40 & 120.00 & 1.00 & 126.78 & 1.05 \\
\hline Zero & 89.51 & 120.00 & 1.34 & 126.78 & 1.42 \\
\hline Work & 64.14 & 120.00 & 1.87 & 126.78 & 1.98 \\
\hline Burst & 120.76 & 120.00 & 0.99 & 127.78 & 1.06 \\
\hline$[20,90$ & $\sigma_{\text {hoop }}[k s i]$ & FPF $_{\text {hoop }}[\mathrm{ksi}]$ & S.F. & $\mathrm{FF}_{\text {hoop }}[\mathrm{ksi}]$ & S.F. \\
\hline Test & 97.25 & 25.35 & 0.26 & 131.42 & 1.35 \\
\hline Zero & 37.92 & 25.35 & 0.67 & 131.42 & 3.47 \\
\hline Work & 77.51 & 25.35 & 0.33 & 131.42 & 1.70 \\
\hline \multirow[t]{2}{*}{ Burst } & 151.80 & 25.35 & 0.17 & 131.42 & 0.87 \\
\hline & $\sigma_{\text {long }}[\mathrm{ksi}]$ & $\mathrm{FPF}_{\text {long }}[\mathrm{ksi}]$ & S.F. & $\mathrm{FF}_{\text {long }}[\mathrm{ksi}]$ & S.F. \\
\hline Test & 28.12 & 11.56 & 0.41 & 123.50 & 4.39 \\
\hline Zero & 9.96 & 11.56 & 1.16 & 123.50 & 12.40 \\
\hline Work & 22.21 & 11.56 & 0.52 & 123.50 & 5.56 \\
\hline Burst & 46.52 & 11.56 & 0.25 & 123.50 & 2.65 \\
\hline
\end{tabular}


Table 5.5 - Maximum stresses and factors of safety from the finite element analysis of the TR50/Kevlar ${ }^{\circledR}$ design.

\begin{tabular}{|c|c|c|c|c|c|}
\hline \multicolumn{2}{|r|}{$t_{\text {steel }}=.065$} & \multicolumn{4}{|c|}{$t_{\left[ \pm 20^{\circ}, 90^{\circ}\right]}=.178 \mathrm{w} / 120 \mathrm{ksi}$ Steel } \\
\hline Liner & $\sigma_{\text {Von Mises }}[k s i]$ & $\sigma_{\text {Yield }}[k s i]$ & S.F. & $\sigma_{U l t}[k s i]$ & S.F. \\
\hline Test & 125.20 & 120.00 & 0.96 & 126.78 & 1.01 \\
\hline Zero & 107.20 & 120.00 & 1.12 & 126.78 & 1.18 \\
\hline Work & 89.90 & 120.00 & 1.33 & 126.78 & 1.41 \\
\hline Burst & 129.07 & 120.00 & 0.93 & 126.78 & 0.98 \\
\hline Humps & $\sigma_{\text {Von Mises }}[\mathrm{ksi}]$ & $\sigma_{\text {Yield }}[k s i]$ & S.F. & $\sigma_{\text {Ult }}[\mathrm{ksi}]$ & S.F. \\
\hline Test & 126.10 & 120.00 & 0.95 & 126.78 & 1.01 \\
\hline Zero & 71.50 & 120.00 & 1.68 & 126.78 & 1.77 \\
\hline Work & 99.70 & 120.00 & 1.20 & 126.78 & 1.27 \\
\hline Burst & 124.50 & 120.00 & 0.96 & 126.78 & 1.02 \\
\hline$[20,90]$ & $\sigma_{\text {hoop }}[k s i]$ & $\mathrm{FPF}_{\text {hoop }}[\mathrm{ksi}]$ & S.F. & $\mathrm{FF}_{\text {hoop }}[\mathrm{ksi}]$ & S.F. \\
\hline Test & 97.80 & 25.35 & 0.26 & 131.42 & 1.34 \\
\hline Zero & 38.30 & 25.35 & 0.66 & 131.42 & 3.43 \\
\hline Work & 78.00 & 25.35 & 0.33 & 131.42 & 1.68 \\
\hline \multirow[t]{2}{*}{ Burst } & 152.70 & 25.35 & 0.17 & 131.42 & 0.86 \\
\hline & $\sigma_{\text {long }}[\mathrm{ksi}]$ & $\mathrm{FPF}_{\text {long }}[\mathrm{ksi}]$ & S.F. & $\mathrm{FF}_{\text {long }}[\mathrm{ksi}]$ & S.F. \\
\hline Test & 42.20 & 11.56 & 0.27 & 123.50 & 2.93 \\
\hline Zero & 17.20 & 11.56 & 0.67 & 123.50 & 7.18 \\
\hline Work & 34.00 & 11.56 & 0.34 & 123.50 & 3.63 \\
\hline Burst & 76.01 & 11.56 & 0.15 & 123.50 & 1.62 \\
\hline [90] & $\sigma_{\text {hoop }}[k s i]$ & FPF $_{\text {hoop }}[\mathrm{ksi}]$ & S.F. & $\mathrm{FF}_{\text {hoop }}[\mathrm{ksi}]$ & S.F. \\
\hline Test & 115.10 & 221.61 & 1.93 & 256.47 & 2.23 \\
\hline Zero & 45.70 & 221.61 & 4.85 & 256.47 & 5.61 \\
\hline Work & 89.70 & 221.61 & 2.47 & 256.47 & 2.86 \\
\hline \multirow[t]{2}{*}{ Burst } & 187.50 & 221.61 & 1.18 & 256.47 & 1.37 \\
\hline & $\sigma_{\text {long }}[\mathrm{ksi}]$ & FPF $_{\text {long }}[\mathrm{ksi}]$ & S.F. & $\mathrm{FF}_{\text {long }}[\mathrm{ksi}]$ & S.F. \\
\hline Test & 17.20 & 3.69 & 0.21 & - & - \\
\hline Zero & 8.59 & 3.69 & 0.43 & - & - \\
\hline Work & 14.20 & 3.69 & 0.26 & - & - \\
\hline Burst & 32.78 & 3.69 & 0.11 & - & - \\
\hline
\end{tabular}


Table 5.6 - Modified design of TR50 and $\operatorname{Kevlar}^{\circledR} 49$ in a $\left[ \pm 20^{\circ}, 90^{\circ}\right]$ lay-up with a $10 \%$ increase in base composite thickness.

$\begin{aligned} E_{x}[p s i] & =2.13 \mathrm{E}+06 \\ E_{y}[p s i] & =5.54 \mathrm{E}+06 \\ E_{z}[p s i] & =1.10 \mathrm{E}+07 \\ v_{x y} & =0.2049 \\ v_{x z} & =0.0806 \\ v_{y z} & =0.0967 \\ G_{x y}[p s i] & =4.15 \mathrm{E}+05 \\ G_{x z}[p s i] & =4.21 \mathrm{E}+05 \\ G_{y z}[p s i] & =9.92 \mathrm{E}+05 \\ t_{k e v l a r[20]}[i n] & =0.0992 \\ t_{T R 50[90]}[i n] & =0.0959 \\ t_{[20,90]}[i n] & =0.1951 \\ t_{s}[i n] & =0.0650 \\ \sigma_{s}[p s i] & =1.20 \mathrm{E}+05\end{aligned}$

Table 5.7 - FEA results for the constant thickness section of the TR50/Kevlar ${ }^{\circledR}$ design with a $10 \%$ increase in base composite thickness.

\begin{tabular}{|c|c|c|c|c|c|}
\hline \multicolumn{6}{|c|}{$t_{\text {steel }}=.065 t_{\left[ \pm 20^{\circ}, 90^{\circ}\right]}=.195 \mathrm{w} / 120 \mathrm{ksi}$ Steel } \\
\hline Sleeve & $\sigma_{\text {Von Mises }}[\mathrm{ksi}]$ & $\sigma_{\text {Yield }}[k s i]$ & S.F. & $\sigma_{U l t}[k s i]$ & S.F. \\
\hline Test & 120.30 & 120.00 & 1.00 & 126.78 & 1.05 \\
\hline Zero & 83.95 & 120.00 & 1.43 & 126.78 & 1.51 \\
\hline \multirow{2}{*}{ Work } & 65.13 & 120.00 & 1.84 & 126.78 & 1.95 \\
\hline & 120.70 & 120.00 & 0.99 & 127.78 & 1.06 \\
\hline$[20,90]$ & $\sigma_{\text {hoop }}[k s i]$ & $\operatorname{FPF}_{\text {hoop }}[\mathrm{ksi}]$ & S.F. & $\mathrm{FF}_{\text {hoop }}[\mathrm{ksi}]$ & S.F. \\
\hline Test & 90.04 & 25.35 & 0.28 & 131.42 & 1.46 \\
\hline Zero & 32.75 & 25.35 & 0.77 & 131.42 & 4.01 \\
\hline Work & 70.98 & 25.35 & 0.36 & 131.42 & 1.85 \\
\hline \multirow[t]{2}{*}{ Burst } & 140.50 & 25.35 & 0.18 & 131.42 & 0.94 \\
\hline & $\sigma_{\text {long }}[k s i]$ & $\mathrm{FPF}_{\text {long }}[\mathrm{ksi}]$ & S.F. & $\mathrm{FF}_{\text {long }}[\mathrm{ksi}]$ & S.F. \\
\hline Test & 25.89 & 11.56 & 0.45 & 123.50 & 4.77 \\
\hline Zero & 8.43 & 11.56 & 1.37 & 123.50 & 14.66 \\
\hline Work & 20.19 & 11.56 & 0.57 & 123.50 & 6.12 \\
\hline Burst & 42.74 & 11.56 & 0.27 & 123.50 & 2.89 \\
\hline
\end{tabular}


Table 5.8 - Maximum stresses and factors of safety from the TR50/Kevlar ${ }^{\circledR}$ design with a $10 \%$ increase in base composite thickness.

\begin{tabular}{|c|c|c|c|c|c|}
\hline \multicolumn{6}{|c|}{$t_{\text {steel }}=.065 t_{\left[ \pm 20^{\circ}, 90^{\circ}\right]}=.195 \mathrm{w} / 120 \mathrm{ksi}$ Steel } \\
\hline Liner & $\sigma_{\text {Von Mises }}[k s i]$ & $\sigma_{\text {Yield }}[k s i]$ & S.F. & $\sigma_{\text {UIt }}[k s i]$ & S.F. \\
\hline Test & 125.80 & 120.00 & 0.95 & 126.78 & 1.01 \\
\hline Zero & 105.10 & 120.00 & 1.14 & 126.78 & 1.21 \\
\hline Work & 90.20 & 120.00 & 1.33 & 126.78 & 1.41 \\
\hline Burst & 128.50 & 120.00 & 0.93 & 126.78 & 0.99 \\
\hline Humps & $\sigma_{\text {Von Mises }}[k s i]$ & $\sigma_{\text {Yield }}[k s i]$ & S.F. & $\sigma_{\text {Ult }}[k s i]$ & S.F. \\
\hline$\overline{\text { Test }}$ & 126.50 & 120.00 & 0.95 & 126.78 & 1.00 \\
\hline Zero & 70.50 & 120.00 & 1.70 & 126.78 & 1.80 \\
\hline Work & 99.80 & 120.00 & 1.20 & 126.78 & 1.27 \\
\hline Burst & 124.00 & 120.00 & 0.97 & 126.78 & 1.02 \\
\hline$[20,90]$ & $\sigma_{\text {hoop }}[k s i]$ & $\mathrm{FPF}_{\text {hoop }}[\mathrm{ksi}]$ & S.F. & $\mathrm{FF}_{\text {hoop }}[\mathrm{ksi}]$ & S.F. \\
\hline Test & 90.50 & 25.35 & 0.28 & 131.42 & 1.45 \\
\hline Zero & 33.10 & 25.35 & 0.77 & 131.42 & 3.97 \\
\hline Work & 71.40 & 25.35 & 0.36 & 131.42 & 1.84 \\
\hline \multirow[t]{2}{*}{ Burst } & 141.20 & 25.35 & 0.18 & 131.42 & 0.93 \\
\hline & $\sigma_{\text {long }}[k s i]$ & $\mathrm{FPF}_{\text {long }}[\mathrm{ksi}]$ & S.F. & $\mathrm{FF}_{\text {long }}[\mathrm{ksi}]$ & S.F. \\
\hline Test & 41.10 & 11.56 & 0.28 & 123.50 & 3.00 \\
\hline Zero & 15.50 & 11.56 & 0.75 & 123.50 & 7.97 \\
\hline Work & 32.60 & 11.56 & 0.35 & 123.50 & 3.79 \\
\hline Burst & 73.90 & 11.56 & 0.16 & 123.50 & 1.67 \\
\hline [90] & $\sigma_{\text {hoop }}[k s i]$ & $\mathrm{FPF}_{\text {hoop }}[\mathrm{ksi}]$ & S.F. & $\mathrm{FF}_{\text {hoop }}[\mathrm{ksi}]$ & S.F. \\
\hline Test & 105.30 & 221.61 & 2.10 & 256.47 & 2.44 \\
\hline Zero & 38.60 & 221.61 & 5.74 & 256.47 & 6.64 \\
\hline Work & 81.30 & 221.61 & 2.73 & 256.47 & 3.15 \\
\hline \multirow[t]{2}{*}{ Burst } & 169.10 & 221.61 & 1.31 & 256.47 & 1.52 \\
\hline & $\sigma_{\text {long }}[k s i]$ & $\mathrm{FPF}_{\text {long }}[\mathrm{ksi}]$ & S.F. & $\mathrm{FF}_{\text {long }}[\mathrm{ksi}]$ & S.F. \\
\hline Test & 14.90 & 3.69 & 0.25 & - & - \\
\hline Zero & 7.08 & 3.69 & 0.52 & - & - \\
\hline Work & 12.20 & 3.69 & 0.30 & - & - \\
\hline Burst & 28.60 & 3.69 & 0.13 & - & - \\
\hline
\end{tabular}




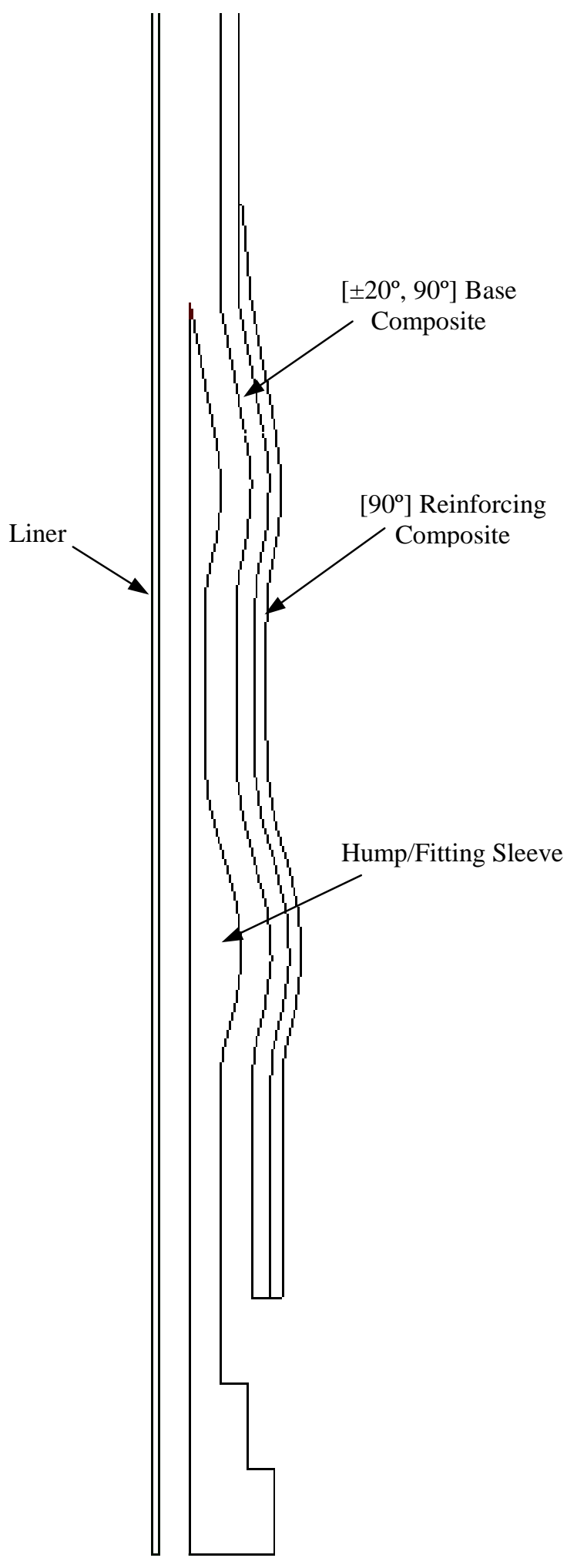

Figure 5.1 - Exploded view of the sleeve model with base and reinforcement composites modeled as a single part. 


\section{Chapter Six}

\section{Conclusions and Recommendations}

\subsection{Conclusions}

The main objective of this research was to design a lightweight replacement for an all-steel pipe used by the Halliburton Company for hydraulic fracturing. The incorporation of high strength composite materials and autofrettage was the cornerstone of the design. The initial design using a bi-directional laminate was shown to be inferior to the weight reduction capabilities of a three-directional lay-up. A $\left[ \pm 20^{\circ}, 90^{\circ}\right]$ lay-up was determined to be more effective when dealing with the bi-directional (hoop and longitudinal) loading inflicted on a pipe through pressurization. It was also realized that for this application steel with high yield strength is more efficient than low yield strength steel.

Initially it was thought that an existing all-steel pipe could be modified and used as the liner on which the composite would be filament wound. This idea was abandoned because after the pipe is machined to a thickness less than its original, its ability to bear longitudinal stress would be diminished in a manner for which the composite is unable to compensate. So the hump design was formed consisting of two custom end fittings welded to a thin-walled tube. It was concluded that such a design was efficient but the location of the weld would be a concentration point for erosion/corrosion, so the sleeve design was proposed in which the hump/fitting fits over the liner and is welded at its end.

Lastly, a loading scenario was discovered which required a method to transfer torque from the fitting to the composite thereby avoiding damage to the thin-walled liner. The track design was implemented and proved to be effective for this purpose. 
The pipe was fabricated and weighed $74 \mathrm{lbs}$, a weight difference of $29.5 \%$ less than the all-steel pipe. The prototype was tested successfully to the autofrettage pressure of $22.5 \mathrm{ksi}$ and then pressurized to failure at $29.4 \mathrm{ksi}$. The burst pressure was nearly equal to the predicted value of $30.0 \mathrm{ksi}$, however, the pipe did not fail as expected. Results from FEA showed that the pipe would fail in the hoop direction resulting in longitudinal splitting, but the test showed that the pipe started to split and then broke into three separate parts. It was concluded that once the hoop-wound fibers failed, the hoop stress was transferred to the $\pm 20^{\circ}$ fibers causing their failure.

The design was modified by replacing the $\pm 20^{\circ}$ TR50 fibers with Kevlar ${ }^{\circledR} 49$ fibers so that the greater elongation to failure of $\operatorname{Kevlar}^{\circledR}$ would promote failure of the hoop-wound fibers at burst pressure. Analysis showed that the modified design resulted in a greater safety factor in the longitudinal direction while the hoop safety factor remained nearly the same. It was determined that this design modification was an improvement and would be recommended for the second prototype for future fabrication and testing.

\subsection{Recommendations}

Recommendations to refine and optimize the design of the hybrid steel/composite pipe for high pressure applications are as follows:

- Optimize the design of the humps and fittings to reduce weight. Consider thickness reduction of the large humps, the reduction of space between humps or possibly single hump fittings. 
- Consider the use of triangular shaped raised guides for the fibers coming out of the tracks to have better alignment at the turnaround region. Figure 6.2.1 is a possible design for the riser.

- Align the fittings accurately to aid in computer aided filament winding. The four original prototypes had randomly aligned fittings. Also use a nut-less connector to simplify winding.

- Consider a bi-directional angle less than $\pm 20^{\circ}$ for the longitudinal fibers in the base composite. As the angle approaches $0^{\circ}$, the amount of hoop stress loaded on these fibers also moves toward zero and should promote the desired longitudinal splitting during failure.

- Optimize the thickness of the $90^{\circ}$ reinforcement layer over the humps. Consider using the reinforcement between the inner and outer hump only and not on top of the humps or between the track/hump and the fitting. Calculations were not performed to determine the required thickness of reinforcement, but instead 0.125 inch was chosen.

- Study the effects of changing the selected autofrettage pressure.

- Evaluate padding materials and resin systems for impact and abrasion resistance.

- Consider application of padding layer between CFRP and abrasion/impact resistant outer layer of GFRP for greater distribution of impact. 


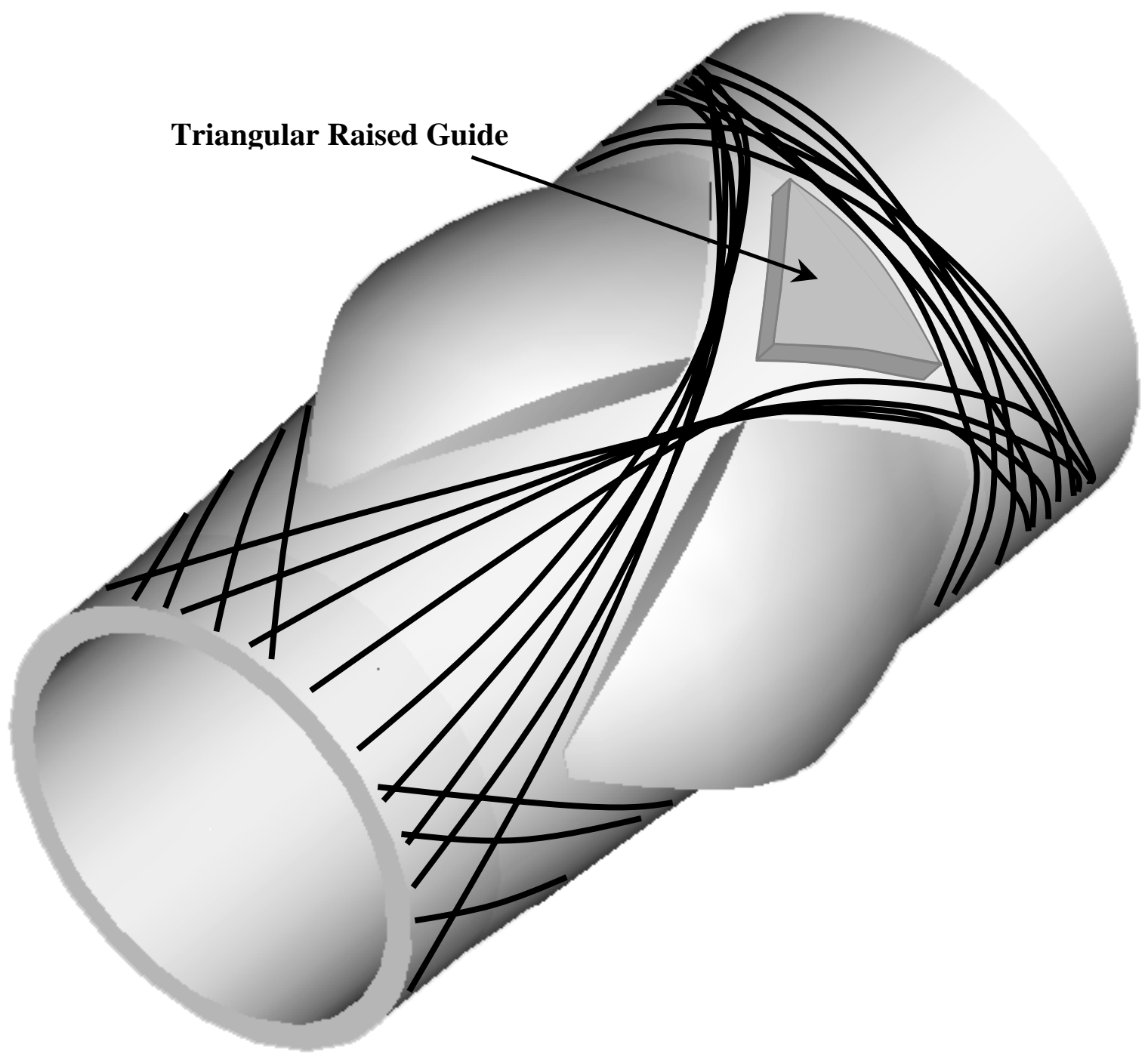

Figure 6.2.1 - Possible design of raised guides for aiding fiber alignment upon exiting the tracks into the turnaround area. 


\section{References}

1. Spencer, B.E., "Advancing the Use of Composites in the Oil Field," SAMPE Journal, Vol. 34, No. 4, July/August 1998, p. 20-25.

2. Lubin, G. et al, Handbook of Composites, Van Nostrand Reinhold Company, 1982.

3. Chung, D.D.L., Carbon Fiber Composites, Butterworth-Heineman, 1994.

4. Jianrong, Y., Fangjing, X. and Yuande, X., "A Study on Failure Behavior of Hybrid Composites Under Static and Fatigue Tortional Loading," Composites, Proceedings of the Eighth International Conference on Composite Materials (ICCM/8), Honolulu, July 15-19, SAMPE, 1991.

5. Glenn, T. A., Chen, J. and Sherwood, J. A., "Carbon/Glass Hybridization: Another Degree of Design Freedom for Composite Structures," SAMPE Journal, Vol. 34, No. 3, May/June 1998, p. 22-31.

6. Agarwal, B. D. and Broutman, L. J., Analysis and Performance of Fiber Composites, John Wiley \& Sons, 1990.

7. Potter, K. D., Wismon, M. R., Lowson, M. V. and Adams, R. D., "Innovative Approaches to composite structures," The Aeronautical Journal, February 1998, p. 107-111.

8. Tortolano, F. W., "Why Composites Are Still Soaring," Design News, September 12, 1994, p. 70-75.

9. Maloney, L. D., “The Many Sides of Composites,” Design News, January 17, 1994, p. $77-79$.

10. Harvey, W. A. and Kremer, J. S., "Design, Process Development, and Fabrication of an All IM7/977-2 12 In. Dia. Pressurized Fuel Line Required to Operate at $-423^{\circ} \mathrm{F}$ While Bolted to an Aluminum Valve," $42^{\text {nd }}$ International SAMPE Symposium, May 4-8, 1997, p. 839-853.

11. Segall, A. E., Tricou, C., Evanko, M. and Conway, Jr., J. C., "Localized Autofrettage as a Design Tool for the Fatigue Improvement of Cross-Bored Cylinders," Journal of Pressure Vessel Technology, Vol. 120, November 1998, p. 393-397.

12. Underwood, J. H., Parker, A. P., Corrigan, D. J. and Audino, M.J., "Fatigue Life Measurements and Analysis for Overstrained Tubes with Evacuator Holes," Transactions of the ASME, Vol. 118, November 1996, p. 424-428.

13. Hussain, M. A., Pu, S. L., Vasilakis, J. D. and O'Hara, P., "Simulation of Partial Autofrettage by Thermal Loads," Journal of pressure Vessel Technology Technical Briefs, August 1980, Vol. 102, p. 314-318. 
14. Feng, H., Mughrabi, H. and Donth, B., "Finite-Element Modelling of LowTemperature Autofrettage of Thick-Walled Tubes ot the Austenitic Stainless Steel AISI 304 L: Part I. Smooth Thick-walled Tubes," Modelling and Simulation in materials Science and Engineering 6, 1998, p. 51-69.

15. Liu, J. and Hirano, T., "Design and Analysis of FRP Pressure Vessels with LoadCarrying Metallic Liners," PVP-Vol. 368, Analysis and Design of Composite, Process, and Power Piping and Vessels, 1998, p. 95-101.

16. Fukuda, H. and Chou, T. W., "Stress Concentrations in a Hybrid Composite Sheet," Journal of Applied Mechanics, December 1983, Vol. 50, p. 845-848.

17. Karbhari, V. M., Falzon, P. J. and Herzberg, I., "Energy Absorbtion Characteristics of Hybrid Braided Composite Tubes," Journal of Composite Materials, Vol. 31, No. 12, 1997, p. 1164-1186.

18. Dhillon, B. S. and Kuo, C. H., "Optimum Design of Composite Hybrid Plate Girders," Journal of Structural Engineering, Vol. 117, No. 7, July 1991, p. 20882098.

19. Kim, J. K. and Mai, Y.W., "Stress transfer in the Fibre Fragmentation Test," Journal of Materials Science, Vol. 30, 1995, p. 3024-3032.

20. Chaudhuri, R. A. and Garala, H. J., "Analytical/Experimental Evaluation of Hybrid Commingled Carbon/Glass/Epoxy Thick-Section Composites under Compression," Journal of Composite Materials, Vol. 29, No. 13, 1995, p.1695-1718.

21. Shigley, J. E. and Mischke, C. R., Mechanical Engineering Design, $5^{\text {th }}$ Edition, McGraw-Hill, Inc., 1989.

22. Barbero, E. J., Introduction to Composite Materials Design, Taylor \& Francis, Inc., 1999.

23. Barbero, E. J., Class Notes on Advanced Mechanics of Composite Materials, from MAE 226 at West Virginia University, 1998.

24. ABAQUS/Standard User's Manual, Vol. 1, Version 5.8, p. 10.2.1-2 - 10.2.1-3, Hibbit, Karlsson \& Sorensen, Inc., 1998.

25. Shell Chemical FaxBack, "Shell Resins - EPI-CURE ${ }^{\circledR} 3140$ Polyamide Curing Agent," Shell Chemical Company Sales Offices, 2000. 


\title{
Appendix A:
}

\section{Instructions for Modification and}

Analysis of the Hybrid Steel/Composite

Pipe Using SDRC $^{\circledR}$ I-DEAS $^{\circledR}$ and

\author{
$\operatorname{ABAQUS}^{\circledR}$
}




\section{Modifying the Model for a New Composite Design}

Open File BASEPIPE.mf1 in IDEAS, and "Save As" a new file. Go to "Master Modeler".

Click and hold the highlighted icon and select "Manage Bin".

Find "ASSEMBLYtemp", click on it to highlight it, then click

(get), then click on "comp curves temp" and get, then "Dismiss".

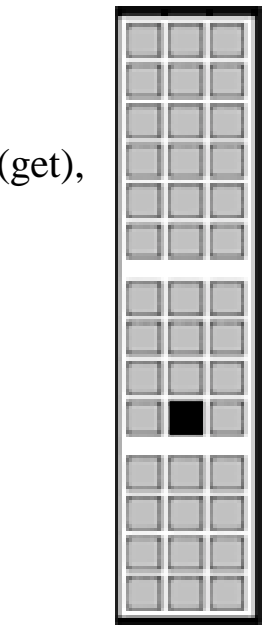

Note: You can change the viewpoint with Pan, Zoom, or Rotate using F1, F2, or F3 respectively. Hold down one of these buttons while moving the mouse. You can also use the highlighted icons:

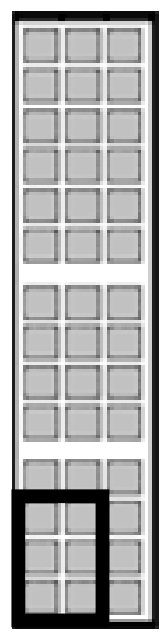

Note: Save often, IDEAS has a very limited "Undo". The model maybe closed and reopened without saving, this will open the model without the most $\underline{\text { recent changes. }}$ 
The green lines and curves are the composite and the red surfaces are the steel sleeve and humps. The steel will probably stay the same for a new design so these directions will focus on changing the composite only.

The first step is to move all straight vertical lines (red arrow) according to the dimensions of the new design. Do not move the lines and curves, which are closest to the red surfaces (blue arrow). Notice that there are two layers of composite over the hump section. The layer closest to the red surface is the 0.21 " $[+/-20,90]$ layer and the outer layer is 0.125 " [90] reinforcement.

Click and hold the highlighted icon and select "Move", then select all of the vertical lines (hold "Shift" key when selecting more than one object to move), press "Enter" then type the translation distance separated by spaces (ex. -..01 00 ).

Next, the angled lines (green arrow) must be moved. Use the move icon again and after selecting the lines and pressing done

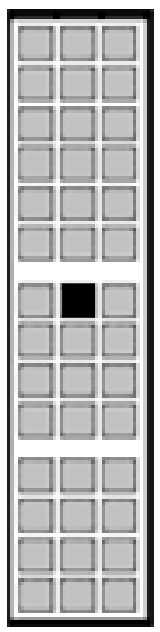
(enter), then select "Move along" from the pop up menu. Pick one of the lines that are perpendicular to the line you are moving. You will be prompted for direction along the vector, choose yes if the arrow is pointing in the correct direction, then enter the translation distance.

Note: Instead of using the move icon for the angled and vertical lines, you may try using the "Offset" icon. This will create an offset copy of the selected line, the selected line must be deleted after the offset. Do not use offset to create the curved sections.

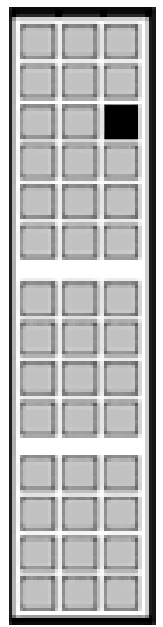


Now before moving the other angled lines (purple arrow), you need to trim/extend a few lines.

Click and hold the highlighted icon and select "trim/extend". Then select the first line (yellow arrow) close to the second line (green arrow), then select the second line as the line to "extend to". Repeat this process but selecting the second line and then the first line. This will ensure the contact of the two lines.

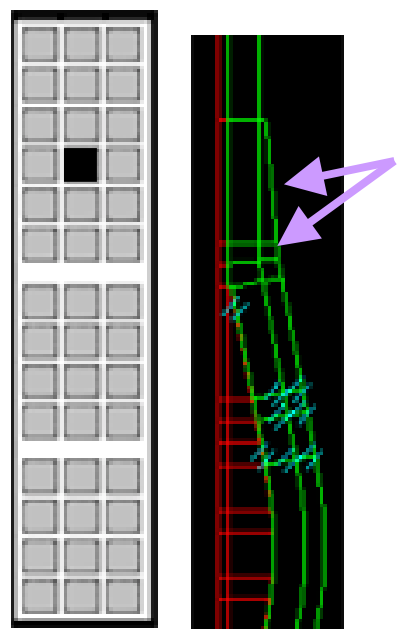

Next, move the other angled lines (purple arrow) using the move icon, and the "Move to" option in the popup menu. When prompted, pick the end of the line (purple arrow) for the "move from" point and then pick the end of the line (green arrow) for the "move to" point. This will create gaps/overlaps elsewhere, which will be fixed later using the trim/extend icon.

Click and hold the black highlighted icon and

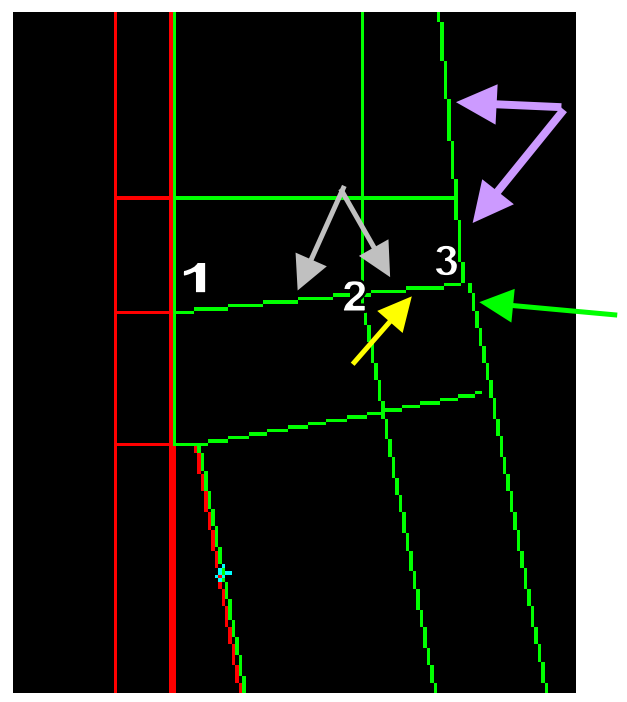
select "Delete" then select the two lines (gray arrow) and press "Enter". Using the green highlighted icon, "Trim/Extend" the two remaining lines at point \#2 (both must be trimmed to the other, zoom extremely close to \#2 to see the gap/overlap).

Now click and hold the white highlighted icon and select "Lines". Click the right mouse button and select "Focus" (this will allow you to place a

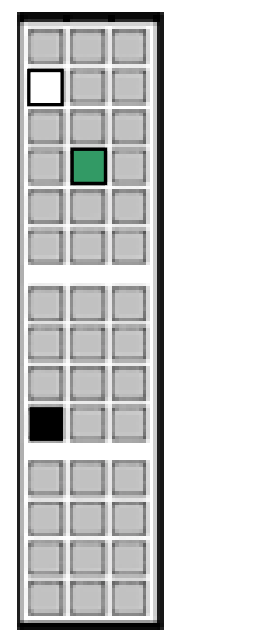


point on a line by snapping the cursor to the endpoint) then select the intersection at \#1 and then select "Focus" and select intersection \#2 and then repeat this for intersection \#3. Now, draw lines from point \#1 to \#2 and \#2 to \#3.

The newly created lines are not associated with the lines and curves of "comp curves temp". Click and hold the highlighted icon and select "Attach". Select the two new lines while holding the "Shift" button and then press "Enter", then select one of the lines (straight or curved) from "comp curves temp". The two new lines are now part of "comp curves temp".

Note: "Trim/Extend" both ends of every single straight line on the part, this will remove gaps and overlaps (intersections) which would prevent the creation of surfaces. Make sure both ends of every straight line has been trim/extended before continuing.

Click and hold the highlighted icon and select "Get", select "curve forms" and then "OK". This part will be used to shape the spline curves of the humps.

Delete the two outer spline curves over each hump (four curves total). Do not delete the curves closest to the red surfaces.

Click and hold the highlighted icon and select "Points". Click right mouse button and select "Focus", this will allow you to place a point on a line by snapping the cursor to the endpoint. Place a point at each location shown in the figure far right (14 points total).
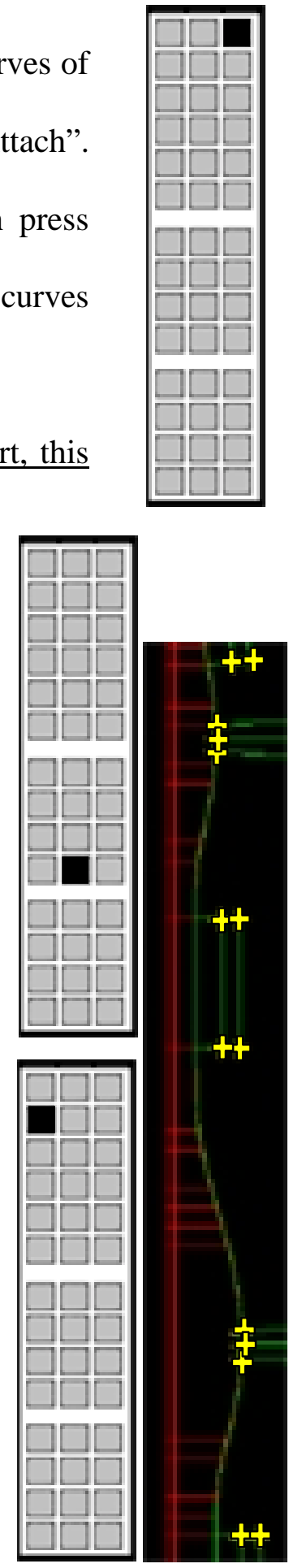
Next, click on "Move" and select the points on the upper end of all the vertical lines (4 points total), click done. Select "Copy sw" from the pop-up menu and "On". Type a translation distance of (0 .01 0$)$, press "Enter" then type 3 for the number of copies, press "Enter". Repeat this for the points on the opposite ends of these lines ( 2 points) but with negative $\mathrm{Y}$ translation. This should result in 4 points at the free ends of each vertical line (the lines between the humps are shown in the figure to the right).

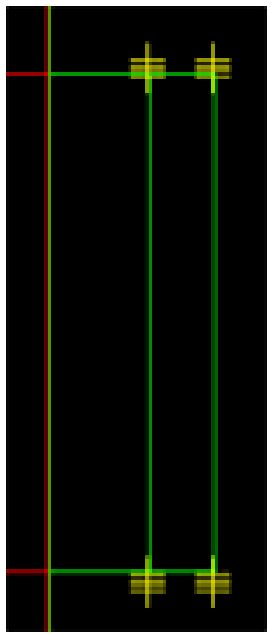

Then, click "Move" and select the points at the ends of the two angled lines. Select "Copy sw", “On”, and "Move Along”. Select the angled line as the vector to move along, and the direction would be away from the end of the line. Type the translation distance of .01 but this time make only one copy. This should result in two points at the bottom end of both angled lines, as shown in the figure to the right.

Now the points on the "curve forms" must be moved/copied to shape the spline curves of the humps. Click "Move" and then select one of the points on the curve, press "Enter" and then pick "Move Along" from the pop down menu and click the line corresponding to that point for the "vector to move along". Select the direction pointing away from the hump and enter the distance according to the thickness of the new design. Then move and copy the same point along the same line with a translation distance of
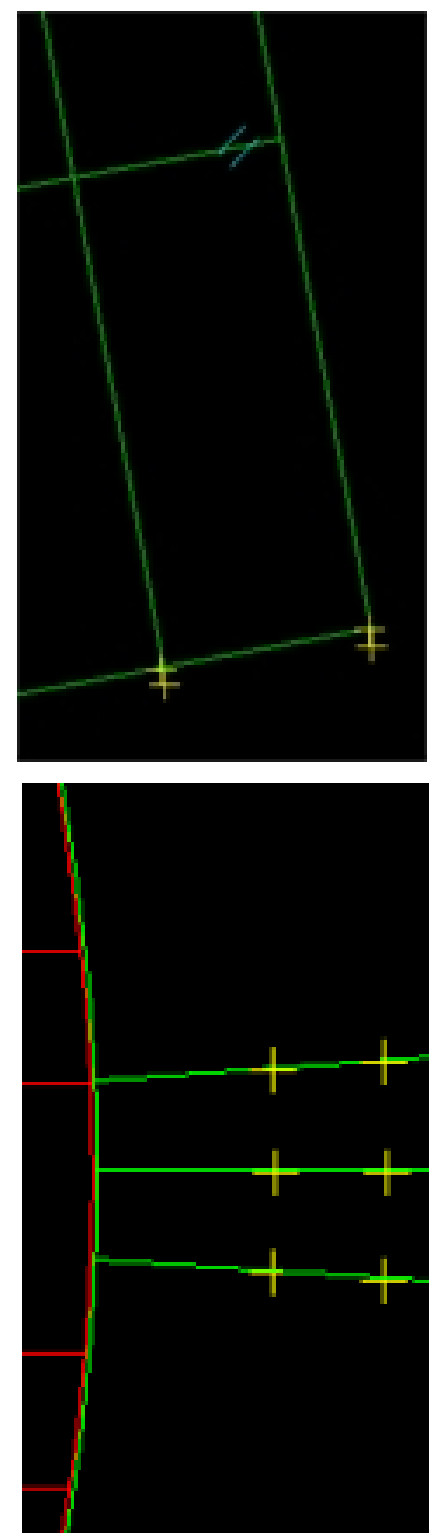
.125 ", the thickness of the outer layer of the composite. These steps should be repeated for the other 5 points over the humps. This should result in 6 points over each hump. These will be used to form the two outer curves over each hump.

Now that the base points have been placed, the splines can be created. Zoom the view to the top half of the top hump. Click and hold the highlighted icon and select "Splines". Select the points according to the numbering in the picture to the right. If the pointer doesn't automatically snap to the points then zoom by hand using F2. Then before pressing "Enter", hold F1 to pan the view downward to the next 4 points, and continue selecting the points as

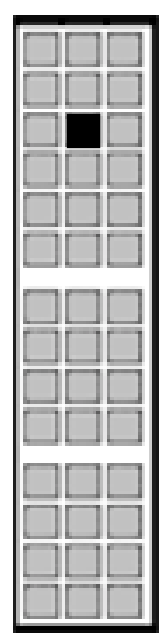
numbered and press "Enter" after selecting point \#9. Repeat with the inner points but in the opposite order, starting at the bottom points and move to the top points. It is important that these lines are drawn in a clockwise direction with respect to the part.

Repeat the creation of the splines on the bottom hump in the same manner as above. From top to bottom on the outside line and from bottom to top on the inside line.

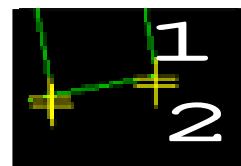

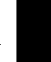


The newly created splines are not associated with the lines and curves of "comp curves temp". Click and hold the highlighted icon and select "Attach". Select the four spline curves while holding the "Shift" button and then press "Enter", then select one of the lines (straight or curved) from "comp curves temp".

Note: To be sure the new splines are attached, click "Put Away" and select one of the vertical lines and if all the lines and curves disappear, including the

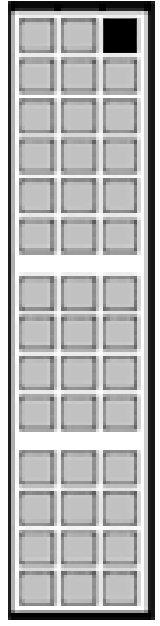
new splines, then the "Attach" process was performed correctly. Now use "Manage Bin" or "Get" to get "comp curves temp" out of the manage bin.

Click the highlighted icon, "Delete". Click the right mouse button and select "Filter" from the pop-up menu, then from the "Filter" window, select "Point..." and click on "Pick Only", then click the right mouse button and select "All" from the pop-up menu, press "Enter" and then "Yes".

Select "Manage Bin" and highlight "comp curves temp", click "Put Away" and then click on ("Copy"), fill out the fields in the pop-up

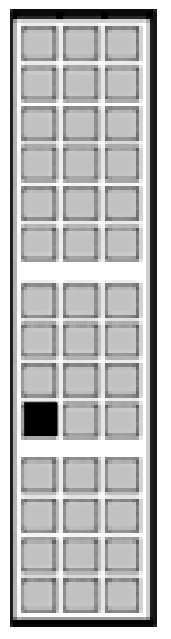
window, name it "Comp Curves" in the "Main" bin (part number not necessary). Now, select "Comp Curves" and click "Get" then "Dismiss".

By pressing $\mathrm{Ctrl}+\mathrm{M}$ on the keyboard an additional menu (on left side of graphics window) may be displayed or hidden. Display this menu if not visible.

There may be more than one menu displayed, select "Create" from the main menu (far left), then select "Planar Surface" from the submenu. Select the outer lines and curves one at a time with the mouse. Zooming with F2 
may be necessary to avoid picking the interior lines. After all outer lines have been selected, they will change to a thicker line with a different color as seen in the picture to the right (the color may vary), press "Enter". These lines will now be regular thickness but a different color than the former green lines and curves. This is now a surface. Notice that many of the interior lines have disappeared as shown in the figure far right. The lines and curves that disappeared are needed to partition the part.

Click on the "Delete" icon, then click the right mouse button and pick "Filter" from the pop-up menu. Select "Curve..." and click "Pick Only", then click the right mouse button and select "All" and press "Enter" and then "Yes".

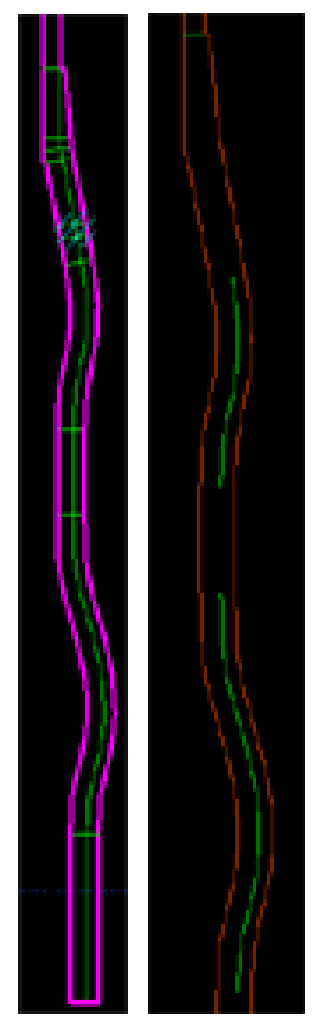

Go to "Manage Bin" and highlight "comp curves temp", click on the "Copy" icon and then click "OK" when the "Copy" window pops up. Highlight "Part1" and click "Get", then "Dismiss".

Zoom in so the display matches the figure to the right. Click and hold the highlighted icon and then select "Extrude". Select

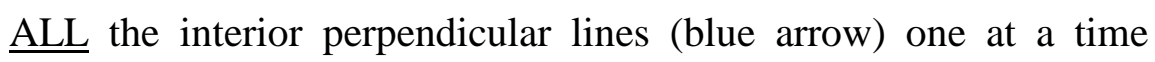
while hitting "Enter" only once after each one or two part line is selected (ex. of a two part line, white arrow). The lines will change color and thickness. Note: If unable to select some of the two part lines in a consecutive manner, then the lines have not been properly

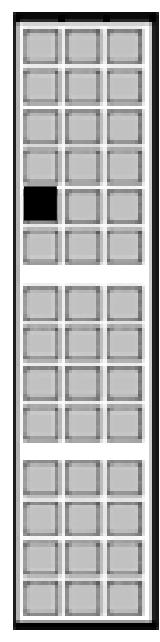
trimmed or extended, click the right mouse button and select "Cancel" from

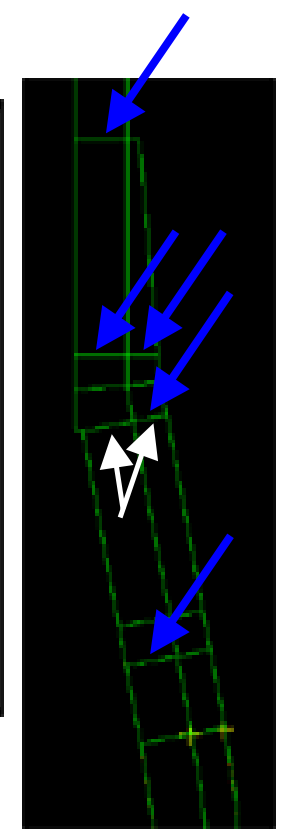
the pop-up menu then trim/extend the lines and then attempt to extrude. 
Note: If the wrong line is selected by accident then click the right mouse button and select "Backup" from the pop-up menu. After the lines in the current view have been selected, use F1 to pan the screen down to the next perpendicular lines and select them for extrusion. Do not select the perimeter line at the very bottom of the part, select only the interior lines. After selection is complete, press "Enter" and "Extrude Section" window will pop up. Change the "Distance" to .1 and change Distance $\square$ to "Thicken" and click "OK". Notice that some of the lines disappeared after this operation.

Click on the "Delete" icon, then click the right mouse button and pick "Filter" from the pop-up menu. Select "Curve..." and click "Pick Only", then click the right mouse button and select "All" and press "Enter".

Click and hold the highlighted icon and select "Partition". Select one of the perpendicular lines that were extruded as the "partitioning part" and then select one of the perimeter lines as the "part to partition". This will divide the composite surface into several surfaces.

Go to "Manage Bin" and highlight "Part1" and click "Delete". Highlight "comp curves temp" and click "Copy" and then click "OK". Select "Part1" then "Get" then "Dismiss". 
Select "Extrude" and select the internal lines and curves (white highlighted) parallel to the perimeter. Select these without pressing "Enter" after each one. After all have been selected, press "Enter" Change the "Distance" to .1 and change Distance to "Thicken" and click "OK".

Note: If unable to select some of the lines in a consecutive manner, then the lines have not been properly trimmed or extended, click the right mouse button and select "Cancel" from the pop-up menu then trim/extend the lines and then attempt to extrude.

Click on the "Delete" icon, then click the right mouse button and pick "Filter" from the pop-up menu. Select "Curve..." and click "Pick Only", then click the right mouse button and select "All" and press "Enter".

Select "Partition" and select the newly extruded curve as the "partitioning part" and then select one of the perimeter lines as the "part to partition".

Zoom to the region in the figure to the far right. Click and hold the black highlighted icon and select "Sketch in place" and then any line on the composite. The surface will change to thick blue lines.

Select "Lines" from the white highlighted icon. Draw lines from \#1 to \#2 and \#2 to \#3. The selector arrow should snap to the

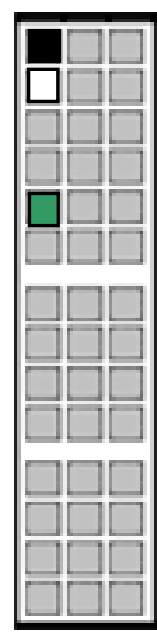
intersection \#1 and the two midpoints \#2 and \#3.

Select "Extrude" from the green highlighted icon above. Click the (1)

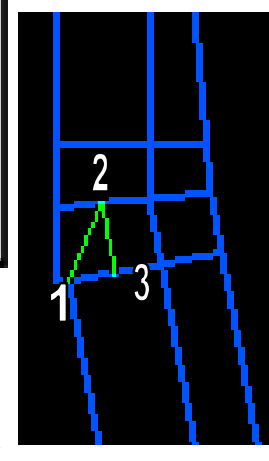
right mouse button and select "Partition" from the pop up menu and then 
select_the new green lines and press "Enter" twice and then "OK" in the "Extrude" window.

Go to "Manage Bin" and highlight "Part1" and click "Delete". Select "ASSEMBLYtemp" and "Get" and "Dismiss".

Go to "Meshing".

\section{Simulation}

Meshing

Click and hold the highlighted icon and select "Create FE Model". Click $L \downarrow$ then select the composite then "OK". Repeat this and select the steel.

Use "Ctrl + M" to display the additional menus if not visible. Select "Manage" from the menu and "Append" from its submenu. The "Select

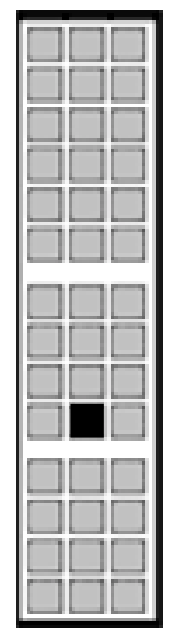
source FE Model" window will appear. If "Comp Curves" is displayed as "Comp Curves..." then double click it to reveal its contents. Select "Fem1" below "Comp Curves" and click "OK". The "Select destination FE Model" window will appear. Select "Fem1" below "ASSEMBLYtemp" and click "OK”.

Go to "Master Modeler".

Simulation

Master Modeler

Go to "Manage Bin" and select "Comp Curves", "Put Away" and "Dismiss". 
Click and hold the black highlighted icon, select "Sketch in place" and then select the steel hump section anywhere between the sleeve and the composite. The humps section will change to thick blue lines as shown in the picture to the far right.

Zoom to the region pictured to the far right. Select "Lines" from the white highlighted icon. Draw freehand lines from the three intersection points on the blue surface in a normal direction (as accurate as possible) to the curves as shown in the picture above far right. Continue on with the last four and then select "Trim/Extend" from the green highlighted icon and trim all of the lines to fit within the composite as shown with line \#5.

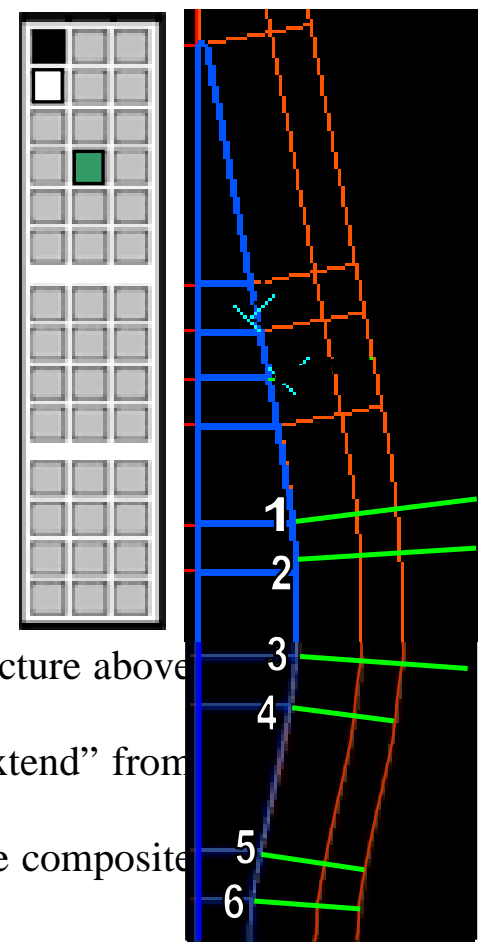

Select the "Extrude" icon then click the right mouse button and select "Partition" from the pop up menu. Select all of the new lines and press "Enter". Click "OK" in the "Extrude section" window.

Select "Sketch in place" and then select the steel hump section anywhere between the sleeve and the composite. Repeat the processes of creating lines, trimming and partitioning on the bottom hump. The model should look like the figure to the right (color may differ).

"Save" the changes to the model file and then "Save as" and change

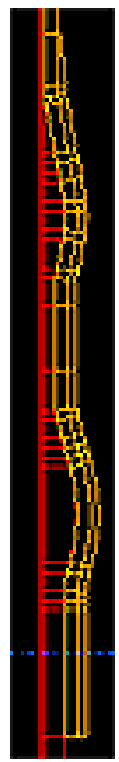
the file name. This is done for protection in the event that the working file becomes corrupt. 


\section{Meshing the New Pipe Design}

Go to "Meshing".

Meshing

Click and hold the highlighted icon and select "Define Shell Mesh...". Select the region shown in the figure to the far right by clicking and dragging a box around those surfaces shown, then press "Enter". The "Define Mesh" window will appear, select Mapped and change "Element Family" to Axisymmetric Solid * then change "Element Type" to Q. and click on

Mapped Options. . The "Mapped Meshing Options" window

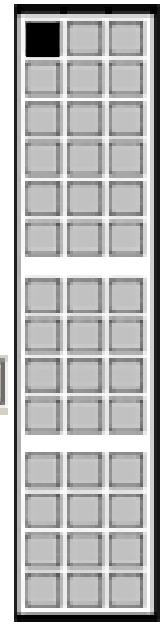
appears. Select Define Corners and when prompted to "Pick any 3 or 4 among highlighted vertices (all)", press enter repeatedly until all surfaces are defined and the "Mapped Meshing Options" window reappears. Select Defne Elements/side , and when prompted to "Enter number $(>0)$ of elements for highlighted sides (1)", type " 6 " for each vertical edge and " 1 " for the horizontal edge of the sleeve and " 2 " for the rest of the horizontal
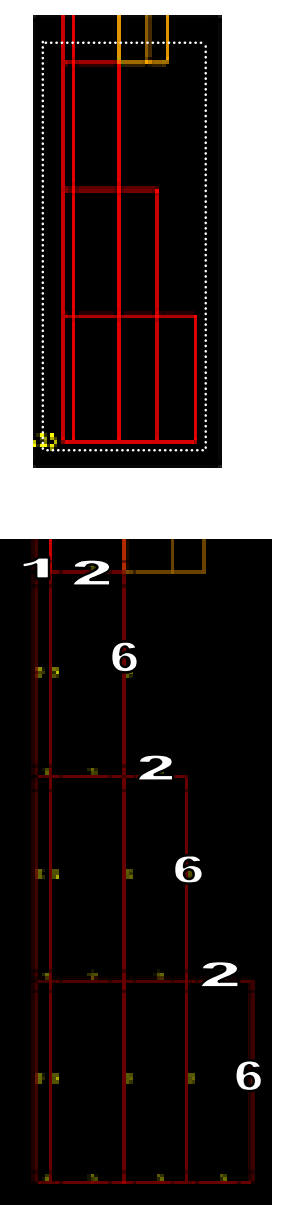
edges as shown in the figure to the right. When the "Mapped Meshing Options" window reappears, select "Dismiss". Select "Set As Default", then select to preview the mesh, and press "Keep Mesh". 
Pan the view up to the region shown in the figure to the right. Define a mesh, for the two selected surfaces in the figure, following the above procedure and defining the number of elements along the vertical edges to be “13”.

Pan the view up to the region shown in the figure to the right. Define a mesh, for the selected surfaces in the figure, following the above procedure define the number of elements along the vertical edges as shown in the figure.

Define a mesh, for the 3 selected surfaces in the figure, set the number of elements along the vertical edges to be the same as the elements on the sleeve defined above. Define the number of elements along the horizontal edges as shown in the figure.

Define a mesh, for the 2 unmeshed surfaces between the 3 selected surfaces in the figure. Choose Free, change "Element Family" to Axisymmetric Solid * and "Element Type" to $\square$. Select preview the mesh and then select "Keep Mesh". These two surfaces should

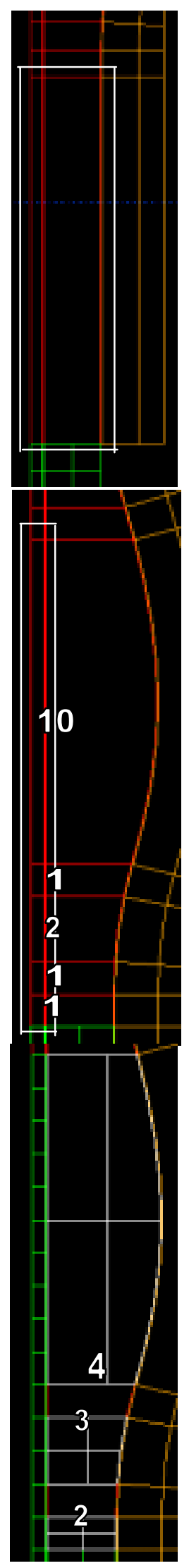


look about like the figure to the right, with triangular elements to step up from 2 to 3 rectangular elements and from 3 to 4 rectangular elements.

Pan the view up to the region shown in the figure to the right. Define a mesh for the selected surfaces. Set the number of elements along the vertical edges as shown in the figure.
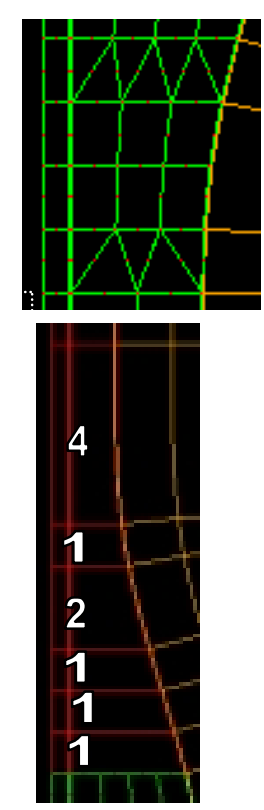

Define a mesh, for the 3 selected surfaces in the figure, set the number of elements along the vertical edges to be the same as the elements on the sleeve defined above. Define the number of elements along the horizontal edges as shown in the figure to the right.

Define a mesh, for the 3 unmeshed surfaces between and below the 3 selected surfaces in the figure. Choose C Free change "Element Family" to Axosymmetric Solid - and "Element Type" to - Select preview the mesh and then select "Keep Mesh". These three surfaces should have triangular elements to step down from 4 to 3 rectangular elements, from 3 to 2 rectangular elements and from 2 to 1 rectangular elements. 
Pan the view up to the region shown in the figure to the right. Define a mesh for the selected surfaces. Set the number of elements along the vertical edges as shown in the figure.

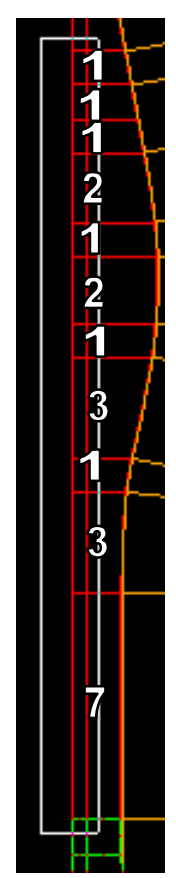

Define a mesh, for the 6 selected surfaces in the figure, set the number of elements along the vertical edges to be the same as the elements on the sleeve defined above. Define the number of elements along the horizontal edges as shown in the figure to the right.

Define a mesh, for the 3 unmeshed surfaces between the selected surfaces in the figure. Choose Free, change "Element Family" to Axisymmetric Solid - and "Element Type" to the mesh and then select "Keep Mesh". These three surfaces should have triangular elements to step up from 1 to 2 rectangular elements, from 2 to 3 rectangular elements and down from 3 to 2 rectangular elements.

Pan the view up to the region shown in the figure to the right. Define a mesh for the selected surfaces. Set the number of elements along the vertical edges as shown in the figure.
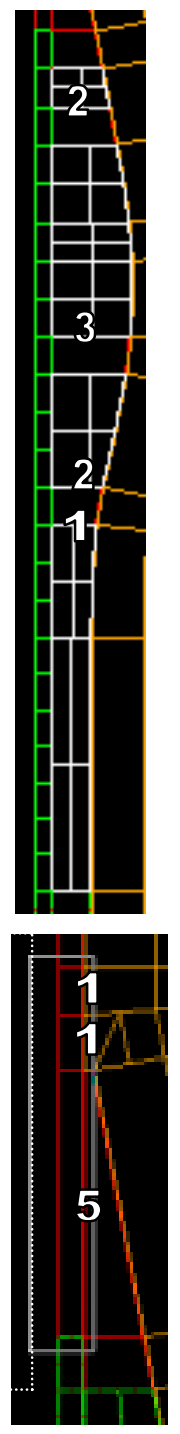
Define a mesh, for the selected surface in the figure, set the number of elements along the vertical edges to be the same as the elements on the sleeve defined above. Define the number of elements along the horizontal edges as shown in the figure to the right.

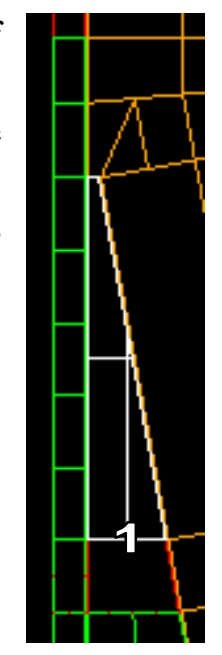

Define a mesh, for the unmeshed surfaces below the selected surface in the figure on the previous page. Choose 6 Free, change "Element Family" to Axisymmetric Solid - and "Element Type" to $\square$. Select preview the mesh and then select "Keep Mesh". This surface should look about like the figure to the right, with triangular elements to step down from 2 to 1 rectangular elements.

Pan the view up to the region shown in the figure to the right. The sleeve only has two unmeshed surfaces at this point. Define a mesh for these two surfaces. Set the number of elements along the vertical edges to be 6 for the short lower surface and 110 for the long upper surface.
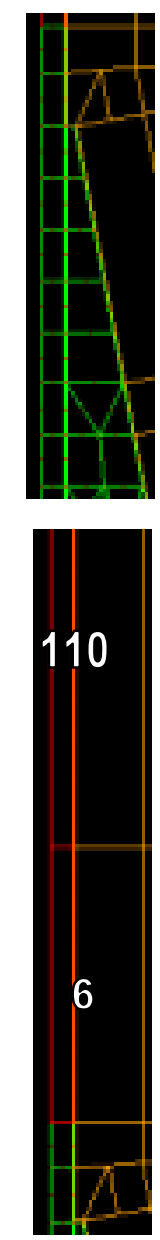
The steel sleeve and humps should now be completely meshed and should resemble the figure pictured to the right. The next step is to mesh the inner layer of composite.

Change the view to the region shown in the figure to the right. Define a mapped mesh for the 5 selected surfaces. In the "Define Mesh" window, change the "Material:" to "Other" and click the "Material Selection..." icon. Choose "Material Type Filter..." and select "ORTHOTROPIC MATERIALS" in "Finite Element Modeling", click "OK". Highlight "COMP2090", click "OK". Click on the "Set As Default" icon. In "Mapped Options..." set the number of elements along the vertical edges to be the same as the number of elements on the steel beside it. Define the number of

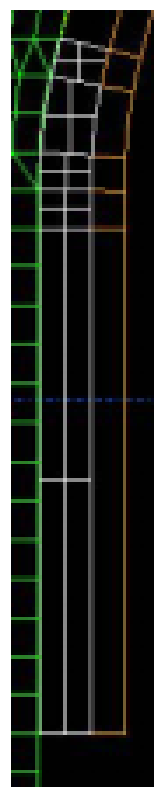
elements along the horizontal edges to be 2 . 
Pan the view to the region shown in the figure to the right. Define a mapped mesh for the 11 selected surfaces. Follow the procedure above. The mesh should match the figure to the far right.

Pan the view to the region shown in the figure to the right. Define a mapped mesh for the 7 selected surfaces. Follow the procedure above. The mesh should match the figure to the far right.

Pan the view to the region shown in the figure to the right. Define a free mesh for the 2 surfaces (red arrow). Follow the procedure above to create one element on each surface. Then define a mesh for the triangular surface (blue arrow). Use $\odot$ Free, Axosymmetric Solid $*$ and $\rightarrow$ then click

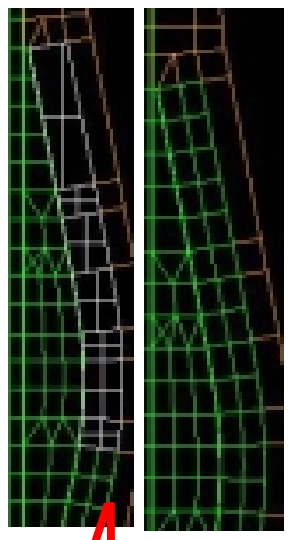
the preview icon and "Keep Mesh". 
Pan the view to the region shown in the figure to the right. Define a mapped mesh for the remaining 3 surfaces on the inner composite layer. Follow the procedure for map meshing. The mesh should match the figure to the far right. Set the number of elements along the vertical edges to be 1 for the short lower surface, 6 for the middle surface and 110 for the long upper surface.

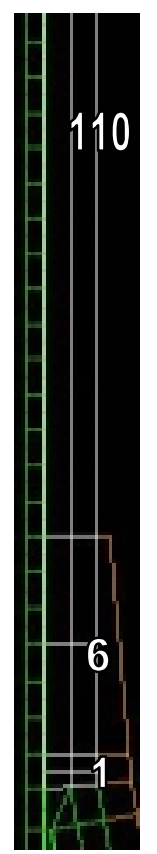

The inner composite layer should now be completely meshed and should resemble the figure pictured to the right. The next step is to mesh the outer layer of composite. 
Pan the view to the region shown in the figure to the right. Define a mapped mesh for the 10 selected surfaces. In the "Define Mesh" window, change the "Material:" to "Other" and click the "Material Selection..." icon. Choose "Material Type Filter..." and select "ORTHOTROPIC MATERIALS" in "Finite Element Modeling", click "OK". Highlight "COMP90", click "OK". Click on the "Set As Default" icon. Follow the procedure for map meshing and define 1 element through the horizontal thickness.

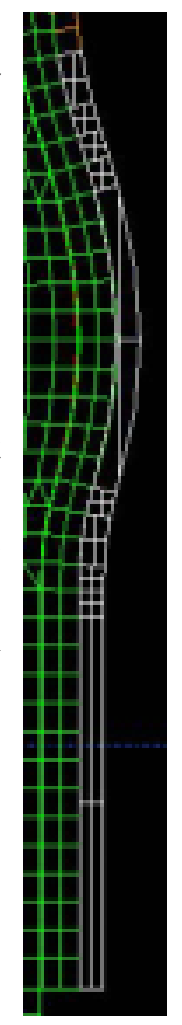

Pan the view to the region shown in the figure to the right. Define a mapped mesh for the remaining 16 surfaces. Follow the procedure for map meshing.

The outer composite layer should now be completely meshed and should resemble the figure pictured to the far right.

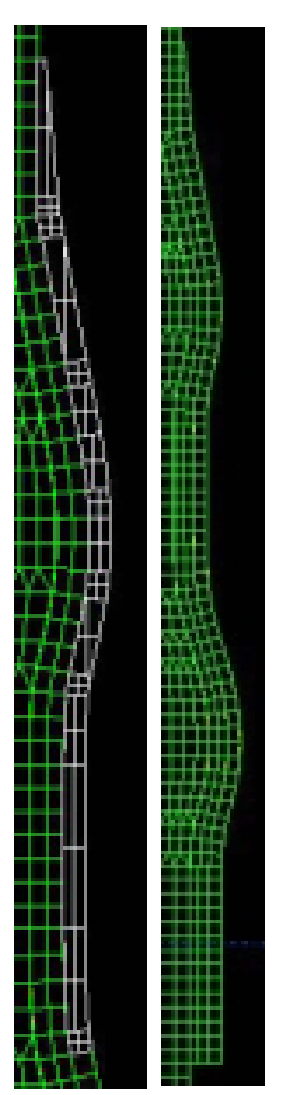


Select the black highlighted icon, select the green highlighted icon form the pop up window. Hold the right mouse button, select "Filter", select "Node" then "Pick Only". Hold the right mouse button again, select "Related To", hold the right mouse button, select "Filter", "Edge" then "Pick Only". Hold the right mouse button and select "All" then press "Enter" twice and then type "gap nodes" when asked to "Enter PERMANENT GROUP name or no.”

Select the white highlighted icon in the pop up window then hold the right mouse button, select "Filter", "Edge" and "Pick Only". Hold the right mouse button and select "All Done". Select the red highlighted icon in the pop up window, this will display the newly created group. Press $\mathrm{Ctrl}+\mathrm{M}$ to bring up the additional menus, select "Display Options" > "Node" > "Asterisk". Then select the blue highlighted icon to redraw the display.

Zoom in on the region shown to the far right. Click and hold the highlighted icon and select "Element". In the "Element" window select "Other, then Gop then Setes Detouts and "OK". Click and drag a box around the nodes as show in the figure to the far right. Repeat this process for ALL nodes along the gaps. This should result in gap elements between every pair of nodes between the sleeve and composite, sleeve and humps, and humps and composite, as

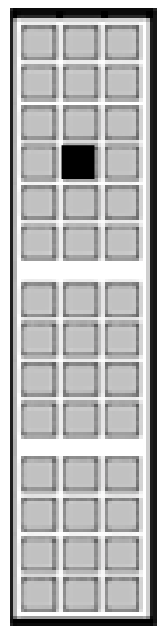
shown in the figure lower far right. 
Zoom out and the model should look like the figure to the right. Now press "Ctrl+M" to display the additional menus and select "Display Options" > "Node" > "Dot", then redraw using the "Redraw" icon.

The meshing should now be complete. The next step is to define the boundary conditions. Save the model file. 


\section{Defining Boundary Conditions for the New Pipe Design}

Go to "Boundary Conditions".

\begin{tabular}{|l|}
\hline Simulation \\
\hline \hline Boundary Conditions \\
\hline
\end{tabular}

Zoom to the region shown in the figure to the far right. Select "Displacement Restraint..." from the highlighted icon and drag a box around the selected edge (white box) exactly as shown in the figure, then press "Enter" and "Node". The "Displacement Restraint on Node" window will appear. Select $\odot$ Specified and SpectyPestant. . Then select Set All Free and change "Y Translation" to Fined च, select "OK" and then "OK".
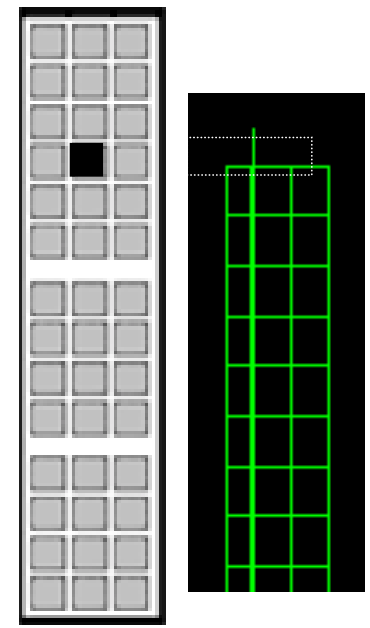

Zoom to the region shown in the figure to the far right. Select "Coupled DOF..." from the highlighted icon and click on the independent node (red arrow) and then drag a box around the dependent nodes (white box) exactly as shown in the figure to the far right, press "Enter". The "Coupled Degrees of Freedom" window will appear. Change the "Y Translation" to $\bullet$ Active, select "OK”.
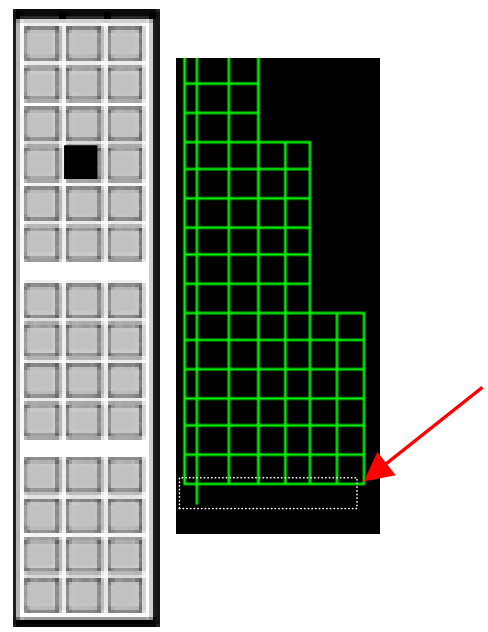
Select "Force..." from the highlighted icon and click the right mouse button and select "Filter" > "Node" > "Pick Only" and then select the node (blue arrow) shown in the figure to the far right and press "Enter". The "Force on Node" window will appear. Change "Y Force" to "-3.14159" and select "OK".
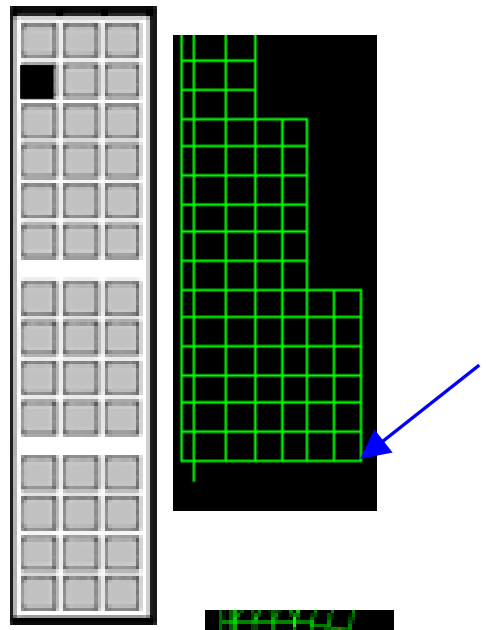

Zoom to the region shown in the figure to the right. Select "Force..." from the icon menu and click the right mouse button and select "Filter" > "Element_Free_Edge" > "Pick Only". Drag a box around the inner edge of the elements on the sleeve as shown to the right (all elements along the inner edge of the sleeve will be selected eventually so accuracy on the number of elements in this selection is not important). Now before pressing "Enter", click the right mouse button and select "Highlight Selection" and then pan the view upwards using the "F1" key and drag a box, while holding the "Shift" key, around the unselected "Element_Free_Edges". Repeat the above steps until all "Element_Free_Edges" along the inner edge of the sleeve has been selected and then press "Enter". The "Force on Element Edge" window will appear. Change the "In Plane Force" to start with an amplitude of " 1 " and end with an amplitude of " 1 " then select "OK". The model should have a distributed load along the length of the sleeve as shown in the figure to the right.
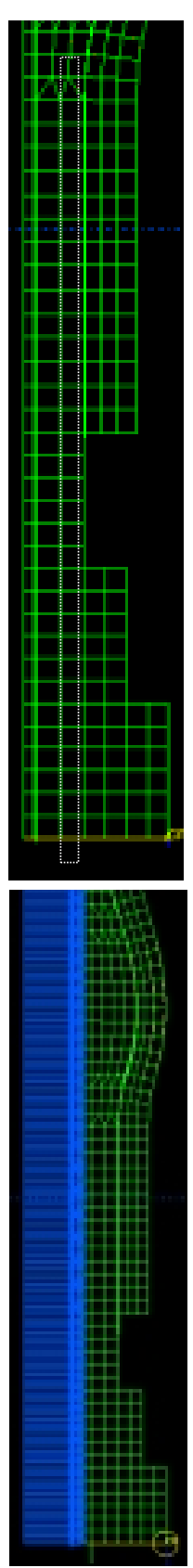
Select the highlighted icon and then select $\sqrt{ }$ Constraint Set and Restraint Set then click on "LOAD SET 1" to highlight it, then press "OK”.

Save the file.

From the "File" menu, select "Export" > "ABAQUS" > "OK". The “ABAQUS File Exporter" window will appear. The filename and path may

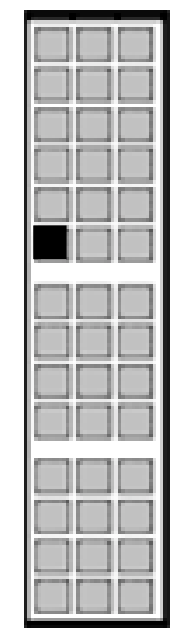
be changed, the default will be saved to the C: drive or the drive from which IDEAS is running. Select HistoryDota. then $\quad$ Oupun Coetrol.. and select "Stress", "Strain", "Plastic Strain" and "Displacement" for output and select "OK". Select Step Peramenors.. from the "ABAQUS History Definition" window and change "Maximum Number of Increments" to "10000" and change "Amplitude Loading Type" to "Ramp", select "OK". Select "Apply" from the "ABAQUS History Definition" window then select "OK". Select "Write" from the "ABAQUS File Exporter" window. 


\section{Editing the ABAQUS Input File}

\section{Open the ABAQUS input file in "WordPad" (or "Notepad") for text}

editing. Go to the bottom and then slowly scroll up until "*solid seCtion," is

seen. Delete the highlighted lines below:

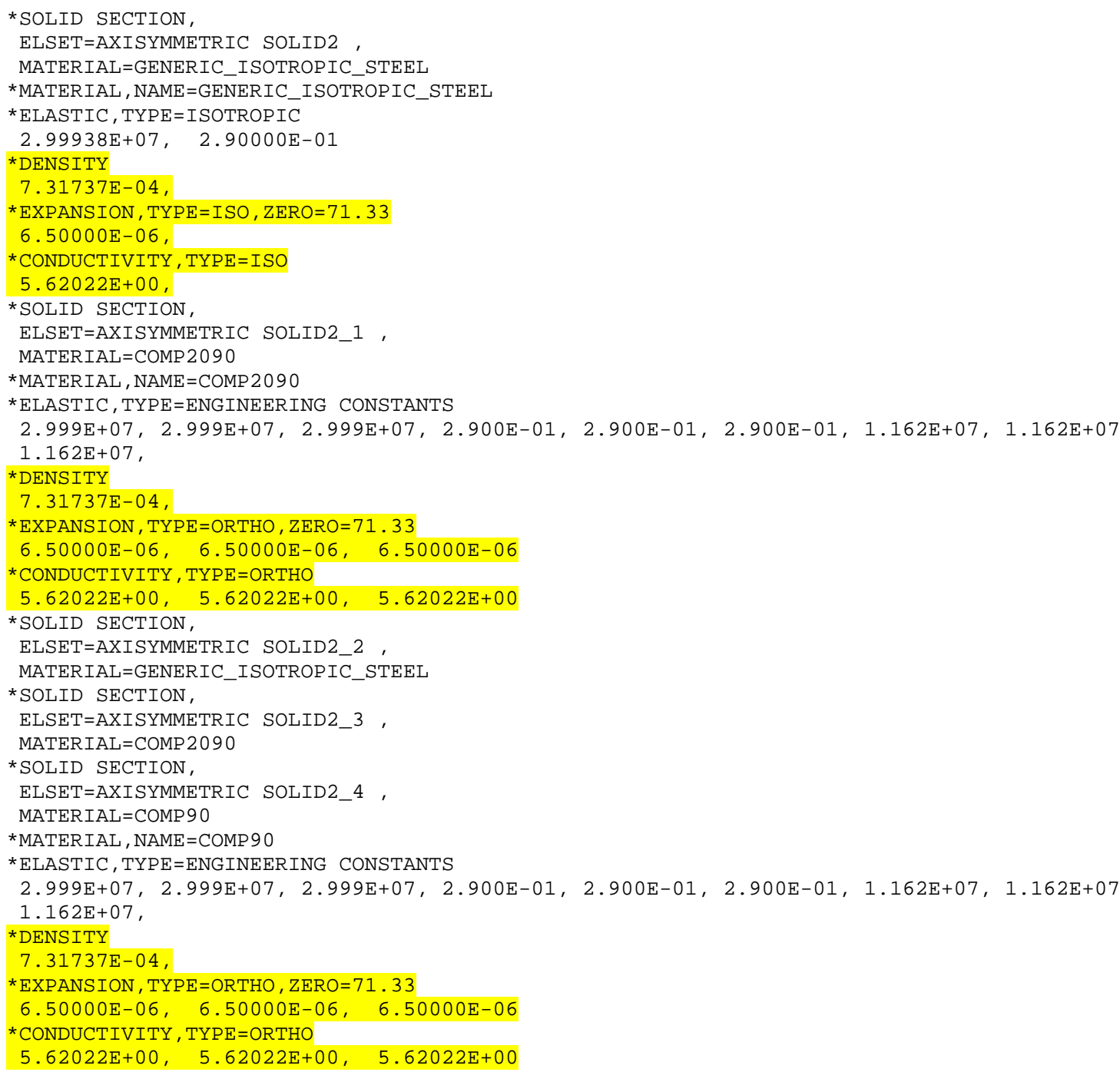


This section should now look similar to the text below:

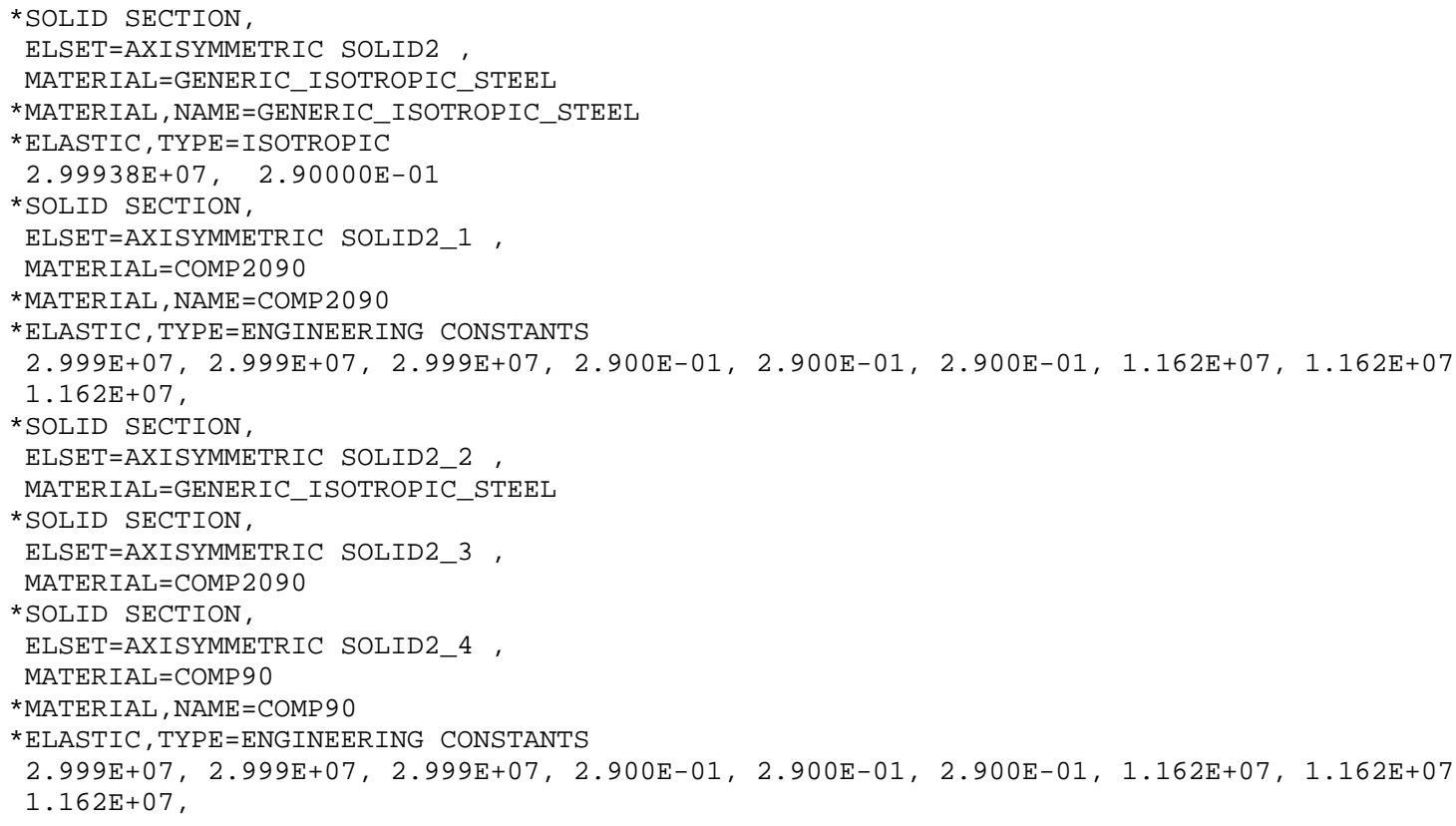

Now define the plastic material definition of the steel by adding the following three

\section{highlighted lines as shown:}

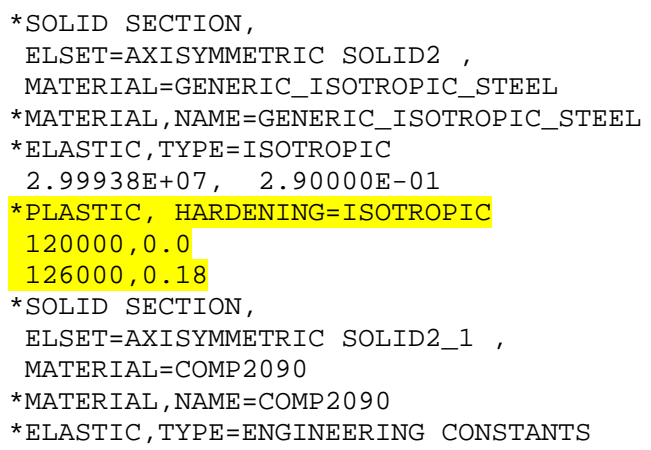




\section{Now modify the properties of [20,90] composite and [90] composite to match}

\section{those calculated in Excel by changing the four yellow highlighted lines below:}

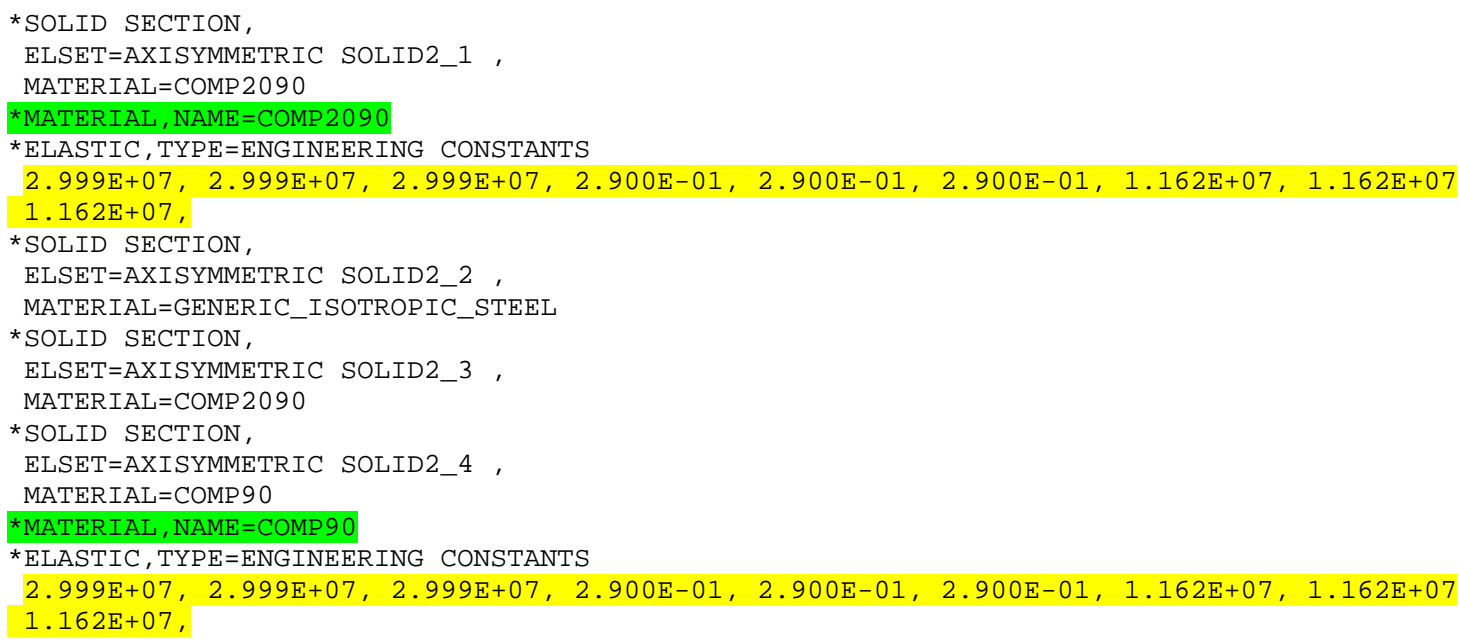

Now go scroll down until “ $\star$ STEP, AMPLItude=RAMP, INC=10000" is seen. Add the

highlighted lines as shown below:

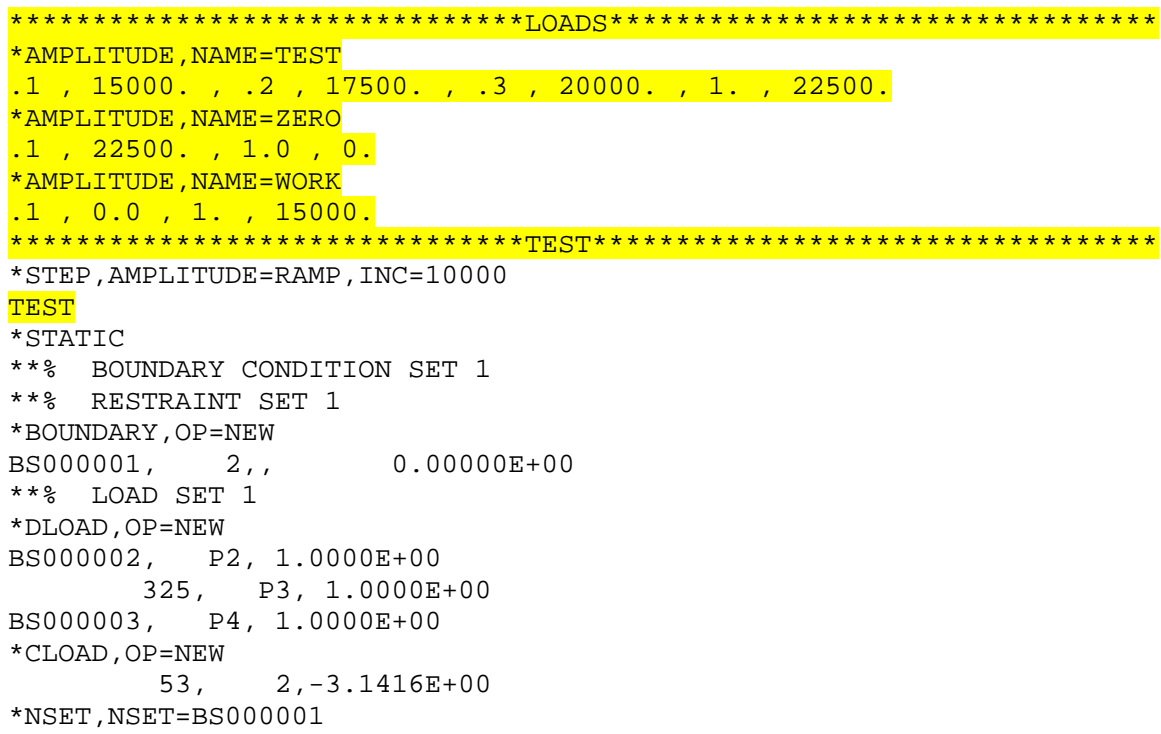




\section{Now go to the very bottom and cut the highlighted lines (cut not delete)}

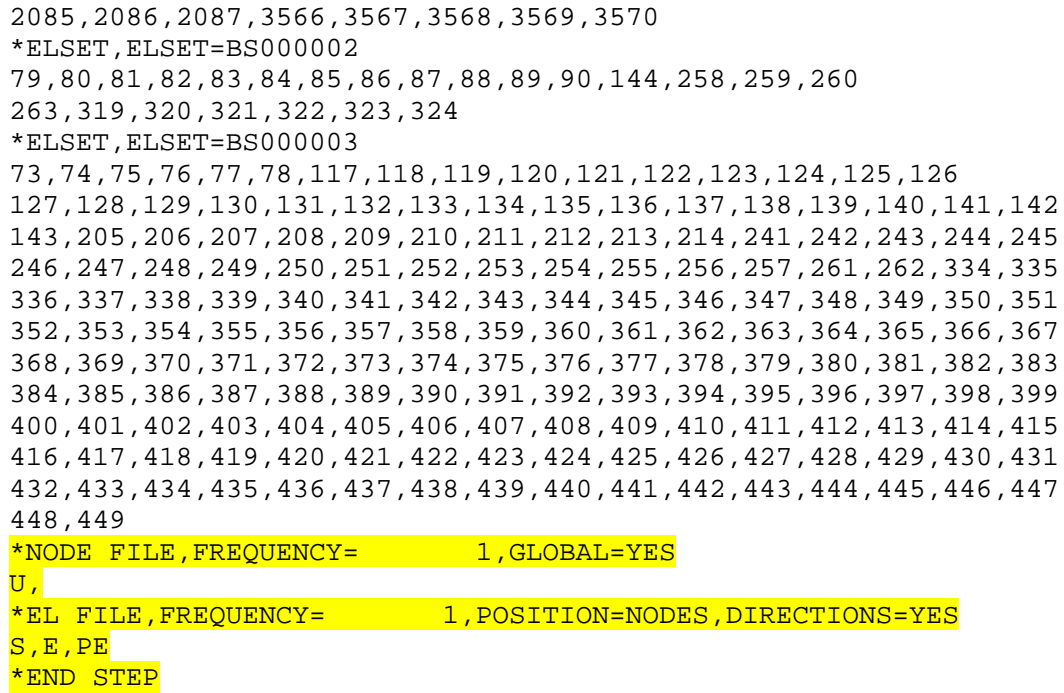

Now paste the "cut lines" and add the green highlighted line as shown below:

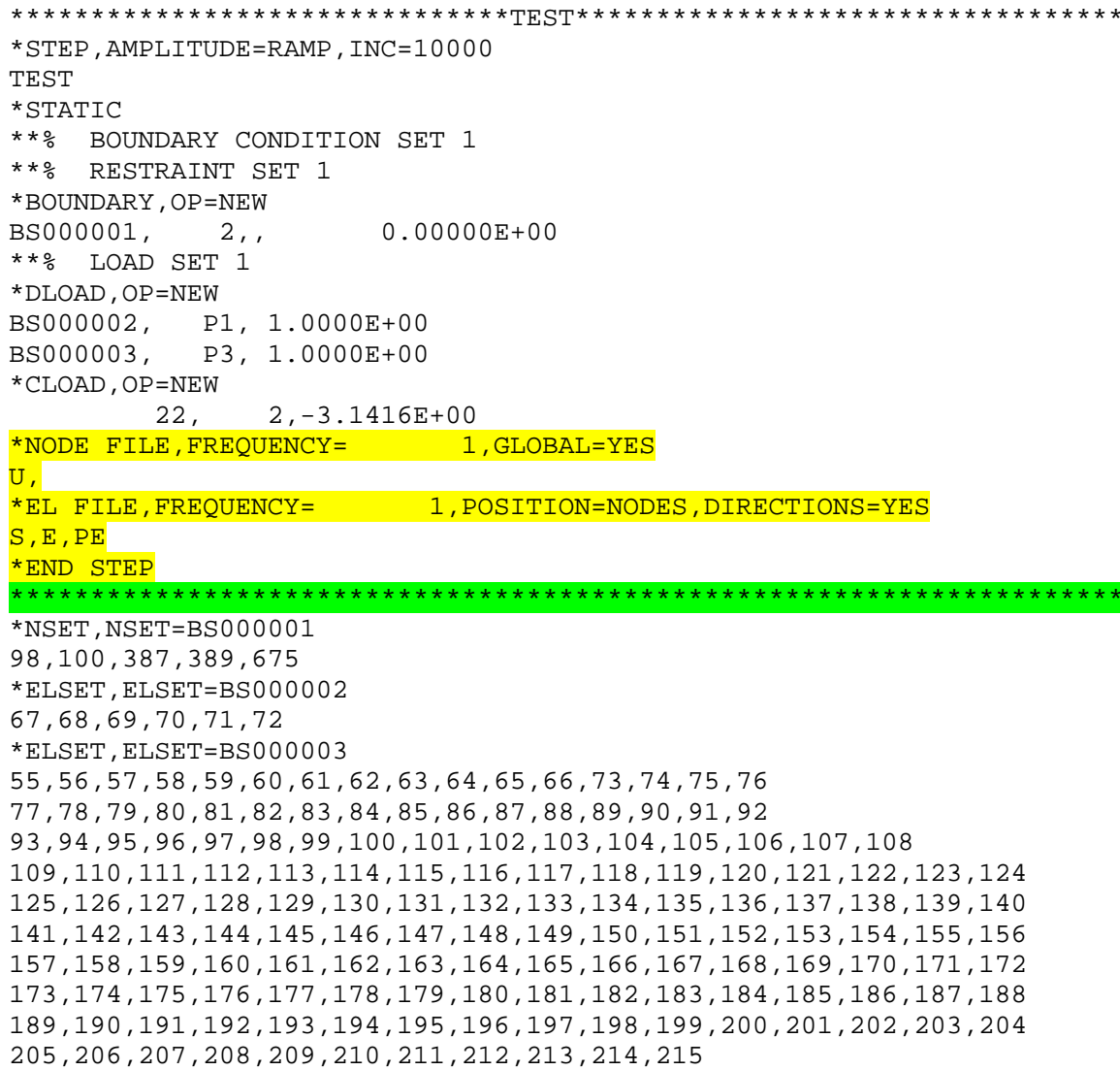


Change the lines " ${ }_{\mathrm{DLOAD}}, \mathrm{OP}=\mathrm{NEW}$ " and " ${ } \mathrm{CLOAD}, \mathrm{OP}=\mathrm{NEW}$ " as shown below:

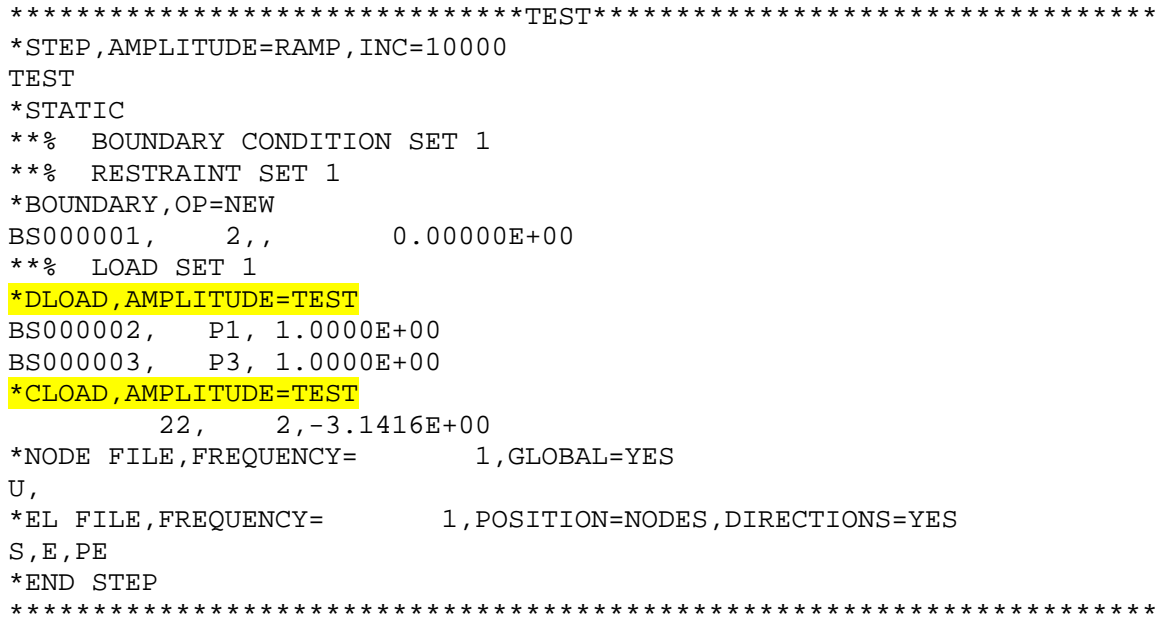

At this point, copy the highlighted lines below:

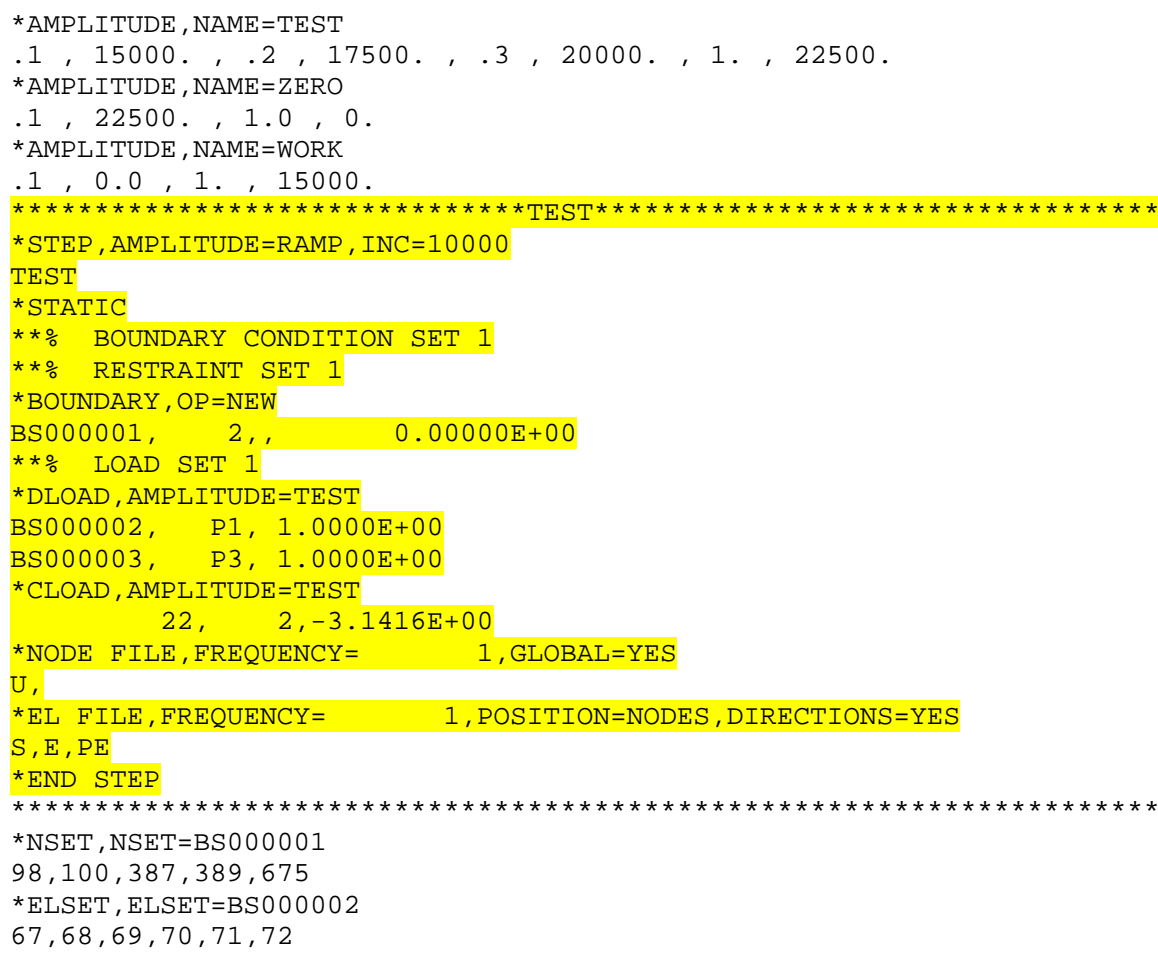


Paste the "copied lines" twice after the line “`END stEP" to look like this:

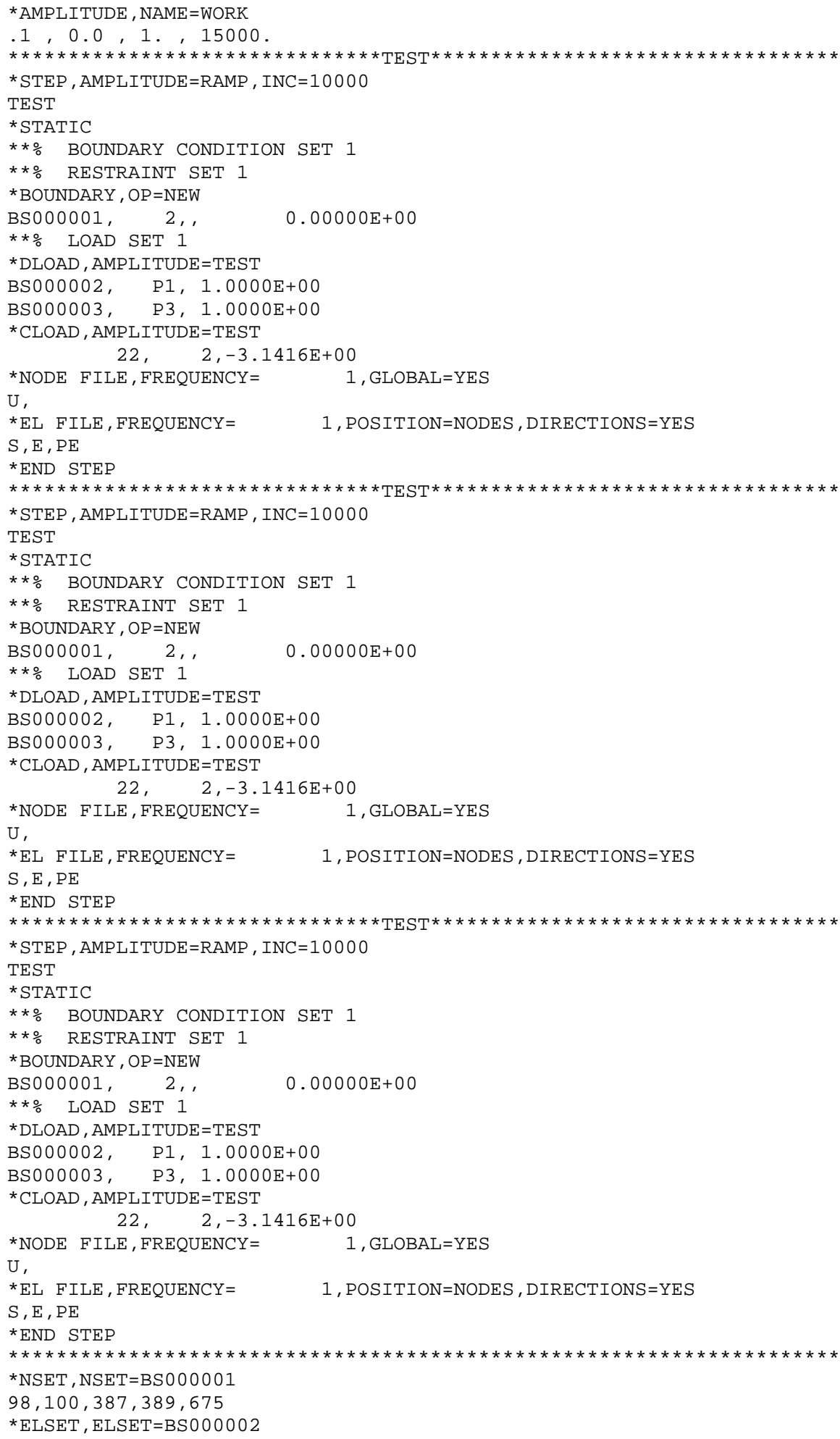




\section{Change the highlighted text below:}

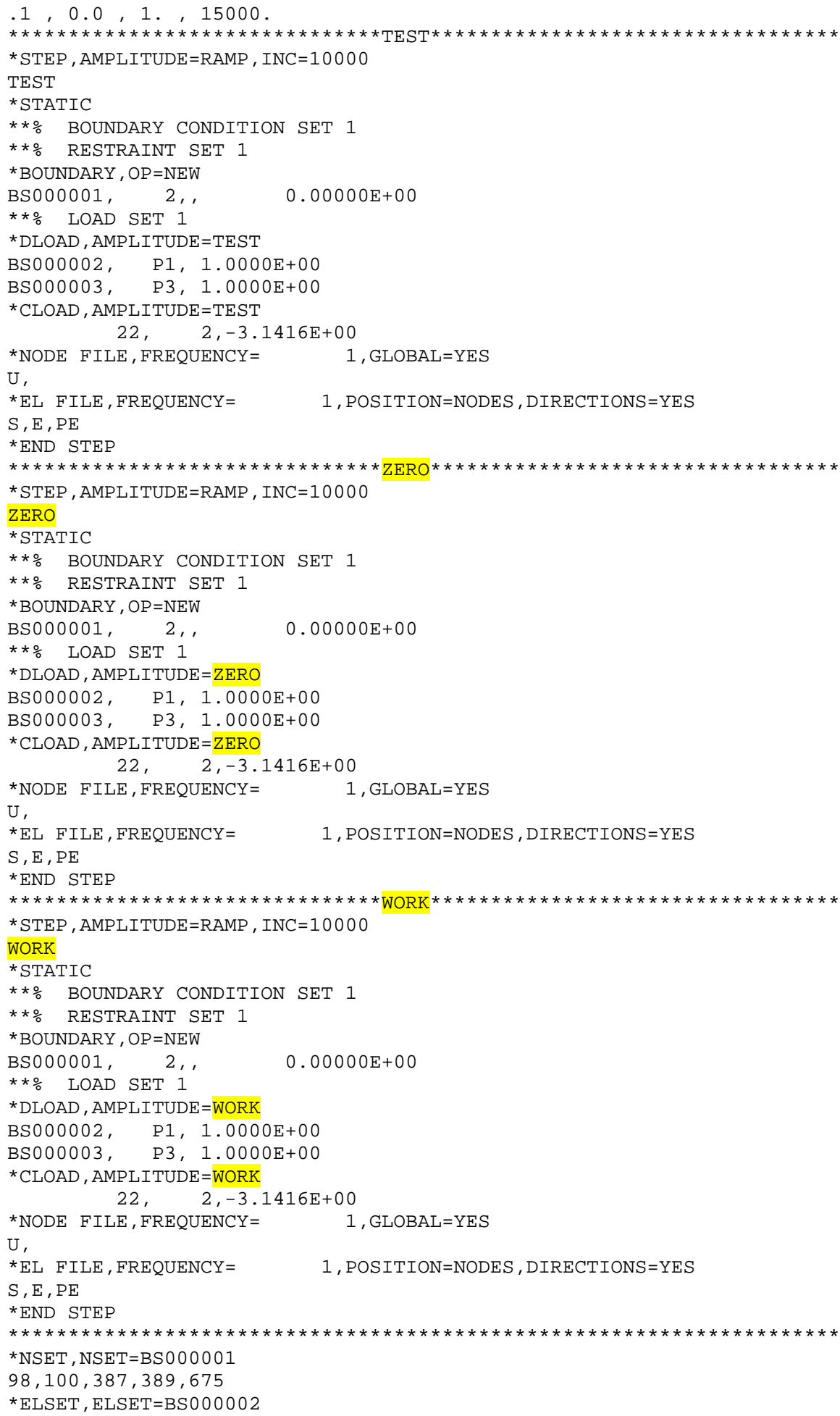

The model is now ready to be solved. After a solution is met, the model must be imported back into IDEAS for post-processing. 
Appendix B:

ABAQUS $^{\circledR}$ Input File (hybrid1.inp) 


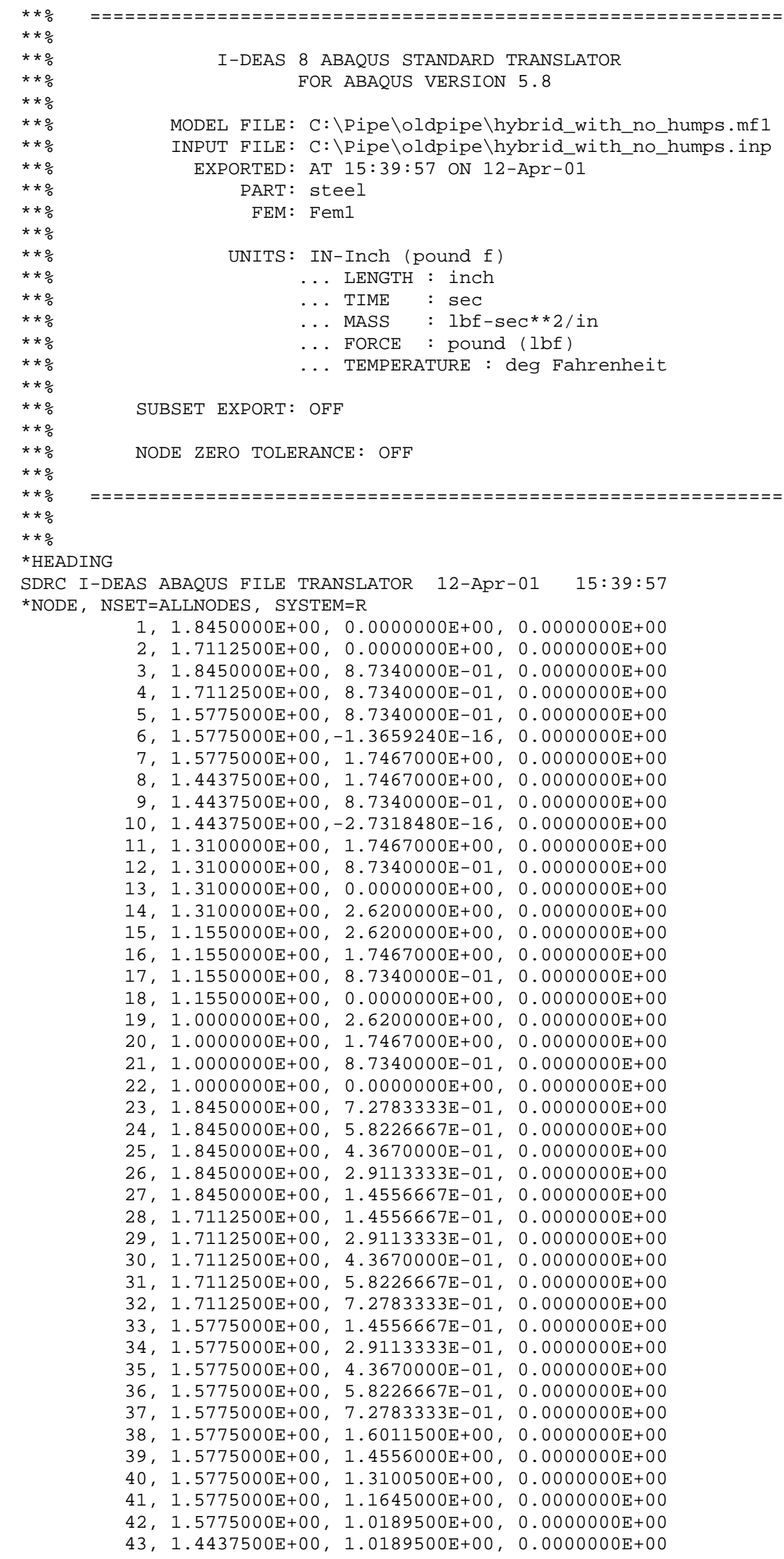


$44,1.4437500 \mathrm{E}+00,1.1645000 \mathrm{E}+00,0.0000000 \mathrm{E}+00$ $45,1.4437500 \mathrm{E}+00,1.3100500 \mathrm{E}+00,0.0000000 \mathrm{E}+00$ $46,1.4437500 \mathrm{E}+00,1.4556000 \mathrm{E}+00,0.0000000 \mathrm{E}+00$ $47,1.4437500 \mathrm{E}+00,1.6011500 \mathrm{E}+00,0.0000000 \mathrm{E}+00$ $48,1.4437500 \mathrm{E}+00,1.4556667 \mathrm{E}-01,0.0000000 \mathrm{E}+00$ $49,1.4437500 \mathrm{E}+00,2.9113333 \mathrm{E}-01,0.0000000 \mathrm{E}+00$ $50,1.4437500 \mathrm{E}+00,4.3670000 \mathrm{E}-01,0.0000000 \mathrm{E}+00$ $51,1.4437500 \mathrm{E}+00,5.8226667 \mathrm{E}-01,0.0000000 \mathrm{E}+00$ $52,1.4437500 \mathrm{E}+00,7.2783333 \mathrm{E}-01,0.0000000 \mathrm{E}+00$ $53,1.3100000 \mathrm{E}+00,1.0189500 \mathrm{E}+00,0.0000000 \mathrm{E}+00$ $54,1.3100000 \mathrm{E}+00,1.1645000 \mathrm{E}+00,0.0000000 \mathrm{E}+00$ $55,1.3100000 \mathrm{E}+00,1.3100500 \mathrm{E}+00,0.0000000 \mathrm{E}+00$ $56,1.3100000 \mathrm{E}+00,1.4556000 \mathrm{E}+00,0.0000000 \mathrm{E}+00$ $57,1.3100000 \mathrm{E}+00,1.6011500 \mathrm{E}+00,0.0000000 \mathrm{E}+00$ $58,1.3100000 \mathrm{E}+00,1.4556667 \mathrm{E}-01,0.0000000 \mathrm{E}+00$ $59,1.3100000 \mathrm{E}+00,2.9113333 \mathrm{E}-01,0.0000000 \mathrm{E}+00$ $60,1.3100000 \mathrm{E}+00,4.3670000 \mathrm{E}-01,0.0000000 \mathrm{E}+00$ $61,1.3100000 \mathrm{E}+00,5.8226667 \mathrm{E}-01,0.0000000 \mathrm{E}+00$ $62,1.3100000 \mathrm{E}+00,7.2783333 \mathrm{E}-01,0.0000000 \mathrm{E}+00$ $63,1.3100000 \mathrm{E}+00,2.4744500 \mathrm{E}+00,0.0000000 \mathrm{E}+00$ $64,1.3100000 \mathrm{E}+00,2.3289000 \mathrm{E}+00,0.0000000 \mathrm{E}+00$ $65,1.3100000 \mathrm{E}+00,2.1833500 \mathrm{E}+00,0.0000000 \mathrm{E}+00$ $66,1.3100000 \mathrm{E}+00,2.0378000 \mathrm{E}+00,0.0000000 \mathrm{E}+00$ $67,1.3100000 \mathrm{E}+00,1.8922500 \mathrm{E}+00,0.0000000 \mathrm{E}+00$ $68,1.1550000 \mathrm{E}+00,1.8922500 \mathrm{E}+00,0.0000000 \mathrm{E}+00$ $69,1.1550000 \mathrm{E}+00,2.0378000 \mathrm{E}+00,0.0000000 \mathrm{E}+00$

$70,1.1550000 \mathrm{E}+00,2.1833500 \mathrm{E}+00,0.0000000 \mathrm{E}+00$

$71,1.1550000 \mathrm{E}+00,2.3289000 \mathrm{E}+00,0.0000000 \mathrm{E}+00$

$72,1.1550000 \mathrm{E}+00,2.4744500 \mathrm{E}+00,0.0000000 \mathrm{E}+00$

$73,1.1550000 \mathrm{E}+00,1.0189500 \mathrm{E}+00,0.0000000 \mathrm{E}+00$

$74,1.1550000 \mathrm{E}+00,1.1645000 \mathrm{E}+00,0.0000000 \mathrm{E}+00$

$75,1.1550000 \mathrm{E}+00,1.3100500 \mathrm{E}+00,0.0000000 \mathrm{E}+00$

$76,1.1550000 \mathrm{E}+00,1.4556000 \mathrm{E}+00,0.0000000 \mathrm{E}+00$

$77,1.1550000 \mathrm{E}+00,1.6011500 \mathrm{E}+00,0.0000000 \mathrm{E}+00$

$78,1.1550000 \mathrm{E}+00,1.4556667 \mathrm{E}-01,0.0000000 \mathrm{E}+00$

$79,1.1550000 \mathrm{E}+00,2.9113333 \mathrm{E}-01,0.0000000 \mathrm{E}+00$

$80,1.1550000 \mathrm{E}+00,4.3670000 \mathrm{E}-01,0.0000000 \mathrm{E}+00$

$81,1.1550000 \mathrm{E}+00,5.8226667 \mathrm{E}-01,0.0000000 \mathrm{E}+00$

$82,1.1550000 \mathrm{E}+00,7.2783333 \mathrm{E}-01,0.0000000 \mathrm{E}+00$

$83,1.0000000 \mathrm{E}+00,1.8922500 \mathrm{E}+00,0.0000000 \mathrm{E}+00$

$84,1.0000000 \mathrm{E}+00,2.0378000 \mathrm{E}+00,0.0000000 \mathrm{E}+00$

$85,1.0000000 \mathrm{E}+00,2.1833500 \mathrm{E}+00,0.0000000 \mathrm{E}+00$

$86,1.0000000 \mathrm{E}+00,2.3289000 \mathrm{E}+00,0.0000000 \mathrm{E}+00$

$87,1.0000000 \mathrm{E}+00,2.4744500 \mathrm{E}+00,0.0000000 \mathrm{E}+00$

$88,1.0000000 \mathrm{E}+00,1.0189500 \mathrm{E}+00,0.0000000 \mathrm{E}+00$

$89,1.0000000 \mathrm{E}+00,1.1645000 \mathrm{E}+00,0.0000000 \mathrm{E}+00$

$90,1.0000000 \mathrm{E}+00,1.3100500 \mathrm{E}+00,0.0000000 \mathrm{E}+00$

$91,1.0000000 \mathrm{E}+00,1.4556000 \mathrm{E}+00,0.0000000 \mathrm{E}+00$

$92,1.0000000 \mathrm{E}+00,1.6011500 \mathrm{E}+00,0.0000000 \mathrm{E}+00$

$93,1.0000000 \mathrm{E}+00,1.4556667 \mathrm{E}-01,0.0000000 \mathrm{E}+00$

$94,1.0000000 \mathrm{E}+00,2.9113333 \mathrm{E}-01,0.0000000 \mathrm{E}+00$

$95,1.0000000 \mathrm{E}+00,4.3670000 \mathrm{E}-01,0.0000000 \mathrm{E}+00$

$96,1.0000000 \mathrm{E}+00,5.8226667 \mathrm{E}-01,0.0000000 \mathrm{E}+00$

$97,1.0000000 \mathrm{E}+00,7.2783333 \mathrm{E}-01,0.0000000 \mathrm{E}+00$

$98,1.1550000 \mathrm{E}+00,2.2620000 \mathrm{E}+01,0.0000000 \mathrm{E}+00$

$100,1.0000000 \mathrm{E}+00,2.2620000 \mathrm{E}+01,0.0000000 \mathrm{E}+00$

$102,1.1550000 \mathrm{E}+00,2.2480140 \mathrm{E}+01,0.0000000 \mathrm{E}+00$

$103,1.1550000 \mathrm{E}+00,2.2340280 \mathrm{E}+01,0.0000000 \mathrm{E}+00$

$104,1.1550000 \mathrm{E}+00,2.2200420 \mathrm{E}+01,0.0000000 \mathrm{E}+00$

$105,1.1550000 \mathrm{E}+00,2.2060559 \mathrm{E}+01,0.0000000 \mathrm{E}+00$

$106,1.1550000 \mathrm{E}+00,2.1920699 \mathrm{E}+01,0.0000000 \mathrm{E}+00$

$107,1.1550000 \mathrm{E}+00,2.1780839 \mathrm{E}+01,0.0000000 \mathrm{E}+00$

$108,1.1550000 \mathrm{E}+00,2.1640979 \mathrm{E}+01,0.0000000 \mathrm{E}+00$

$109,1.1550000 \mathrm{E}+00,2.1501119 \mathrm{E}+01,0.0000000 \mathrm{E}+00$

$110,1.1550000 \mathrm{E}+00,2.1361259 \mathrm{E}+01,0.0000000 \mathrm{E}+00$

$111,1.1550000 \mathrm{E}+00,2.1221399 \mathrm{E}+01,0.0000000 \mathrm{E}+00$

$112,1.1550000 \mathrm{E}+00,2.1081538 \mathrm{E}+01,0.0000000 \mathrm{E}+00$

$113,1.1550000 \mathrm{E}+00,2.0941678 \mathrm{E}+01,0.0000000 \mathrm{E}+00$

$114,1.1550000 \mathrm{E}+00,2.0801818 \mathrm{E}+01,0.0000000 \mathrm{E}+00$

$115,1.1550000 \mathrm{E}+00,2.0661958 \mathrm{E}+01,0.0000000 \mathrm{E}+00$

$116,1.1550000 \mathrm{E}+00,2.0522098 \mathrm{E}+01,0.0000000 \mathrm{E}+00$ 
$117,1.1550000 \mathrm{E}+00,2.0382238 \mathrm{E}+01,0.0000000 \mathrm{E}+00$

$118,1.1550000 \mathrm{E}+00,2.0242378 \mathrm{E}+01,0.0000000 \mathrm{E}+00$

$119,1.1550000 \mathrm{E}+00,2.0102517 \mathrm{E}+01,0.0000000 \mathrm{E}+00$

$120,1.1550000 \mathrm{E}+00,1.9962657 \mathrm{E}+01,0.0000000 \mathrm{E}+00$

$121,1.1550000 \mathrm{E}+00,1.9822797 \mathrm{E}+01,0.0000000 \mathrm{E}+00$

$122,1.1550000 \mathrm{E}+00,1.9682937 \mathrm{E}+01,0.0000000 \mathrm{E}+00$

$123,1.1550000 \mathrm{E}+00,1.9543077 \mathrm{E}+01,0.0000000 \mathrm{E}+00$

$124,1.1550000 \mathrm{E}+00,1.9403217 \mathrm{E}+01,0.0000000 \mathrm{E}+00$

$125,1.1550000 \mathrm{E}+00,1.9263357 \mathrm{E}+01,0.0000000 \mathrm{E}+00$

$126,1.1550000 \mathrm{E}+00,1.9123497 \mathrm{E}+01,0.0000000 \mathrm{E}+00$

$127,1.1550000 \mathrm{E}+00,1.8983636 \mathrm{E}+01,0.0000000 \mathrm{E}+00$

$128,1.1550000 \mathrm{E}+00,1.8843776 \mathrm{E}+01,0.0000000 \mathrm{E}+00$

$129,1.1550000 \mathrm{E}+00,1.8703916 \mathrm{E}+01,0.0000000 \mathrm{E}+00$

$130,1.1550000 \mathrm{E}+00,1.8564056 \mathrm{E}+01,0.0000000 \mathrm{E}+00$

$131,1.1550000 \mathrm{E}+00,1.8424196 \mathrm{E}+01,0.0000000 \mathrm{E}+00$

$132,1.1550000 \mathrm{E}+00,1.8284336 \mathrm{E}+01,0.0000000 \mathrm{E}+00$

$133,1.1550000 \mathrm{E}+00,1.8144476 \mathrm{E}+01,0.0000000 \mathrm{E}+00$

$134,1.1550000 \mathrm{E}+00,1.8004615 \mathrm{E}+01,0.0000000 \mathrm{E}+00$

$135,1.1550000 \mathrm{E}+00,1.7864755 \mathrm{E}+01,0.0000000 \mathrm{E}+00$

$136,1.1550000 \mathrm{E}+00,1.7724895 \mathrm{E}+01,0.0000000 \mathrm{E}+00$

$137,1.1550000 \mathrm{E}+00,1.7585035 \mathrm{E}+01,0.0000000 \mathrm{E}+00$

$138,1.1550000 \mathrm{E}+00,1.7445175 \mathrm{E}+01,0.0000000 \mathrm{E}+00$

$139,1.1550000 \mathrm{E}+00,1.7305315 \mathrm{E}+01,0.0000000 \mathrm{E}+00$

$140,1.1550000 \mathrm{E}+00,1.7165455 \mathrm{E}+01,0.0000000 \mathrm{E}+00$

$141,1.1550000 \mathrm{E}+00,1.7025594 \mathrm{E}+01,0.0000000 \mathrm{E}+00$

$142,1.1550000 \mathrm{E}+00,1.6885734 \mathrm{E}+01,0.0000000 \mathrm{E}+00$

$143,1.1550000 \mathrm{E}+00,1.6745874 \mathrm{E}+01,0.0000000 \mathrm{E}+00$

$144,1.1550000 \mathrm{E}+00,1.6606014 \mathrm{E}+01,0.0000000 \mathrm{E}+00$

$145,1.1550000 \mathrm{E}+00,1.6466154 \mathrm{E}+01,0.0000000 \mathrm{E}+00$

$146,1.1550000 \mathrm{E}+00,1.6326294 \mathrm{E}+01,0.0000000 \mathrm{E}+00$

$147,1.1550000 \mathrm{E}+00,1.6186434 \mathrm{E}+01,0.0000000 \mathrm{E}+00$

$148,1.1550000 \mathrm{E}+00,1.6046573 \mathrm{E}+01,0.0000000 \mathrm{E}+00$

$149,1.1550000 \mathrm{E}+00,1.5906713 \mathrm{E}+01,0.0000000 \mathrm{E}+00$

$150,1.1550000 \mathrm{E}+00,1.5766853 \mathrm{E}+01,0.0000000 \mathrm{E}+00$

$151,1.1550000 \mathrm{E}+00,1.5626993 \mathrm{E}+01,0.0000000 \mathrm{E}+00$

$152,1.1550000 \mathrm{E}+00,1.5487133 \mathrm{E}+01,0.0000000 \mathrm{E}+00$

$153,1.1550000 \mathrm{E}+00,1.5347273 \mathrm{E}+01,0.0000000 \mathrm{E}+00$

$154,1.1550000 \mathrm{E}+00,1.5207413 \mathrm{E}+01,0.0000000 \mathrm{E}+00$

$155,1.1550000 \mathrm{E}+00,1.5067552 \mathrm{E}+01,0.0000000 \mathrm{E}+00$

$156,1.1550000 \mathrm{E}+00,1.4927692 \mathrm{E}+01,0.0000000 \mathrm{E}+00$

$157,1.1550000 \mathrm{E}+00,1.4787832 \mathrm{E}+01,0.0000000 \mathrm{E}+00$

$158,1.1550000 \mathrm{E}+00,1.4647972 \mathrm{E}+01,0.0000000 \mathrm{E}+00$

$159,1.1550000 \mathrm{E}+00,1.4508112 \mathrm{E}+01,0.0000000 \mathrm{E}+00$

$160,1.1550000 \mathrm{E}+00,1.4368252 \mathrm{E}+01,0.0000000 \mathrm{E}+00$

$161,1.1550000 \mathrm{E}+00,1.4228392 \mathrm{E}+01,0.0000000 \mathrm{E}+00$

$162,1.1550000 \mathrm{E}+00,1.4088531 \mathrm{E}+01,0.0000000 \mathrm{E}+00$

$163,1.1550000 \mathrm{E}+00,1.3948671 \mathrm{E}+01,0.0000000 \mathrm{E}+00$

$164,1.1550000 \mathrm{E}+00,1.3808811 \mathrm{E}+01,0.0000000 \mathrm{E}+00$

$165,1.1550000 \mathrm{E}+00,1.3668951 \mathrm{E}+01,0.0000000 \mathrm{E}+00$

$166,1.1550000 \mathrm{E}+00,1.3529091 \mathrm{E}+01,0.0000000 \mathrm{E}+00$

$167,1.1550000 \mathrm{E}+00,1.3389231 \mathrm{E}+01,0.0000000 \mathrm{E}+00$

$168,1.1550000 \mathrm{E}+00,1.3249371 \mathrm{E}+01,0.0000000 \mathrm{E}+00$

$169,1.1550000 \mathrm{E}+00,1.3109510 \mathrm{E}+01,0.0000000 \mathrm{E}+00$

$170,1.1550000 \mathrm{E}+00,1.2969650 \mathrm{E}+01,0.0000000 \mathrm{E}+00$

$171,1.1550000 \mathrm{E}+00,1.2829790 \mathrm{E}+01,0.0000000 \mathrm{E}+00$

$172,1.1550000 \mathrm{E}+00,1.2689930 \mathrm{E}+01,0.0000000 \mathrm{E}+00$

$173,1.1550000 \mathrm{E}+00,1.2550070 \mathrm{E}+01,0.0000000 \mathrm{E}+00$

$174,1.1550000 \mathrm{E}+00,1.2410210 \mathrm{E}+01,0.0000000 \mathrm{E}+00$

$175,1.1550000 \mathrm{E}+00,1.2270350 \mathrm{E}+01,0.0000000 \mathrm{E}+00$

$176,1.1550000 \mathrm{E}+00,1.2130490 \mathrm{E}+01,0.0000000 \mathrm{E}+00$

$177,1.1550000 \mathrm{E}+00,1.1990629 \mathrm{E}+01,0.0000000 \mathrm{E}+00$

$178,1.1550000 \mathrm{E}+00,1.1850769 \mathrm{E}+01,0.0000000 \mathrm{E}+00$

$179,1.1550000 \mathrm{E}+00,1.1710909 \mathrm{E}+01,0.0000000 \mathrm{E}+00$

$180,1.1550000 \mathrm{E}+00,1.1571049 \mathrm{E}+01,0.0000000 \mathrm{E}+00$

$181,1.1550000 \mathrm{E}+00,1.1431189 \mathrm{E}+01,0.0000000 \mathrm{E}+00$

$182,1.1550000 \mathrm{E}+00,1.1291329 \mathrm{E}+01,0.0000000 \mathrm{E}+00$

$183,1.1550000 \mathrm{E}+00,1.1151469 \mathrm{E}+01,0.0000000 \mathrm{E}+00$

$184,1.1550000 \mathrm{E}+00,1.1011608 \mathrm{E}+01,0.0000000 \mathrm{E}+00$

$185,1.1550000 \mathrm{E}+00,1.0871748 \mathrm{E}+01,0.0000000 \mathrm{E}+00$

$186,1.1550000 \mathrm{E}+00,1.0731888 \mathrm{E}+01,0.0000000 \mathrm{E}+00$

$187,1.1550000 \mathrm{E}+00,1.0592028 \mathrm{E}+01,0.0000000 \mathrm{E}+00$ 
$188,1.1550000 \mathrm{E}+00,1.0452168 \mathrm{E}+01,0.0000000 \mathrm{E}+00$

$189,1.1550000 \mathrm{E}+00,1.0312308 \mathrm{E}+01,0.0000000 \mathrm{E}+00$

$190,1.1550000 \mathrm{E}+00,1.0172448 \mathrm{E}+01,0.0000000 \mathrm{E}+00$

$191,1.1550000 \mathrm{E}+00,1.0032587 \mathrm{E}+01,0.0000000 \mathrm{E}+00$

$192,1.1550000 \mathrm{E}+00,9.8927273 \mathrm{E}+00,0.0000000 \mathrm{E}+00$

$193,1.1550000 \mathrm{E}+00,9.7528671 \mathrm{E}+00,0.0000000 \mathrm{E}+00$

$194,1.1550000 \mathrm{E}+00,9.6130070 \mathrm{E}+00,0.0000000 \mathrm{E}+00$

$195,1.1550000 \mathrm{E}+00,9.4731469 \mathrm{E}+00,0.0000000 \mathrm{E}+00$

$196,1.1550000 \mathrm{E}+00,9.3332867 \mathrm{E}+00,0.0000000 \mathrm{E}+00$

$197,1.1550000 \mathrm{E}+00,9.1934266 \mathrm{E}+00,0.0000000 \mathrm{E}+00$

$198,1.1550000 \mathrm{E}+00,9.0535664 \mathrm{E}+00,0.0000000 \mathrm{E}+00$

$199,1.1550000 \mathrm{E}+00,8.9137063 \mathrm{E}+00,0.0000000 \mathrm{E}+00$

$200,1.1550000 \mathrm{E}+00,8.7738462 \mathrm{E}+00,0.0000000 \mathrm{E}+00$

$201,1.1550000 \mathrm{E}+00,8.6339860 \mathrm{E}+00,0.0000000 \mathrm{E}+00$

$202,1.1550000 \mathrm{E}+00,8.4941259 \mathrm{E}+00,0.0000000 \mathrm{E}+00$

$203,1.1550000 \mathrm{E}+00,8.3542657 \mathrm{E}+00,0.0000000 \mathrm{E}+00$

$204,1.1550000 \mathrm{E}+00,8.2144056 \mathrm{E}+00,0.0000000 \mathrm{E}+00$

$205,1.1550000 \mathrm{E}+00,8.0745455 \mathrm{E}+00,0.0000000 \mathrm{E}+00$

$206,1.1550000 \mathrm{E}+00,7.9346853 \mathrm{E}+00,0.0000000 \mathrm{E}+00$

$207,1.1550000 \mathrm{E}+00,7.7948252 \mathrm{E}+00,0.0000000 \mathrm{E}+00$

$208,1.1550000 \mathrm{E}+00,7.6549650 \mathrm{E}+00,0.0000000 \mathrm{E}+00$

$209,1.1550000 \mathrm{E}+00,7.5151049 \mathrm{E}+00,0.0000000 \mathrm{E}+00$

$210,1.1550000 \mathrm{E}+00,7.3752448 \mathrm{E}+00,0.0000000 \mathrm{E}+00$

$211,1.1550000 \mathrm{E}+00,7.2353846 \mathrm{E}+00,0.0000000 \mathrm{E}+00$

$212,1.1550000 \mathrm{E}+00,7.0955245 \mathrm{E}+00,0.0000000 \mathrm{E}+00$

$213,1.1550000 \mathrm{E}+00,6.9556643 \mathrm{E}+00,0.0000000 \mathrm{E}+00$

$214,1.1550000 \mathrm{E}+00,6.8158042 \mathrm{E}+00,0.0000000 \mathrm{E}+00$

$215,1.1550000 \mathrm{E}+00,6.6759441 \mathrm{E}+00,0.0000000 \mathrm{E}+00$

$216,1.1550000 \mathrm{E}+00,6.5360839 \mathrm{E}+00,0.0000000 \mathrm{E}+00$

$217,1.1550000 \mathrm{E}+00,6.3962238 \mathrm{E}+00,0.0000000 \mathrm{E}+00$

$218,1.1550000 \mathrm{E}+00,6.2563636 \mathrm{E}+00,0.0000000 \mathrm{E}+00$

$219,1.1550000 \mathrm{E}+00,6.1165035 \mathrm{E}+00,0.0000000 \mathrm{E}+00$

$220,1.1550000 \mathrm{E}+00,5.9766434 \mathrm{E}+00,0.0000000 \mathrm{E}+00$

$221,1.1550000 \mathrm{E}+00,5.8367832 \mathrm{E}+00,0.0000000 \mathrm{E}+00$

$222,1.1550000 \mathrm{E}+00,5.6969231 \mathrm{E}+00,0.0000000 \mathrm{E}+00$

$223,1.1550000 \mathrm{E}+00,5.5570629 \mathrm{E}+00,0.0000000 \mathrm{E}+00$

$224,1.1550000 \mathrm{E}+00,5.4172028 \mathrm{E}+00,0.0000000 \mathrm{E}+00$

$225,1.1550000 \mathrm{E}+00,5.2773427 \mathrm{E}+00,0.0000000 \mathrm{E}+00$

$226,1.1550000 \mathrm{E}+00,5.1374825 \mathrm{E}+00,0.0000000 \mathrm{E}+00$

$227,1.1550000 \mathrm{E}+00,4.9976224 \mathrm{E}+00,0.0000000 \mathrm{E}+00$

$228,1.1550000 \mathrm{E}+00,4.8577622 \mathrm{E}+00,0.0000000 \mathrm{E}+00$

$229,1.1550000 \mathrm{E}+00,4.7179021 \mathrm{E}+00,0.0000000 \mathrm{E}+00$

$230,1.1550000 \mathrm{E}+00,4.5780420 \mathrm{E}+00,0.0000000 \mathrm{E}+00$

$231,1.1550000 \mathrm{E}+00,4.4381818 \mathrm{E}+00,0.0000000 \mathrm{E}+00$

$232,1.1550000 \mathrm{E}+00,4.2983217 \mathrm{E}+00,0.0000000 \mathrm{E}+00$

$233,1.1550000 \mathrm{E}+00,4.1584615 \mathrm{E}+00,0.0000000 \mathrm{E}+00$

$234,1.1550000 \mathrm{E}+00,4.0186014 \mathrm{E}+00,0.0000000 \mathrm{E}+00$

$235,1.1550000 \mathrm{E}+00,3.8787413 \mathrm{E}+00,0.0000000 \mathrm{E}+00$

$236,1.1550000 \mathrm{E}+00,3.7388811 \mathrm{E}+00,0.0000000 \mathrm{E}+00$

$237,1.1550000 \mathrm{E}+00,3.5990210 \mathrm{E}+00,0.0000000 \mathrm{E}+00$

$238,1.1550000 \mathrm{E}+00,3.4591608 \mathrm{E}+00,0.0000000 \mathrm{E}+00$

$239,1.1550000 \mathrm{E}+00,3.3193007 \mathrm{E}+00,0.0000000 \mathrm{E}+00$

$240,1.1550000 \mathrm{E}+00,3.1794406 \mathrm{E}+00,0.0000000 \mathrm{E}+00$

$241,1.1550000 \mathrm{E}+00,3.0395804 \mathrm{E}+00,0.0000000 \mathrm{E}+00$

$242,1.1550000 \mathrm{E}+00,2.8997203 \mathrm{E}+00,0.0000000 \mathrm{E}+00$

$243,1.1550000 \mathrm{E}+00,2.7598601 \mathrm{E}+00,0.0000000 \mathrm{E}+00$

$244,1.0000000 \mathrm{E}+00,2.7598601 \mathrm{E}+00,0.0000000 \mathrm{E}+00$

$245,1.0000000 \mathrm{E}+00,2.8997203 \mathrm{E}+00,0.0000000 \mathrm{E}+00$

$246,1.0000000 \mathrm{E}+00,3.0395804 \mathrm{E}+00,0.0000000 \mathrm{E}+00$

$247,1.0000000 \mathrm{E}+00,3.1794406 \mathrm{E}+00,0.0000000 \mathrm{E}+00$

$248,1.0000000 \mathrm{E}+00,3.3193007 \mathrm{E}+00,0.0000000 \mathrm{E}+00$

$249,1.0000000 \mathrm{E}+00,3.4591608 \mathrm{E}+00,0.0000000 \mathrm{E}+00$

$250,1.0000000 \mathrm{E}+00,3.5990210 \mathrm{E}+00,0.0000000 \mathrm{E}+00$

$251,1.0000000 \mathrm{E}+00,3.7388811 \mathrm{E}+00,0.0000000 \mathrm{E}+00$

$252,1.0000000 \mathrm{E}+00,3.8787413 \mathrm{E}+00,0.0000000 \mathrm{E}+00$

$253,1.0000000 \mathrm{E}+00,4.0186014 \mathrm{E}+00,0.0000000 \mathrm{E}+00$

$254,1.0000000 \mathrm{E}+00,4.1584615 \mathrm{E}+00,0.0000000 \mathrm{E}+00$

$255,1.0000000 \mathrm{E}+00,4.2983217 \mathrm{E}+00,0.0000000 \mathrm{E}+00$

$256,1.0000000 \mathrm{E}+00,4.4381818 \mathrm{E}+00,0.0000000 \mathrm{E}+00$

$257,1.0000000 \mathrm{E}+00,4.5780420 \mathrm{E}+00,0.0000000 \mathrm{E}+00$

$258,1.0000000 \mathrm{E}+00,4.7179021 \mathrm{E}+00,0.0000000 \mathrm{E}+00$ 
$259,1.0000000 \mathrm{E}+00,4.8577622 \mathrm{E}+00,0.0000000 \mathrm{E}+00$ $260,1.0000000 \mathrm{E}+00,4.9976224 \mathrm{E}+00,0.0000000 \mathrm{E}+00$

$261,1.0000000 \mathrm{E}+00,5.1374825 \mathrm{E}+00,0.0000000 \mathrm{E}+00$ $262,1.0000000 \mathrm{E}+00,5.2773427 \mathrm{E}+00,0.0000000 \mathrm{E}+00$ $263,1.0000000 \mathrm{E}+00,5.4172028 \mathrm{E}+00,0.0000000 \mathrm{E}+00$ $264,1.0000000 \mathrm{E}+00,5.5570629 \mathrm{E}+00,0.0000000 \mathrm{E}+00$ $265,1.0000000 \mathrm{E}+00,5.6969231 \mathrm{E}+00,0.0000000 \mathrm{E}+00$ $266,1.0000000 \mathrm{E}+00,5.8367832 \mathrm{E}+00,0.0000000 \mathrm{E}+00$ $267,1.0000000 \mathrm{E}+00,5.9766434 \mathrm{E}+00,0.0000000 \mathrm{E}+00$ $268,1.0000000 \mathrm{E}+00,6.1165035 \mathrm{E}+00,0.0000000 \mathrm{E}+00$ $269,1.0000000 \mathrm{E}+00,6.2563636 \mathrm{E}+00,0.0000000 \mathrm{E}+00$ $270,1.0000000 \mathrm{E}+00,6.3962238 \mathrm{E}+00,0.0000000 \mathrm{E}+00$ $271,1.0000000 \mathrm{E}+00,6.5360839 \mathrm{E}+00,0.0000000 \mathrm{E}+00$ $272,1.0000000 \mathrm{E}+00,6.6759441 \mathrm{E}+00,0.0000000 \mathrm{E}+00$ $273,1.0000000 \mathrm{E}+00,6.8158042 \mathrm{E}+00,0.0000000 \mathrm{E}+00$ $274,1.0000000 \mathrm{E}+00,6.9556643 \mathrm{E}+00,0.0000000 \mathrm{E}+00$ $275,1.0000000 \mathrm{E}+00,7.0955245 \mathrm{E}+00,0.0000000 \mathrm{E}+00$ $276,1.0000000 \mathrm{E}+00,7.2353846 \mathrm{E}+00,0.0000000 \mathrm{E}+00$ $277,1.0000000 \mathrm{E}+00,7.3752448 \mathrm{E}+00,0.0000000 \mathrm{E}+00$ $278,1.0000000 \mathrm{E}+00,7.5151049 \mathrm{E}+00,0.0000000 \mathrm{E}+00$ $279,1.0000000 \mathrm{E}+00,7.6549650 \mathrm{E}+00,0.0000000 \mathrm{E}+00$ $280,1.0000000 \mathrm{E}+00,7.7948252 \mathrm{E}+00,0.0000000 \mathrm{E}+00$ $281,1.0000000 \mathrm{E}+00,7.9346853 \mathrm{E}+00,0.0000000 \mathrm{E}+00$ $282,1.0000000 \mathrm{E}+00,8.0745455 \mathrm{E}+00,0.0000000 \mathrm{E}+00$ $283,1.0000000 \mathrm{E}+00,8.2144056 \mathrm{E}+00,0.0000000 \mathrm{E}+00$ $284,1.0000000 \mathrm{E}+00,8.3542657 \mathrm{E}+00,0.0000000 \mathrm{E}+00$ $285,1.0000000 \mathrm{E}+00,8.4941259 \mathrm{E}+00,0.0000000 \mathrm{E}+00$ $286,1.0000000 \mathrm{E}+00,8.6339860 \mathrm{E}+00,0.0000000 \mathrm{E}+00$ $287,1.0000000 \mathrm{E}+00,8.7738462 \mathrm{E}+00,0.0000000 \mathrm{E}+00$ $288,1.0000000 \mathrm{E}+00,8.9137063 \mathrm{E}+00,0.0000000 \mathrm{E}+00$ $289,1.0000000 \mathrm{E}+00,9.0535664 \mathrm{E}+00,0.0000000 \mathrm{E}+00$ $290,1.0000000 \mathrm{E}+00,9.1934266 \mathrm{E}+00,0.0000000 \mathrm{E}+00$ $291,1.0000000 \mathrm{E}+00,9.3332867 \mathrm{E}+00,0.0000000 \mathrm{E}+00$ $292,1.0000000 \mathrm{E}+00,9.4731469 \mathrm{E}+00,0.0000000 \mathrm{E}+00$ $293,1.0000000 \mathrm{E}+00,9.6130070 \mathrm{E}+00,0.0000000 \mathrm{E}+00$ $294,1.0000000 \mathrm{E}+00,9.7528671 \mathrm{E}+00,0.0000000 \mathrm{E}+00$ $295,1.0000000 \mathrm{E}+00,9.8927273 \mathrm{E}+00,0.0000000 \mathrm{E}+00$ $296,1.0000000 \mathrm{E}+00,1.0032587 \mathrm{E}+01,0.0000000 \mathrm{E}+00$ $297,1.0000000 \mathrm{E}+00,1.0172448 \mathrm{E}+01,0.0000000 \mathrm{E}+00$ $298,1.0000000 \mathrm{E}+00,1.0312308 \mathrm{E}+01,0.0000000 \mathrm{E}+00$ $299,1.0000000 \mathrm{E}+00,1.0452168 \mathrm{E}+01,0.0000000 \mathrm{E}+00$ $300,1.0000000 \mathrm{E}+00,1.0592028 \mathrm{E}+01,0.0000000 \mathrm{E}+00$ $301,1.0000000 \mathrm{E}+00,1.0731888 \mathrm{E}+01,0.0000000 \mathrm{E}+00$ $302,1.0000000 \mathrm{E}+00,1.0871748 \mathrm{E}+01,0.0000000 \mathrm{E}+00$ $303,1.0000000 \mathrm{E}+00,1.1011608 \mathrm{E}+01,0.0000000 \mathrm{E}+00$ $304,1.0000000 \mathrm{E}+00,1.1151469 \mathrm{E}+01,0.0000000 \mathrm{E}+00$ $305,1.0000000 \mathrm{E}+00,1.1291329 \mathrm{E}+01,0.0000000 \mathrm{E}+00$ $306,1.0000000 \mathrm{E}+00,1.1431189 \mathrm{E}+01,0.0000000 \mathrm{E}+00$ $307,1.0000000 \mathrm{E}+00,1.1571049 \mathrm{E}+01,0.0000000 \mathrm{E}+00$ $308,1.0000000 \mathrm{E}+00,1.1710909 \mathrm{E}+01,0.0000000 \mathrm{E}+00$ $309,1.0000000 \mathrm{E}+00,1.1850769 \mathrm{E}+01,0.0000000 \mathrm{E}+00$ $310,1.0000000 \mathrm{E}+00,1.1990629 \mathrm{E}+01,0.0000000 \mathrm{E}+00$ $311,1.0000000 \mathrm{E}+00,1.2130490 \mathrm{E}+01,0.0000000 \mathrm{E}+00$ $312,1.0000000 \mathrm{E}+00,1.2270350 \mathrm{E}+01,0.0000000 \mathrm{E}+00$ $313,1.0000000 \mathrm{E}+00,1.2410210 \mathrm{E}+01,0.0000000 \mathrm{E}+00$ $314,1.0000000 \mathrm{E}+00,1.2550070 \mathrm{E}+01,0.0000000 \mathrm{E}+00$ $315,1.0000000 \mathrm{E}+00,1.2689930 \mathrm{E}+01,0.0000000 \mathrm{E}+00$ $316,1.0000000 \mathrm{E}+00,1.2829790 \mathrm{E}+01,0.0000000 \mathrm{E}+00$ $317,1.0000000 \mathrm{E}+00,1.2969650 \mathrm{E}+01,0.0000000 \mathrm{E}+00$ $318,1.0000000 \mathrm{E}+00,1.3109510 \mathrm{E}+01,0.0000000 \mathrm{E}+00$ $319,1.0000000 \mathrm{E}+00,1.3249371 \mathrm{E}+01,0.0000000 \mathrm{E}+00$ $320,1.0000000 \mathrm{E}+00,1.3389231 \mathrm{E}+01,0.0000000 \mathrm{E}+00$ $321,1.0000000 \mathrm{E}+00,1.3529091 \mathrm{E}+01,0.0000000 \mathrm{E}+00$ $322,1.0000000 \mathrm{E}+00,1.3668951 \mathrm{E}+01,0.0000000 \mathrm{E}+00$ $323,1.0000000 \mathrm{E}+00,1.3808811 \mathrm{E}+01,0.0000000 \mathrm{E}+00$ $324,1.0000000 \mathrm{E}+00,1.3948671 \mathrm{E}+01,0.0000000 \mathrm{E}+00$ $325,1.0000000 \mathrm{E}+00,1.4088531 \mathrm{E}+01,0.0000000 \mathrm{E}+00$ $326,1.0000000 \mathrm{E}+00,1.4228392 \mathrm{E}+01,0.0000000 \mathrm{E}+00$ $327,1.0000000 \mathrm{E}+00,1.4368252 \mathrm{E}+01,0.0000000 \mathrm{E}+00$ $328,1.0000000 \mathrm{E}+00,1.4508112 \mathrm{E}+01,0.0000000 \mathrm{E}+00$ $329,1.0000000 \mathrm{E}+00,1.4647972 \mathrm{E}+01,0.0000000 \mathrm{E}+00$ 
$330,1.0000000 \mathrm{E}+00,1.4787832 \mathrm{E}+01,0.0000000 \mathrm{E}+00$ $331,1.0000000 \mathrm{E}+00,1.4927692 \mathrm{E}+01,0.0000000 \mathrm{E}+00$ $332,1.0000000 \mathrm{E}+00,1.5067552 \mathrm{E}+01,0.0000000 \mathrm{E}+00$ $333,1.0000000 \mathrm{E}+00,1.5207413 \mathrm{E}+01,0.0000000 \mathrm{E}+00$ $334,1.0000000 \mathrm{E}+00,1.5347273 \mathrm{E}+01,0.0000000 \mathrm{E}+00$ $335,1.0000000 \mathrm{E}+00,1.5487133 \mathrm{E}+01,0.0000000 \mathrm{E}+00$ $336,1.0000000 \mathrm{E}+00,1.5626993 \mathrm{E}+01,0.0000000 \mathrm{E}+00$ $337,1.0000000 \mathrm{E}+00,1.5766853 \mathrm{E}+01,0.0000000 \mathrm{E}+00$ $338,1.0000000 \mathrm{E}+00,1.5906713 \mathrm{E}+01,0.0000000 \mathrm{E}+00$ $339,1.0000000 \mathrm{E}+00,1.6046573 \mathrm{E}+01,0.0000000 \mathrm{E}+00$ $340,1.0000000 \mathrm{E}+00,1.6186434 \mathrm{E}+01,0.0000000 \mathrm{E}+00$ $341,1.0000000 \mathrm{E}+00,1.6326294 \mathrm{E}+01,0.0000000 \mathrm{E}+00$ $342,1.0000000 \mathrm{E}+00,1.6466154 \mathrm{E}+01,0.0000000 \mathrm{E}+00$ $343,1.0000000 \mathrm{E}+00,1.6606014 \mathrm{E}+01,0.0000000 \mathrm{E}+00$ $344,1.0000000 \mathrm{E}+00,1.6745874 \mathrm{E}+01,0.0000000 \mathrm{E}+00$ $345,1.0000000 \mathrm{E}+00,1.6885734 \mathrm{E}+01,0.0000000 \mathrm{E}+00$ $346,1.0000000 \mathrm{E}+00,1.7025594 \mathrm{E}+01,0.0000000 \mathrm{E}+00$ $347,1.0000000 \mathrm{E}+00,1.7165455 \mathrm{E}+01,0.0000000 \mathrm{E}+00$ $348,1.0000000 \mathrm{E}+00,1.7305315 \mathrm{E}+01,0.0000000 \mathrm{E}+00$ $349,1.0000000 \mathrm{E}+00,1.7445175 \mathrm{E}+01,0.0000000 \mathrm{E}+00$ $350,1.0000000 \mathrm{E}+00,1.7585035 \mathrm{E}+01,0.0000000 \mathrm{E}+00$ $351,1.0000000 \mathrm{E}+00,1.7724895 \mathrm{E}+01,0.0000000 \mathrm{E}+00$ $352,1.0000000 \mathrm{E}+00,1.7864755 \mathrm{E}+01,0.0000000 \mathrm{E}+00$ $353,1.0000000 \mathrm{E}+00,1.8004615 \mathrm{E}+01,0.0000000 \mathrm{E}+00$ $354,1.0000000 \mathrm{E}+00,1.8144476 \mathrm{E}+01,0.0000000 \mathrm{E}+00$ $355,1.0000000 \mathrm{E}+00,1.8284336 \mathrm{E}+01,0.0000000 \mathrm{E}+00$ $356,1.0000000 \mathrm{E}+00,1.8424196 \mathrm{E}+01,0.0000000 \mathrm{E}+00$ $357,1.0000000 \mathrm{E}+00,1.8564056 \mathrm{E}+01,0.0000000 \mathrm{E}+00$ $358,1.0000000 \mathrm{E}+00,1.8703916 \mathrm{E}+01,0.0000000 \mathrm{E}+00$ $359,1.0000000 \mathrm{E}+00,1.8843776 \mathrm{E}+01,0.0000000 \mathrm{E}+00$ $360,1.0000000 \mathrm{E}+00,1.8983636 \mathrm{E}+01,0.0000000 \mathrm{E}+00$ $361,1.0000000 \mathrm{E}+00,1.9123497 \mathrm{E}+01,0.0000000 \mathrm{E}+00$ $362,1.0000000 \mathrm{E}+00,1.9263357 \mathrm{E}+01,0.0000000 \mathrm{E}+00$ $363,1.0000000 \mathrm{E}+00,1.9403217 \mathrm{E}+01,0.0000000 \mathrm{E}+00$ $364,1.0000000 \mathrm{E}+00,1.9543077 \mathrm{E}+01,0.0000000 \mathrm{E}+00$ $365,1.0000000 \mathrm{E}+00,1.9682937 \mathrm{E}+01,0.0000000 \mathrm{E}+00$ $366,1.0000000 \mathrm{E}+00,1.9822797 \mathrm{E}+01,0.0000000 \mathrm{E}+00$ $367,1.0000000 \mathrm{E}+00,1.9962657 \mathrm{E}+01,0.0000000 \mathrm{E}+00$ $368,1.0000000 \mathrm{E}+00,2.0102517 \mathrm{E}+01,0.0000000 \mathrm{E}+00$ $369,1.0000000 \mathrm{E}+00,2.0242378 \mathrm{E}+01,0.0000000 \mathrm{E}+00$ $370,1.0000000 \mathrm{E}+00,2.0382238 \mathrm{E}+01,0.0000000 \mathrm{E}+00$ $371,1.0000000 \mathrm{E}+00,2.0522098 \mathrm{E}+01,0.0000000 \mathrm{E}+00$ $372,1.0000000 \mathrm{E}+00,2.0661958 \mathrm{E}+01,0.0000000 \mathrm{E}+00$ $373,1.0000000 \mathrm{E}+00,2.0801818 \mathrm{E}+01,0.0000000 \mathrm{E}+00$ $374,1.0000000 \mathrm{E}+00,2.0941678 \mathrm{E}+01,0.0000000 \mathrm{E}+00$ $375,1.0000000 \mathrm{E}+00,2.1081538 \mathrm{E}+01,0.0000000 \mathrm{E}+00$ $376,1.0000000 \mathrm{E}+00,2.1221399 \mathrm{E}+01,0.0000000 \mathrm{E}+00$ $377,1.0000000 \mathrm{E}+00,2.1361259 \mathrm{E}+01,0.0000000 \mathrm{E}+00$ $378,1.0000000 \mathrm{E}+00,2.1501119 \mathrm{E}+01,0.0000000 \mathrm{E}+00$ $379,1.0000000 \mathrm{E}+00,2.1640979 \mathrm{E}+01,0.0000000 \mathrm{E}+00$ $380,1.0000000 \mathrm{E}+00,2.1780839 \mathrm{E}+01,0.0000000 \mathrm{E}+00$ $381,1.0000000 \mathrm{E}+00,2.1920699 \mathrm{E}+01,0.0000000 \mathrm{E}+00$ $382,1.0000000 \mathrm{E}+00,2.2060559 \mathrm{E}+01,0.0000000 \mathrm{E}+00$ $383,1.0000000 \mathrm{E}+00,2.2200420 \mathrm{E}+01,0.0000000 \mathrm{E}+00$ $384,1.0000000 \mathrm{E}+00,2.2340280 \mathrm{E}+01,0.0000000 \mathrm{E}+00$ $385,1.0000000 \mathrm{E}+00,2.2480140 \mathrm{E}+01,0.0000000 \mathrm{E}+00$ $386,1.1600000 \mathrm{E}+00,2.6200000 \mathrm{E}+00,0.0000000 \mathrm{E}+00$ $387,1.1600000 \mathrm{E}+00,2.2620000 \mathrm{E}+01,0.0000000 \mathrm{E}+00$ $388,1.4240000 \mathrm{E}+00,2.6200000 \mathrm{E}+00,0.0000000 \mathrm{E}+00$ $389,1.4240000 \mathrm{E}+00,2.2620000 \mathrm{E}+01,0.0000000 \mathrm{E}+00$ $390,1.1600000 \mathrm{E}+00,2.7598601 \mathrm{E}+00,0.0000000 \mathrm{E}+00$ $391,1.1600000 \mathrm{E}+00,2.8997203 \mathrm{E}+00,0.0000000 \mathrm{E}+00$ $392,1.1600000 \mathrm{E}+00,3.0395804 \mathrm{E}+00,0.0000000 \mathrm{E}+00$ $393,1.1600000 \mathrm{E}+00,3.1794406 \mathrm{E}+00,0.0000000 \mathrm{E}+00$ $394,1.1600000 \mathrm{E}+00,3.3193007 \mathrm{E}+00,0.0000000 \mathrm{E}+00$ $395,1.1600000 \mathrm{E}+00,3.4591608 \mathrm{E}+00,0.0000000 \mathrm{E}+00$ $396,1.1600000 \mathrm{E}+00,3.5990210 \mathrm{E}+00,0.0000000 \mathrm{E}+00$ $397,1.1600000 \mathrm{E}+00,3.7388811 \mathrm{E}+00,0.0000000 \mathrm{E}+00$ $398,1.1600000 \mathrm{E}+00,3.8787413 \mathrm{E}+00,0.0000000 \mathrm{E}+00$ $399,1.1600000 \mathrm{E}+00,4.0186014 \mathrm{E}+00,0.0000000 \mathrm{E}+00$ $400,1.1600000 \mathrm{E}+00,4.1584615 \mathrm{E}+00,0.0000000 \mathrm{E}+00$ 
$401,1.1600000 \mathrm{E}+00,4.2983217 \mathrm{E}+00,0.0000000 \mathrm{E}+00$ $402,1.1600000 \mathrm{E}+00,4.4381818 \mathrm{E}+00,0.0000000 \mathrm{E}+00$ $403,1.1600000 \mathrm{E}+00,4.5780420 \mathrm{E}+00,0.0000000 \mathrm{E}+00$ $404,1.1600000 \mathrm{E}+00,4.7179021 \mathrm{E}+00,0.0000000 \mathrm{E}+00$ $405,1.1600000 \mathrm{E}+00,4.8577622 \mathrm{E}+00,0.0000000 \mathrm{E}+00$ $406,1.1600000 \mathrm{E}+00,4.9976224 \mathrm{E}+00,0.0000000 \mathrm{E}+00$ $407,1.1600000 \mathrm{E}+00,5.1374825 \mathrm{E}+00,0.0000000 \mathrm{E}+00$ $408,1.1600000 \mathrm{E}+00,5.2773427 \mathrm{E}+00,0.0000000 \mathrm{E}+00$ $409,1.1600000 \mathrm{E}+00,5.4172028 \mathrm{E}+00,0.0000000 \mathrm{E}+00$ $410,1.1600000 \mathrm{E}+00,5.5570629 \mathrm{E}+00,0.0000000 \mathrm{E}+00$ $411,1.1600000 \mathrm{E}+00,5.6969231 \mathrm{E}+00,0.0000000 \mathrm{E}+00$ $412,1.1600000 \mathrm{E}+00,5.8367832 \mathrm{E}+00,0.0000000 \mathrm{E}+00$ $413,1.1600000 \mathrm{E}+00,5.9766434 \mathrm{E}+00,0.0000000 \mathrm{E}+00$ $414,1.1600000 \mathrm{E}+00,6.1165035 \mathrm{E}+00,0.0000000 \mathrm{E}+00$ $415,1.1600000 \mathrm{E}+00,6.2563636 \mathrm{E}+00,0.0000000 \mathrm{E}+00$ $416,1.1600000 \mathrm{E}+00,6.3962238 \mathrm{E}+00,0.0000000 \mathrm{E}+00$ $417,1.1600000 \mathrm{E}+00,6.5360839 \mathrm{E}+00,0.0000000 \mathrm{E}+00$ $418,1.1600000 \mathrm{E}+00,6.6759441 \mathrm{E}+00,0.0000000 \mathrm{E}+00$ $419,1.1600000 \mathrm{E}+00,6.8158042 \mathrm{E}+00,0.0000000 \mathrm{E}+00$ $420,1.1600000 \mathrm{E}+00,6.9556643 \mathrm{E}+00,0.0000000 \mathrm{E}+00$ $421,1.1600000 \mathrm{E}+00,7.0955245 \mathrm{E}+00,0.0000000 \mathrm{E}+00$ $422,1.1600000 \mathrm{E}+00,7.2353846 \mathrm{E}+00,0.0000000 \mathrm{E}+00$ $423,1.1600000 \mathrm{E}+00,7.3752448 \mathrm{E}+00,0.0000000 \mathrm{E}+00$ $424,1.1600000 \mathrm{E}+00,7.5151049 \mathrm{E}+00,0.0000000 \mathrm{E}+00$ $425,1.1600000 \mathrm{E}+00,7.6549650 \mathrm{E}+00,0.0000000 \mathrm{E}+00$ $426,1.1600000 \mathrm{E}+00,7.7948252 \mathrm{E}+00,0.0000000 \mathrm{E}+00$ $427,1.1600000 \mathrm{E}+00,7.9346853 \mathrm{E}+00,0.0000000 \mathrm{E}+00$ $428,1.1600000 \mathrm{E}+00,8.0745455 \mathrm{E}+00,0.0000000 \mathrm{E}+00$ $429,1.1600000 \mathrm{E}+00,8.2144056 \mathrm{E}+00,0.0000000 \mathrm{E}+00$ $430,1.1600000 \mathrm{E}+00,8.3542657 \mathrm{E}+00,0.0000000 \mathrm{E}+00$ $431,1.1600000 \mathrm{E}+00,8.4941259 \mathrm{E}+00,0.0000000 \mathrm{E}+00$ $432,1.1600000 \mathrm{E}+00,8.6339860 \mathrm{E}+00,0.0000000 \mathrm{E}+00$ $433,1.1600000 \mathrm{E}+00,8.7738462 \mathrm{E}+00,0.0000000 \mathrm{E}+00$ $434,1.1600000 \mathrm{E}+00,8.9137063 \mathrm{E}+00,0.0000000 \mathrm{E}+00$ $435,1.1600000 \mathrm{E}+00,9.0535664 \mathrm{E}+00,0.0000000 \mathrm{E}+00$ $436,1.1600000 \mathrm{E}+00,9.1934266 \mathrm{E}+00,0.0000000 \mathrm{E}+00$ $437,1.1600000 \mathrm{E}+00,9.3332867 \mathrm{E}+00,0.0000000 \mathrm{E}+00$ $438,1.1600000 \mathrm{E}+00,9.4731469 \mathrm{E}+00,0.0000000 \mathrm{E}+00$ $439,1.1600000 \mathrm{E}+00,9.6130070 \mathrm{E}+00,0.0000000 \mathrm{E}+00$ $440,1.1600000 \mathrm{E}+00,9.7528671 \mathrm{E}+00,0.0000000 \mathrm{E}+00$ $441,1.1600000 \mathrm{E}+00,9.8927273 \mathrm{E}+00,0.0000000 \mathrm{E}+00$ $442,1.1600000 \mathrm{E}+00,1.0032587 \mathrm{E}+01,0.0000000 \mathrm{E}+00$ $443,1.1600000 \mathrm{E}+00,1.0172448 \mathrm{E}+01,0.0000000 \mathrm{E}+00$ $444,1.1600000 \mathrm{E}+00,1.0312308 \mathrm{E}+01,0.0000000 \mathrm{E}+00$ $445,1.1600000 \mathrm{E}+00,1.0452168 \mathrm{E}+01,0.0000000 \mathrm{E}+00$ $446,1.1600000 \mathrm{E}+00,1.0592028 \mathrm{E}+01,0.0000000 \mathrm{E}+00$ $447,1.1600000 \mathrm{E}+00,1.0731888 \mathrm{E}+01,0.0000000 \mathrm{E}+00$ $448,1.1600000 \mathrm{E}+00,1.0871748 \mathrm{E}+01,0.0000000 \mathrm{E}+00$ $449,1.1600000 \mathrm{E}+00,1.1011608 \mathrm{E}+01,0.0000000 \mathrm{E}+00$ $450,1.1600000 \mathrm{E}+00,1.1151469 \mathrm{E}+01,0.0000000 \mathrm{E}+00$ $451,1.1600000 \mathrm{E}+00,1.1291329 \mathrm{E}+01,0.0000000 \mathrm{E}+00$ $452,1.1600000 \mathrm{E}+00,1.1431189 \mathrm{E}+01,0.0000000 \mathrm{E}+00$ $453,1.1600000 \mathrm{E}+00,1.1571049 \mathrm{E}+01,0.0000000 \mathrm{E}+00$ $454,1.1600000 \mathrm{E}+00,1.1710909 \mathrm{E}+01,0.0000000 \mathrm{E}+00$ $455,1.1600000 \mathrm{E}+00,1.1850769 \mathrm{E}+01,0.0000000 \mathrm{E}+00$ $456,1.1600000 \mathrm{E}+00,1.1990629 \mathrm{E}+01,0.0000000 \mathrm{E}+00$ $457,1.1600000 \mathrm{E}+00,1.2130490 \mathrm{E}+01,0.0000000 \mathrm{E}+00$ $458,1.1600000 \mathrm{E}+00,1.2270350 \mathrm{E}+01,0.0000000 \mathrm{E}+00$ $459,1.1600000 \mathrm{E}+00,1.2410210 \mathrm{E}+01,0.0000000 \mathrm{E}+00$ $460,1.1600000 \mathrm{E}+00,1.2550070 \mathrm{E}+01,0.0000000 \mathrm{E}+00$ $461,1.1600000 \mathrm{E}+00,1.2689930 \mathrm{E}+01,0.0000000 \mathrm{E}+00$ $462,1.1600000 \mathrm{E}+00,1.2829790 \mathrm{E}+01,0.0000000 \mathrm{E}+00$ $463,1.1600000 \mathrm{E}+00,1.2969650 \mathrm{E}+01,0.0000000 \mathrm{E}+00$ $464,1.1600000 \mathrm{E}+00,1.3109510 \mathrm{E}+01,0.0000000 \mathrm{E}+00$ $465,1.1600000 \mathrm{E}+00,1.3249371 \mathrm{E}+01,0.0000000 \mathrm{E}+00$ $466,1.1600000 \mathrm{E}+00,1.3389231 \mathrm{E}+01,0.0000000 \mathrm{E}+00$ $467,1.1600000 \mathrm{E}+00,1.3529091 \mathrm{E}+01,0.0000000 \mathrm{E}+00$ $468,1.1600000 \mathrm{E}+00,1.3668951 \mathrm{E}+01,0.0000000 \mathrm{E}+00$ $469,1.1600000 \mathrm{E}+00,1.3808811 \mathrm{E}+01,0.0000000 \mathrm{E}+00$ $470,1.1600000 \mathrm{E}+00,1.3948671 \mathrm{E}+01,0.0000000 \mathrm{E}+00$ $471,1.1600000 \mathrm{E}+00,1.4088531 \mathrm{E}+01,0.0000000 \mathrm{E}+00$ 
$472,1.1600000 \mathrm{E}+00,1.4228392 \mathrm{E}+01,0.0000000 \mathrm{E}+00$ $473,1.1600000 \mathrm{E}+00,1.4368252 \mathrm{E}+01,0.0000000 \mathrm{E}+00$ $474,1.1600000 \mathrm{E}+00,1.4508112 \mathrm{E}+01,0.0000000 \mathrm{E}+00$ $475,1.1600000 \mathrm{E}+00,1.4647972 \mathrm{E}+01,0.0000000 \mathrm{E}+00$ $476,1.1600000 \mathrm{E}+00,1.4787832 \mathrm{E}+01,0.0000000 \mathrm{E}+00$ $477,1.1600000 \mathrm{E}+00,1.4927692 \mathrm{E}+01,0.0000000 \mathrm{E}+00$ $478,1.1600000 \mathrm{E}+00,1.5067552 \mathrm{E}+01,0.0000000 \mathrm{E}+00$ $479,1.1600000 \mathrm{E}+00,1.5207413 \mathrm{E}+01,0.0000000 \mathrm{E}+00$ $480,1.1600000 \mathrm{E}+00,1.5347273 \mathrm{E}+01,0.0000000 \mathrm{E}+00$ $481,1.1600000 \mathrm{E}+00,1.5487133 \mathrm{E}+01,0.0000000 \mathrm{E}+00$ $482,1.1600000 \mathrm{E}+00,1.5626993 \mathrm{E}+01,0.0000000 \mathrm{E}+00$ $483,1.1600000 \mathrm{E}+00,1.5766853 \mathrm{E}+01,0.0000000 \mathrm{E}+00$ $484,1.1600000 \mathrm{E}+00,1.5906713 \mathrm{E}+01,0.0000000 \mathrm{E}+00$ $485,1.1600000 \mathrm{E}+00,1.6046573 \mathrm{E}+01,0.0000000 \mathrm{E}+00$ $486,1.1600000 \mathrm{E}+00,1.6186434 \mathrm{E}+01,0.0000000 \mathrm{E}+00$ $487,1.1600000 \mathrm{E}+00,1.6326294 \mathrm{E}+01,0.0000000 \mathrm{E}+00$ $488,1.1600000 \mathrm{E}+00,1.6466154 \mathrm{E}+01,0.0000000 \mathrm{E}+00$ $489,1.1600000 \mathrm{E}+00,1.6606014 \mathrm{E}+01,0.0000000 \mathrm{E}+00$ $490,1.1600000 \mathrm{E}+00,1.6745874 \mathrm{E}+01,0.0000000 \mathrm{E}+00$ $491,1.1600000 \mathrm{E}+00,1.6885734 \mathrm{E}+01,0.0000000 \mathrm{E}+00$ $492,1.1600000 \mathrm{E}+00,1.7025594 \mathrm{E}+01,0.0000000 \mathrm{E}+00$ $493,1.1600000 \mathrm{E}+00,1.7165455 \mathrm{E}+01,0.0000000 \mathrm{E}+00$ $494,1.1600000 \mathrm{E}+00,1.7305315 \mathrm{E}+01,0.0000000 \mathrm{E}+00$ $495,1.1600000 \mathrm{E}+00,1.7445175 \mathrm{E}+01,0.0000000 \mathrm{E}+00$ $496,1.1600000 \mathrm{E}+00,1.7585035 \mathrm{E}+01,0.0000000 \mathrm{E}+00$ $497,1.1600000 \mathrm{E}+00,1.7724895 \mathrm{E}+01,0.0000000 \mathrm{E}+00$ $498,1.1600000 \mathrm{E}+00,1.7864755 \mathrm{E}+01,0.0000000 \mathrm{E}+00$ $499,1.1600000 \mathrm{E}+00,1.8004615 \mathrm{E}+01,0.0000000 \mathrm{E}+00$ $500,1.1600000 \mathrm{E}+00,1.8144476 \mathrm{E}+01,0.0000000 \mathrm{E}+00$ $501,1.1600000 \mathrm{E}+00,1.8284336 \mathrm{E}+01,0.0000000 \mathrm{E}+00$ $502,1.1600000 \mathrm{E}+00,1.8424196 \mathrm{E}+01,0.0000000 \mathrm{E}+00$ $503,1.1600000 \mathrm{E}+00,1.8564056 \mathrm{E}+01,0.0000000 \mathrm{E}+00$ $504,1.1600000 \mathrm{E}+00,1.8703916 \mathrm{E}+01,0.0000000 \mathrm{E}+00$ $505,1.1600000 \mathrm{E}+00,1.8843776 \mathrm{E}+01,0.0000000 \mathrm{E}+00$ $506,1.1600000 \mathrm{E}+00,1.8983636 \mathrm{E}+01,0.0000000 \mathrm{E}+00$ $507,1.1600000 \mathrm{E}+00,1.9123497 \mathrm{E}+01,0.0000000 \mathrm{E}+00$ $508,1.1600000 \mathrm{E}+00,1.9263357 \mathrm{E}+01,0.0000000 \mathrm{E}+00$ $509,1.1600000 \mathrm{E}+00,1.9403217 \mathrm{E}+01,0.0000000 \mathrm{E}+00$ $510,1.1600000 \mathrm{E}+00,1.9543077 \mathrm{E}+01,0.0000000 \mathrm{E}+00$ $511,1.1600000 \mathrm{E}+00,1.9682937 \mathrm{E}+01,0.0000000 \mathrm{E}+00$ $512,1.1600000 \mathrm{E}+00,1.9822797 \mathrm{E}+01,0.0000000 \mathrm{E}+00$ $513,1.1600000 \mathrm{E}+00,1.9962657 \mathrm{E}+01,0.0000000 \mathrm{E}+00$ $514,1.1600000 \mathrm{E}+00,2.0102517 \mathrm{E}+01,0.0000000 \mathrm{E}+00$ $515,1.1600000 \mathrm{E}+00,2.0242378 \mathrm{E}+01,0.0000000 \mathrm{E}+00$ $516,1.1600000 \mathrm{E}+00,2.0382238 \mathrm{E}+01,0.0000000 \mathrm{E}+00$ $517,1.1600000 \mathrm{E}+00,2.0522098 \mathrm{E}+01,0.0000000 \mathrm{E}+00$ $518,1.1600000 \mathrm{E}+00,2.0661958 \mathrm{E}+01,0.0000000 \mathrm{E}+00$ $519,1.1600000 \mathrm{E}+00,2.0801818 \mathrm{E}+01,0.0000000 \mathrm{E}+00$ $520,1.1600000 \mathrm{E}+00,2.0941678 \mathrm{E}+01,0.0000000 \mathrm{E}+00$ $521,1.1600000 \mathrm{E}+00,2.1081538 \mathrm{E}+01,0.0000000 \mathrm{E}+00$ $522,1.1600000 \mathrm{E}+00,2.1221399 \mathrm{E}+01,0.0000000 \mathrm{E}+00$ $523,1.1600000 \mathrm{E}+00,2.1361259 \mathrm{E}+01,0.0000000 \mathrm{E}+00$ $524,1.1600000 \mathrm{E}+00,2.1501119 \mathrm{E}+01,0.0000000 \mathrm{E}+00$ $525,1.1600000 \mathrm{E}+00,2.1640979 \mathrm{E}+01,0.0000000 \mathrm{E}+00$ $526,1.1600000 \mathrm{E}+00,2.1780839 \mathrm{E}+01,0.0000000 \mathrm{E}+00$ $527,1.1600000 \mathrm{E}+00,2.1920699 \mathrm{E}+01,0.0000000 \mathrm{E}+00$ $528,1.1600000 \mathrm{E}+00,2.2060559 \mathrm{E}+01,0.0000000 \mathrm{E}+00$ $529,1.1600000 \mathrm{E}+00,2.2200420 \mathrm{E}+01,0.0000000 \mathrm{E}+00$ $530,1.1600000 \mathrm{E}+00,2.2340280 \mathrm{E}+01,0.0000000 \mathrm{E}+00$ $531,1.1600000 \mathrm{E}+00,2.2480140 \mathrm{E}+01,0.0000000 \mathrm{E}+00$ $532,1.2920000 \mathrm{E}+00,2.6200000 \mathrm{E}+00,0.0000000 \mathrm{E}+00$ $533,1.4240000 \mathrm{E}+00,2.2480140 \mathrm{E}+01,0.0000000 \mathrm{E}+00$ $534,1.4240000 \mathrm{E}+00,2.2340280 \mathrm{E}+01,0.0000000 \mathrm{E}+00$ $535,1.4240000 \mathrm{E}+00,2.2200420 \mathrm{E}+01,0.0000000 \mathrm{E}+00$ $536,1.4240000 \mathrm{E}+00,2.2060559 \mathrm{E}+01,0.0000000 \mathrm{E}+00$ 537, $1.4240000 \mathrm{E}+00,2.1920699 \mathrm{E}+01,0.0000000 \mathrm{E}+00$ $538,1.4240000 \mathrm{E}+00,2.1780839 \mathrm{E}+01,0.0000000 \mathrm{E}+00$ $539,1.4240000 \mathrm{E}+00,2.1640979 \mathrm{E}+01,0.0000000 \mathrm{E}+00$ $540,1.4240000 \mathrm{E}+00,2.1501119 \mathrm{E}+01,0.0000000 \mathrm{E}+00$ $541,1.4240000 \mathrm{E}+00,2.1361259 \mathrm{E}+01,0.0000000 \mathrm{E}+00$ $542,1.4240000 \mathrm{E}+00,2.1221399 \mathrm{E}+01,0.0000000 \mathrm{E}+00$ 
$543,1.4240000 \mathrm{E}+00,2.1081538 \mathrm{E}+01,0.0000000 \mathrm{E}+00$

$544,1.4240000 \mathrm{E}+00,2.0941678 \mathrm{E}+01,0.0000000 \mathrm{E}+00$

$545,1.4240000 \mathrm{E}+00,2.0801818 \mathrm{E}+01,0.0000000 \mathrm{E}+00$

$546,1.4240000 \mathrm{E}+00,2.0661958 \mathrm{E}+01,0.0000000 \mathrm{E}+00$

$547,1.4240000 \mathrm{E}+00,2.0522098 \mathrm{E}+01,0.0000000 \mathrm{E}+00$

$548,1.4240000 \mathrm{E}+00,2.0382238 \mathrm{E}+01,0.0000000 \mathrm{E}+00$

$549,1.4240000 \mathrm{E}+00,2.0242378 \mathrm{E}+01,0.0000000 \mathrm{E}+00$

$550,1.4240000 \mathrm{E}+00,2.0102517 \mathrm{E}+01,0.0000000 \mathrm{E}+00$

$551,1.4240000 \mathrm{E}+00,1.9962657 \mathrm{E}+01,0.0000000 \mathrm{E}+00$

$552,1.4240000 \mathrm{E}+00,1.9822797 \mathrm{E}+01,0.0000000 \mathrm{E}+00$

$553,1.4240000 \mathrm{E}+00,1.9682937 \mathrm{E}+01,0.0000000 \mathrm{E}+00$

$554,1.4240000 \mathrm{E}+00,1.9543077 \mathrm{E}+01,0.0000000 \mathrm{E}+00$

$555,1.4240000 \mathrm{E}+00,1.9403217 \mathrm{E}+01,0.0000000 \mathrm{E}+00$

$556,1.4240000 \mathrm{E}+00,1.9263357 \mathrm{E}+01,0.0000000 \mathrm{E}+00$

$557,1.4240000 \mathrm{E}+00,1.9123497 \mathrm{E}+01,0.0000000 \mathrm{E}+00$

$558,1.4240000 \mathrm{E}+00,1.8983636 \mathrm{E}+01,0.0000000 \mathrm{E}+00$

$559,1.4240000 \mathrm{E}+00,1.8843776 \mathrm{E}+01,0.0000000 \mathrm{E}+00$

$560,1.4240000 \mathrm{E}+00,1.8703916 \mathrm{E}+01,0.0000000 \mathrm{E}+00$

$561,1.4240000 \mathrm{E}+00,1.8564056 \mathrm{E}+01,0.0000000 \mathrm{E}+00$

$562,1.4240000 \mathrm{E}+00,1.8424196 \mathrm{E}+01,0.0000000 \mathrm{E}+00$

$563,1.4240000 \mathrm{E}+00,1.8284336 \mathrm{E}+01,0.0000000 \mathrm{E}+00$

$564,1.4240000 \mathrm{E}+00,1.8144476 \mathrm{E}+01,0.0000000 \mathrm{E}+00$

$565,1.4240000 \mathrm{E}+00,1.8004615 \mathrm{E}+01,0.0000000 \mathrm{E}+00$

$566,1.4240000 \mathrm{E}+00,1.7864755 \mathrm{E}+01,0.0000000 \mathrm{E}+00$

$567,1.4240000 \mathrm{E}+00,1.7724895 \mathrm{E}+01,0.0000000 \mathrm{E}+00$

$568,1.4240000 \mathrm{E}+00,1.7585035 \mathrm{E}+01,0.0000000 \mathrm{E}+00$

$569,1.4240000 \mathrm{E}+00,1.7445175 \mathrm{E}+01,0.0000000 \mathrm{E}+00$

$570,1.4240000 \mathrm{E}+00,1.7305315 \mathrm{E}+01,0.0000000 \mathrm{E}+00$

$571,1.4240000 \mathrm{E}+00,1.7165455 \mathrm{E}+01,0.0000000 \mathrm{E}+00$

$572,1.4240000 \mathrm{E}+00,1.7025594 \mathrm{E}+01,0.0000000 \mathrm{E}+00$

$573,1.4240000 \mathrm{E}+00,1.6885734 \mathrm{E}+01,0.0000000 \mathrm{E}+00$

$574,1.4240000 \mathrm{E}+00,1.6745874 \mathrm{E}+01,0.0000000 \mathrm{E}+00$

$575,1.4240000 \mathrm{E}+00,1.6606014 \mathrm{E}+01,0.0000000 \mathrm{E}+00$

$576,1.4240000 \mathrm{E}+00,1.6466154 \mathrm{E}+01,0.0000000 \mathrm{E}+00$

$577,1.4240000 \mathrm{E}+00,1.6326294 \mathrm{E}+01,0.0000000 \mathrm{E}+00$

$578,1.4240000 \mathrm{E}+00,1.6186434 \mathrm{E}+01,0.0000000 \mathrm{E}+00$

$579,1.4240000 \mathrm{E}+00,1.6046573 \mathrm{E}+01,0.0000000 \mathrm{E}+00$

$580,1.4240000 \mathrm{E}+00,1.5906713 \mathrm{E}+01,0.0000000 \mathrm{E}+00$

$581,1.4240000 \mathrm{E}+00,1.5766853 \mathrm{E}+01,0.0000000 \mathrm{E}+00$

$582,1.4240000 \mathrm{E}+00,1.5626993 \mathrm{E}+01,0.0000000 \mathrm{E}+00$

$583,1.4240000 \mathrm{E}+00,1.5487133 \mathrm{E}+01,0.0000000 \mathrm{E}+00$

$584,1.4240000 \mathrm{E}+00,1.5347273 \mathrm{E}+01,0.0000000 \mathrm{E}+00$

$585,1.4240000 \mathrm{E}+00,1.5207413 \mathrm{E}+01,0.0000000 \mathrm{E}+00$

$586,1.4240000 \mathrm{E}+00,1.5067552 \mathrm{E}+01,0.0000000 \mathrm{E}+00$

$587,1.4240000 \mathrm{E}+00,1.4927692 \mathrm{E}+01,0.0000000 \mathrm{E}+00$

$588,1.4240000 \mathrm{E}+00,1.4787832 \mathrm{E}+01,0.0000000 \mathrm{E}+00$

$589,1.4240000 \mathrm{E}+00,1.4647972 \mathrm{E}+01,0.0000000 \mathrm{E}+00$

$590,1.4240000 \mathrm{E}+00,1.4508112 \mathrm{E}+01,0.0000000 \mathrm{E}+00$

$591,1.4240000 \mathrm{E}+00,1.4368252 \mathrm{E}+01,0.0000000 \mathrm{E}+00$

$592,1.4240000 \mathrm{E}+00,1.4228392 \mathrm{E}+01,0.0000000 \mathrm{E}+00$

$593,1.4240000 \mathrm{E}+00,1.4088531 \mathrm{E}+01,0.0000000 \mathrm{E}+00$

$594,1.4240000 \mathrm{E}+00,1.3948671 \mathrm{E}+01,0.0000000 \mathrm{E}+00$

$595,1.4240000 \mathrm{E}+00,1.3808811 \mathrm{E}+01,0.0000000 \mathrm{E}+00$

$596,1.4240000 \mathrm{E}+00,1.3668951 \mathrm{E}+01,0.0000000 \mathrm{E}+00$

$597,1.4240000 \mathrm{E}+00,1.3529091 \mathrm{E}+01,0.0000000 \mathrm{E}+00$

$598,1.4240000 \mathrm{E}+00,1.3389231 \mathrm{E}+01,0.0000000 \mathrm{E}+00$

$599,1.4240000 \mathrm{E}+00,1.3249371 \mathrm{E}+01,0.0000000 \mathrm{E}+00$

$600,1.4240000 \mathrm{E}+00,1.3109510 \mathrm{E}+01,0.0000000 \mathrm{E}+00$

$601,1.4240000 \mathrm{E}+00,1.2969650 \mathrm{E}+01,0.0000000 \mathrm{E}+00$

$602,1.4240000 \mathrm{E}+00,1.2829790 \mathrm{E}+01,0.0000000 \mathrm{E}+00$

$603,1.4240000 \mathrm{E}+00,1.2689930 \mathrm{E}+01,0.0000000 \mathrm{E}+00$

$604,1.4240000 \mathrm{E}+00,1.2550070 \mathrm{E}+01,0.0000000 \mathrm{E}+00$

$605,1.4240000 \mathrm{E}+00,1.2410210 \mathrm{E}+01,0.0000000 \mathrm{E}+00$

$606,1.4240000 \mathrm{E}+00,1.2270350 \mathrm{E}+01,0.0000000 \mathrm{E}+00$

$607,1.4240000 \mathrm{E}+00,1.2130490 \mathrm{E}+01,0.0000000 \mathrm{E}+00$

$608,1.4240000 \mathrm{E}+00,1.1990629 \mathrm{E}+01,0.0000000 \mathrm{E}+00$

$609,1.4240000 \mathrm{E}+00,1.1850769 \mathrm{E}+01,0.0000000 \mathrm{E}+00$

$610,1.4240000 \mathrm{E}+00,1.1710909 \mathrm{E}+01,0.0000000 \mathrm{E}+00$

$611,1.4240000 \mathrm{E}+00,1.1571049 \mathrm{E}+01,0.0000000 \mathrm{E}+00$

$612,1.4240000 \mathrm{E}+00,1.1431189 \mathrm{E}+01,0.0000000 \mathrm{E}+00$

$613,1.4240000 \mathrm{E}+00,1.1291329 \mathrm{E}+01,0.0000000 \mathrm{E}+00$ 
$614,1.4240000 \mathrm{E}+00,1.1151469 \mathrm{E}+01,0.0000000 \mathrm{E}+00$ $615,1.4240000 \mathrm{E}+00,1.1011608 \mathrm{E}+01,0.0000000 \mathrm{E}+00$ $616,1.4240000 \mathrm{E}+00,1.0871748 \mathrm{E}+01,0.0000000 \mathrm{E}+00$ $617,1.4240000 \mathrm{E}+00,1.0731888 \mathrm{E}+01,0.0000000 \mathrm{E}+00$ $618,1.4240000 \mathrm{E}+00,1.0592028 \mathrm{E}+01,0.0000000 \mathrm{E}+00$ $619,1.4240000 \mathrm{E}+00,1.0452168 \mathrm{E}+01,0.0000000 \mathrm{E}+00$ $620,1.4240000 \mathrm{E}+00,1.0312308 \mathrm{E}+01,0.0000000 \mathrm{E}+00$ $621,1.4240000 \mathrm{E}+00,1.0172448 \mathrm{E}+01,0.0000000 \mathrm{E}+00$ $622,1.4240000 \mathrm{E}+00,1.0032587 \mathrm{E}+01,0.0000000 \mathrm{E}+00$ $623,1.4240000 \mathrm{E}+00,9.8927273 \mathrm{E}+00,0.0000000 \mathrm{E}+00$ $624,1.4240000 \mathrm{E}+00,9.7528671 \mathrm{E}+00,0.0000000 \mathrm{E}+00$ $625,1.4240000 \mathrm{E}+00,9.6130070 \mathrm{E}+00,0.0000000 \mathrm{E}+00$ $626,1.4240000 \mathrm{E}+00,9.4731469 \mathrm{E}+00,0.0000000 \mathrm{E}+00$ $627,1.4240000 \mathrm{E}+00,9.3332867 \mathrm{E}+00,0.0000000 \mathrm{E}+00$ $628,1.4240000 \mathrm{E}+00,9.1934266 \mathrm{E}+00,0.0000000 \mathrm{E}+00$ $629,1.4240000 \mathrm{E}+00,9.0535664 \mathrm{E}+00,0.0000000 \mathrm{E}+00$ $630,1.4240000 \mathrm{E}+00,8.9137063 \mathrm{E}+00,0.0000000 \mathrm{E}+00$ $631,1.4240000 \mathrm{E}+00,8.7738462 \mathrm{E}+00,0.0000000 \mathrm{E}+00$ $632,1.4240000 \mathrm{E}+00,8.6339860 \mathrm{E}+00,0.0000000 \mathrm{E}+00$ $633,1.4240000 \mathrm{E}+00,8.4941259 \mathrm{E}+00,0.0000000 \mathrm{E}+00$ $634,1.4240000 \mathrm{E}+00,8.3542657 \mathrm{E}+00,0.0000000 \mathrm{E}+00$ $635,1.4240000 \mathrm{E}+00,8.2144056 \mathrm{E}+00,0.0000000 \mathrm{E}+00$ $636,1.4240000 \mathrm{E}+00,8.0745455 \mathrm{E}+00,0.0000000 \mathrm{E}+00$ $637,1.4240000 \mathrm{E}+00,7.9346853 \mathrm{E}+00,0.0000000 \mathrm{E}+00$ $638,1.4240000 \mathrm{E}+00,7.7948252 \mathrm{E}+00,0.0000000 \mathrm{E}+00$ $639,1.4240000 \mathrm{E}+00,7.6549650 \mathrm{E}+00,0.0000000 \mathrm{E}+00$ $640,1.4240000 \mathrm{E}+00,7.5151049 \mathrm{E}+00,0.0000000 \mathrm{E}+00$ $641,1.4240000 \mathrm{E}+00,7.3752448 \mathrm{E}+00,0.0000000 \mathrm{E}+00$ $642,1.4240000 \mathrm{E}+00,7.2353846 \mathrm{E}+00,0.0000000 \mathrm{E}+00$ $643,1.4240000 \mathrm{E}+00,7.0955245 \mathrm{E}+00,0.0000000 \mathrm{E}+00$ $644,1.4240000 \mathrm{E}+00,6.9556643 \mathrm{E}+00,0.0000000 \mathrm{E}+00$ $645,1.4240000 \mathrm{E}+00,6.8158042 \mathrm{E}+00,0.0000000 \mathrm{E}+00$ $646,1.4240000 \mathrm{E}+00,6.6759441 \mathrm{E}+00,0.0000000 \mathrm{E}+00$ $647,1.4240000 \mathrm{E}+00,6.5360839 \mathrm{E}+00,0.0000000 \mathrm{E}+00$ $648,1.4240000 \mathrm{E}+00,6.3962238 \mathrm{E}+00,0.0000000 \mathrm{E}+00$ $649,1.4240000 \mathrm{E}+00,6.2563636 \mathrm{E}+00,0.0000000 \mathrm{E}+00$ $650,1.4240000 \mathrm{E}+00,6.1165035 \mathrm{E}+00,0.0000000 \mathrm{E}+00$ $651,1.4240000 \mathrm{E}+00,5.9766434 \mathrm{E}+00,0.0000000 \mathrm{E}+00$ $652,1.4240000 \mathrm{E}+00,5.8367832 \mathrm{E}+00,0.0000000 \mathrm{E}+00$ $653,1.4240000 \mathrm{E}+00,5.6969231 \mathrm{E}+00,0.0000000 \mathrm{E}+00$ $654,1.4240000 \mathrm{E}+00,5.5570629 \mathrm{E}+00,0.0000000 \mathrm{E}+00$ $655,1.4240000 \mathrm{E}+00,5.4172028 \mathrm{E}+00,0.0000000 \mathrm{E}+00$ $656,1.4240000 \mathrm{E}+00,5.2773427 \mathrm{E}+00,0.0000000 \mathrm{E}+00$ $657,1.4240000 \mathrm{E}+00,5.1374825 \mathrm{E}+00,0.0000000 \mathrm{E}+00$ $658,1.4240000 \mathrm{E}+00,4.9976224 \mathrm{E}+00,0.0000000 \mathrm{E}+00$ $659,1.4240000 \mathrm{E}+00,4.8577622 \mathrm{E}+00,0.0000000 \mathrm{E}+00$ $660,1.4240000 \mathrm{E}+00,4.7179021 \mathrm{E}+00,0.0000000 \mathrm{E}+00$ $661,1.4240000 \mathrm{E}+00,4.5780420 \mathrm{E}+00,0.0000000 \mathrm{E}+00$ $662,1.4240000 \mathrm{E}+00,4.4381818 \mathrm{E}+00,0.0000000 \mathrm{E}+00$ $663,1.4240000 \mathrm{E}+00,4.2983217 \mathrm{E}+00,0.0000000 \mathrm{E}+00$ $664,1.4240000 \mathrm{E}+00,4.1584615 \mathrm{E}+00,0.0000000 \mathrm{E}+00$ $665,1.4240000 \mathrm{E}+00,4.0186014 \mathrm{E}+00,0.0000000 \mathrm{E}+00$ $666,1.4240000 \mathrm{E}+00,3.8787413 \mathrm{E}+00,0.0000000 \mathrm{E}+00$ $667,1.4240000 \mathrm{E}+00,3.7388811 \mathrm{E}+00,0.0000000 \mathrm{E}+00$ $668,1.4240000 \mathrm{E}+00,3.5990210 \mathrm{E}+00,0.0000000 \mathrm{E}+00$ $669,1.4240000 \mathrm{E}+00,3.4591608 \mathrm{E}+00,0.0000000 \mathrm{E}+00$ $670,1.4240000 \mathrm{E}+00,3.3193007 \mathrm{E}+00,0.0000000 \mathrm{E}+00$ $671,1.4240000 \mathrm{E}+00,3.1794406 \mathrm{E}+00,0.0000000 \mathrm{E}+00$ $672,1.4240000 \mathrm{E}+00,3.0395804 \mathrm{E}+00,0.0000000 \mathrm{E}+00$ $673,1.4240000 \mathrm{E}+00,2.8997203 \mathrm{E}+00,0.0000000 \mathrm{E}+00$ $674,1.4240000 \mathrm{E}+00,2.7598601 \mathrm{E}+00,0.0000000 \mathrm{E}+00$ $675,1.2920000 \mathrm{E}+00,2.2620000 \mathrm{E}+01,0.0000000 \mathrm{E}+00$ $676,1.2920000 \mathrm{E}+00,1.2689930 \mathrm{E}+01,0.0000000 \mathrm{E}+00$ $677,1.2920000 \mathrm{E}+00,1.7585035 \mathrm{E}+01,0.0000000 \mathrm{E}+00$ $678,1.2920000 \mathrm{E}+00,1.5207413 \mathrm{E}+01,0.0000000 \mathrm{E}+00$ $679,1.2920000 \mathrm{E}+00,1.6326294 \mathrm{E}+01,0.0000000 \mathrm{E}+00$ $680,1.2920000 \mathrm{E}+00,1.5766853 \mathrm{E}+01,0.0000000 \mathrm{E}+00$ $681,1.2920000 \mathrm{E}+00,1.6046573 \mathrm{E}+01,0.0000000 \mathrm{E}+00$ $682,1.2920000 \mathrm{E}+00,1.5906713 \mathrm{E}+01,0.0000000 \mathrm{E}+00$ $683,1.2920000 \mathrm{E}+00,1.6186434 \mathrm{E}+01,0.0000000 \mathrm{E}+00$ $684,1.2920000 \mathrm{E}+00,1.5487133 \mathrm{E}+01,0.0000000 \mathrm{E}+00$ 
$685,1.2920000 \mathrm{E}+00,1.5626993 \mathrm{E}+01,0.0000000 \mathrm{E}+00$ $686,1.2920000 \mathrm{E}+00,1.5347273 \mathrm{E}+01,0.0000000 \mathrm{E}+00$ $687,1.2920000 \mathrm{E}+00,1.6885734 \mathrm{E}+01,0.0000000 \mathrm{E}+00$ $688,1.2920000 \mathrm{E}+00,1.6606014 \mathrm{E}+01,0.0000000 \mathrm{E}+00$ $689,1.2920000 \mathrm{E}+00,1.6745874 \mathrm{E}+01,0.0000000 \mathrm{E}+00$ $690,1.2920000 \mathrm{E}+00,1.6466154 \mathrm{E}+01,0.0000000 \mathrm{E}+00$ $691,1.2920000 \mathrm{E}+00,1.7165455 \mathrm{E}+01,0.0000000 \mathrm{E}+00$ $692,1.2920000 \mathrm{E}+00,1.7025594 \mathrm{E}+01,0.0000000 \mathrm{E}+00$ $693,1.2920000 \mathrm{E}+00,1.7305315 \mathrm{E}+01,0.0000000 \mathrm{E}+00$ $694,1.2920000 \mathrm{E}+00,1.7445175 \mathrm{E}+01,0.0000000 \mathrm{E}+00$ $695,1.2920000 \mathrm{E}+00,1.3948671 \mathrm{E}+01,0.0000000 \mathrm{E}+00$ $696,1.2920000 \mathrm{E}+00,1.4508112 \mathrm{E}+01,0.0000000 \mathrm{E}+00$ $697,1.2920000 \mathrm{E}+00,1.4228392 \mathrm{E}+01,0.0000000 \mathrm{E}+00$ $698,1.2920000 \mathrm{E}+00,1.4368252 \mathrm{E}+01,0.0000000 \mathrm{E}+00$ $699,1.2920000 \mathrm{E}+00,1.4088531 \mathrm{E}+01,0.0000000 \mathrm{E}+00$ $700,1.2920000 \mathrm{E}+00,1.4787832 \mathrm{E}+01,0.0000000 \mathrm{E}+00$ $701,1.2920000 \mathrm{E}+00,1.4647972 \mathrm{E}+01,0.0000000 \mathrm{E}+00$ $702,1.2920000 \mathrm{E}+00,1.4927692 \mathrm{E}+01,0.0000000 \mathrm{E}+00$ $703,1.2920000 \mathrm{E}+00,1.5067552 \mathrm{E}+01,0.0000000 \mathrm{E}+00$ $704,1.2920000 \mathrm{E}+00,1.3389231 \mathrm{E}+01,0.0000000 \mathrm{E}+00$ $705,1.2920000 \mathrm{E}+00,1.3668951 \mathrm{E}+01,0.0000000 \mathrm{E}+00$ $706,1.2920000 \mathrm{E}+00,1.3529091 \mathrm{E}+01,0.0000000 \mathrm{E}+00$ $707,1.2920000 \mathrm{E}+00,1.3808811 \mathrm{E}+01,0.0000000 \mathrm{E}+00$ $708,1.2920000 \mathrm{E}+00,1.3109510 \mathrm{E}+01,0.0000000 \mathrm{E}+00$ $709,1.2920000 \mathrm{E}+00,1.3249371 \mathrm{E}+01,0.0000000 \mathrm{E}+00$ $710,1.2920000 \mathrm{E}+00,1.2969650 \mathrm{E}+01,0.0000000 \mathrm{E}+00$ $711,1.2920000 \mathrm{E}+00,1.2829790 \mathrm{E}+01,0.0000000 \mathrm{E}+00$ $712,1.2920000 \mathrm{E}+00,2.0102517 \mathrm{E}+01,0.0000000 \mathrm{E}+00$ $713,1.2920000 \mathrm{E}+00,1.8843776 \mathrm{E}+01,0.0000000 \mathrm{E}+00$ $714,1.2920000 \mathrm{E}+00,1.9403217 \mathrm{E}+01,0.0000000 \mathrm{E}+00$ $715,1.2920000 \mathrm{E}+00,1.9123497 \mathrm{E}+01,0.0000000 \mathrm{E}+00$ $716,1.2920000 \mathrm{E}+00,1.9263357 \mathrm{E}+01,0.0000000 \mathrm{E}+00$ $717,1.2920000 \mathrm{E}+00,1.8983636 \mathrm{E}+01,0.0000000 \mathrm{E}+00$ $718,1.2920000 \mathrm{E}+00,1.9682937 \mathrm{E}+01,0.0000000 \mathrm{E}+00$ $719,1.2920000 \mathrm{E}+00,1.9543077 \mathrm{E}+01,0.0000000 \mathrm{E}+00$ $720,1.2920000 \mathrm{E}+00,1.9822797 \mathrm{E}+01,0.0000000 \mathrm{E}+00$ $721,1.2920000 \mathrm{E}+00,1.9962657 \mathrm{E}+01,0.0000000 \mathrm{E}+00$ $722,1.2920000 \mathrm{E}+00,1.8284336 \mathrm{E}+01,0.0000000 \mathrm{E}+00$ $723,1.2920000 \mathrm{E}+00,1.8564056 \mathrm{E}+01,0.0000000 \mathrm{E}+00$ $724,1.2920000 \mathrm{E}+00,1.8424196 \mathrm{E}+01,0.0000000 \mathrm{E}+00$ $725,1.2920000 \mathrm{E}+00,1.8703916 \mathrm{E}+01,0.0000000 \mathrm{E}+00$ $726,1.2920000 \mathrm{E}+00,1.8004615 \mathrm{E}+01,0.0000000 \mathrm{E}+00$ $727,1.2920000 \mathrm{E}+00,1.8144476 \mathrm{E}+01,0.0000000 \mathrm{E}+00$ $728,1.2920000 \mathrm{E}+00,1.7864755 \mathrm{E}+01,0.0000000 \mathrm{E}+00$ $729,1.2920000 \mathrm{E}+00,1.7724895 \mathrm{E}+01,0.0000000 \mathrm{E}+00$ $730,1.2920000 \mathrm{E}+00,2.1361259 \mathrm{E}+01,0.0000000 \mathrm{E}+00$ $731,1.2920000 \mathrm{E}+00,2.0801818 \mathrm{E}+01,0.0000000 \mathrm{E}+00$ $732,1.2920000 \mathrm{E}+00,2.1081538 \mathrm{E}+01,0.0000000 \mathrm{E}+00$ $733,1.2920000 \mathrm{E}+00,2.0941678 \mathrm{E}+01,0.0000000 \mathrm{E}+00$ $734,1.2920000 \mathrm{E}+00,2.1221399 \mathrm{E}+01,0.0000000 \mathrm{E}+00$ $735,1.2920000 \mathrm{E}+00,2.0522098 \mathrm{E}+01,0.0000000 \mathrm{E}+00$ $736,1.2920000 \mathrm{E}+00,2.0661958 \mathrm{E}+01,0.0000000 \mathrm{E}+00$ $737,1.2920000 \mathrm{E}+00,2.0382238 \mathrm{E}+01,0.0000000 \mathrm{E}+00$ $738,1.2920000 \mathrm{E}+00,2.0242378 \mathrm{E}+01,0.0000000 \mathrm{E}+00$ $739,1.2920000 \mathrm{E}+00,2.1920699 \mathrm{E}+01,0.0000000 \mathrm{E}+00$ $740,1.2920000 \mathrm{E}+00,2.1640979 \mathrm{E}+01,0.0000000 \mathrm{E}+00$ $741,1.2920000 \mathrm{E}+00,2.1780839 \mathrm{E}+01,0.0000000 \mathrm{E}+00$ $742,1.2920000 \mathrm{E}+00,2.1501119 \mathrm{E}+01,0.0000000 \mathrm{E}+00$ $743,1.2920000 \mathrm{E}+00,2.2200420 \mathrm{E}+01,0.0000000 \mathrm{E}+00$ $744,1.2920000 \mathrm{E}+00,2.2060559 \mathrm{E}+01,0.0000000 \mathrm{E}+00$ $745,1.2920000 \mathrm{E}+00,2.2340280 \mathrm{E}+01,0.0000000 \mathrm{E}+00$ $746,1.2920000 \mathrm{E}+00,2.2480140 \mathrm{E}+01,0.0000000 \mathrm{E}+00$ $747,1.2920000 \mathrm{E}+00,7.6549650 \mathrm{E}+00,0.0000000 \mathrm{E}+00$ $748,1.2920000 \mathrm{E}+00,1.0172448 \mathrm{E}+01,0.0000000 \mathrm{E}+00$ $749,1.2920000 \mathrm{E}+00,8.9137063 \mathrm{E}+00,0.0000000 \mathrm{E}+00$ $750,1.2920000 \mathrm{E}+00,9.4731469 \mathrm{E}+00,0.0000000 \mathrm{E}+00$ $751,1.2920000 \mathrm{E}+00,9.1934266 \mathrm{E}+00,0.0000000 \mathrm{E}+00$ $752,1.2920000 \mathrm{E}+00,9.3332867 \mathrm{E}+00,0.0000000 \mathrm{E}+00$ $753,1.2920000 \mathrm{E}+00,9.0535664 \mathrm{E}+00,0.0000000 \mathrm{E}+00$ $754,1.2920000 \mathrm{E}+00,9.7528671 \mathrm{E}+00,0.0000000 \mathrm{E}+00$ $755,1.2920000 \mathrm{E}+00,9.6130070 \mathrm{E}+00,0.0000000 \mathrm{E}+00$ 
$756,1.2920000 \mathrm{E}+00,9.8927273 \mathrm{E}+00,0.0000000 \mathrm{E}+00$ $757,1.2920000 \mathrm{E}+00,1.0032587 \mathrm{E}+01,0.0000000 \mathrm{E}+00$ $758,1.2920000 \mathrm{E}+00,8.3542657 \mathrm{E}+00,0.0000000 \mathrm{E}+00$ $759,1.2920000 \mathrm{E}+00,8.6339860 \mathrm{E}+00,0.0000000 \mathrm{E}+00$ $760,1.2920000 \mathrm{E}+00,8.4941259 \mathrm{E}+00,0.0000000 \mathrm{E}+00$ $761,1.2920000 \mathrm{E}+00,8.7738462 \mathrm{E}+00,0.0000000 \mathrm{E}+00$ $762,1.2920000 \mathrm{E}+00,8.0745455 \mathrm{E}+00,0.0000000 \mathrm{E}+00$ $763,1.2920000 \mathrm{E}+00,8.2144056 \mathrm{E}+00,0.0000000 \mathrm{E}+00$ $764,1.2920000 \mathrm{E}+00,7.9346853 \mathrm{E}+00,0.0000000 \mathrm{E}+00$ $765,1.2920000 \mathrm{E}+00,7.7948252 \mathrm{E}+00,0.0000000 \mathrm{E}+00$ $766,1.2920000 \mathrm{E}+00,1.1431189 \mathrm{E}+01,0.0000000 \mathrm{E}+00$ $767,1.2920000 \mathrm{E}+00,1.0871748 \mathrm{E}+01,0.0000000 \mathrm{E}+00$ $768,1.2920000 \mathrm{E}+00,1.1151469 \mathrm{E}+01,0.0000000 \mathrm{E}+00$ $769,1.2920000 \mathrm{E}+00,1.1011608 \mathrm{E}+01,0.0000000 \mathrm{E}+00$ $770,1.2920000 \mathrm{E}+00,1.1291329 \mathrm{E}+01,0.0000000 \mathrm{E}+00$ $771,1.2920000 \mathrm{E}+00,1.0592028 \mathrm{E}+01,0.0000000 \mathrm{E}+00$ $772,1.2920000 \mathrm{E}+00,1.0731888 \mathrm{E}+01,0.0000000 \mathrm{E}+00$ $773,1.2920000 \mathrm{E}+00,1.0452168 \mathrm{E}+01,0.0000000 \mathrm{E}+00$ $774,1.2920000 \mathrm{E}+00,1.0312308 \mathrm{E}+01,0.0000000 \mathrm{E}+00$ $775,1.2920000 \mathrm{E}+00,1.1990629 \mathrm{E}+01,0.0000000 \mathrm{E}+00$ $776,1.2920000 \mathrm{E}+00,1.1710909 \mathrm{E}+01,0.0000000 \mathrm{E}+00$ $777,1.2920000 \mathrm{E}+00,1.1850769 \mathrm{E}+01,0.0000000 \mathrm{E}+00$ $778,1.2920000 \mathrm{E}+00,1.1571049 \mathrm{E}+01,0.0000000 \mathrm{E}+00$ $779,1.2920000 \mathrm{E}+00,1.2270350 \mathrm{E}+01,0.0000000 \mathrm{E}+00$ $780,1.2920000 \mathrm{E}+00,1.2130490 \mathrm{E}+01,0.0000000 \mathrm{E}+00$ $781,1.2920000 \mathrm{E}+00,1.2410210 \mathrm{E}+01,0.0000000 \mathrm{E}+00$ $782,1.2920000 \mathrm{E}+00,1.2550070 \mathrm{E}+01,0.0000000 \mathrm{E}+00$ $783,1.2920000 \mathrm{E}+00,5.1374825 \mathrm{E}+00,0.0000000 \mathrm{E}+00$ $784,1.2920000 \mathrm{E}+00,6.3962238 \mathrm{E}+00,0.0000000 \mathrm{E}+00$ $785,1.2920000 \mathrm{E}+00,5.8367832 \mathrm{E}+00,0.0000000 \mathrm{E}+00$ $786,1.2920000 \mathrm{E}+00,6.1165035 \mathrm{E}+00,0.0000000 \mathrm{E}+00$ $787,1.2920000 \mathrm{E}+00,5.9766434 \mathrm{E}+00,0.0000000 \mathrm{E}+00$ $788,1.2920000 \mathrm{E}+00,6.2563636 \mathrm{E}+00,0.0000000 \mathrm{E}+00$ $789,1.2920000 \mathrm{E}+00,5.5570629 \mathrm{E}+00,0.0000000 \mathrm{E}+00$ $790,1.2920000 \mathrm{E}+00,5.6969231 \mathrm{E}+00,0.0000000 \mathrm{E}+00$ $791,1.2920000 \mathrm{E}+00,5.4172028 \mathrm{E}+00,0.0000000 \mathrm{E}+00$ $792,1.2920000 \mathrm{E}+00,5.2773427 \mathrm{E}+00,0.0000000 \mathrm{E}+00$ $793,1.2920000 \mathrm{E}+00,6.9556643 \mathrm{E}+00,0.0000000 \mathrm{E}+00$ $794,1.2920000 \mathrm{E}+00,6.6759441 \mathrm{E}+00,0.0000000 \mathrm{E}+00$ $795,1.2920000 \mathrm{E}+00,6.8158042 \mathrm{E}+00,0.0000000 \mathrm{E}+00$ $796,1.2920000 \mathrm{E}+00,6.5360839 \mathrm{E}+00,0.0000000 \mathrm{E}+00$ $797,1.2920000 \mathrm{E}+00,7.2353846 \mathrm{E}+00,0.0000000 \mathrm{E}+00$ $798,1.2920000 \mathrm{E}+00,7.0955245 \mathrm{E}+00,0.0000000 \mathrm{E}+00$ $799,1.2920000 \mathrm{E}+00,7.3752448 \mathrm{E}+00,0.0000000 \mathrm{E}+00$ $800,1.2920000 \mathrm{E}+00,7.5151049 \mathrm{E}+00,0.0000000 \mathrm{E}+00$ $801,1.2920000 \mathrm{E}+00,3.8787413 \mathrm{E}+00,0.0000000 \mathrm{E}+00$ $802,1.2920000 \mathrm{E}+00,4.4381818 \mathrm{E}+00,0.0000000 \mathrm{E}+00$ $803,1.2920000 \mathrm{E}+00,4.1584615 \mathrm{E}+00,0.0000000 \mathrm{E}+00$ $804,1.2920000 \mathrm{E}+00,4.2983217 \mathrm{E}+00,0.0000000 \mathrm{E}+00$ $805,1.2920000 \mathrm{E}+00,4.0186014 \mathrm{E}+00,0.0000000 \mathrm{E}+00$ $806,1.2920000 \mathrm{E}+00,4.7179021 \mathrm{E}+00,0.0000000 \mathrm{E}+00$ $807,1.2920000 \mathrm{E}+00,4.5780420 \mathrm{E}+00,0.0000000 \mathrm{E}+00$ $808,1.2920000 \mathrm{E}+00,4.8577622 \mathrm{E}+00,0.0000000 \mathrm{E}+00$ $809,1.2920000 \mathrm{E}+00,4.9976224 \mathrm{E}+00,0.0000000 \mathrm{E}+00$ $810,1.2920000 \mathrm{E}+00,3.3193007 \mathrm{E}+00,0.0000000 \mathrm{E}+00$ $811,1.2920000 \mathrm{E}+00,3.5990210 \mathrm{E}+00,0.0000000 \mathrm{E}+00$ $812,1.2920000 \mathrm{E}+00,3.4591608 \mathrm{E}+00,0.0000000 \mathrm{E}+00$ $813,1.2920000 \mathrm{E}+00,3.7388811 \mathrm{E}+00,0.0000000 \mathrm{E}+00$ $814,1.2920000 \mathrm{E}+00,3.0395804 \mathrm{E}+00,0.0000000 \mathrm{E}+00$ $815,1.2920000 \mathrm{E}+00,3.1794406 \mathrm{E}+00,0.0000000 \mathrm{E}+00$ $816,1.2920000 \mathrm{E}+00,2.8997203 \mathrm{E}+00,0.0000000 \mathrm{E}+00$ $817,1.2920000 \mathrm{E}+00,2.7598601 \mathrm{E}+00,0.0000000 \mathrm{E}+00$ *ELEMENT, TYPE=CAX4 , ELSET=AXISYMMETRIC SOLID1

$\begin{array}{rrrrr}1, & 2, & 1, & 27, & 28 \\ 2, & 32, & 23, & 3, & 4 \\ 3, & 31, & 24, & 23, & 32 \\ 4, & 30, & 25, & 24, & 31 \\ 5, & 29, & 26, & 25, & 30 \\ 6, & 28, & 27, & 26, & 29 \\ 7, & 28, & 33, & 6, & 2 \\ 8, & 4, & 5, & 37, & 32\end{array}$




\begin{tabular}{|c|c|c|c|c|}
\hline 9, & 29, & 34, & 33, & 28 \\
\hline 10, & 30, & 35, & 34, & 29 \\
\hline 11, & 31 , & 36, & 35 , & 30 \\
\hline 12, & 32, & 37, & 36, & 31 \\
\hline 13, & 5, & 42 , & 43, & 9 \\
\hline 14, & 38, & 7 & 8, & 47 \\
\hline 15, & 39, & 38, & 47, & 46 \\
\hline 16, & 40, & 39, & 46, & 45 \\
\hline 17, & 41 , & 40, & 45 , & 44 \\
\hline 18, & 42 , & 41, & 44, & 43 \\
\hline 19, & 9, & 52, & 37 , & 5 \\
\hline 20, & 48, & 10, & 6, & 33 \\
\hline 21 , & 49, & 48, & 33, & 34 \\
\hline 22 , & 50, & 49, & 34, & 35 \\
\hline 23, & 51, & 50, & 35, & 36 \\
\hline 24, & 52 , & 51, & 36, & 37 \\
\hline 25, & 47 , & 8, & 11, & 57 \\
\hline 26, & 9 & 43, & 53, & 12 \\
\hline 27, & 43, & 44, & 54, & 53 \\
\hline 28, & 44, & 45, & 55, & 54 \\
\hline 29, & 45, & 46, & 56, & 55 \\
\hline 30, & 46, & 47, & 57, & 56 \\
\hline 31, & 12, & 62, & 52, & 9 \\
\hline 32 , & 58, & 13, & 10, & 48 \\
\hline 33, & 59, & 58, & 48, & 49 \\
\hline 34, & 60, & 59, & 49, & 50 \\
\hline 35, & 61, & 60, & 50, & 51 \\
\hline 36, & 62, & 61, & 51, & 52 \\
\hline 37, & 11, & 67, & 68, & 16 \\
\hline 38, & 63, & 14, & 15, & 72 \\
\hline 39, & 64, & 63, & 72 , & 71 \\
\hline 40, & 65, & 64, & 71, & 70 \\
\hline 41, & 66 , & 65, & 70, & 69 \\
\hline 42 , & 67 , & 66, & 69, & 68 \\
\hline 43, & 57, & 11, & 16, & 77 \\
\hline 44 , & 12, & 53, & 73, & 17 \\
\hline 45, & 53, & 54, & 74, & 73 \\
\hline 46, & 54, & 55, & 75, & 74 \\
\hline 47, & 55, & 56, & 76, & 75 \\
\hline 48, & 56, & 57, & 77 , & 76 \\
\hline 49, & 17 , & 82 , & 62 , & 12 \\
\hline 50, & 78, & 18, & 13, & 58 \\
\hline 51 , & 79, & 78, & 58, & 59 \\
\hline 52 , & 80 , & 79, & 59, & 60 \\
\hline 53, & 81, & 80, & 60, & 61 \\
\hline 54, & 82 , & 81, & 61, & 62 \\
\hline 55, & 72 , & 15, & 19, & 87 \\
\hline 56, & 16, & 68, & 83, & 20 \\
\hline 57, & 68, & 69, & 84, & 83 \\
\hline 58, & 69, & 70, & 85, & 84 \\
\hline 59, & 70, & 71, & 86, & 85 \\
\hline 60, & 71, & 72, & 87, & 86 \\
\hline 61, & 77 , & 16, & 20, & 92 \\
\hline 62 , & 17 , & 73, & 88, & 21 \\
\hline 63, & 73 & 74, & 89, & 88 \\
\hline 64, & 74, & 75, & 90, & 89 \\
\hline 65, & 75, & 76, & 91, & 90 \\
\hline 66, & 76, & 77, & 92, & 91 \\
\hline 67 , & 21, & 97, & 82 , & 17 \\
\hline 68, & 93, & 22, & 18, & 78 \\
\hline 69, & 94, & 93, & 78, & 79 \\
\hline 70, & 95, & 94, & 79, & 80 \\
\hline 71 , & 96, & 95, & 80 , & 81 \\
\hline 72 , & 97 , & 96, & 81, & 82 \\
\hline 73, & 102 , & 98, & 100, & 385 \\
\hline 74, & 15, & 243 & 244 , & 19 \\
\hline 75 , & 103, & 102 , & 385, & 384 \\
\hline 76, & 104, & 103, & 384, & 383 \\
\hline 77 , & 105, & 104, & 383, & 382 \\
\hline 78, & 106, & 105, & 382 , & 381 \\
\hline 79 , & 107, & 106, & 381, & 380 \\
\hline
\end{tabular}




\begin{tabular}{|c|c|c|c|c|}
\hline 80, & 108, & 107, & 380 , & 379 \\
\hline 81, & 109, & 108, & 379 , & 378 \\
\hline 82 , & 110, & 109, & 378, & 377 \\
\hline 83, & 111, & 110, & 377 , & 376 \\
\hline 84, & 112 , & 111, & 376 , & 375 \\
\hline 85, & 113, & 112 , & 375 , & 374 \\
\hline 86, & 114, & 113, & 374, & 373 \\
\hline 87, & 115 & 114 & 373, & 372 \\
\hline 88, & 116, & 115, & 372 , & 371 \\
\hline 89, & 117, & 116, & 371 , & 370 \\
\hline 90 & 118, & 117, & 370 , & 369 \\
\hline 91, & 119, & 118, & 369, & 368 \\
\hline 92 , & 120, & 119, & 368, & 367 \\
\hline 93, & 121, & 120, & 367 , & 366 \\
\hline 94, & 122, & 121, & 366 , & 365 \\
\hline 95, & 123, & 122 & 365 , & 364 \\
\hline 96, & 124 & 123, & 364 , & 363 \\
\hline 97, & 125 & 124 & 363 , & 362 \\
\hline 98, & 126, & 125 & 362 , & 361 \\
\hline 99, & 127, & 126, & 361 , & 360 \\
\hline 100, & 128 & 127 & 360 , & 359 \\
\hline 101, & 129, & 128 & 359, & 358 \\
\hline 102 , & 130 & 129, & 358, & 357 \\
\hline 103, & 131, & 130, & 357 , & 356 \\
\hline 104, & 132, & 131, & 356, & 355 \\
\hline 105, & 133, & 132 & 355, & 354 \\
\hline 106, & 134 & 133, & 354, & 353 \\
\hline 107, & 135, & 134 & 353, & 352 \\
\hline 108, & 136, & 135, & 352 , & 351 \\
\hline 109, & 137, & 136, & 351 , & 350 \\
\hline 110 , & 138, & 137, & 350 , & 349 \\
\hline 111, & 139, & 138, & 349 , & 348 \\
\hline 112 , & 140 & 139, & 348 , & 347 \\
\hline 113 & 141 , & 140, & 347 , & 346 \\
\hline 114, & 142, & 141, & 346 , & 345 \\
\hline 115 & 143 & 142 , & 345 , & 344 \\
\hline 116, & 144 & 143 & 344, & 343 \\
\hline 117 & 145 , & 144 & 343 , & 342 \\
\hline 118, & 146, & 145, & 342 , & 341 \\
\hline 119, & 147, & 146, & 341 , & 340 \\
\hline 120 & 148, & 147 , & 340 , & 339 \\
\hline 121, & 149 , & 148 & 339, & 338 \\
\hline 122, & 150, & 149, & 338, & 337 \\
\hline 123 & 151 , & 150, & 337 , & 336 \\
\hline 124, & 152 , & 151, & 336, & 335 \\
\hline 125 & 153 , & 152 , & 335, & 334 \\
\hline 126, & 154, & 153, & 334, & 333 \\
\hline 127 & 155 , & 154 & 333, & 332 \\
\hline 128, & 156, & 155, & 332 , & 331 \\
\hline 129, & 157, & 156, & 331, & 330 \\
\hline 130 & 158, & 157, & 330, & 329 \\
\hline 131, & 159, & 158, & 329, & 328 \\
\hline 132 , & 160 & 159, & 328, & 327 \\
\hline 133, & 161, & 160 & 327 , & 326 \\
\hline 134, & 162 , & 161, & 326, & 325 \\
\hline 135, & 163, & 162 & 325, & 324 \\
\hline 136, & 164, & 163, & 324, & 323 \\
\hline 137, & 165, & 164 & 323, & 322 \\
\hline 138, & 166, & 165, & 322 , & 321 \\
\hline 139, & 167, & 166, & 321, & 320 \\
\hline 140, & 168, & 167, & 320, & 319 \\
\hline 141, & 169, & 168, & 319, & 318 \\
\hline 142 , & 170, & 169, & 318, & 317 \\
\hline 143 & 171, & 170, & 317 , & 316 \\
\hline 144, & 172, & 171, & 316, & 315 \\
\hline 145 & 173, & 172 , & 315 , & 314 \\
\hline 146, & 174, & 173 & 314, & 313 \\
\hline 147, & 175, & 174 & 313, & 312 \\
\hline 148, & 176, & 175, & 312 , & 311 \\
\hline 149, & 177, & 176, & 311, & 310 \\
\hline 150, & 178, & 177 , & 310 , & 309 \\
\hline
\end{tabular}




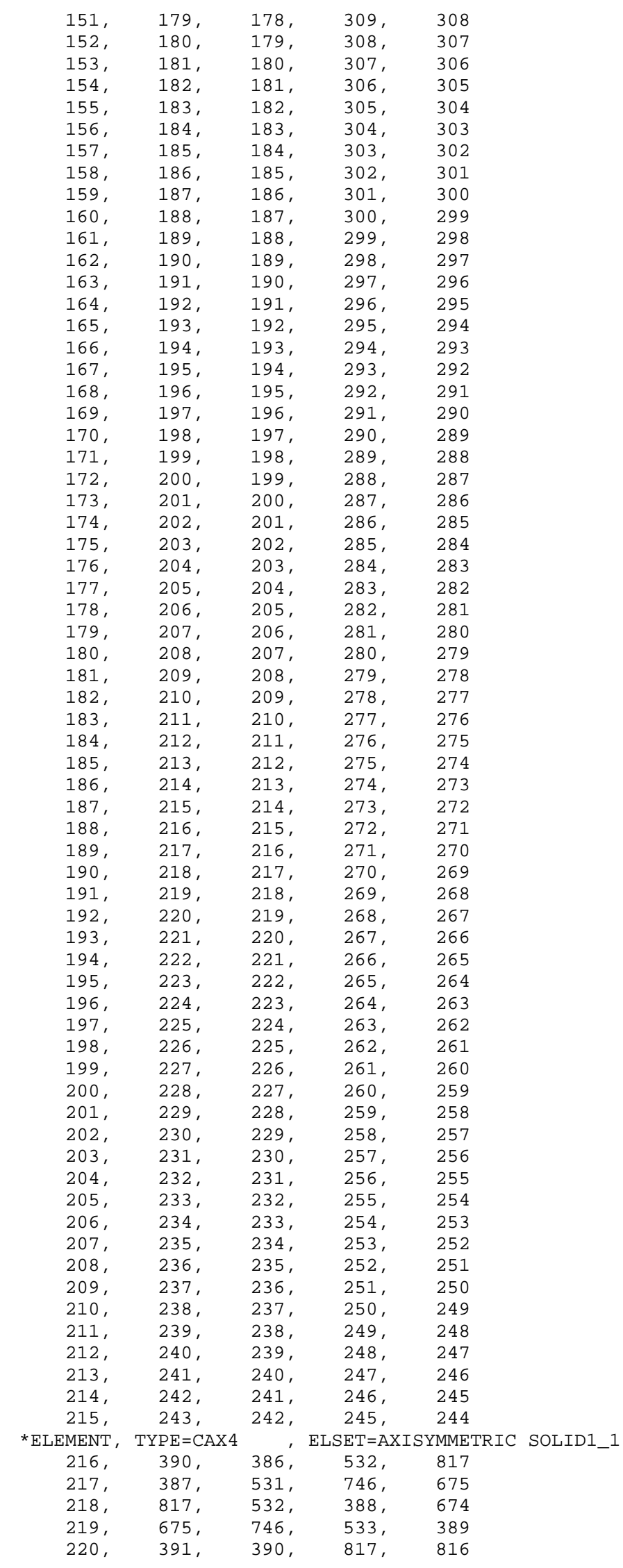




\begin{tabular}{|c|c|c|c|c|}
\hline 221, & 392 , & 391, & 816 , & 814 \\
\hline 222, & 393, & 392 , & 814, & 815 \\
\hline 223 & 394, & 393, & 815 , & 810 \\
\hline 224, & 395, & 394, & 810 , & 812 \\
\hline 225, & 396, & 395, & 812 , & 811 \\
\hline 226, & 397, & 396, & 811, & 813 \\
\hline 227 & 398, & 397, & 813, & 801 \\
\hline 228, & 399, & 398, & 801 , & 805 \\
\hline 229, & 400 & 399, & 805, & 803 \\
\hline 230, & 401, & 400, & 803, & 804 \\
\hline 231 , & 402 , & 401, & 804, & 802 \\
\hline 232 , & 403 , & 402 , & 802 , & 807 \\
\hline 233, & 404, & 403, & 807 , & 806 \\
\hline 234, & 405 , & 404, & 806 , & 808 \\
\hline 235, & 406, & 405, & 808, & 809 \\
\hline 236, & 407 , & 406 , & 809 , & 783 \\
\hline 237, & 408, & 407, & 783, & 792 \\
\hline 238 , & 409 , & 408 , & 792 , & 791 \\
\hline 239, & 410 , & 409 , & 791, & 789 \\
\hline 240, & 411, & 410, & 789, & 790 \\
\hline 241 , & 412 , & 411, & 790, & 785 \\
\hline 242 , & 413, & 412 , & 785 , & 787 \\
\hline 243, & 414 , & 413, & 787 , & 786 \\
\hline 244 , & 415 , & 414, & 786, & 788 \\
\hline 245, & 416, & 415 , & 788, & 784 \\
\hline 246, & 417 , & 416 , & 784 & 796 \\
\hline 247, & 418, & 417 , & 796, & 794 \\
\hline 248, & 419, & 418, & 794, & 795 \\
\hline 249, & 420 , & 419, & 795, & 793 \\
\hline 250, & 421 , & 420 , & 793, & 798 \\
\hline 251, & 422 , & 421 , & 798, & 797 \\
\hline 252 , & 423 & 422 , & 797, & 799 \\
\hline 253, & 424 , & 423, & 799, & 800 \\
\hline 254 , & 425 , & 424 , & 800 , & 747 \\
\hline 255 , & 426, & 425 , & 747, & 765 \\
\hline 256, & 427, & 426, & 765 & 764 \\
\hline 257, & 428, & 427 , & 764 & 762 \\
\hline 258, & 429, & 428, & 762 , & 763 \\
\hline 259, & 430 , & 429 , & 763, & 758 \\
\hline 260, & 431 , & 430 , & 758, & 760 \\
\hline 261 , & 432 , & 431 , & 760 , & 759 \\
\hline 262 , & 433, & 432 , & 759, & 761 \\
\hline 263 , & 434 , & 433, & 761, & 749 \\
\hline 264 , & 435 , & 434 , & 749, & 753 \\
\hline 265 , & 436 , & 435 , & 753, & 751 \\
\hline 266 , & 437 , & 436 , & 751, & 752 \\
\hline 267 , & 438 , & 437 , & 752 , & 750 \\
\hline 268, & 439, & 438, & 750, & 755 \\
\hline 269, & 440 , & 439 , & 755, & 754 \\
\hline 270 , & 441 , & 440, & 754, & 756 \\
\hline 271 , & 442 , & 441 , & 756, & 757 \\
\hline 272 , & 443 & 442 , & 757, & 748 \\
\hline 273 , & 444 & 443 , & 748, & 774 \\
\hline 274 , & 445 , & 444 , & 774 , & 773 \\
\hline 275 , & 446 , & 445 , & 773 , & 771 \\
\hline 276 , & 447 , & 446 , & 771 , & 772 \\
\hline 277 , & 448 & 447 , & 772 , & 767 \\
\hline 278, & 449 , & 448 , & 767 , & 769 \\
\hline 279 , & 450 , & 449 , & 769 , & 768 \\
\hline 280, & 451 , & 450 , & 768 , & 770 \\
\hline 281, & 452 , & 451 , & 770, & 766 \\
\hline 282 , & 453, & 452 , & 766, & 778 \\
\hline 283, & 454 , & 453, & 778, & 776 \\
\hline 284 , & 455 , & 454 , & 776 , & 777 \\
\hline 285, & 456, & 455, & 777 , & 775 \\
\hline 286, & 457 , & 456 , & 775 , & 780 \\
\hline 287, & 458, & 457 , & 780 & 779 \\
\hline 288, & 459, & 458, & 779, & 781 \\
\hline 289, & 460 , & 459 , & 781, & 782 \\
\hline 290, & 461 , & 460 , & 782 , & 676 \\
\hline 291, & 462 , & 461, & 676, & 711 \\
\hline
\end{tabular}




\begin{tabular}{|c|c|c|c|c|}
\hline 292, & 463, & 462 , & 711, & 710 \\
\hline 293, & 464, & 463, & 710, & 708 \\
\hline 294, & 465 , & 464 , & 708, & 709 \\
\hline 295, & 466 , & 465 , & 709 , & 704 \\
\hline 296, & 467 , & 466, & 704, & 706 \\
\hline 297, & 468, & 467, & 706 , & 705 \\
\hline 298, & 469, & 468, & 705, & 707 \\
\hline 299, & 470 , & 469, & 707 , & 695 \\
\hline 300, & 471, & 470, & 695, & 699 \\
\hline 301 , & 472 , & 471 , & 699, & 697 \\
\hline 302 , & 473, & 472 , & 697, & 698 \\
\hline 303, & 474 , & 473 , & 698, & 696 \\
\hline 304, & 475 , & 474, & 696, & 701 \\
\hline 305 , & 476 , & 475 , & 701, & 700 \\
\hline 306, & 477 , & 476, & 700, & 702 \\
\hline 307, & 478 , & 477 , & 702 , & 703 \\
\hline 308, & 479, & 478, & 703, & 678 \\
\hline 309 , & 480 & 479 , & 678 , & 686 \\
\hline 310 , & 481 , & 480, & 686, & 684 \\
\hline 311, & 482 , & 481, & 684, & 685 \\
\hline 312 , & 483, & 482 , & 685, & 680 \\
\hline 313, & 484 & 483, & 680, & 682 \\
\hline 314 , & 485 , & 484 , & 682 , & 681 \\
\hline 315 , & 486 , & 485 , & 681, & 683 \\
\hline 316, & 487, & 486, & 683, & 679 \\
\hline 317, & 488, & 487 , & 679, & 690 \\
\hline 318, & 489, & 488, & 690, & 688 \\
\hline 319, & 490, & 489, & 688, & 689 \\
\hline 320, & 491, & 490, & 689, & 687 \\
\hline 321, & 492 , & 491, & 687 , & 692 \\
\hline 322 , & 493, & 492 , & 692 , & 691 \\
\hline 323, & 494, & 493, & 691, & 693 \\
\hline 324, & 495, & 494, & 693, & 694 \\
\hline 325, & 496, & 495, & 694, & 677 \\
\hline 326, & 497, & 496, & 677 , & 729 \\
\hline 327, & 498, & 497, & 729, & 728 \\
\hline 328, & 499, & 498, & 728, & 726 \\
\hline 329, & 500, & 499, & 726, & 727 \\
\hline 330, & 501, & 500, & 727 , & 722 \\
\hline 331, & 502, & 501, & 722 & 724 \\
\hline 332 , & 503, & 502 , & 724 & 723 \\
\hline 333, & 504, & 503, & 723 & 725 \\
\hline 334 , & 505, & 504, & 725 , & 713 \\
\hline 335, & 506, & 505, & 713, & 717 \\
\hline 336, & 507, & 506, & 717 , & 715 \\
\hline 337, & 508, & 507, & 715 , & 716 \\
\hline 338, & 509, & 508, & 716, & 714 \\
\hline 339, & 510, & 509, & 714 & 719 \\
\hline 340 , & 511, & 510, & 719, & 718 \\
\hline 341 , & 512, & 511, & 718, & 720 \\
\hline 342 , & 513, & 512 , & 720 & 721 \\
\hline 343, & 514, & 513, & 721, & 712 \\
\hline 344 , & 515 , & 514, & 712 , & 738 \\
\hline 345 , & 516, & 515 , & 738, & 737 \\
\hline 346 , & 517, & 516, & 737 , & 735 \\
\hline 347 , & 518, & 517, & 735 , & 736 \\
\hline 348, & 519, & 518, & 736, & 731 \\
\hline 349 , & 520, & 519, & 731, & 733 \\
\hline 350 , & 521, & 520, & 733, & 732 \\
\hline 351 , & 522, & 521, & 732 , & 734 \\
\hline 352 , & 523, & 522 , & 734 & 730 \\
\hline 353, & 524, & 523, & 730, & 742 \\
\hline 354, & 525, & 524, & 742 , & 740 \\
\hline 355 , & 526, & 525, & 740 , & 741 \\
\hline 356, & 527, & 526, & 741, & 739 \\
\hline 357 , & 528, & 527, & 739, & 744 \\
\hline 358, & 529, & 528, & 744 & 743 \\
\hline 359, & 530, & 529, & 743, & 745 \\
\hline 360 , & 531, & 530, & 745 & 746 \\
\hline 361 , & 746 , & 745 , & 534, & 533 \\
\hline 362 , & 745, & 743, & 535, & 534 \\
\hline
\end{tabular}




\begin{tabular}{|c|c|c|c|c|}
\hline 363, & 743, & 744 & 536, & 535 \\
\hline 364 , & 744 & 739 & 537, & 536 \\
\hline 365 , & 739 , & 741, & 538, & 537 \\
\hline 366, & 741 , & 740 & 539, & 538 \\
\hline 367 , & 740, & 742 & 540, & 539 \\
\hline 368, & 742 , & 730 & 541, & 540 \\
\hline 369, & 730, & 734 & 542, & 541 \\
\hline 370 , & 734 & 732 & 543, & 542 \\
\hline 371, & 732 , & 733 & 544, & 543 \\
\hline 372 , & 733, & 731, & 545, & 544 \\
\hline 373, & 731, & 736, & 546 , & 545 \\
\hline 374 , & 736, & 735, & 547 , & 546 \\
\hline 375 , & 735, & 737, & 548, & 547 \\
\hline 376, & 737 , & 738, & 549, & 548 \\
\hline 377 , & 738, & 712, & 550, & 549 \\
\hline 378, & 712 , & 721, & 551, & 550 \\
\hline 379, & 721, & 720 & 552 , & 551 \\
\hline 380 , & 720 & 718, & 553, & 552 \\
\hline 381, & 718, & 719, & 554, & 553 \\
\hline 382 , & 719, & 714, & 555, & 554 \\
\hline 383, & 714, & 716, & 556, & 555 \\
\hline 384, & 716 , & 715, & 557, & 556 \\
\hline 385, & 715, & 717, & 558, & 557 \\
\hline 386, & 717 , & 713, & 559, & 558 \\
\hline 387, & 713, & 725, & 560, & 559 \\
\hline 388, & 725 , & 723 & 561, & 560 \\
\hline 389, & 723, & 724 & 562 , & 561 \\
\hline 390, & 724 , & 722 , & 563, & 562 \\
\hline 391, & 722 , & 727, & 564, & 563 \\
\hline 392 , & 727 , & 726, & 565, & 564 \\
\hline 393, & 726, & 728 & 566, & 565 \\
\hline 394, & 728, & 729, & 567 , & 566 \\
\hline 395, & 729, & 677, & 568, & 567 \\
\hline 396, & 677 , & 694, & 569, & 568 \\
\hline 397, & 694, & 693, & 570, & 569 \\
\hline 398, & 693, & 691, & 571, & 570 \\
\hline 399, & 691 , & 692, & 572, & 571 \\
\hline 400 , & 692 , & 687, & 573 , & 572 \\
\hline 401 , & 687 , & 689, & 574, & 573 \\
\hline 402 , & 689, & 688, & 575 , & 574 \\
\hline 403 , & 688, & 690, & 576, & 575 \\
\hline 404, & 690, & 679, & 577 , & 576 \\
\hline 405 , & 679 , & 683, & 578, & 577 \\
\hline 406, & 683, & 681, & 579 , & 578 \\
\hline 407 , & 681, & 682, & 580, & 579 \\
\hline 408, & 682 , & 680, & 581, & 580 \\
\hline 409 , & 680, & 685, & 582, & 581 \\
\hline 410 & 685, & 684, & 583, & 582 \\
\hline 411, & 684, & 686, & 584, & 583 \\
\hline 412 , & 686, & 678, & 585, & 584 \\
\hline 413, & 678, & 703, & 586, & 585 \\
\hline 414 , & 703, & 702 , & 587, & 586 \\
\hline 415 , & 702 , & 700 & 588, & 587 \\
\hline 416, & 700 , & 701, & 589, & 588 \\
\hline 417 , & 701, & 696, & 590, & 589 \\
\hline 418 & 696, & 698, & 591, & 590 \\
\hline 419, & 698, & 697, & 592 , & 591 \\
\hline 420 , & 697, & 699, & 593, & 592 \\
\hline 421 , & 699, & 695, & 594, & 593 \\
\hline 422 , & 695, & 707 , & 595, & 594 \\
\hline 423 & 707 , & 705, & 596, & 595 \\
\hline 424 , & 705 , & 706, & 597, & 596 \\
\hline 425 , & 706, & 704, & 598, & 597 \\
\hline 426 , & 704 , & 709, & 599, & 598 \\
\hline 427 , & 709, & 708, & 600, & 599 \\
\hline 428 , & 708, & 710 & 601, & 600 \\
\hline 429 , & 710, & 711, & 602 , & 601 \\
\hline 430, & 711, & 676, & 603, & 602 \\
\hline 431 , & 676 , & 782, & 604, & 603 \\
\hline 432 , & 782 , & 781, & 605, & 604 \\
\hline 433 , & 781, & 779, & 606, & 605 \\
\hline
\end{tabular}




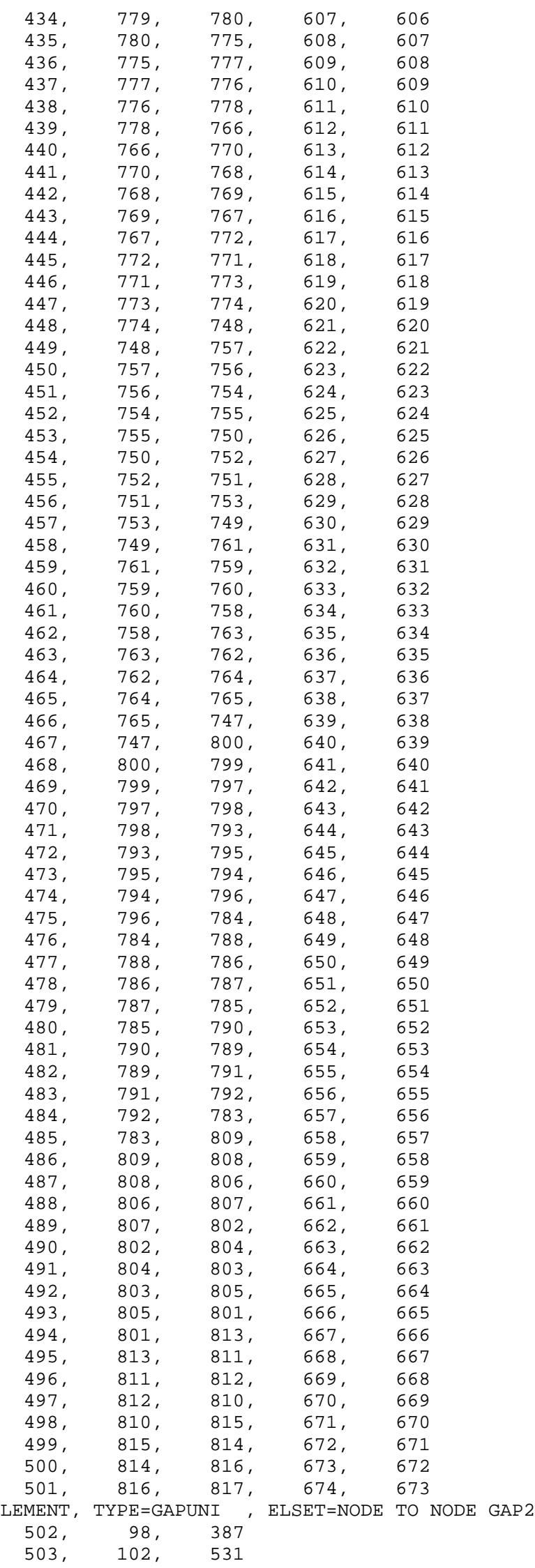




\begin{tabular}{|c|c|c|}
\hline 504, & 103, & 530 \\
\hline 505 , & 104, & 529 \\
\hline 506 , & 105, & 528 \\
\hline 507 , & 106, & 527 \\
\hline 508, & 107, & 526 \\
\hline 509 , & 108, & 525 \\
\hline 510, & 109, & 524 \\
\hline 511, & 110, & 523 \\
\hline 512, & 111 , & 522 \\
\hline 513, & 112, & 521 \\
\hline 514, & 113, & 520 \\
\hline 515, & 114, & 519 \\
\hline 516, & 115, & 518 \\
\hline 517, & 116, & 517 \\
\hline 518, & 117, & 516 \\
\hline 519, & 118, & 515 \\
\hline 520, & 119, & 514 \\
\hline 521, & 120, & 513 \\
\hline 522 , & 121, & 512 \\
\hline 523, & 122 , & 511 \\
\hline 524, & 123 & 510 \\
\hline 525, & 124 & 509 \\
\hline 526, & 125 & 508 \\
\hline 527, & 126 & 507 \\
\hline 528, & 127 & 506 \\
\hline 529, & 128 & 505 \\
\hline 530, & 129, & 504 \\
\hline 531, & 130, & 503 \\
\hline 532 , & 131, & 502 \\
\hline 533, & 132, & 501 \\
\hline 534, & 133, & 500 \\
\hline 535, & 134, & 499 \\
\hline 536, & 135, & 498 \\
\hline 537, & 136, & 497 \\
\hline 538, & 137, & 496 \\
\hline 539, & 138, & 495 \\
\hline 540, & 139, & 494 \\
\hline 541, & 140 & 493 \\
\hline 542 , & 141, & 492 \\
\hline 543 , & 142 , & 491 \\
\hline 544, & 143 & 490 \\
\hline 545 , & 144, & 489 \\
\hline 546, & 145 , & 488 \\
\hline 547, & 146 , & 487 \\
\hline 548, & 147 , & 486 \\
\hline 549, & 148, & 485 \\
\hline 550, & 149 , & 484 \\
\hline 551, & 150, & 483 \\
\hline 552 , & 151, & 482 \\
\hline 553, & 152 , & 481 \\
\hline 554, & 153, & 480 \\
\hline 555 , & 154, & 479 \\
\hline 556, & 155, & 478 \\
\hline 557, & 156, & 477 \\
\hline 558, & 157, & 476 \\
\hline 559, & 158, & 475 \\
\hline 560 , & 159, & 474 \\
\hline 561, & 160, & 473 \\
\hline 562 , & 161, & 472 \\
\hline 563, & 162 , & 471 \\
\hline 564, & 163, & 470 \\
\hline 565, & 164, & 469 \\
\hline 566, & 165, & 468 \\
\hline 567 , & 166, & 467 \\
\hline 568, & 167, & 466 \\
\hline 569, & 168, & 465 \\
\hline 570, & 169, & 464 \\
\hline 571, & 170 , & 463 \\
\hline 572 , & 171, & 462 \\
\hline 573, & 172 , & 461 \\
\hline 574, & 173, & 460 \\
\hline
\end{tabular}




\begin{tabular}{|c|c|c|}
\hline 575, & 174, & 459 \\
\hline 576, & 175, & 458 \\
\hline 577 , & 176, & 457 \\
\hline 578, & 177 , & 456 \\
\hline 579, & 178 & 455 \\
\hline 580, & 179, & 454 \\
\hline 581, & 180 & 453 \\
\hline 582, & 181, & 452 \\
\hline 583, & 182, & 451 \\
\hline 584, & 183, & 450 \\
\hline 585, & 184, & 449 \\
\hline 586, & 185, & 448 \\
\hline 587, & 186, & 447 \\
\hline 588, & 187, & 446 \\
\hline 589, & 188, & 445 \\
\hline 590, & 189, & 444 \\
\hline 591, & 190, & 443 \\
\hline 592 , & 191, & 442 \\
\hline 593, & 192, & 441 \\
\hline 594, & 193, & 440 \\
\hline 595, & 194, & 439 \\
\hline 596, & 195, & 438 \\
\hline 597, & 196, & 437 \\
\hline 598, & 197, & 436 \\
\hline 599, & 198, & 435 \\
\hline 600, & 199, & 434 \\
\hline 601, & 200 & 433 \\
\hline 602 , & 201 & 432 \\
\hline 603, & 202 , & 431 \\
\hline 604, & 203 & 430 \\
\hline 605, & 204 & 429 \\
\hline 606, & 205 & 428 \\
\hline 607 & 206 & 427 \\
\hline 608, & 207, & 426 \\
\hline 609, & 208 & 425 \\
\hline 610 & 209 & 424 \\
\hline 611, & 210, & 423 \\
\hline 612, & 211 & 422 \\
\hline 613, & 212 & 421 \\
\hline 614, & 213 & 420 \\
\hline 615 & 214 & 419 \\
\hline 616, & 215 & 418 \\
\hline 617, & 216 & 417 \\
\hline 618 & 217 , & 416 \\
\hline 619, & 218 & 415 \\
\hline 620 & 219, & 414 \\
\hline 621, & 220 & 413 \\
\hline 622 , & 221 & 412 \\
\hline 623 & 222 & 411 \\
\hline 624 & 223 & 410 \\
\hline 625 & 224 & 409 \\
\hline 626 & 225 & 408 \\
\hline 627 & 226 & 407 \\
\hline 628, & 227 & 406 \\
\hline 629 , & 228 & 405 \\
\hline 630, & 229, & 404 \\
\hline 631, & 230, & 403 \\
\hline 632 , & 231 , & 402 \\
\hline 633, & 232 , & 401 \\
\hline 634, & 233, & 400 \\
\hline 635 & 234 & 399 \\
\hline 636, & 235 & 398 \\
\hline 637 & 236 & 397 \\
\hline 638, & 237 , & 396 \\
\hline 639, & 238 & 395 \\
\hline 640 & 239, & 394 \\
\hline 641, & 240 & 393 \\
\hline 642 , & 241, & 392 \\
\hline 643, & 242 & 391 \\
\hline 644 & 243 & 390 \\
\hline 645 , & 15, & 386 \\
\hline
\end{tabular}




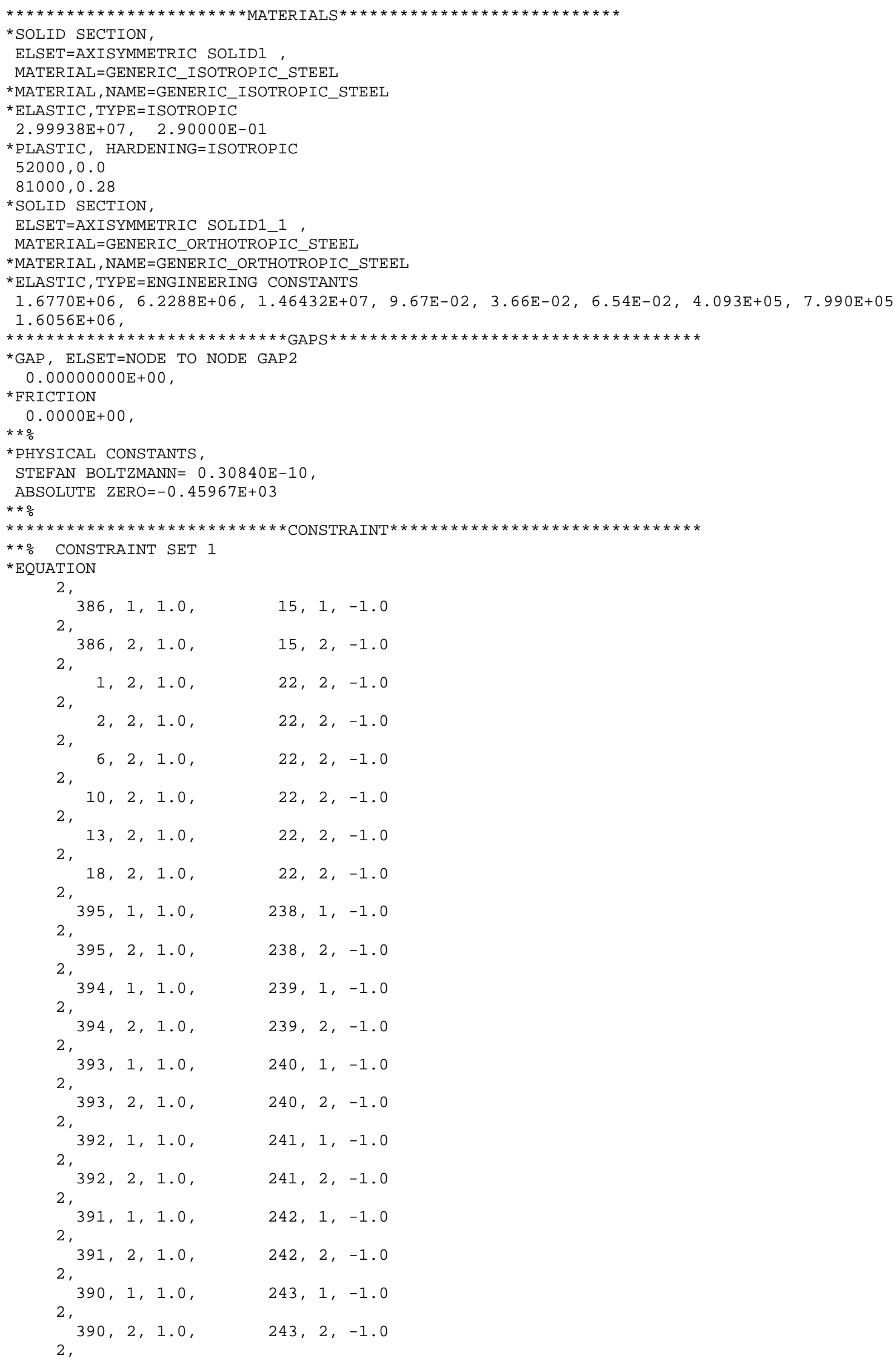




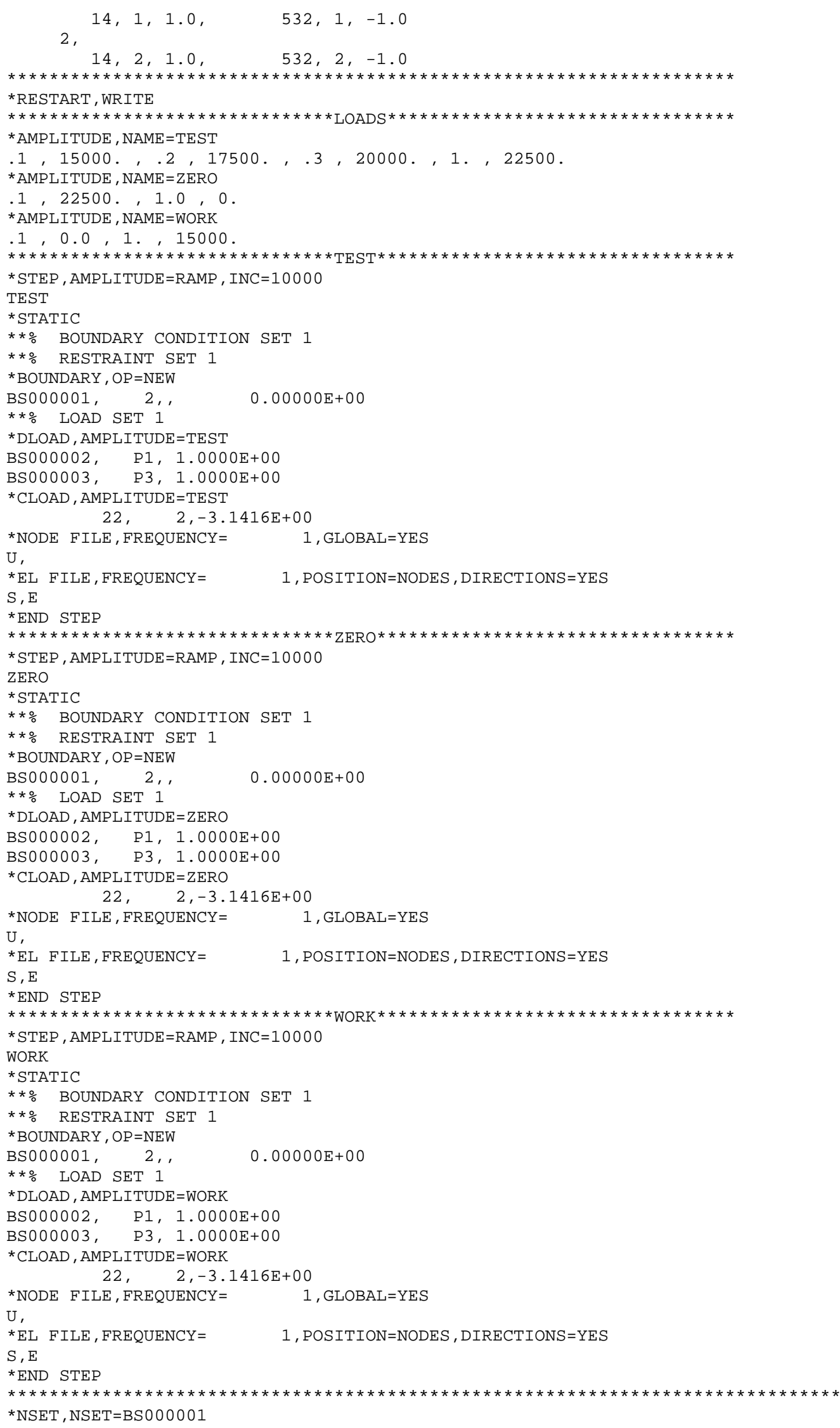


$98,100,387,389,675$

$\star \mathrm{ELSET}, \mathrm{ELSET}=\mathrm{BS} 000002$

$67,68,69,70,71,72$

$\star \mathrm{ELSET}, \mathrm{ELSET}=\mathrm{BS} 000003$

$55,56,57,58,59,60,61,62,63,64,65,66,73,74,75,76$

$77,78,79,80,81,82,83,84,85,86,87,88,89,90,91,92$

$93,94,95,96,97,98,99,100,101,102,103,104,105,106,107,108$

$109,110,111,112,113,114,115,116,117,118,119,120,121,122,123,124$

$125,126,127,128,129,130,131,132,133,134,135,136,137,138,139,140$

$141,142,143,144,145,146,147,148,149,150,151,152,153,154,155,156$

$157,158,159,160,161,162,163,164,165,166,167,168,169,170,171,172$

$173,174,175,176,177,178,179,180,181,182,183,184,185,186,187,188$

$189,190,191,192,193,194,195,196,197,198,199,200,201,202,203,204$

$205,206,207,208,209,210,211,212,213,214,215$ 